\title{
Compartilhamento de Conhecimento entre Sistemas Baseados em Conhecimento: um Estudo de Caso
}

Roberto Cássio de Araújo

\author{
TESE APRESENTADA \\ $\mathrm{AO}$ \\ INSTITUTO DE MATEMÁTICA E ESTATÍSTICA \\ DA \\ UNIVERSIDADE DE SÃO PAULO \\ PARA \\ OBTENÇÃO DO GRAU DE DOUTOR \\ EM \\ CIÊNCIA DA COMPUTAÇÃO
}

Área de Concentração : Ciência da Computação

Orientador : Prof. Dr. Flávio Soares Correa da Silva

O autor recebeu auxílio financeiro da CAPES e do British Council.

- São Paulo, Novenbro de 2000 - 


\section{Compartilhamento de Conhecimento entre Sistemas Baseados em Conhecimento: um Estudo de Caso}

Este exemplar corresponde à redação final da dissertação devidamente corrigida e defendida por Roberto Cássio de Araújo e aprovada pela comissão julgadora.

São Paulo, abril de 2001.

Banca examinadora:

- Prof. Dr. Flávio Soares Corrêa da Silva (presidente) - IME-USP

- Prof. Dra. Ana Cristina Vieira de Melo - IME-USP

- Prof. Dr. José Reinaldo Silva - EP-USP

- Prof. Dr. Fábio Gagliardi Cozman - EP-USP

- Prof. Dra. Sandra Aparecida Sandri - INPE 


\title{
Resumo
}

O compartilhamento e reuso de conhecimento tem sido considerado um tema importante para o uso eficiente de sistemas baseados em conhecimento. Até agora, a maioria das pesquisas abordando esse tema se basearam na hipótese da existência de uma descrição do domínio comum dos sistemas - uma ontologia compartilhada pelos sistemas - adequada a todos com um interesse no conhecimento representado. Infelizmente, a obtenção de uma ontologia de consenso para uma coleção de sistemas pode ser um problema difícil e, mesmo quando uma solução é possível, ela pode não ser suficiente para efetivar o compartilhamento de conhecimento, uma vez que a forma com que o conhecimento é representado está intimamente relacionada com as inferências que podem ser feitas nos sistemas. Um bom exemplo dessa situação pode ser encontrada nos sistemas para raciocínio com incerteza, onde, mesmo que não tenhamos uma ontologia compartilhada para o problema sendo resolvido, precisamos ainda estabelecer as ligações semânticas entre as inferências realizadas dentro de cada sistema para o conhecimento ser realmente compartilhado e reutilizado.

Neste trabalho nós estudamos um caso específico desse problema. Introduzimos dois formalismos para o raciocínio com incerteza, um baseado no raciocínio probabilístico com intervalos e o outro baseado no raciocínio probabilístico puro, e estudamos o compartilhamento de conhecimento entre eles.

\begin{abstract}
Knowledge sharing and reuse has been considered an important issue for cost-effective use of knowledge-based systems. Up until now, the majority of research tackling this issue has been founded on the assumption that there can be a common domain description - a shared ontology - which suits everyone with an interest in the knowledge. Unfortunately, getting an agreed ontology for a collection of systems can be a difficult problem and, even when this problem can be solved, it may not be enough for effective knowledge sharing, since the way we represent knowledge is intimately linked to the inferences we expect to perform with it. A nice example of this situation can be found in systems for reasoning under uncertainty, where even if we do have a shared ontology for the problem being solved we must still establish semantic links between the inferences performed within each system to actually have knowledge being shared and reused.

In this work we study a significant instance of this problem. We introduce two formalisms for reasoning with uncertainty, one for interval-based probabilistic reasoning and another for pure probabilistic reasoning, and study the knowledge sharing between them.
\end{abstract}


ao futuro 


\section{Agradecimentos}

Ao Flávio, por tudo e algo mais.

Aos demais membros do grupo de pesquisa DECaFf-KB, Wamberto Weber Vasconcelos, David Stuart Robertson, Jaume Agusti, Ana Cristina Vieira de Melo e Marcelo Finger, uma vez que muitas das idéias e convenções aqui adotadas foram direta ou indiretamente influenciadas pelo trabalho de todo o grupo.

Ao pessoal de Edinburgo, Escócia, pela grande receptividade durante a minha visita no mês de junho de 2000. E à própria cidade de Edinburgo também!

Ao pessoal da secretaria da CPG e da secretaria do Departamento de Computação do IME-USP pela grande ajuda durante o desenvolvimento deste trabalho.

A todo o pessoal bacana do IME-USP, como aqueles que se sentiram homenageados por esta menção.

À Katia, pelo grande apoio durante a fase final do trabalho.

E a três indispensáveis musas:

Ane, Mini e Dani.

Como sempre, aos que não atrapalharam, também!

Muito obrigado. 


\section{Sumário}

1 Introdução 1

1.1 Plano do Trabalho . . . . . . . . . . . . . . . . 2

1.2 Estudo de Caso . . . . . . . . . . . . . . . . . . . 4

1.3 Organização do Trabalho . . . . . . . . . . . . . . . . . 6

1.4 Créditos . . . . . . . . . . . . . . . . . 7

2 Compartilhamento de Conhecimento $\quad 9$

2.1 Introdução . . . . . . . . . . . . . . . . . . . . . 9

2.2 Conceitos Fundamentais Relacionados com o Compartilhamento de Conhecimento . . . . . . . . . . . . . . . 11

2.2 .1 Reuso de Software . . . . . . . . . . . . . . . . 12

2.2 .2 Semântica . . . . . . . . . . . . . . . . 13

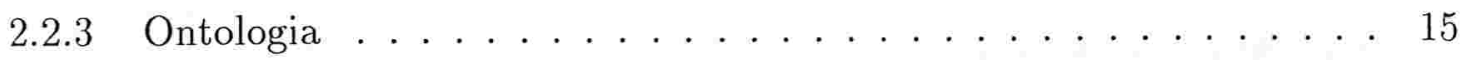

2.2 .4 Linguagens . . . . . . . . . . . . . . . 17

2.2.5 Protocolos de Comunicação . . . . . . . . . . . . . . 18

2.2.6 Processamento Distribuído . . . . . . . . . . . . . . . . 19

2.2.7 Resolução Distribuída de Problemas . . . . . . . . . . . . . . 20

2.2.8 Bancos de Dados Distribuídos . . . . . . . . . . . . . 20

2.2 .9 Mediadores . . . . . . . . . . . . . . . . . 21

2.2 .10 Capacitações . . . . . . . . . . . . . . . . . 22

2.2.11 Programação por Agentes . . . . . . . . . . . . . . 23

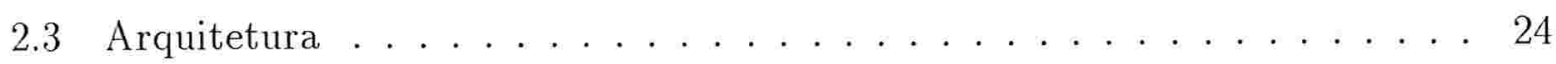

2.4 Linguagens . . . . . . . . . . . . . . . . . . . 26

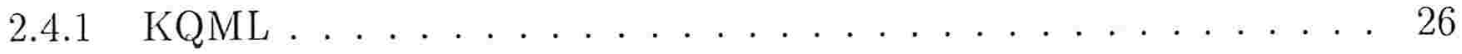




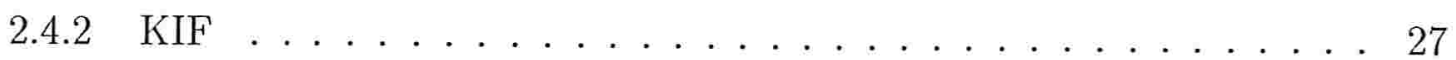

2.5 Experiências em Compartilhamento de Conhecimento . . . . . . . . . . 28

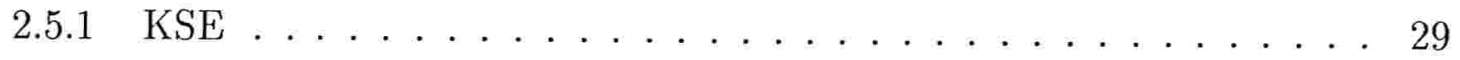

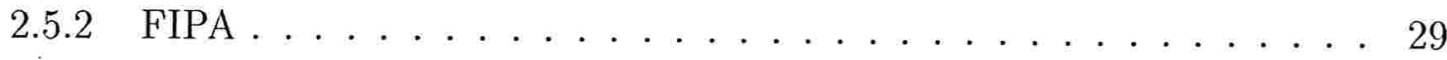

2.5.3 HERMES . . . . . . . . . . . . . . . . 30

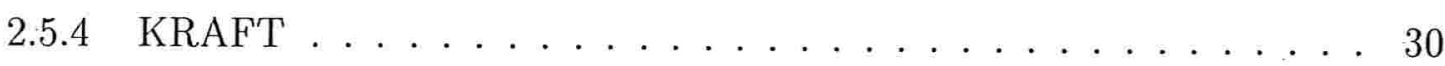

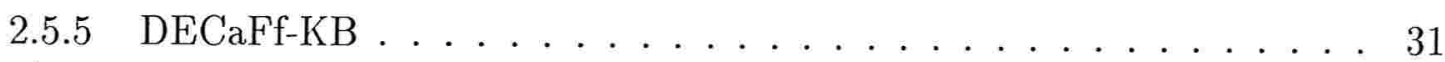

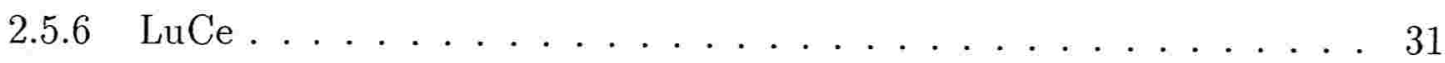

2.6 Considerações Finais . . . . . . . . . . . . . . . . . . . 32

3 Um Modelo de Compartilhamento de Conhecimento $\quad 33$

3.1 Introdução . . . . . . . . . . . . . . . . . . . 33

3.2 Q Modelo Utilizado . . . . . . . . . . . . . . . . . . . . 36

32.1 Relacionamento entre Termos Equivalentes . . . . . . . . . . . 37

3.2 .2 Pré-condições . . . . . . . . . . . . . . 37

3.2 .3 Validade dos Resultados Calculados . . . . . . . . . . . 38

3.2 .4 Descrição Final do Modelo . . . . . . . . . . . . . . . . . . 39

3.3 Arquitetura Computacional . . . . . . . . . . . . . . . . 39

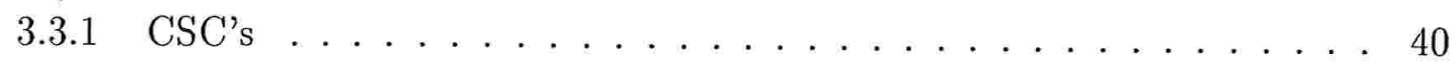

3.3 .2 Broker ............................ 42

3.4 Arquitetura Geral . . . . . . . . . . . . . . . . . . . 44

3.4.1 Compartilhamento de Conhecimento Usando a Arquitetura Geral . 45

3.5 Aspectos Formais do Compartilhamento . . . . . . . . . . . . . 46

3.5.1 Mapeamento entre Termos da Linguagem . . . . . . . . . . . . 47

3.5.2 Análise das Medidas de Crença . . . . . . . . . . . . . . . 48

3.5.3 Análise Semântica . . . . . . . . . . . . . . . . . . 49

3.5.4 Restrições ao Compartilhamento. . . . . . . . . . . . . . . 49

3.6 Considerações Finais . . . . . . . . . . . . . . . . . . . 50

4 Formalismos Utilizados $\quad 53$

4.1 Introdução . . . . . . . . . . . . . . . . . . 53

4.1 .1 Raciocínio com Incerteza . . . . . . . . . . . . . . . . 54 
4.1 .2 Mundos Possíveis . . . . . . . . . . . . . . . 56

4.2 Fundamentos Matemáticos . . . . . . . . . . . . . . . . 57

4.2 .1 Probabilidades ........................ 57

4.2 .2 Programação em Lógica . . . . . . . . . . . . . . . . . . 59

4.2 .3 Teoria de Evidência de Dempster e Shafer . . . . . . . . . . . . 62

4.3 Redes Bayesianas . . . . . . . . . . . . . . . . 65

4.4 Programação em Lógica com Probabilidades . . . . . . . . . . . . . 67

4.4.1 Inferência na Programação em Lógica DSFH . . . . . . . . . . . . 67

4.5 Comparação entre os Formalismos . . . . . . . . . . . . . . . . 69

4.5 .1 Análise Estrutural . . . . . . . . . . . . . . . . . 69

4.5 .2 Análise Operacional . . . . . . . . . . . . . . . 72

4.5 .3 Síntese da Comparação . . . . . . . . . . . . . . 73

4.6 Considerações Complementares . . . . . . . . . . . . . . . 73

5 Compartilhamento de Conhecimento entre Programação em Lógica DSFH e Redes Bayesianas

5.1 Introdução . . . . . . . . . . . . . . . . . . . . 75

5.2 Consistência dos Sistemas . . . . . . . . . . . . . . 78

5.2 .1 Programação em Lógica DSFH . . . . . . . . . . . . . . 79

5.2 .2 Redes Bayesianas . . . . . . . . . . . . . . . . 79

5.3 Mapeamentos entre Sistemas . . . . . . . . . . . . . . 80

5.3.1 Sistema DSFH consulta Sistema DSFH . . . . . . . . . . . . 81

5.3 .2 Sistema DSFH consulta Rede . . . . . . . . . . . . 82

5.3 .3 Rede Consulta Rede . . . . . . . . . . . . . . . 84

5.3 .4 Rede Consulta Sistema DSFH . . . . . . . . . . . . . 86

5.4 Consultas Unidirecionais . . . . . . . . . . . . . . . . . . 88

5.4.1 Sistema DSFH Consulta Sistema DSFH . . . . . . . . . . 89

5.4 .2 Sistema DSFH Consulta Rede . . . . . . . . . . . . . . 89

5.4 .3 Rede Consulta Rede . . . . . . . . . . . . . . . . . . . 92

5.4 .4 Rede Consulta Sistema DSFH . . . . . . . . . . . . . . . 93

5.5 Consultas Bidirecionais Restritas . . . . . . . . . . . . . . . . . . . 94

5.5.1 Sistema DSFH Consulta Sistema DSFH . . . . . . . . . . . 96 
5.5 .2 Sistema DSFH Consulta Rede . . . . . . . . . . . . . . . 98

5.5 .3 Rede Consulta Rede . . . . . . . . . . . . . . . . . . . . . 99

5.5.4 Rede Consulta Sistema DSFH . . . . . . . . . . . . . . . . . 101

5.6 Consultas Bidirecionais Genéricas . . . . . . . . . . . . . . . . . . . 102

5.7 Análise dos Resultados . . . . . . . . . . . . . . . . . . . . 104

5.7 .1 Consultas Unidirecionais . . . . . . . . . . . . . . 105

5.7 .2 Consultas Bidirecionais Restritas . . . . . . . . . . . . 106

5.7 .3 Consultas Bidirecionais Genéricas . . . . . . . . . . . . . 106

5.8 Considerações Finais . . . . . . . . . . . . . . . . . . 107

6 Conclusões Finais 109

$\begin{array}{ll}\text { Apêndice A } & 113\end{array}$

Introdução . . . . . . . . . . . . . . . . . . . . . . . 113

Arquitetura Computacional Proposta . . . . . . . . . . . . . 113

Implementação dos Formalismos . . . . . . . . . . . . . . . . . . . . 114

Implementação do Interpretador para Rede Bayesiana . . . . . . . . 114

Implementação do Interpretador para a Programação em Lógica

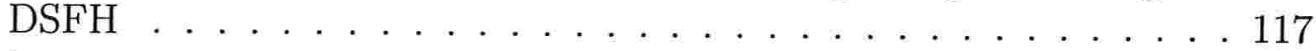

Implementação da Arquitetura . . . . . . . . . . . . . . . . . 118

Implementação da Comunicação entre Componentes . . . . . . . . . 118

$\begin{array}{ll}\text { Apêndice B } & 123\end{array}$

Referências Bibliográficas 133 


\section{Lista de Figuras}

2.1 Prova de $\mathrm{p}(\mathrm{a})$ usando equivalências semanticas entre $S_{1}$ e $S_{2} \ldots \ldots$

2.2 Três sistemas comprometidos com uma ontologia $D \ldots \ldots \ldots$

2.3 Arquitetura ontológica composta pelas ontologias $O_{1}, O_{2}$ e $O_{3} \ldots \ldots$

2.4 Arquitetura do sistema de bancos de dados federados . . . . . . . . . . 21

2.5 Arquitetura de três níveis dos mediadores . . . . . . . . . . . . . 22

2.6 Arquitetura de três níveis dos mediadores . . . . . . . . . . . . . 25

2.7 Arquitetura de três níveis dos mediadores . . . . . . . . . . . . . 25

3.1 Prova de $\mathrm{p}(\mathrm{a})$ por $S_{1}$ com compartilhamento de conhecimento de $S_{2} \ldots \ldots$

3.2 Arquitetura de um CSC . . . . . . . . . . . . . . . 40

3.3 Esquematização de compartilhamento de conhecimento entre CSC's . . . . 41

3.4 Esquematização da arquitetura geral para compartilhamento de conhecimento entre CSC's com capacitações . . . . . . . . . . . . . . . . . . 44

3.5 Reticulados representando valores-verdade dos formalismos $S_{1}$ e $S_{2}$. . . 49

4.1 Classificação de incerteza para sistemas baseados em conhecimento . . . . 56

4.2 Rede bayesiana PobreRB . . . . . . . . . . . . . . . . 66

4.3 Árvore de prova e intervalo para $\mathrm{p}(\mathrm{X}) \ldots \ldots \ldots \ldots \ldots$

5.1 Esquema geral da interação dos sistemas $S_{1}$ e $S_{2}$ onde $|p|_{S_{1}} \equiv|q|_{S_{2}} \ldots 77$

5.2 Esquema geral de uma consulta unidirecional de $S_{1}$ a $S_{2} \ldots \ldots$. . . . . 88

5.3 Dois sistemas DSFH: $S_{1}$, à esquerda, e $S_{2}$, à direita. . . . . . . . . . 89

5.4 Prova de $\mathrm{p}(\mathrm{a})$ de $S_{1}$ usando $\mathrm{m}(\mathrm{e})$ de $S_{2} \ldots \ldots \ldots$. . . . . . 90

5.5 Rede bayesiana que modela a "qualidade" de um estudante . . . . . . . . . . 9 91

5.6 Árvore de prova de mereceAlojamento(John) com compartilhamento de conhecimento . . . . . . . . . . . . . . . . . . . . . 92 
5.7 Consulta unidirecional com uma rede consultando outra . . . . . . . . . 93

5.8 Consulta unidirecional com uma rede bayesiana consultando um sistema lógico . . . . . . . . . . . . . . . . . . . . . . 94

5.9 Esquema geral de uma consulta bidirecinal restrita de $S_{1}$ a $S_{2} \ldots \ldots$. . . 95

5.10 Sistemas $S_{1}$, à esquerda, e $S_{2}$, à direita. . . . . . . . . . . . . . 97

5.11 Consulta bidirecional restrita com um sistema DSFH consultando outro sistema DSFH . . . . . . . . . . . . . . . . . . 97

5.12 Consulta bidirecional restrita com um sistema DSFH consultando uma rede 99

5.13 Esquema de um circuito dirigido em uma rede bayesiana . . . . . . . . 100

5.14 Um exemplo de consulta bidirecional restrita com uma rede bayesiana consultando outra rede bayesiana . . . . . . . . . . . . . . . . . . . 101

$5.15 \mathrm{Um}$ exemplo de consulta bidirecional restrita com uma rede consultando um sistema DSFH . . . . . . . . . . . . . . . . . . . 102

5.16 Esquema geral de uma consulta bidirecional genérica de $S_{1}$ a $S_{2} \ldots \ldots$

6.1 Esquematização de compartilhamento de conhecimento entre CSC's . . . . 114 


\section{Lista de Tabelas}

2.1 Tipos de performativas da linguagem KQML . . . . . . . . . . . . . . 27

4.1 Similaridades estruturais entre programação em lógica DSFH e redes bayesianas para raciocínio com incerteza . . . . . . . . . . . . 73

4.2 Diferenças operacionais entre programação em lógica DSFH e redes bayesianas para raciocínio com incerteza . . . . . . . . . . . . . . . 74 


\section{Capítulo 1}

\section{Introdução}

Desde sua origem, a inteligência artificial tem buscado novas formas de resolução de problemas cuja solução não era satisfatória pelos métodos de computação tradicionais. Devido ao grande número de (tipos de) problemas candidatos a serem resolvidos por técnicas de inteligência artificial, surgiu, paralelamente, um grande número de formalismos não tradicionais, que englobavam técnicas e linguagens de programação. Desta forma, para cada problema específico, buscava-se um formalismo mais adequado para sua modelagem e solução. Os programas resultantes da modelagem de problemas através desses formalismos são chamados de sistemas baseados em conhecimento.

Entretanto, sistemas baseados em conhecimento isoladamente têm se mostrado insuficientes para a resolução de problemas mais complexos, os quais necessitam, para se obter uma solução satisfatória, recursos disponíveis em diversos formalismos existentes.

Uma tentativa de solução desses problemas consiste na elaboração de um novo formalismo lógico que tenha embutido as características dos vários outros formalismos necessários para a solução do problema. Entretanto, o formalismo assim obtido mostra-se complexo demais, tanto nas características da linguagem de programação resultante, quanto nos recursos que o formalismo deve apresentar para controlar (internamente) a "coexistência" de vários modelos de computação distintos. Uma experiência de construção de um único formalismo englobando recursos oferecidos por diversos formalismos para tratamento de incerteza pode ser encontrada em [4]. Outra tentativa consiste na criação de sistemas que oferecem uma representação que possibilita a descrição de sistemas em vários formalismos ao mesmo tempo, como o Pulcinella [33].

Uma solução alternativa consiste em permitir que diversos sistemas baseados em conhecimento compartilhem seus conhecimentos para resolver um problema. Nesta forma de solução de problemas, temos uma arquitetura na qual sistemas baseados em conhecimento, construídos cada qual segundo um formalismo específico, solicitam que outros sistemas baseados em conhecimento resolvam partes de problemas que não consigam resolver. Assim como temos o conceito de "reutilização de software" na computação tradicional, temos agora o princípio de "reutilização de conhecimento" na inteligência artificial. A este pro- 
cesso formal de "cooperação" entre sistemas baseados em conhecimento chamamos de compartilhamento de conhecimento.

O objetivo deste trabalho consiste em estudar e implementar o compartilhamento de conhecimento entre sistemas baseados em conhecimento. Como este problema, do ponto de vista geral, é complexo demais, pois depende das características dos formalismos considerados, optamos por escolher dois formalismos arbitrários e trabalhar com sistemas baseados em conhecimento construídos através deles. Os formalismos considerados são:

- as redes bayesianas, e

- a teoria de evidência de Dempster-Shafer.

Sua escolha baseia-se na comprovada utilidade para modelagem de um mesmo fenômeno, o raciocínio com incerteza, utilizado na construção de sistemas. Além disso, as diferenças entre eles, tanto na forma com que representam o conhecimento, como na forma como o manipulam, apresentam desafios cujo estudo detalhado tem o poder de revelar aspectos do compartilhamento de conhecimento que são dependentes dessas características.

Por se tratar de uma área recente, a bibliografia referente ao compartilhamento de conhecimento ainda é bastante reduzida e as melhores referências correspondem a descrições de projetos de pesquisa documentados na Internet. Os exemplos mais notáveis são os sistemas HERMES [36] e o KRAFT [18] e os projetos "Knowledge Sharing Effort", que deu origem às linguagens KIF [28] e KQML[15], e FIPA[16].

\subsection{Plano do Trabalho}

Neste trabalho, estaremos tratando fundamentalmente de teorias formais. Desta forma, cada sistema baseado em conhecimento considerado será tratado através da teoria formal que implementa. Conseqüentemente, consideraremos um sistema completamente definido através da caracterização da linguagem na qual ele é codificado, seus axiomas e regras de inferências válidas para seu funcionamento. Sob esta ótica, torna-se possível caracterizar o processo de compartilhamento de conhecimento como a interação dos formalismos implementados pelos sistemas participantes.

Entretanto, é importante que os resultados teóricos obtidos sejam também reproduzidos nas implementações de sistemas que codifiquem, em linguagens executáveis por computadores, os formalismos analisados e os métodos propostos. Torna-se, então, útil a elaboração de programas que ilustrem os resultados obtidos. Claramente, o trabalho aqui proposto não tem como objetivo principal a construção de um programa. A importância do desenvolvimento e implementação de um sistema reside na possibilidade de se avaliar um modelo teórico através do comportamento de um programa. Enfim, todos os programas propostos e desenvolvidos no decorrer desta pesquisa têm como objetivo dar suporte a uma teoria e não compor um sistema comercial. 
Neste texto, a palavra "sistema" será usada livremente onde seu significado possa ser abstraído pelo contexto onde ela está inserida. Quando houver ambiguidades, por exemplo, entre sistema formal e software, serão usados sinônimos tais como "formalismo e "programa", respectivamente. Num aspecto mais geral, termos como agente, processo, base de informação, etc. também correspondem a sinônimos do termo "sistema" empregado. Tomamos um cuidado extra com a escolha da terminologia adotada porque certos princípios relacionados com o compartilhamento de conhecimento são presentes em diversas áreas da ciência da computação, como programação por agentes e bancos de dados distribuídos. Na literatura referente, termos como "cooperação", "colaboração", "resolução distribuída de problemas", aparecem, muitas vezes, como sinônimos do "compartilhamento de conhecimento" que adotamos aqui.

No decorrer deste trabalho usaremos o termo Sistema para Compartilhamento de Conhecimento como um termo técnico, definido segundo convenções e escolhas adotadas exclusivamente para a apresentação desta pesquisa. A apresentação dessas convenções está no capítulo 3 .

Embora, no capítulo 2, apresentemos uma visão geral de compartilhamento de conhecimento, no contexto deste trabalho estamos assumindo que sistemas são equivalentes a teorias formais. Essa escolha deve-se à nossa abordagem de compartilhamento de conhecimento como um problema matemático no qual:

1. cada sistema é considerado uma teoria formal e codificado em uma linguagem com sintaxe e semântica bem definidas;

2. a resolução de um problema por um sistema é considerada uma "prova", na qual a teoria formal, com seu mecanismo de inferência, e as hipóteses assumidas pelo sistema são suficientes para se averiguar a validade da prova;

3. o primeiro passo para se estabelecer compartilhamento de conhecimento corresponde ao "mapeamento" entre elementos dos sistemas participantes; este mapeamento relaciona termos nos sistemas que têm significados equivalentes "no mundo real"; e

4. para que o compartilhamento de conhecimento seja possível, é necessário que os sistemas (teorias formais) que compartilham conhecimento não sejam conflitantes.

Uma dificuldade fundamental da nossa abordagem refere-se exatamente ao ítem 4 listado acima: afinal, o que são sistemas conflitantes? Dizemos que dois sistemas estão em conflito se o resultado fornecido por um sistema faz com que o outro sistema torne-se formalmente inconsistente ao aceitar este resultado. Consideramos dois tipos básicos de inconsistência:

1. o valor-verdade do resultado fornecido causa uma inconsistência lógica; e

2. o valor-verdade é aceitável, mas a forma com que ele foi obtido não é. 
Neste trabalho, estamos particularmente interessados em determinar critérios para aceitação de um resultado fornecido por outro sistema. Baseado nesses critérios, concluímos que a dificuldade do estabelecimento do compartilhamento de conhecimento está tão relacionada com o mecanismo de inferência dos formalismos quanto com as teorias formais representadas pelos sistemas.

$\mathrm{Na}$ nossa análise, a especificação da ontologia do domínio a que se referem os sistemas não resolve completamente o problema de compartilhamento de conhecimento [7]. Ainda é necessária uma análise detalhada da linguagem formal especificada pelo sistema, considerando, dentre tantos aspectos, a forma com que os sistemas produzem um resultado, ou seja, seus mecanismos de inferência. Em particular, mostramos, no capítulo 5, a importância do estudo da semântica dos sistemas para se validar uma informação obtida por compartilhamento de conhecimento. Para resolver o problema da análise semântica, do ponto de vista prático, é necessário, ainda, estabelecer formas automáticas de realizá-la.

Além do estudo formal do compartilhamento de conhecimento, acreditamos ser fundamental a aplicação dos resultados obtidos em casos concretos. Idealmente, gostaríamos de atingir um nível tal que, a partir dos resultados teóricos, a implementação dos programas "surgisse" de forma natural e imediata. Adicionalmente, uma implementação apresenta diversas vantagens:

- uma implementação executável do modelo de compartilhamento de conhecimento possibilita uma análise realista dos processos propostos e das convenções adotadas;

- considerando que, do ponto de vista formal, nem sempre é possível o compartilhamento de conhecimento, torna-se útil averiguar, através da análise de testes abrangentes, que fatores impossibilitam, ou até mesmo restríngem, o compartilhamento e como eles podem ser tratados; e

- considerando as restrições ao compartilhamento de conhecimento, analisar o impacto da imposição de restrições nas exigências formais que devem ser obedecidas pelos sistemas para que o compartilhamento seja formalmente possível; naturalmente, quanto mais "fortes" forem as restrições, mais difícil torna-se a possibilidade de haver compartilhamento.

Enfim, esses detalhes "só" podem ser analisados a partir de um estudo de caso concreto de compartilhamento de conhecimento. É exatamente isso o que propomos para este trabalho.

\subsection{Estudo de Caso}

Para avaliar o modelo de compartilhamento de conhecimento proposto, implementaremos sistemas para tratamento de raciocínio com incerteza. Esta opção justifica-se, primordialmente, pela variedade e quantidade de métodos existentes para tratamento deste tipo 
de inferência e, sobretudo, às diferenças formais entre os métodos existentes, tanto no mecanismo de inferência adotado como na medida de incerteza utilizada.

Para trabalharmos com dois formalismos conceitualmente distintos, com a intenção de averiguar seu papel na possibilidade e viabilidade do estabelecimento do compartilhamento de conhecimento entre eles, optamos por um modelo baseado em programação em lógica, que usa a teoria de evidência de Dempster e Shafer como medida de incerteza, e um probabilístico puro, as redes bayesianas.

Acreditamos que, ao resolvermos o problema de compartilhamento de conhecimento para sistemas codificados nesses dois formalismos, estaremos resolvendo uma série de problemas relacionados com as naturezas distintas, tanto na sintaxe quanto na semântica, dessas duas linguagens. Um estudo formal da interação desses dois formalismos propicia a avaliação do papel dessas diferenças em casos reais de compartilhamento de conhecimento.

No estudo de caso, no lugar de considerar ưm problema real e buscar uma solução baseada no compartilhamento de conhecimento, nosso trabalho consiste na escolha de dois formalismos e no estudo do compartilhamento de conhecimento entre sistemas codificados através deles. Para isso,

- consideramos um par de sistemas $S_{1}$ e $S_{2}$, que podem estar codificados em qualquer um dos dois formalismos;

- consideramos que $S_{1}$ deve resolver um problema $p$ e que obtenha, como resposta, um grau de crença $c$ para $p$

- $c$ é considerado um valor "insatisfatório" como suporte para se acreditar em $p$;

- baseado no cálculo de $c$, identificamos alguma informação $t$ que, ao se obter uma melhor estimativa para sua crença, influencie no valor de $c$;

- consideramos que $S_{2}$ é capaz de resolver um problema q que é considerado semanticamente equivalente a $t$; e

- usamos o compartilhamento de conhecimento para que, quando $S_{1}$ resolver um problema e obtiver um resultado "insatisfatório", tenha a opção de usar $S_{2}$ para atribuir um novo grau de crença a $t$ e obter, eventualmente, um resultado que seja considerado "satisfatório".

Descrevemos, dessa forma, um cenário constituído por dois sistemas já existentes e a nossa intenção é fazer com que eles compartilhem seu conhecimento para torná-los "mais eficientes", com relação aos resultados que produzem, ao utilizar informações produzidas pelo outro. No entanto, devemos garantir que o uso, por parte de $S_{1}$, de um grau de crença para $t$ que seja distinto daquele considerado internamente pelo próprio sistema, não o torne formalmente inconsistente.

$\mathrm{Na}$ formulação do estudo de caso considerado, a avaliação do que significa "satisfatório" depende, fundamentalmente, de uma interpretação do usuário, humano, que necessita da 
solução do problema proposto. Por exemplo, considerando um sistema de análise de risco de ataque contra um país, um valor 0,6 pode ser considerado, eventualmente, suficiente para justificar a adoção de estratégias de espionagem contra um país inimigo; por outro lado, o mesmo valor pode ser considerado como insatisfatório para justificar o uso de uma arma nuclear contra o inimigo. No uso do termo satisfatório, imaginamos um cenário onde a resposta a uma consulta feita a um sistema será usada como suporte para se tomar uma decisão. Dessa forma, cabe ao usuário decidir se uma resposta é satisfatória ou não.

Outro detalhe importante corresponde à escolha dos formalismos usados nesse estudo. O fato de eles estarem pré-fixados implica que será descartada a hipótese de, eventualmente, usar um único formalismo que os substitua e que, segundo algum critério, possa ser considerado como uma alternativa à abordagem proposta. Da mesma forma, não consideraremos a hipótese de se alterar ou substituir um dos formalismos para melhorar, de alguma forma, o grau de interação entre os sistemas. Por exemplo, não usaremos o fato de a Teoria de Evidência de Dempster-Shafer ser baseada em intervalos para substituir uma rede bayesiana por um outro tipo de rede, similar mas baseada em intervalos [8].

\subsection{Organização do Trabalho}

No capítulo 2 é apresentado um resumo da área de compartilhamento de conhecimento. Além de introduzir grande parte da terminologia técnica utilizada, abordaremos várias de suas facetas, encontradas em áreas como programação por agentes e bancos de dados distribuídos. Ainda, vale a pena destacar áreas como engenharia de software, processamento distribuído, lógica abstrata, que também estão relacionadas com certos aspectos do compartilhamento de conhecimento.

Dedicado ao modelo de compartilhamento de conhecimento que será efetivamente usado nesse trabalho, o capítulo 3 apresenta, dentre os recursos descritos no capítulo anterior, aqueles que se mostraram úteis ao modelo formal com o qual propomos trabalhar. Apresentaremos uma arquitetura adequada ao modelo adotado, destacando o papel de cada sistema dentro da arquitetura. Completaremos o capítulo abordando o impacto de imposição de restrições no processo de compartilhamento de conhecimento. Apesar de, por um lado, as restrições aumentarem as exigências a serem atendidas por um sistema candidato a compartilhar seus conhecimentos, por outro, aumenta a confiança no resultado obtido (desde que, é claro, as restrições sejam especificadas de forma a detectar situações indesejáveis nas quais o compartilhamento deve ser evitado).

O capítulo 4 oferece uma descrição dos formalismos das redes bayesianas e da teoria de evidência de Dempster-Shafer, que será usada com a função de crença de Fagin e Halpen. Além de apresentar um resumo das características de cada um desses formalismos, será feita uma análise para identificar os aspectos formais que facilitam ou que dificultam o compartilhamento de conhecimento entre sistemas modelados segundo esses formalismos.

Usando detalhes da análise feita no capítulo anterior, o capítulo 5 descreve o problema 
de compartilhamento de conhecimento entre os formalismos propostos e apresenta as soluções encontradas. Descreveremos exemplos de consultas aos sistemas nos quais os sistemas individualmente são incapazes de resolver satisfatoriamente certos problemas e o compartilhamento de conhecimento será usado para se encontrar boas soluções. Nesses experimentos, analisaremos o papel das restrições como forma de garantir a consistência dos resultados obtidos e seu "custo" ao dificultar a realização do compartilhamento.

Finalmente, o apêndice A descreve a implementação dos programas utilizados para executar os sistemas escritos nos formalismos considerados, enquanto o apêndice B apresenta o artigo [6], apresentado na conferência IPMU 2000 e que descreve algumas idéias básicas consideradas neste trabalho.

Com esta organização, os capítulos 2 e 3 são genéricos, independentes dos formalismos considerados no compartilhamento de conhecimento. Os resultados dos capítulos 4 e 5, em geral, foram obtidos especificamente para os formalismos de redes bayesianas e teoria de evidência de Dempster-Shafer, mas acreditamos que a forma de abordagem do problema possa sugerir formas de tratamento de compartilhamento de conhecimento para outros formalismos, em especial para aqueles dedicados ao raciocínio com incerteza. Os resultados do apêndice A são dependentes não só dos formalismos considerados, como da plataforma computacional onde foram implementados os programas.

\subsection{Créditos}

Este trabalho está diretamente relacionado com o projeto "Cooperação Entre Sistemas Baseados em Conhecimento", financiado pelo convênio CAPES/British Council, 070/98, sob coordenação geral do Prof. Flávio Soares Correa da Silva. 


\section{Capítulo 2}

\section{Compartilhamento de Conhecimento}

Neste capítulo apresentamos o problema geral de compartilhamento de conhecimento através da descrição dos diversos conceitos, idéias, métodos e princípios presentes nas suas abordagens mais comuns encontradas na literatura. Essas diversas abordagens, concentradas principalmente nas áreas de inteligência artificial distribuída, com programação por agentes em particular, e bancos de dados distribuídos, deparam-se com um problema comum que tem como aspecto principal a combinação de informações disponíveis em localidades diferentes. Concluímos o capítulo com a descrição de projetos de pesquisa que visam a criação de métodos, padrões e tecnologias que auxiliem no compartilhamento de conhecimento.

\subsection{Introdução}

Dado um sistema baseado em conhecimento, seu conhecimento é caracterizado pelo conjunto das respostas que ele é capaz de fornecer como resultado para as consultas possíveis de serem feitas. Chamamos de compartilhamento de conhecimento o processo pelo qual um conjunto de sistemas participam coletivamente da resolução de um problema. O compartilhamento de conhecimento é totalmente caracterizado pela interação de um conjunto de sistemas para se resolver um problema.

$\mathrm{Na}$ inteligência artificial, a idéia de compartilhamento de conhecimento torna-se fundamental, uma vez que problemas complexos apresentam aspectos que são difíceis de ser tratados através de um único formalismo. Além disso, a divisão de um sistema em subsistemas modulares individuais, formalmente bem definidos e sistematicamente construídos, auxilia no processo de desenvolvimento do sistema. Esse caráter modular do sistema desenvolvido permite que certos módulos sejam substituídos por "consultas" a sistemas pré-existentes, eliminando, dessa forma, a necessidade de redesenvolver certas partes do sistema. Assim, no lugar de se considerar um sistema como uma "unidade" fundamental básica, passa-se a tratá-lo como o resultado da combinação de diversos subsistemas, cada qual especializado para a solução de certos aspectos específicos de um problema. Do 
ponto de vista formal, a principal desvantagem do compartilhamento de conhecimento é a dificuldade de se garantir a consistência de um sistema após assumir alguma informação produzida externamente.

Para se estabelecer o compartilhamento de conhecimento devemos resolver os seguintes problemas básicos:

1. permitir a interação entre sistemas; para isto, recorre-se a arquiteturas que incluam os sistemas como componentes e protocolos de comunicação que padronizem a interação entre eles;

2. permitir a troca de mensagens entre os sistemas, seguindo-se os padrões especificados no protocolo de comunicação;

3. permitir o compartilhamento de conhecimento entre sistemas heterogêneos, cada qual projetado e implementado de forma particular e específica para seu fim;

que constituem o mínimo que se espera numa proposta de solução desse problema. Adicionalmente, propomos os seguintes problemas como relevantes para se obter uma solução geral e útil do problema:

4. ter a possibilidade de testar a validade dos resultados compartilhados para a solução de um problema; a rejeição de um resultado pode ser motivada por:

(a) o valor-verdade associado ao resultado é considerado insatisfatório;

(b) as premissas utilizadas na geração do resultado podem não ser consideradas válidas;

(c) a forma com que o resultado foi produzido pode ser considerada inadequada.

5. conseguir uma forma padronizada de estabelecer compartilhamento de conhecimento de forma natural e que seja o mais independente possível das características individuais dos sistemas participantes.

Em geral o problema referente ao item 4 não é muito explorado: assume-se que um resultado fornecido é válido, independentemente disso causar efeitos colaterais ou não. O item 5 já é bastante ambicioso, constituindo o "estado da arte" na área de compartilhamento de conhecimento.

No compartilhamento de conhecimento, um sistema que solicita que algum outro sistema compartilhe seu conhecimento com ele é chamado de cliente, enquanto que um sistema que fornece algum resultado é chamado de servidor. Note que, dependendo do contexto, um mesmo sistema pode atuar tanto como um cliente quanto como um servidor. Dizemos que um sistema $A$ compartilha conhecimento com um sistema $B$ se o conhecimento de $A$ pode ser acessado por $B$. Note que a propriedade de compartilhar conhecimento não é, necessariamente, simétrica. Ou seja, o fato de $A$ compartilhar seu conhecimento com $B$ não implica que $B$ compartilha seu conhecimento com $A$. Chamamos simplesmente de sistema disponível um sistema baseado em conhecimento que disponibiliza o seu conhecimento para compartilhá-lo com outros sistemas. A seguir apresentamos: 
- uma descrição dos conceitos fundamentais relacionados com o compartilhamento de conhecimento;

- o papel da arquitetura dos sistemas no compartilhamento de conhecimento;

- o papel das linguagens no compartilhamento de conhecimento; e

- uma descrição de alguns projetos que buscam desenvolver padrões ou tecnologias que amparem o compartilhamento de conhecimento.

\subsection{Conceitos Fundamentais Relacionados com o Compartilhamento de Conhecimento}

Por estar presente em diversas áreas da ciência da computação, o compartilhamento de conhecimento é apresentado em diversas abordagens que exploram, de formas particulares, métodos, terminologias e objetivos específicos dessas áreas. Considerando a dificuldade de elaboração de uma abordagem geral, optamos pela apresentação dos aspectos principais que as fundamentam. As principais áreas relacionadas com o compartilhamento de conhecimento são:

- inteligência artificial distribuída, e agentes de software, em particular;

- processamento distribuído;

- bancos de dados distribuídos.

Independentemente dos interesses particulares de cada uma dessas áreas, todas elas têm de, pelo menos, considerar o problema de combinar informações disponíveis em um conjunto de sistemas individuais. Na nossa apresentação, não nos preocuparemos com os detalhes muito específicos dessas áreas. Concentraremos todo o nosso esforço em apresentar os conceitos de forma genérica, enfatizando de que forma o compartilhamento de conhecimento está relacionado com eles:

- reuso de software

- semântica

- ontologia

- linguagens

- protocolos de comunicação

- processamento distribuído

- resolução distribuída de problemas

- bancos de dados distribuídos

- mediadores

- capacitações

- programação por agentes 
A seguir apresentamos separadamente cada um desses temas, enfatizando sua relevância no compartilhamento de conhecimento.

\subsubsection{Reuso de Software}

Reuso de software é o processo de criação de sistemas de software a partir de software previamente existente [23]. Apesar de existir uma grande diversidade nas tecnologias de engenharia de software que envolvem alguma forma de reuso de software, elas apresentam, geralmente, vários aspectos comuns:

abstração: Todas as abordagens de reuso de software utilizam alguma forma de abstração para os artefatos de software. Abstração é a característica essencial de qualquer técnica de reuso. Sem abstrações, desenvolvedores de software seriam forçados a examinar uma coleção de artefatos reusáveis na tentativa de determinar o que cada artefato faz, quando pode ser reusado e como reusá-lo.

seleção: A maioria das abordagens de reuso auxiliam os desenvolvedores a localizar, comparar e selecionar artefatos de software.

especialização. Em muitas tecnologias de reuso, artefatos similares são integrados em um único artefato genérico. Depois de selecionar o artefato genérico, o desenvolvedor especializa o artefato através de parâmetros, transformações, restrições ou outra forma de refinamento.

integração: Tecnologias de reuso tipicamente têm uma estrutura conceitual de integração. O desenvolvedor de software usa essa estrutura para combinar uma coleção de softwares selecionados e especializados em um sistema de software completo.

No entanto, reuso, no contexto relacionado acima, refere-se principalmente com a engenharia de software nos métodos de computação tradicionais. Na inteligência artificial, a preocupação fundamental não é simplesmente reuso de software, mas reuso de conhecimento. Na adaptação dos aspectos relacionados acima para o reuso de conhecimento na inteligência artificial, obtemos:

Abstração. Na inteligência artificial, uma preocupação fundamental é com a descrição da semântica dos sistemas. A partir dela, torna-se possível o uso de métodos formais voltados para a descrição e manipulação dos sistemas. Ela também auxilia na descrição do domínio no qual um conjunto de sistemas se relacionam com a especificação da ontologia desse domínio.

Integração. $\mathrm{Na}$ inteligência artificial, em geral, os artefatos são integrados através de uma arquitetura na qual eles interagem. Os mediadores (vide seção 2.2.9) constituem uma primeira tentativa de especificar o funcionamento de um gerente voltado para a integração de informações provenientes de diversas bases de dados. Em plataformas 
para compartilhamento de conhecimento, como o HERMES e o KRAFT, a semântica "externa" de cada sistema é bem caracterizada através da descrição dos sistemas com relação a ontologias. Além da especificação de domínios e de arquiteura, para a integração é importante dispor de métodos (formais) para se testar a consistência dos resultados obtidos.

Seleção. É feita com o auxílio de uma descrição da semântica dos sistemas. A partir dela é possível identificar as capacidades e habilidades dos componentes e selecionar o mais adequado. Para isso recorre-se à especificação da ontologia do domínio no qual se descreve o item a ser selecionado e o uso de capacitações para a especificação dos sistemas capazes de fornecê-lo.

Especialização. Também feita através da descrição semântica, a partir de especificações formais dos sistemas e domínios e com o uso de instanciação de variáveis livres.

Conforme destacado na apresentação acima, a descrição da semântica dos componentes de um conjunto de sistemas disponíveis para compartilhamento de conhecimento é o principal fator que influencia o reuso de conhecimento, e, consequentemente, o compartilhamento de conhecimento, entre eles. Essa situação estimula o desenvolvimento de recursos que auxiliem na descrição da semântica e, também, na sua manipulação. Alguns exemplos de tais recursos são os mediadores, apresentados na seção 2.2.9, que constituem uma das primeiras propostas de arquitetura para auxiliar na integração de informações distribuídas, e as ontologias, apresentados na seção 2.2.3, uma descrição formal das características da semântica do domínio relacionado com um sistema.

\subsubsection{Semântica}

Um aspecto fundamental no compartilhamento de conhecimento é a interpretação do significado dos vocabulários dos sistemas. O compartilhamento de conhecimento só é possível a partir de uma correspondência entre termos semanticamente equivalentes dos sistemas, ou seja, sistemas que compartilham conhecimento devem concordar em um vocabulário básico constituído de termos semanticamente comuns aos sistemas. Por exemplo, o termo "árvore", usado por um botânico, não pode ser traduzido para o termo "árvore", usado por um matemático da área de combinatória. No entanto, o mesmo termo "árvore", usado por um matemático da área de combinatória, pode ser traduzido para o termo "grafo conexo acíclico", usado por um matemático da área de teoria dos grafos.

Uma abordagem comum do problema da especificação da semântica de um sistema é a caracterização da ontologia à qual ele se refere. No entanto, as ontologias tratam apenas da caracterização de um domínio comum ao qual os sistemas se referem. Outros detalhes, como, por exemplo, a forma como cada sistema realiza suas deduções, são ignorados. Por exemplo, um sistema baseado em lógica intuicionista não deve aceitar um resultado produzido por outro sistema que, para sua dedução, usa a validade de uma fórmula como 
$p \vee \neg p$. Esse tipo de fenômeno não é possível de ser abordado somente através das ontologias.

\section{Como a Semântica é Usada}

A partir do estudo da semântica dos sistemas podemos resolver uma série de problemas, como:

- a análise da semântica dos sistemas auxilia na caracterização do domínio ao qual os sistemas se referem;

- a caracterização do domínio dos sistemas permite o mapeamento entre termos comuns das linguagens de sistemas de tal forma que informações não disponíveis em um sistema sejam associadas a consultas dirigidas aos sistemas capazes de fornecê-las;

- o estudo dos domínios dos sistemas auxilia no desenvolvimento de métodos formais para a descrição e manipulação de ontologias;

- a análise dos conceitos de verdade associados aos sistemas e a definição de equivalências entre os valores-verdade de sistemas (formalmente) heterogêneos.

A partir do estudo desses problemas, torna-se possível a combinação de conhecimento proveniente de bases de conhecimento formalmente heterogêneas $\mathrm{O}$ exemplo 2.2.1, logo abaixo, ilustra o papel da análise da semântica dos sistemas no compartilhamento de conhecimento.

Neste texto, usamos a seguinte notação: dados os sistemas $S_{1}$ e $S_{2}$ e os termos $a$ e $b$ tais que $a$ pertence à linguagem formal usada pelo sistema $S_{1}$ e $b$ pertence à linguagem formal usada pelo sistema $S_{2}$, escrevemos $|a|_{S_{1}} \equiv|b|_{S_{2}}$ para exprimir que o significado de $a$ em $S_{1}$ é equivalente ao significado de $b$ em $S_{2}$.

Exemplo 2.2.1 Considere os seguintes fragmentos de sistemas codificados em Prolog:

$$
\begin{array}{ll}
\text { Sistema } S_{1} & \text { Sistema } S_{2} \\
\mathrm{p}(\mathrm{X}):-\mathrm{q}(\mathrm{X}), \mathrm{r}(\mathrm{X}) . & \mathrm{u}(\mathrm{Y}):-\mathrm{v}(\mathrm{Y}) . \\
\mathrm{q}(\mathrm{a}) . & \mathrm{v}(\mathrm{d}) . \\
\mathrm{r}(\mathrm{b}) . &
\end{array}
$$

Assuma que, baseado em observações de pessoas que conheçam profundamente esses sistemas, $|r(a)|_{S_{1}} \equiv|u(c)|_{S_{2}}$ e que $|v(c)|_{S_{2}} \equiv|r(b)|_{S_{1}}$. Esse mapeamento entre termos semanticamente equivalentes torna válida a prova de $\mathrm{p}$ (a) exibida na figura 2.2.1. Nessa prova, usa-se $\mathrm{r}(\mathrm{b})$ para provar $\mathrm{r}(\mathrm{a})$. Isso se deve à interpretação das equivalências entre os sistemas. No exemplo, $S_{2}$ é usado para renomear as constantes a e b. Uma forma de $S_{1}$ evitar tais tipos de demonstrações é ele assumir a política de somente aceitar provas de $S_{2}$ que não usem a cláusula $\mathrm{u}(\mathrm{Y}):-\mathrm{v}(\mathrm{Y})$. 


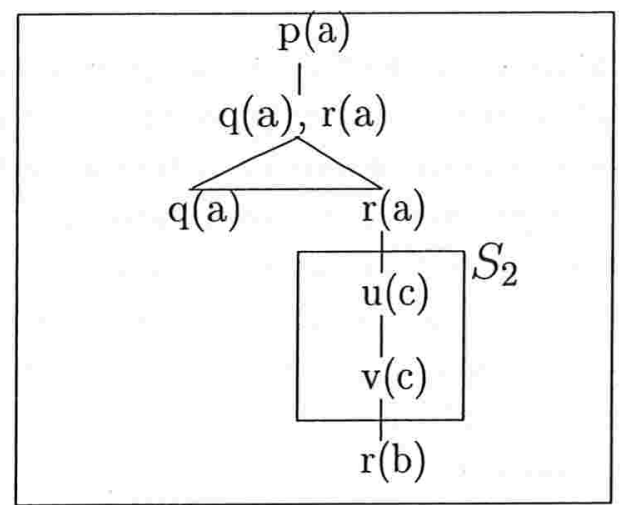

Figura 2.1: Prova de $\mathrm{p}(\mathrm{a})$ usando equivalências semanticas entre $S_{1}$ e $S_{2}$

\subsubsection{Ontologia}

Ontologia [19] é uma especificação explícita de uma conceitualização. Quando o conhecimento sobre um domínio é representado em um formalismo declarativo, o conjunto dos objetos que podem ser representados é chamado de universo de discurso. Este conjunto de objetos, e os relacionamentos descritíveis entre eles, são refletidos no vocabulário através do qual um sistema baseado em conhecimento representa conhecimento. Em uma ontologia, definições associam os nomes de entidades no universo de discurso (por exemplo, classes, relações, funções ou outros objetos) com um texto fácil de ser compreendido descrevendo qual o significado dos nomes e axiomas formais que restringem a interpretação e uso correto desses termos. Formalmente, uma ontologia é a especificação de uma teoria formal. O exemplo 2.2.2 apresenta um exemplo de um fragmento de uma especificação de ontologia.

Exemplo 2.2.2 O seguinte código, escrito na linguagem KIF, consultado em [19], define physical-quantity como um objeto caracterizado por magnitude e unidade de medida. A definição especifica que a magnitude e a unidade devem estar definidas para todos os objetos considerados como physical-quantity e que a magnitude é do tipo double-float $e$ que a unidade de medida pertence a um conjunto dado.

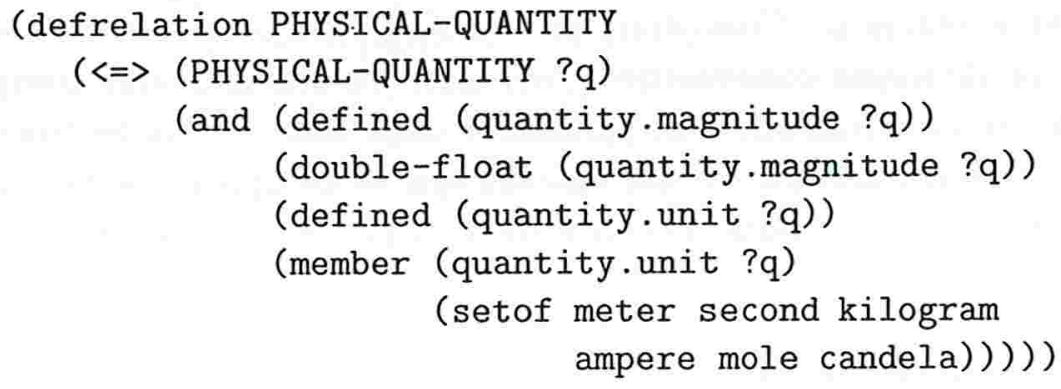

Como a definição é feita com a condição se-e-somente-se $(<=>)$, ela especifica que todo objeto que pode ser caracterizado por essa magnitude e medida define uma quantidade física. 
Usamos ontologias comuns para descrever compromissos ontológicos [19] entre um conjunto de sistemas de tal forma que eles possam se comunicar sobre um domínio de discursos sem necessariamente operar sobre uma teoria globalmente compartilhada. Dizemos que um sistema se compromete com uma ontologia se suas ações observáveis são consistentes com as definições na ontologia. Por exemplo, todos os sistemas que se comprometem com a definição de quantidade física apresentada no exemplo 2.2.2 devem concordar exatamente com a declaração especificada pelo código em KIF. O exemplo 2.2.3 descreve esquematicamente o papel da ontologia na especificação de um domínio para o compartilhamento de conhecimento.

Exemplo 2.2.3 A figura 2.2 representa uma ontologia $D$ de um dominio e três sistemas, $S_{1}, S_{2}$ e $S_{3}$, comprometidos com essa ontologia. Cada sistema apresenta sua ontologia local, $O_{S_{1}}, O_{S_{2}}$ e $O_{S_{3}}$, respectivamente, e a parte comum delas com $D$, representadas por, $O_{D_{1}}, O_{D_{2}}$ e $O_{D_{3}}$, respectivamente, descreve a visão de cada sistema do domínio especificado por $D$.

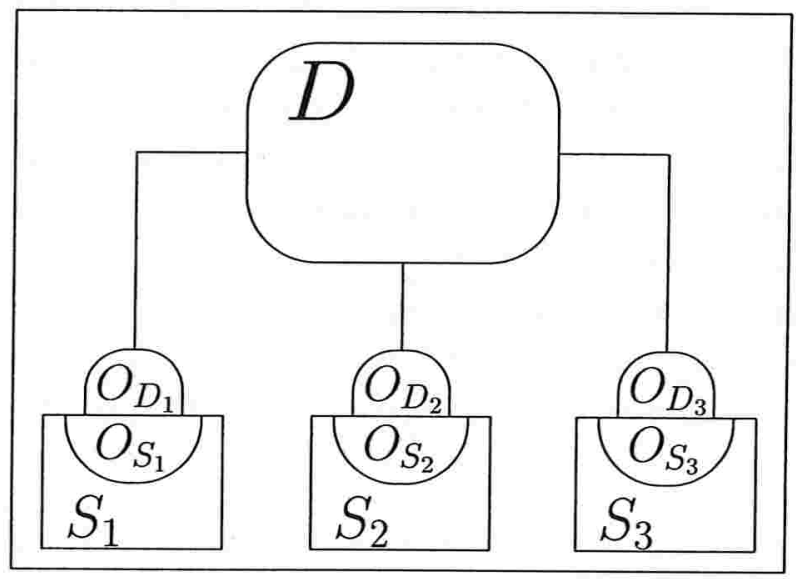

Figura 2.2: Três sistemas comprometidos com uma ontologia $D$

Dessa forma, uma ontologia compartilhada define o vocabulário com o qual consultas e asserções são trocadas entre sistemas. Compromissos ontológicos são acordos de usar o vocabulário compartilhados de forma consistente e coerente. Os sistemas que compartilham um vocabulário não necessariamente compartilham uma base de conhecimento; cada um sabe de coisas que o outro não sabe e um sistema que se compromete com uma ontologia não é obrigado a responder a todas as consultas que podem ser formuladas no vocabulário compartilhado.

\section{Arquitetura do Domínio dos Sistemas}

Quando os sistemas que participam de uma arquitetura para compartilhamento de conhecimento se comprometem com uma ontologia, a ontologia caracteriza o domínio no qual os sistemas se inserem. Na sua forma mais simples, temos um único domínio e todos 
os sistemas seguem, consensualmente, às especificações dele, como representado na figura 2.2 .

Uma outra forma de caracterizar o domínio é fazer com que ele seja definido por pares de sistemas: a parte comum das ontogias de um par de sistemas é suficiente para se caracterizar a ontologia do domínio definido pelo par. Dessa forma, não é necessário impor que todos os demais sistemas concordem com o mesmo significado atribuído aos termos do domínio. A parte semelhante de cada par de sistemas constitui informação suficiente para caracterizar completamente o domínio definido pela interação deles.

Uma alternativa, intermediária a essas duas abordagens, é proposta dentro do projeto KRAFT [34], que descreve uma arquitetura ontológica para representar a ontologia de uma arquitetura de compartilhamento de conhecimento. Essa arquitetura é útil para representar bases de conhecimento que tomam parte de um domínio de interesse comum mas que variam nas suas especializações de interesse dentro do domínio. Na figura 2.2.3 representamos uma ontologia geral, chamada $O_{1}$, e as ontologias $O_{2}$ e $O_{3}$, especializações de $O_{1}$. Com essa organização de ontologias podemos fazer com que os sistemas se comprometam com a ontologia mais adequada para seu papel dentro do domínio.

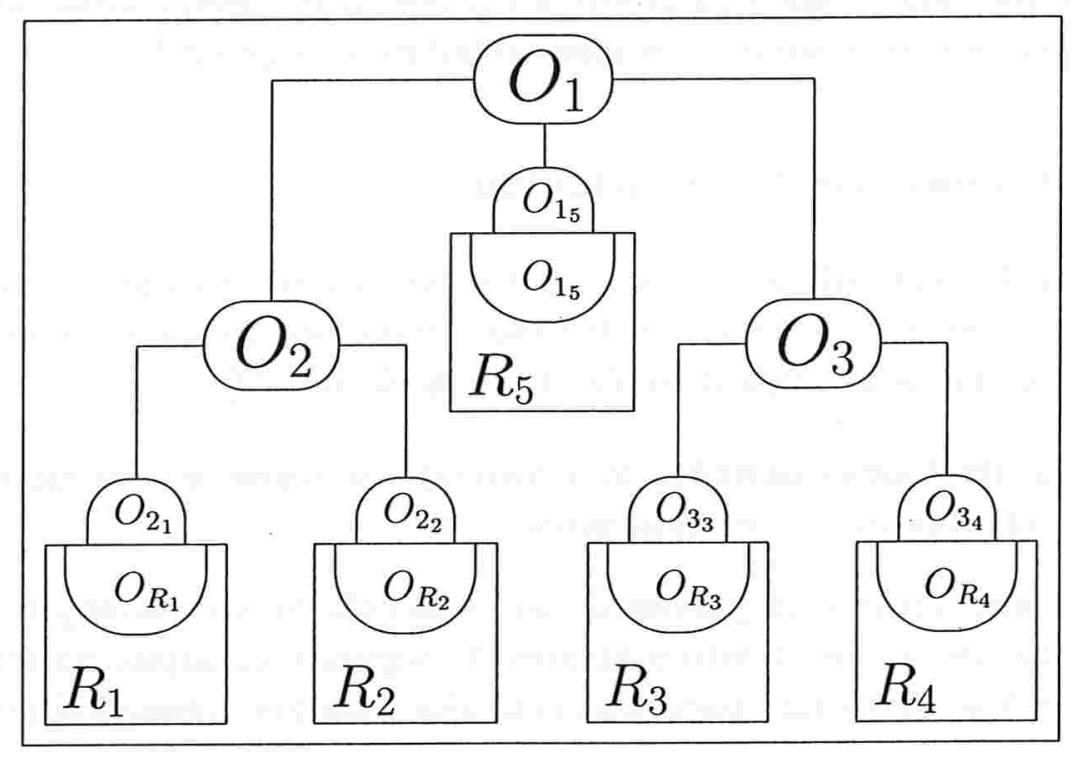

Figura 2.3: Arquitetura ontológica composta pelas ontologias $O_{1}, \mathrm{O}_{2}$ e $\mathrm{O}_{3}$

\subsubsection{Linguagens}

As linguagens de comunicação são fundamentais para o compartilhamento de conhecimento pois é necessário estabelecer uma forma através da qual os sistemas troquem informações entre si. No compartilhamento de conhecimento, as linguagens desempenham as seguintes funções: 
1. descrever as propriedades dos sistemas;

2. descrever o domínio a que se referem os sistemas;

3. permitir a troca de mensagens entre sistemas;

4. padronizar a interação entre sistemas.

As duas primeiras propriedades se referem, basicamente, à descrição da ontologia do domínio no qual os sistemas se inserem e das propriedades apresentadas pelos sistemas. Essas características são usadas para se descrever um vocabulário comum através do qual os sistemas são capazes de trocar mensagens. As duas últimas referem-se à capacidade dessas linguagens como meio de estabelecimento de um protocolo de comunicações entre os sistemas.

As linguagens de comunicação devem ser definidas externamente aos sistemas, que se comprometem na sua adoção como linguagem de comunicação com outros sistemas. Isso permite que um sistema seja codificado na sua linguagem mais adequada e use a linguagem de comunicação somente quando necessitar de trocar mensagens com outros sistemas.

Devido à importância das linguagens no processo de compartilhamento de conhecimento, estudaremos esse assunto com mais detalhes na seção 2.4.

\subsubsection{Protocolos de Comunicação}

Em decorrência da necessidade de troca de mensagens entre os sistemas, surge a necessidade de se padronizar a interação entre eles. Para isto torna-se necessário introduzir protocolos de comunicação (cuja definição foi tomada de [29]):

Protocolo de Comunicação: É o conjunto de regras e convenções de conversação entre entidades comunicantes.

Uma forma de identificar a importância do protocolo de comunicação no processo de compartilhamento de conhecimento é através do seguinte exemplo, no qual descrevemos o mecanismo de "backtracking" para uma consulta feita por compartilhamento de conhecimento:

Exemplo 2.2.4 Sejam $S_{1}$ e $S_{2}$ dois sistemas que compartilham conhecimento. Suponha que $S_{1}$ tenha acesso direto ao conhecimento de $S_{2}$. Assim, no caso de $S_{1}$ fazer uma consulta " $q$ ?" a $S_{2}$, obter uma resposta " $r_{1}(q)$ " e considerá-la insatisfatória, o próprio $S_{1}$ pode refazer a mesma consulta " $q$ ?" ao mesmo sistema. Mas, como ocorre usualmente, a nova consulta produzirá a mesma resposta obtida anteriormente. Uma forma de se contornar esse problema é padronizar que a primeira consulta "q?" inicia um protocolo de comunicação entre $S_{1}$ e $S_{2}$. A cada nova solução solicitada, $S_{1}$ envia a mesma mensagem "q?" a $S_{2}$ e a cada nova consulta $S_{2}$ envia a resposta seguinte ou uma mensagem indicando que não existem mais soluções. Por sua vez, $S_{1}$ pode interromper, a qualquer instante, o backtracking ao enviar a $S_{2}$ uma mensagem como " $q$. ". 
Estenderemos nossa apresentação de protocolos de comunicação na seção 2.4.1, onde apresentamos a linguagem KQML, usada para a especificação de protocolos de comunicação entre sistemas.

\subsubsection{Processamento Distribuído}

Processamento distribuído é um tipo de computação no qual o processamento não é centralizado em um único sistema, mas realizado por vários. Com relação ao compartilhamento de conhecimento, o processamento distribuído deu origem a áreas como inteligência artificial distribuída, agentes de software e bancos de dados distribuídos. Assim como nos sistemas distribuídos, no compartilhamento de conhecimento temos uma série de questões relacionadas ao comportamento dos sistemas:

coordenação: Algumas abordagens pressupõem a existência de um módulo de software que seja responsável pela coordenação da tarefa executada pelos sistemas. Uma alternativa é considerar que, no processamento distribuído, os sistemas sejam responsáveis pela coordenação dos problemas que eles, individualmente, resolvem. Assim, um sistema $S$ pode delegar partes do problema para que sejam resolvidas por outros sistemas e impor certas condições que os demais sistemas devem atender para que sua solução dessas partes do problema sejam aproveitadas por $S$. De certa forma, o sistema que dirige uma consulta tem o direito de coordenar o processo de obtenção da resposta. Em geral, a opção por um determinado modelo de coordenação é embutida na arquitetura do sistema para compartilhamento de conhecimento utilizado, conforme apresentado na seção 2.3 e ilustrado nas figuras 2.6 e 2.7.

"deadlock": dependendo de como for implementada a interação entre os sistemas, existe a possibilidade de um sistema aguardar que um outro se disponibilize para uma consulta, enquanto que o outro sistema esteja indisponivel por estar aguardando que o primeiro se disponibilize para resolver uma consulta sua.

problema do ciclo: Um problema criado com o processamento distribuído é a possibilidade de criação de ciclos durante a resolução de problemas. Isto ocorre, na sua forma mais simples, quando um sistema $A$ solicita ajuda para um sistema $B$ e $B$, ao auxiliar $A$, pede ajuda a $A$, que pede ajuda a $B$, etc. Note que nem sempre essas chamadas recorrentes são indícios de problemas: pode ocorrer casos em que em cada ciclo $A \rightarrow B \rightarrow A$ as consultas tornem-se cada vez mais simples até que se chegue a uma resposta. O problema principal é detectar previamente os casos em que existe alto risco de se gerar um ciclo infinito.

Existem outros aspectos importantes de sistemas distribuídos que, dependendo da abordagem assumida, podem ser relevantes para o compartilhamento de conhecimento. Dentre eles encontramos o idéia de tempo, o sincronismo, a tolerância a falhas, o estabelecimento de consenso, etc. 


\subsubsection{Resolução Distribuída de Problemas}

O compartilhamento de conhecimento tem muitos aspectos similares aos encontrados na área de resolução distribuída de problemas [11], cujo objetivo é resolver problemas através da colaboração de um conjunto de sistemas.

O compartilhamento de conhecimento, enquanto modelo de resolução de problemas, pode adotar, genericamente, duas estratégias no tratamento do problema a ser resolvido:

problema global aos sistemas: o problema a ser resolvido é representado em uma área global aos sistemas que colaboram para resolvê-lo. Cada sistema se encarrega de resolver certos aspectos do problema e, no final do processo, chega-se à solucão do problema.

problema local a um sistema: nesse caso, temos um problema cuja solução é buscada por um sistema específico. A incapacidade do sistema em resolvê-lo satisfatoriamente faz com que ele próprio procure outros sistemas capazes de auxiliá-lo na resolução certos aspectos do problema. Não necessariamente os sistemas que compartilham conhecimento têm acesso à descrição do problema que o sistema original está resolvendo.

\subsubsection{Bancos de Dados Distribuídos}

Embora constitua uma área um tanto distante da inteligência artificial, muitos dos problemas enfrentados na IA distribuída são também tratados na área de Bancos de Dados Distribuídos [21, 35]. Nesta também ocorre o problema de se combinar informações provenientes de várias bases de informação independentes entre si, descritas através de modelos de dados distintos, com formas de consultas particulares e com dados cuja semântica é específica para cada sistema individual.

Um Sistema de Banco de Dados Federados (SBDF)[35] é uma coleção de sistemas de bancos de dados cooperantes mas autônomos. O software que proporciona a manipulação controlada e coordenada dos sistemas de banco de dados componentes é chamado de Sistema de Administração de Banco de Dados Federados (SABDF). A figura 2.4 apresenta a arquitetura desse modelo de banco de dados: o SABDF, recebe consultas feitas pelos usuários do sistema e ele próprio se responsabiliza em acessar os bancos de dados, combinar as informações obtidas e retornar a resposta ao usuário.

Um problema central encontrado na implementação dos bancos de dados federados é a integração de informações semanticamente heterogêneas [3], pois, assim como no compartilhamento de conhecimento, não existe nenhum padrão na representação dos dados e na interpretação da sua semântica. 


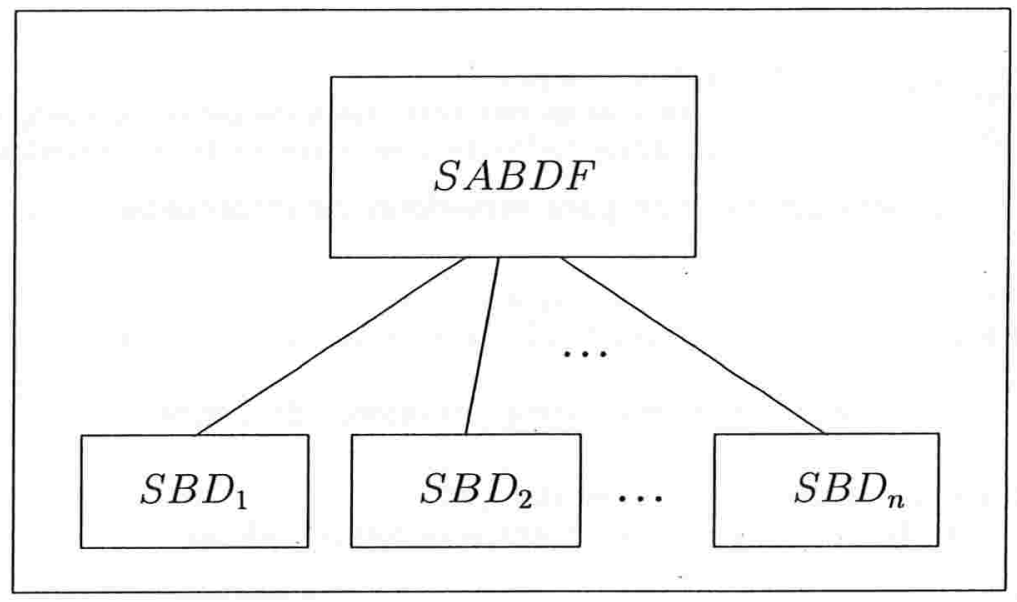

Figura 2.4: Arquitetura do sistema de bancos de dados federados

\subsubsection{Mediadores}

O conceito de mediador foi recentemente introduzido por Wiederhold [39]. Na sua apresentação original, era considerado o problema do acesso rápido a uma grande variedade de bases de dados, destacando-se os seguintes aspectos:

- o volume e a abstração dos dados disponíveis em diversos bancos de dados;

- inconsistências existentes nas descrições dos dados disponíveis, o que torna difícil sua integração.

Mediadores podem ser considerados como uma estrutura conceitual para realizar a integração semântica de múltiplos sistemas de raciocínio e bases de dados, funcionando como uma espécie de "gerente" dos sistemas disponíveis. Um usuário que busca uma dada informação identifica qual mediador é um bom candidato a fornecê-la. Ele, então, faz a consulta ao mediador, que se encarrega de obter a informação acessando as bases de dados necessárias para isso. O usuário nem mesmo precisa saber quais ou quantos bancos de dados foram consultados para responder à sua consulta e nem mesmo onde eles estão fisicamente localizados.

Para implementar esse comportamento, Wiederhold propôs uma arquitetura de três níveis para os mediadores, conforme esquematizado na figura 2.5. Na base da arquitetura, encontram-se as bases de dados, cada qual com seu próprio administrador de bancos de dados. Na camada intermediária tem-se os mediadores que, através de serviços de rede para servidores de dados, acessam os bancos de dados necessários para gerar as informações buscadas. Nessa camada, podemos ter diversos mediadores, administrados por especialistas de domínio, que usam os bancos de dados disponíveis da forma mais adequada para seu propósito. Finalmente, na camada superior temos a camada de usuário que, através de serviços de rede para servidores de informação, faz consultas aos mediadores, que se encarregam de localizar, acessar e combinar as informações disponíveis nas bases de dados. 


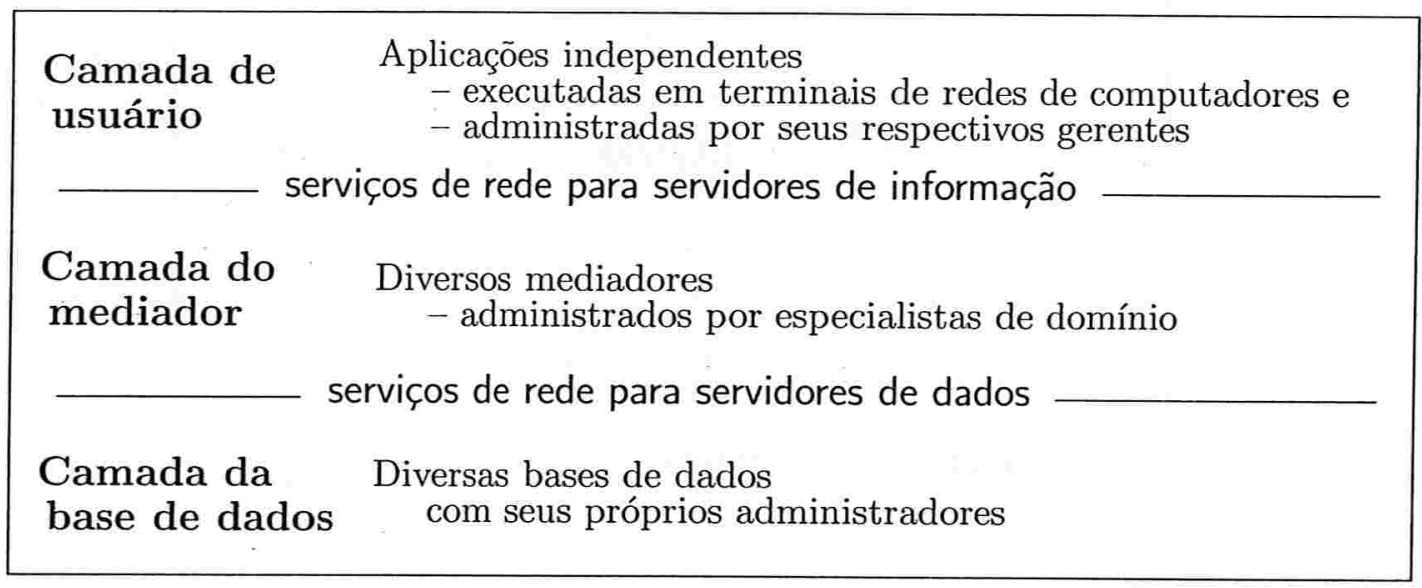

Figura 2.5: Arquitetura de três níveis dos mediadores

No compartilhamento de conhecimento, os mediadores são utilizados em sistemas como HERMES, apresentado na seção 2.5.3, e KRAFT, apresentado na seção 2.5.4. Além disso, os bancos de dados federados usam os facilitadores, que são de uma adaptação de mediadores.

\subsubsection{Capacitações}

Capacitações $^{1}$ são descrições, em uma linguagem formal e previamente definida, das capacidades e habilidades de sistemas. Através delas, é possível averiguar se um sistema é capaz de responder a uma determinada consulta. [32] apresenta uma arquitetura para compartilhamento de conhecimento baseada nas capacitações.

Nessa arquitetura, se um sistema for capaz de responder a uma consulta, basta especificar esta propriedade nas suas capacitações. Assim, o mapeamento entre termos semanticamente equivalentes é feito entre fórmulas que o cliente não é capaz de provar e fórmulas presentes nas listas de capacitações dos demais sistemas da arquitetura.

Numa arquitetura com capacitações, geralmente é utilizado um sistema intermediário que se responsabiliza em receber a consulta do cliente e, baseado nas capacitações dos demais sistemas, determinar um candidato para respondê-la. Dessa forma, quando um sistema $S_{1}$ faz uma consulta $q$, o intermediário definirá, baseado nas listas de capacitações a que tem acesso, um servidor adequado para resolver $q$. Definindo um servidor $S_{2}$, basta encaminha $q$ para ele. Após obter a resposta de $S_{2}$, o intermediário se encarrega de enviála para $S_{1}$. Isso não completa a consulta de $q$ feita por $S_{1}$ ao intermediário, pois ele ainda deverá receber uma mensagem de $S_{1}$ contendo

- um aviso de conclusão da consulta $q$; ou

- um aviso para que o broker obtenha uma nova resposta para $q$.

Note que, segundo esse modelo, não existe nenhuma ligação direta entre sistemas.

\footnotetext{
${ }^{1}$ Tradução do termo 'capabilities', do inglês.
} 


\subsubsection{Programação por Agentes}

Não existe consenso na caracterização do significado de agentes. Michael Genesereth define agentes de software como "componentes de software que se comunicam com seus parceiros através da troca de mensagens em uma linguagem de comunicação de agentes expressiva" [17]. No mesmo artigo, o autor completa: "O critério para classificar algo como um agente é comportamental. Uma entidade é um agente de software se e somente se ela se comunica corretamente em uma linguagem de comunicação de agentes como ACL".

Na seção 2.4 tratamos das linguagens utilizadas para a comunicação de agentes. Em particular, na seção 2.4.1, apresentamos a linguagem KQML, uma linguagem e protocolo de comunicações voltada para troca de mensagens dentro de uma comunidade de agentes.

\section{Caracterização de Agentes de Wooldridge e Jennings}

Na sua caracterização fraca de agentes, Wooldridge e Jennings [40] apontam que a forma mais geral na qual o termo agente é usado é para denotar um sistema computacional baseado em hardware ou software que goza das seguintes propriedades:

autonomia: agentes operam sem a intervenção direta de humanos ou outros, e tem algum tipo de controle sobre suas ações e estado interno;

habilidade social: agentes interagem com outros agentes (e possivelmente com humanos) através de alguma espécie de linguagem de comunicação de agentes, que são apresentadas na seção 2.4 ;

reatividade: agentes percebem seu ambiente e respondem de modo oportuno a mudanças que ocorrem nele;

pró-atividade: agentes não atuam simplesmente em resposta ao seu ambiente, ele são capazes de exibir um comportamento dirigido a objetivos com a "tomada de iniciativa".

No mesmo texto, é constatado que, segundo essa mesma caracterização, até mesmo um processo do sistema Unix pode ser considerado um agente. Outras características são usadas para atribuir um significado mais preciso para o termo. Em geral, são empregadas noções mentais como conhecimento, crença, intenção e obrigação. Além desses, atributos como mobilidade, veracidade, benevolência, racionalidade são geralmente discutidos no contexto de agentes.

\section{Classificação de agentes de Nwana}

Nwana [30] apresenta uma classificação de agentes que considera o papel desempenhado pelo agente para classificá-lo dentre os seguintes tipos:

colaborativo: agentes colaborativos enfatizam a autonomia e cooperação com outros agentes para executar tarefas para seus proprietários em ambientes multi-agentes 
abertos e com restrições de tempo. Para a coordenação de suas atividades, os agentes devem negociar entre si até definirem consenso mutuamente aceitável.

interface: agentes de interface enfatizam a autonomia e aprendizagem para executar tarefas para seus proprietários. O agente observa e monitora as ações tomadas pelo usuário na interface com o agente, aprende atalhos e sugere formas mais adequadas para se realizar certas tarefas. Para a aprendizagem, tipicamente, os agentes de interface aprendem a assistir seus usuários nas seguintes formas:

- pela observação e imitação do usuário;

- pelo recebimento de opiniões positivas ou negativas dos usuários;

- pelo recebimento de instruções explícitas do usuário;

- pela consulta a outros agentes para conselhos.

móvel: agentes móveis são processos (de software) capazes de migrar de uma máquina para outra em uma rede de computadores, interagindo com hospedeiros estrangeiros, reunindo informação em nome de seus proprietários, e então retornar para seu local de origem tendo executado suas obrigações.

informação/internet: agentes de informação executam o papel de administrar, manipular ou confrontar informação de diversas fontes distribuídas.

reativo: agentes reativos representam uma categoria especial de agentes que não possuem modelos internos e simbólicos de seus ambientes; eles respondem de maneira estímulo-resposta ao estado presente do ambiente no qual eles estão embutidos;

híbrido: agentes híbridos são aqueles cuja constituição envolve a combinação de dois ou mais modelos de agentes dentre os cinco exibidos acima.

\subsection{Arquitetura}

Normalmente, descrevemos a arquitetura de um sistema, na sua forma mais simplificada, através de um grafo no qual os nós representam subsistemas e arcos ligando subsistemas indicam que os subsistemas representados pelos nós têm a capacidade de se comunicarem. Eventualmente, usa-se um grafo dirigido quando supomos que os arcos representam canais de comunicação unidirecionais. A comunicação entre sistemas é feita através da troca de mensagens, obedecendo-se a um protocolo de comunicação adotado pelos sistemas presentes na arquitetura. A topologia do grafo descreve a forma com que os sistemas interagem entre si para obter a solução de um problema. Consideramos dois tipos básicos de arquitetura no compartilhamento de conhecimento.

A primeira delas, ilustrada na figura 2.6, apresenta um módulo $M$, responsável pela integração dos sistemas $S_{1}, S_{2}$ e $S_{3}$ na arquitetura. Nesse modelo, em geral, o usuário acessa diretamente $M$, que se responsabiliza pela solução do problema proposto com a ativação dos sistemas necessários para a obtenção da resposta. Além disso, não existe contato direto entre os sistemas, sendo sempre necessária a utilização de $M$ como intermediário. 


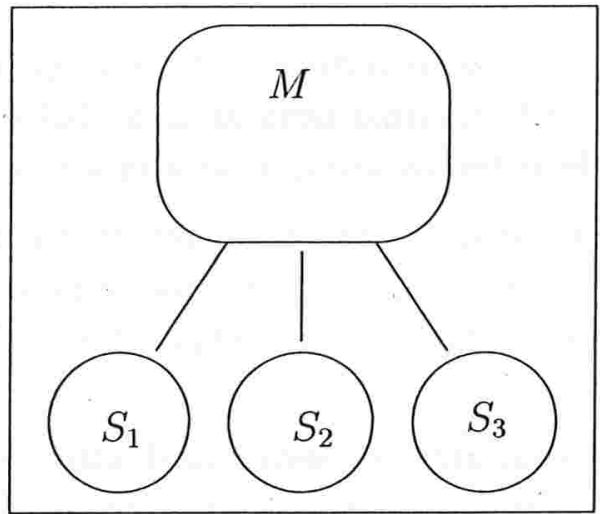

Figura 2.6: Arquitetura de três níveis dos mediadores

A outra arquitetura não utiliza nenhum intermediário: os sistemas têm acesso direto ao conhecimento do outro. Nesse caso, cada sistema disponibiliza seu conhecimento para os outros. Como não existe intermediário, o mapeamento entre informações dos sistemas é feito através da análise de cada par de sistemas considerando a semântica do conhecimento representado por eles. Na figura 2.7 apresentamos um exemplo com quatro sistemas, $S_{1}$, $S_{2}, S_{3}$ e $S_{4}$, de tal forma que

- $S_{1}$ tem acesso ao conhecimento de $S_{3}$;

- $S_{2}$ tem acesso ao conhecimento de $S_{4}$;

- $S_{3}$ tem acesso ao conhecimento de $S_{2}$ e $S_{4}$; e

- $S_{4}$ tem acesso ao conhecimento de $S_{2}$ e $S_{3}$.

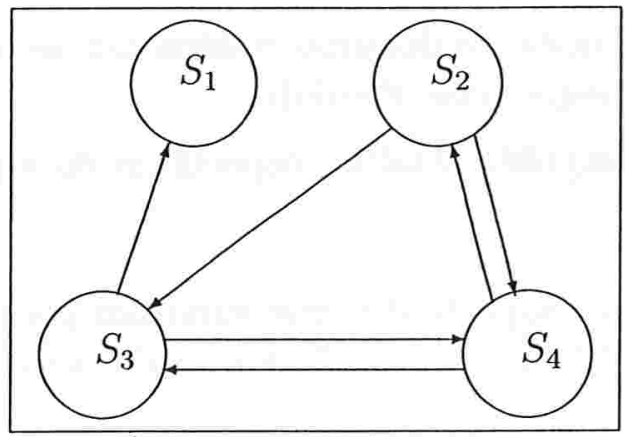

Figura 2.7: Arquitetura de três níveis dos mediadores

No entanto, é ambicioso demais propor uma arquitetura geral capaz de resolver todos os tipos de problemas. Em geral, cada arquitetura aproveita, da forma mais adequada possível, as características de uma família de problemas apresentando recursos para sua 
solução satisfatória. Dentre essas arquitetura específicas, temos, por exemplo, a arquitetura do tipo "blackboard" [12], na qual uma área de dados global aos sistemas é acessada e alterada pelo conjunto de sistemas até que se atinja a solução do problema.

Um outro critério de se avaliar uma arquitetura para compartilhamento de conhecimento é constatar se os sistemas disponíveis são dependentes da arquitetura ou não e como falhas em sistemas ou componentes da arquitetura influenciam no desempenho local dos sistemas.

Uma outra forma de se organizar os sistemas dentro de uma arquitetura é implementada com a organização do domínio dos sistemas em subdomínios de tal forma que cada sistema, no lugar de se comprometer com uma ontologia comum a todos os demais sistemas, compromete-se somente com a ontologia do subdomínio ao qual pertence. Esse tipo de organização é proposta na arquitetura ontológica do sistema KRAFT, apresentada na seção 2.5.4.

\subsection{Linguagens}

A importância do estudo de linguagens em compartilhamento de conhecimento vem da necessidade de se estabelecer comunicação entre os sistemas. São bastante estudadas e usadas na área de agentes de software, que influenciou profundamente no seu desenvolvimento e aperfeiçoamento. As linguagens de comunicação de sistemas apresentam alguns dos seguintes tipos de componentes básicos[20]:

nível de performativa: serviços entre agentes, especificados por intermédio de protocolos através dos quais os agentes podem estabelecer alguma forma de troca de informações ${ }^{2}$;

nível de serviço: descrição das capacitações dos sistemas;

nível de conteúdo: semântica do domínio comum dos sistemas, feito, em geral, com a especificação da ontologia desse domínio;

nível de recursos de controle: detalhes específicos do agente ou do sistema no qual ele está hospedado.

As duas linguagens mais importantes que surgiram para o compartilhamento de conhecimento são a KIF e a KQML, que serão abordadas separadamente a seguir.

\subsubsection{KQML}

KQML ("Knowledge Query and Manipulation Language" - Linguagem para Consulta e Manipulação de Conhecimento)[15] é uma linguagem e protocolo para troca de informação e conhecimento, desenvolvida dentro do "Knowledge Sharing Effort", patrocinado pelo

\footnotetext{
${ }^{2} \mathrm{Na}$ falta de uma boa tradução para o termo inglês 'performative', adotamos performativa.
} 
DARPA, em 1993. Ela é usada como uma linguagem para um sistema interagir com outros sistemas para permitir o compartilhamento de conhecimento.

Trata-se de uma linguagem com notação prefixa e estrutura similar à da linguagem LISP através da qual podemos enviar mensagens, codificadas em linguagens arbitrárias, como LISP, Prolog, KIF, texto ASCII, etc., para outros sistemas. Do ponto de vista prático, KQML funciona como um "envelope" através do qual são trocadas mensagens entre sistemas. Além disso, KQML fornece meios para se estabelecer protocolos de comunicação entre sistemas. Conceitualmente, a linguagem é dividida em três níveis:

nível de comunicação : identificação do remetente, destinatário e da mensagem;

nível de mensagem : propósito da mensagem e ontologia assumida;

nível de conteúdo : mensagem codificada na linguagem do remetente.

A linguagem é baseada em um conjunto de performativas, que define as operações permitidas que os sistemas podem solicitar aos outros. A tabela 2.1 apresenta os tipos de performativas disponíveis na linguagem KQML.

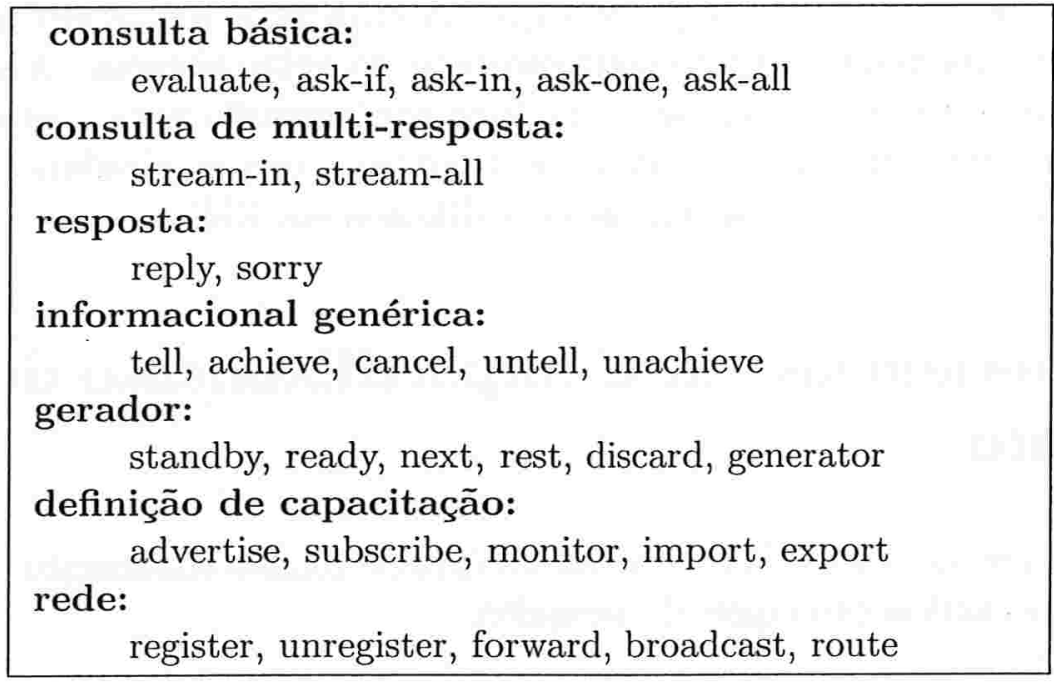

Tabela 2.1: Tipos de performativas da linguagem KQML

Além disso, KQML também apresenta uma arquitetura básica para o compartilhamento de conhecimento através de uma classe especial de agentes chamados de facilitadores de comunicação que coordenam a interação de outros sistemas.

\subsubsection{KIF}

O KIF ("Knowledge Interchange Format" - Formato de Intercâmbio de Conhecimento) é uma linguagem formal para especificar a troca de conhecimento entre sistemas. As seguintes características gerais são fundamentais na linguagem KIF: 
1. a linguagem tem uma semântica declarativa (o significado das expressões representadas pode ser compreendido sem a necessidade de traduções);

2. a linguagem é logicamente compreensível (baseada no cálculo de predicados de primeira ordem);

3. a linguagem oferece recursos para a representação de conhecimento sobre a representação de conhecimento.

4. ela apresenta recursos para a representação de raciocínio não monotônico; e

5. ela apresenta recursos para a definição de objetos, funções e relações.

A característica de número 3 é que permite que seja descrita a forma na qual o conhecimento está codificado nos diversos sistemas baseados em conhecimento. Tipicamente, quando um sistema lê uma base de conhecimento em KIF, ele converte os dados para a sua representação interna. Por outro lado, quando o sistema necessita se comunicar com outro sistema, ele converte sua representação interna para KIF e envia uma mensagem solicitando o compartilhamento do conhecimento do outro sistema. A grande vantagem de KIF é proporcionar uma linguagem, de fácil compreensão para o usuário padrão, que facilita o desenvolvimento independente de programas que manipulam conhecimento. $\mathrm{O}$ exemplo 2.2.2 apresenta uma especificação codificada em KIF.

\subsection{Experiências em Compartilhamento de Conheci- mento}

Dentre as experiências sendo desenvolvidas na área de compartilhamento de conhecimento, encontramos três linhas principais de pesquisa:

produtos: plataformas especificamente desenvolvidas para a implementação de sistemas para compartilhamento de conhecimento;

fundamentos: desenvolvimento de tecnologias auxiliares para o compartilhamento de conhecimento, como linguagens, protocolos, arquiteturas, etc;

aspectos formais: pesquisa de aspectos formais relacionados com o compartilhamento de conhecimento.

Por tratar-se de uma área em pleno desenvolvimento atualmente, as referências bibliográficas principais referentes a esses projetos de compartilhamento de conhecimento correspondem às documentações disponíveis dos próprios projetos que, em geral, estão disponíveis na internet $[37,18,28,16]$. 
Apesar das experiências em áreas como como robótica, planejamento, arquitetura blackboard, etc., enfatizamos nossa análise nos projetos gerais que buscam o desenvolvimento de tecnologias que auxiliem na criação de sistemas que amparem o compartilhamento de conhecimento entre sistemas baseados em conhecimento independentes.

\subsubsection{KSE}

O KSE ("Knowledge Sharing Effort" - Força Tarefa de Compartilhamento de Conhecimento)[28] é um consórcio patrocinado pelo DARPA ("Defense Advanced Research Projects Agency" - Agência de Projetos de Pesquisas Avançadas do Governo Norte-Americano) com a finalidade de desenvolver padrões, metodologia e software que facilitem o compartilhamento e reuso de bases de conhecimento e sistemas baseados em conhecimento. Seu objetivo é definir, desenvolver e testar infraestrutura e tecnologia de suporte que permitam aos participantes construir sistemas maiores e mais abrangentes do que aqueles que seriam obtidos trabalhando sozinhos. Dentre os resultados já obtidos, destacam-se:

- linguagem KQML (apresentada na seção 2.4.1),

- linguagem KIF (apresentada na seção 2.4.2),

- tecnologias para auxiliar na construção de ontologias compartilhadas, e

- tecnologias para a definição de protocolos compartilhados.

\subsubsection{FIPA}

A idéia do projeto FIPA ("Foundation for Intelligent Physical Agents" - Fundação para Agentes Físicos Inteligentes) [16] nasceu em 1995. Trata-se de uma organização sem fins lucrativos cuja finalidade é produzir padrões para a interoperação de agentes de software heterogêneos. Sua criação foi motivada por uma série de constatações:

1. as tecnologias de agentes fornecem um novo paradigma para resolver problemas;

2. algumas tecnologias de agentes já haviam alcançado um estágio de maturação considerável;

3. para serem úteis, as tecnologias de agentes necessitam de padronização;

4. a padronização de tecnologias genéricas já tinha se mostrado possível.

De janeiro a março de 1996, um conjunto de documentos ("Rationale" e "Scope") foram distribuídos a um grupo seleto de indivíduos que contribuiram no refinamento das idéias básicas. A partir de então foi estabelecida a organização internacional FIPA que, dentre outros resultados, produziu a linguagem FIPA ACL. 


\subsubsection{HERMES}

No HERMES ("Heterogeneous Reasoning and Mediator System" - Sistema de Raciocínio e Mediação Heterogêneo)[37], um sistema para integrar bases de dados e paradigmas de raciocínio heterogêneos, um fator fundamental na sua arquitetura é a presença de mediadores. Com o HERMES, a cada sistema incluído, o mediador deve ser alterado para acusar a presença do novo sistema participante, bem como suas características e semântica individuais. Na construção e manutenção de um mediador, temos dois aspectos importantes:

Integração de domínio : é a tarefa de adicionar uma nova base de dados ou sistema de raciocínio a um sistema integrado de tal forma que os recursos oferecidos pelo novo item passe a ser disponível aos demais elementos do sistema.

Integração de semântica : é o processo de especificação de métodos para resolver conflitos, agregar informações e definir novos operadores compostos com base nos operadores pré-existentes nos sistemas individuais.

No HERMES, a semântica definida pelo mediador é comum a todos os sistemas que participam do sistema integrado.

O sistema HERMES é baseado na teoria de bases de conhecimento híbridas de Lu, Nerode e Subrahmanian. Nesta estrutura conceitual, fontes de informações externas são abstraídas como domínios que executam certas funções com tipos de entrada e saída pré-definidos. Esses domínios são acessados em mediadores usando-se uma linguagem declarativa baseada em lógica. Essa linguagem é baseada na lógica anotada de Kifer e Subrahmanian e proporciona um ambiente de programação poderoso e extensível. O sistema ainda proporciona um ambiente uniforme para facilitar a adição de fontes externas aos mediadores existentes.

\subsubsection{KRAFT}

O projeto KRAFT ("Knowledge Reuse and Fusion/Transformation" - Reuso e Fusão/ Transformação de Conhecimento)[18] busca desenvolver uma combinação de tecnologias de bancos de dados e inteligência artificial para permitir que cientistas e engenheiros encontrem e explorem conhecimentos disponíveis na Internet.

$\mathrm{Na}$ sua forma mais simples, uma rede de bases de conhecimento que colaboram no KRAFT pode ser vista como um domínio onde todas as bases de conhecimento concordaram no compromisso de seguir uma única ontologia compartilhada por todas as bases de conhecimento. Está é a ontologia do domínio. No KRAFT, toda comunicação entre suas bases de conhecimento é codificada em uma sintaxe uniforme. Para isso, um Formato Comum de Intercâmbio ("Common Interchange Format") foi definido como lingua franca das redes implementadas no KRAFT. Desta forma, cada sistema participante pode ser 
escrito com sua linguagem original, mas toda comunicação com os demais sistemas deve ser feita através do Formato Comum de Intercâmbio.

Uma outra forma de implementar o compartilhamento de conhecimento no KRAFT é implementar relacionamentos entre pares de sistemas. Desta forma, não é necessário que os dois sistemas atendam à semântica de todo um domínio; neste caso, basta que os dois sistemas concordem numa ontologia comum a ambos.

Temos, assim, dois casos extremos: no primeiro, um único domínio com todas as bases de conhecimento concordando com uma única ontologia; no segundo, cada par de bases de conhecimento inter-relacionadas definem uma ontologia. Uma alternativa intermediária também oferecida pelo KRAFT é a possibilidade de hierarquizar o domínio em subdomínios de tal forma que, em vez dos sistemas participantes serem obrigados a concordarem com a ontologia de todo o domínio, eles necessitem apenas concordar com a ontologia do subdomínio no qual o sistema é embutido. Esta idéia leva à noção de hierarquia ontológica, similar ao conceito de herança na programação orientada a objetos: descendo os níveis da hierarquia, conceitos tornam-se mais detalhados e mais especializados.

\subsubsection{DECaFf-KB}

O projeto DECaFf-KB ("Distributed Environment for Cooperation among Formalisms for Knowledge Bases" - Ambiente Distribuído para a Cooperação entre Formalismos para Bases de Conhecimento) [9] realizado conjuntamente por pesquisadores da Universidade de São Paulo, Universidade Estadual do Ceará e Universidade de Edinburgo, na Escócia, desde 1996, tem como objetivos principais:

- reconstrução formal das teorias de representação de conhecimento, considerando uma caracterização uniforme dos padrões de entrada e saída para diferentes teorias;

- formulação de uma teoria geral de passagem de mensagens e cooperação entre representações de conhecimento baseada nesses padrões;

- implementação dessa teoria geral como um ambiente de desenvolvimento de sistemas que permita com que sistemas diferentes cooperem durante a resolução de problemas.

A pesquisa do grupo, até agora, concentrou-se no estudo dos aspectos formais relacionados com o compartilhamento de conhecimento entre sistemas heterogêneos, dedicando uma atenção especial para as questões relacionadas com a preservação da consistência formal dos sistemas que compartilham conhecimento.

\subsubsection{LuCe}

O sistema de coordenação LuCe ("Logic Tuple Centres" - Centros de Tuplas Lógicas) $[26,10]$ é utilizado para o desenvolvimento de aplicações multiagentes na rede mundial 
de computadores. Tuplas são coleções ordenadas de itens de informações possivelmente heterogêneos. O LuCe, baseado na integração de recursos das linguagens Java e Prolog, implementa um modelo de coordenação baseado na noção de centro de tuplas lógicas, caracterizada por uma linguagem de comunicação de agentes baseada na lógica de primeira ordem onde os agentes interagem através da troca de tuplas.

Aplicações envolvendo multiagentes pela internet necessitam de modelos de coordenação, linguagens e padrões poderosos e efetivos. Isso exige uma tecnologia de coordenação efetiva, não somente implementando um modelo de coordenação, mas também amparando suas metáforas do nível de desenvolvimento do sistema, permitindo que os desenvolvedores trabalhem no nível de abstração mais apropriado.

\subsection{Considerações Finais}

O compartilhamento de conhecimento tem despertado a atenção da comunidade científica nesses últimos anos devido, principalmente, à disponibilidade de serviços eficientes de redes de computadores, tendo como caso particular a internet. Além disso, a divulgação de tecnologias com os mediadores e de linguagens como KQML tem motivado o estudo e a implementação de sistemas para compartilhamento de conhecimento. No entanto, em geral tem-se buscado a caracterização do problema do ponto de vista da arquitetura, como um conjunto de sistemas que cooperam para resolver um problema.

$\mathrm{O}$ estudo das características individuais dos sistemas presentes numa arquitetura, em geral, se limita à especificação de ontologias com as quais os sistemas adotam um consenso a respeito do significado de termos comuns a eles. Infelizmente, nem sempre as ontologias são suficientes. Para se garantir o funcionamento formalmente consistente dos sistemas é de fundamental importância garantir que todos os resultados por ele admitidos não coloquem em conflito os fundamentos básicos de sua especificação formal. 


\section{Capítulo 3}

\section{Um Modelo de Compartilhamento de Conhecimento}

Depois da visão panorâmica dos aspectos gerais relacionados com o problema de compartilhamento de conhecimento, apresentada no capítulo anterior, neste descreveremos a nossa abordagem para a resolução do problema. Para isso, definiremos uma arquitetura genérica na qual serão incluídos os componentes básicos para estabelecer o compartilhamento de conhecimento entre sistemas. Através da análise dessa arquitetura, destacaremos a importância do estudo dos aspectos formais relacionados com o problema. Esses aspectos formais, fundamentalmente, constituem o núcleo desta pesquisa.

Antes de introduzir a arquitetura, apresentaremos uma visão inicial da nossa abordagem do problema e a exploraremos através de um exemplo simples e ilustrativo. Para completar, uma vez identificado o nosso objeto de estudo, apresentaremos nosso plano para este trabalho, que será concretizado nos capítulos posteriores.

\subsection{Introdução}

Em geral, quando se fala em compartilhamento de conhecimento, pressupõe-se uma arquitetura através da qual são disponibilizados sistemas baseados em conhecimento para serem consultados por outros sistemas e que permita que esses mesmos sistemas tenham acesso ao conhecimento oferecido pelos demais. Na literatura, percebe-se um grande destaque no estudo do comportamento de agentes dentro de uma arquitetura, com ênfase em suas intenções, negociações, comportamento, etc. Esse estudo motivou o desenvolvimento de linguagens com recursos especiais para o estabelecimento de protocolos de comunicação entre os agentes.

Sem desmerecer os méritos dessa visão geral de agentes, focalizada no comportamento dos sistemas dentro de uma arquitetura, acreditamos ser de fundamental importância o estudo da influência do uso de informações externas por um sistema. Para realizar esse estudo, a arquitetura e linguagens de comunicação tornam-se irrelevantes, cedendo o 
foco ao estudo das caractrísticas formais dos sistemas que trocam informações. Dessa forma, evidenciamos um aspecto do problema de compartilhamento de conhecimento, a consistência formal dos sistemas, que é deixado no segundo plano, mas que se torna fundamental quando se quer garantir a validade dos resultados obtidos através da combinação de uma série de resultados parciais provenientes de sistemas distintos e, eventualmente, formalmente heterogêneos.

Na seção 3.3 projetamos uma arquitetura geral para o compartilhamento de conhecimento e dentro dela identificaremos o objetivo central da nossa pesquisa. A forma final dessa arquitetura é descrita na seção 3.4. Não exploraremos com detalhes supérfluos (para a nossa apresentação) as características dessa arquitetura. A escolha a respeito da inclusão ou não de algum detalhe na arquitetura será feita exclusivamente com base na sua relevância para os objetivos específicos desta pesquisa. O núcleo deste trabalho refere-se à interação dos sistemas presentes na arquitetura, independentemente de detalhes particulares encontrados nela. A função da arquitetura aqui limita-se a destacar o contexto geral no qual nosso trabalho se insere.

O exemplo 3.1.1 ilustra a nossa abordagem do problema de compartilhamento de conhecimento, apresentada detalhadamente no decorrer deste capítulo. Por simplicidade, usaremos sistemas escritos em Prolog que, à primeira vista, não parece adequado devido à proposta do estudo de caso desta tese. No entanto, sua utilização neste ponto torna-se indicada para apresentar a nossa abordagem sem sobrecarregá-la com detalhes técnicos dos formalismos, que serão introduzidos posteriormente.

Exemplo 3.1.1 Considere o seguinte sistema, chamado $S_{1}$, escrito em Prolog:

$$
\begin{aligned}
& p(X):-q(X), r(X), 1+t(X) . \\
& r(b) . \\
& t(b) . \\
& q(a) . \\
& q(b) .
\end{aligned}
$$

Em $S_{1}$, para se provar que $\mathrm{p}(\mathrm{X})$ é verdadeiro deve-se provar que $\mathrm{q}(\mathrm{X})$ e $\mathrm{r}(\mathrm{X})$ são verdadeiros e que, ao mesmo tempo, não seja possivel provar que $\mathrm{t}(\mathrm{X})$ é verdadeiro. Detalhes adicionais sobre a programação em lógica podem ser consultados em 4.2.2. Note que $\mathrm{p}(\mathrm{X})$ não pode ser provado por $S_{1}$, pois não existe informação suficiente para provar $\mathrm{r}(\mathrm{X}) e$ $\mathrm{t}(\mathrm{X})$. No entanto, se estiver disponivel o seguinte sistema, chamado $S_{2}$, para consultas feitas por $S_{1}$

$$
\begin{aligned}
& m(X):-n(X), \quad !, k(X) . \\
& m(X):-l(X) . \\
& n(d) . \\
& n(e) . \\
& l(e) . \\
& k(e) .
\end{aligned}
$$


e usando a informação de que $|\mathrm{r}(\mathrm{a})|_{S_{1}} \equiv|\mathrm{I}(\mathrm{e})|_{S_{2}},|\mathrm{t}(\mathrm{a})|_{S_{1}} \equiv|\mathrm{m}(\mathrm{e})|_{S_{2}},|\mathrm{r}(\mathrm{b})|_{S_{1}} \equiv|\mathrm{l}(\mathrm{d})|_{S_{2}}$, $|\mathrm{t}(\mathrm{b})|_{S_{1}} \equiv|\mathrm{m}(\mathrm{d})|_{S_{2}}$, torna-se possivel provar $\mathrm{p}(\mathrm{a})$, como representado na figura 3.1, que apresenta a árvore de prova para a consulta $\mathrm{p}(\mathrm{a})$ feita pelo sistema $S_{1}$. Como $S_{1}$ não consegue provar $\mathrm{r}(\mathrm{a})$, ele dirige a consulta $\mathrm{r}(\mathrm{a})$ ao sistema $S_{2}$, que, usando o fato de que $\left.\operatorname{lr}(\mathrm{a})\right|_{S_{1}} \equiv|\mathrm{I}(\mathrm{e})|_{S_{2}}$, prova $\mathrm{I}(\mathrm{e})$, cuja árvore de prova está exibida no retângulo no centro na parte inferior da figura. Da mesma forma, como $S_{1}$ não consegue provar $\mathrm{t}(\mathrm{a})$, ele dirige a consulta $\mathrm{t}(\mathrm{a})$ ao sistema $S_{2}$, que, usando o fato de que $|\mathrm{t}(\mathrm{a})|_{S_{1}} \equiv|\mathrm{m}(\mathrm{e})|_{S_{2}}$, refuta $\mathrm{m}(\mathrm{e})$, cuja árvore de prova está exibida no retângulo à direita na parte inferior da figura. Usando a prova de $\mathrm{t}(\mathrm{a})$ obtida através do compartilhamento do conhecimento de $S_{2}, S_{1}$ torna-se capaz de provar a validade de $\mathrm{p}(\mathrm{a})$.

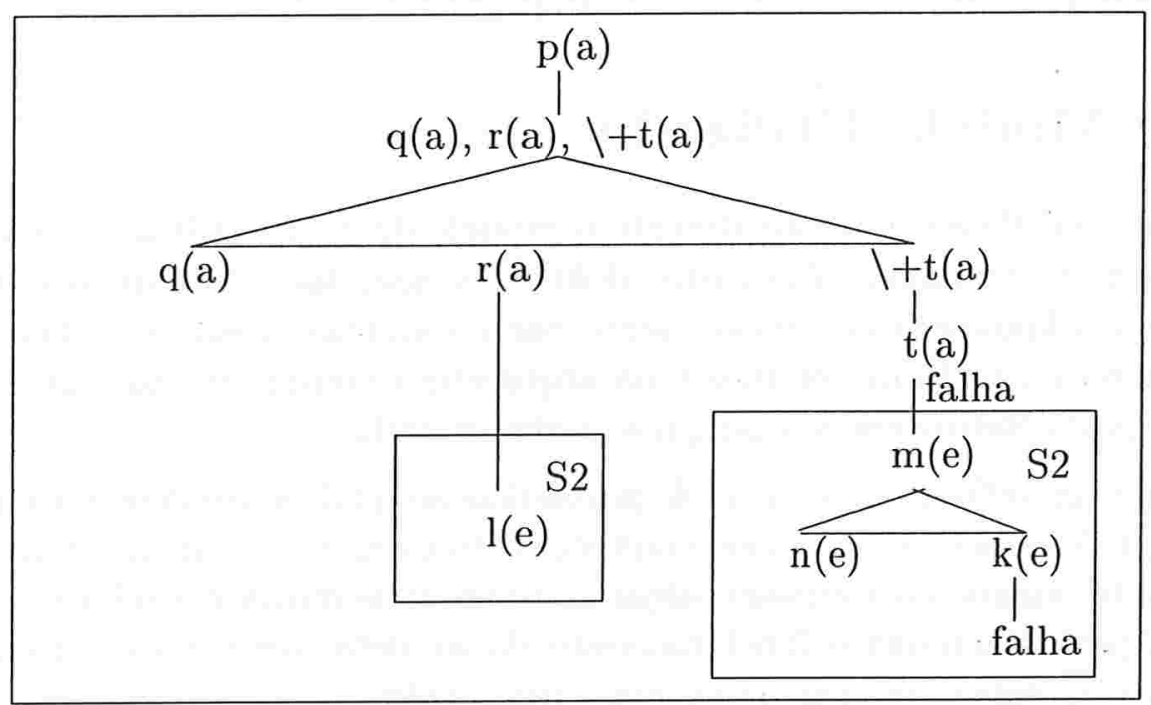

Figura 3.1: Prova de p(a) por $S_{1}$ com compartilhamento de conhecimento de $S_{2}$

Através da análise dos sistemas $S_{1}$ e $S_{2}$ é possível questionar a validade da demonstração de $\mathrm{m}(\mathrm{e})$ feita por $S_{2}$, uma vez que, para obtê-la, foi utilizado, no processo dedutivo, o comando "!" ("cut") $)^{1}$ e, considerando-se que $S_{1}$ é baseado em Prolog "puro", $S_{1}$ pode rejeitar uma demonstraçâo que use tal recurso. Ou seja, no compartilhamento, além do resultado final produzido para uma consulta, existem outros aspectos que podem ser importantes e que dependem do rigor formal que se queira dar à interação entre os sistemas.

Conforme mostrado no exemplo, estamos supondo que toda informação externa que o cliente recebe deve obedecer aos mesmos cuidados previstos pelo mecanismo de inferência do seu próprio formalismo. Cabe ao cliente, se necessário, estipular relaxamentos e/ou

\footnotetext{
${ }^{1}$ A função do "cut" é limitar o backtracking efetuado pelo interpretador do programa em Prolog ao se buscar a solução de uma consulta. Devido às suas características extra-lógicas, seu emprego é contestado por aqueles que consideram um programa em Prolog como um objeto matemático baseado exclusivamente na lógica matemática.
} 
imposições adicionais a serem obedecidas pelas informações compartilhadas de outros sistemas. Uma informação recebida não é considerada simplesmente como "uma informação adicional que alguém calculou", mas uma informação formalmente deduzida cuja prova deverá ser aceita pelo sistema cliente.

Assim, no caso de dois sistemas escritos em Prolog, a incapacidade na obtenção de uma solução corresponde à impossibilidade de construir uma árvore que prove uma consulta. Para solicitar o compartilhamento de conhecimento, o cliente identifica algum nó $n$ da árvore que não consegue provar e solicita que um outro sistema forneça uma prova do subproblema representado por $n$. Isso corresponde a completar a árvore de prova do cliente com uma demonstração fornecida pelo servidor para o nó $n$. É exatamente essa característica que está exibida na árvore de prova da figura 3.1.

\subsection{O Modelo Utilizado}

Nesta seção especificamos informalmente o modelo de compartilhamento de conhecimento adotado neste trabalho. Para isto, definimos que tipo de resultado queremos obter com o compartilhamento de conhecimento entre sistemas. Essa especificação será usada na próxima seção, onde projetamos uma arquitetura computacional que a implemente e através da qual conduziremos a pesquisa deste trabalho.

Buscamos um método de solução de problemas no qual os problemas são resolvidos, inicialmente, por sistemas baseados em conhecimento e que esses sistemas tenham a opção de solicitar ajuda quando encontrarem alguma dificuldade durante a solução dos problemas; essa convenção caracteriza o funcionamento do modelo como uma estrutura conceitual para a interação entre um sistema cliente e um servidor.

Inicialmente, vamos descrever o que esperamos do modelo. No modelo de compartilhamento de conhecimento que propomos assumimos que:

- todo o conhecimento disponível está distribuído entre os sistemas baseados em conhecimento que compõem o modelo;

- nenhum sistema incluso no modelo apresenta, a priori, qualquer tipo de preferência sobre os demais;

- o modelo é centralizado nos sistemas: se o modelo for usado para resolver algum problema é porque algum dos sistemas que o compõem está resolvendo o problema e necessita de ajuda;

- o sistema que resolve um problema e solicita ajuda pode, se necessário, especificar critérios a serem atendidos pelos sistemas candidatos a fornecer a ajuda; se a ajuda for, eventualmente, aceita, o sistema não é obrigado a aceitar o resultado fornecido.

- nenhum sistema disponível no modelo depende dos demais; ou seja, ele é independente do modelo; 
Devido à nossa ênfase no sistema, buscamos um modelo que não altere suas propriedades fundamentais e que a sua inclusão no modelo apenas obrigue-o a adotar uma camada de interface para comunicação com os demais componentes do modelo. Por isso, queremos uma forma de adaptar os sistemas para acoplá-los ao modelo que se limite a:

1. criar uma camada de interface adequada para o sistema;

2. alterar minimamente o sistema para que ele acesse sua camada de interface para resolver partes de problemas que não for capaz de resolver isoladamente.

Da forma como o especificamos, o modelo caracteriza a interação entre sistemas cliente e servidor. A correspondência entre um sistema cliente e um servidor é feita a partir da necessidade de o cliente obter um resultado $r$ que não dispõe. Essa necessidade faz com que o cliente procure um servidor tal que

1. exista relacionamento entre seus termos semanticamente equivalentes e que seja possível formular $r$ através desses termos;

2. o servidor atenda às pré-condições impostas pelo cliente;

3. o resultado oferecido pelo servidor seja aceito pelo cliente (baseado em critérios estabelecidos pelo próprio cliente).

Basicamente, esses quesitos constituem os pontos centrais da nossa abordagem, que analisaremos com mais detalhes a seguir.

\subsubsection{Relacionamento entre Termos Equivalentes}

Dois termos das linguagens de dois sistemas são semanticamente equivalentes se eles referem-se ao mesmo conceito que está modelado nos sistemas. A correspondência entre termos equivalentes é realizada manualmente por pessoas que conheçam bem os sistemas e que concordem com uma interpretação comum dada aos termos. Como exemplo da importância da correspondência entre termos semanticamente equivalentes, considere o caso do termo "árvore", apresentado em 2.2.2.

O relacionamento é de fundamental importância no compartilhamento de conhecimento porque é através dele que será definida uma linguagem através da qual os dois sistemas trocarão mensagens entre si. Normalmente, o relacionamento entre termos semanticamente semelhantes é feito com o auxílio de uma ontologia, que descreve o domínio sobre o qual os sistemas trocam mensagens. Na nossa abordagem, limitamo-nos a indicar quais termos são equivalentes diretamente, sem fazer uso de ontologias ou linguagens intermediárias.

\subsubsection{Pré-condições}

Pré-condições são imposições definidas pelo cliente que o servidor deve atender para que seja aceito como um candidato a resolver uma consulta. Uma pré-condição básica é que o servidor deve ser capaz de calcular o resultado buscado.

Adicionalmente, o cliente pode estipular outras condições que os candidatos a provar um resultado devem obedecer. Por exemplo, pode-se estipular condições sobre o valor- 
verdade que deve ser obtido para uma consulta; esse caso é importante nos casos em que temos mais valores-verdade e não somente verdadeiro e falso.

\subsubsection{Validade dos Resultados Calculados}

Conforme apresentado no exemplo 3.1.1, no processo de compartilhamento de conhecimento, o cliente não é obrigado a aceitar um resultado fornecido pelo servidor. Ele pode efetivamente recusar um resultado oferecido baseado em critérios obtidos a partir das características formais dos sistemas cliente e servidor.

Os motivos para uma eventual recusa de um resultado permite-nos estabelecer os seguintes tipos de critérios para aceitação:

estrutural: Cliente não aceita a forma como o resultado foi obtido pelo servidor.

No exemplo 3.1.1, o servidor usa o comando "cut" na prova de m(e), o que permite que o cliente não aceite o resultado fornecido se só admitir demonstrações em Prolog "puro".

Daí torna-se necessário não somente o resultado final obtido para a consulta, mas também uma descrição de como ele foi obtido. Em sistemas lógicos baseados na linguagem Prolog, por exemplo, uma informação adicional ao resultado obtido pode ser a árvore de prova construída para o resultado.

consistência parcial: Para chegar a um resultado $\varphi$, o servidor usa a validade de uma fórmula $\psi$ que o cliente assume que é falsa.

Para o cliente analisar um resultado segundo esse critério, basta analisar a prova do resultado e verificar se durante a prova foi assumido algum resultado considerado inválido.

consistência total: $O$ servidor prova a validade de uma fórmula $\varphi$ usando somente inferências e fórmulas aceitas pelo cliente mas, adicionalmente, o servidor está assumindo a validade de uma fórmula $\psi$ enquanto que o cliente está assumindo que $\psi$ é falso.

A verificação desse caso é muito mais complicada que a verificação da consistência parcial, pois torna-se necessário provar cada fórmula cujo valor-verdade precisar ser considerado, o que é computacionalmente inviável.

insuficiência: $\mathrm{O}$ valor-verdade fornecido pelo servidor para o resultado é considerado insatisfatório pelo cliente.

No exemplo 3.1 .1 não ocorre este caso, pois só existem as opções de as fórmulas serem verdadeiras ou falsas. No entanto, esse critério torna-se importante quando consideramos formalismos que trabalham com um conjunto mais abrangente de valores-verdade. Nesse caso, o cliente pode considerar o valor-verdade obtido para uma consulta como "insuficiente" para seu propósito. 
Esses motivos listados abrangem apenas aspectos formais relacionados com as teorias subjacentes aos sistemas. Podemos, eventualmente, considerar outros motivos como estabelecer um limite no comprimento de uma prova, estabelecer um limite no tempo para que seja retornada uma resposta a uma consulta, etc. Neste trabalho, por estarmos interessados nos aspectos formais relacionados com a interação dos sistemas, consideraremos apenas os quatro motivos apresentados inicialmente.

\subsubsection{Descrição Final do Modelo}

O exemplo 3.1.1 ilustra fielmente a abordagem formal do compartilhamento de conhecimento que adotamos neste trabalho. Por causa dessa abordagem, assumimos os seguintes princípios básicos:

1. o compartilhamento de conhecimento é realizado entre pares de sistemas;

2. cada sistema é considerado como uma teoria formal, que é profundamente influenciada pela linguagem na qual a teoria é codificada;

3. para o compartilhamento de conhecimento ser possível, é necessário que os sistemas troquem mensagens, que podem ser restritas à pergunta do cliente e à resposta do servidor;

4. as mensagens trocadas pelos sistemas são baseadás exclusivamente em um vocabulário de termos comuns aos sistemas;

5. para se definir o vocabulário comum, é necessário um mapeamento entre termos dos sistemas que relacione termos semanticamente equivalentes ${ }^{2}$;

6. uma resposta a uma consulta de compartilhamento de conhecimento pode não ser aceita pelo sistema que fez a consulta;

7. a rejeição de um resultado deve ser baseada em critérios; esses critérios constituirão os fundamentos básicos usados no estabelecimento de restrições que deverão ser atendidas na interação entre os sistemas.

Daqui em diante, no lugar do modelo que apresentamos nesta seção, usaremos uma arquitetura para compartilhamento de conhecimento. Essa arquitetura, apresentada na seção 3.3, será criada especificamente como uma estrutura conceitual que implementa os requisitos considerados no modelo que caracterizamos informalmente nesta seção.

\subsection{Arquitetura Computacional}

Depois de descrever informalmente a nossa abordagem do problema de compartilhamento de conhecimento, vamos apresentar uma arquitetura que a realize. Essa arquitetura será

\footnotetext{
${ }^{2}$ Como não existe forma de se averiguar automaticamente quais termos possuem semântica comum, essa análise deverá ser realizada por pessoas que conheçam profundamente os dois sistemas e concordem em um mapeamento satisfatório.
} 
projetada de forma econômica, no tocante aos seus detalhes, de forma que ela exiba uma configuração mínima capaz de ser utilizada como plataforma para compartilhamento de conhecimento conforme apresentado no exemplo 3.1.1.

Através de uma arquitetura, especificamos a forma com que cada sistema tem acesso ao conhecimento dos demais sistemas. Neste texto, a arquitetura será definida de forma abstrata, identificando conceitual e funcionalmente os seus componentes básicos e limitando-os ao menor número possível e necessário para descrever uma plataforma simples e útil para o compartilhamento de conhecimento e que seja capaz de ser implementada sem grandes dificuldades e sem impor tecnologias ou acessórios sofisticados demais.

Caracterizamos os sistemas para compartilhamento de conhecimento identificando os elementos necessários para o estabelecimento destes sistemas e, desde já, introduzindo a terminologia técnica utilizada neste trabalho. A arquitetura proposta nesta seção limitase a implementar o modelo de compartilhamento de conhecimento apresentado na seção 3.2. Uma vez fixada a arquitetura do sistema para compartilhamento de conhecimento, teremos fixada uma plataforma sobre a qual trabalharemos no restante deste texto. Esta arquitetura, junto com as suposições dela decorrentes, condiciona o restante do trabalho: define sua abordagem, abrangência e escopo.

\subsubsection{CSC's}

O primeiro conceito que introduzimos caracteriza um sistema baseado em conhecimento participante de um sistema para compartilhamento.

Componente de Sistema para Compartilhamento (CSC): Chamamos de Componente de Sistema para Compartilhamento um sistema baseado em conhecimento construído segundo algum formalismo específico e participante de um sistema para compartilhamento. Um CSC é completamente definido pelo formalismo lógico que usa e pelos axiomas (conhecimento) que possui.

A partir de um sistema baseado em conhecimento, obtemos um CSC através da construção de uma camada de interface. Esta camada de interface é responsável pela comunicação do CSC com os demais CSC's com os quais deseja compartilhar conhecimento. A representação gráfica de um CSC está apresentada na figura 3.2.

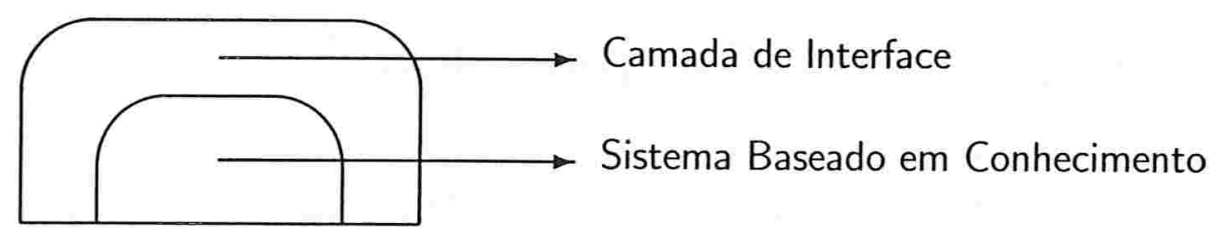

Figura 3.2: Arquitetura de um CSC 


\section{Comunicação entre CSC's}

Para permitir o compartilhamento de conhecimento entre CSC's, é necessário estabelecer conexões que permitam a troca de informações entre eles. Pela existência de uma conexão entre $C S C_{1}$ e $C S C_{2}$, especificamos que uma fórmula do $C S C_{1}$ pode ser "traduzida" 3 para o $C S C_{2}$ e que o programa de tradução está disponível no sistema.

O estabelecimento da conexão entre dois CSC's é determinado através do acordo entre as pessoas responsáveis pelos dois CSC's. A partir daí cada responsável concorda no tipo de acesso que o outro CSC terá ao seu e implementa tradutores que convertem uma fórmula escrita no formalismo lógico referente a um dos CSC's para o formalismo referente ao outro. Note que este "acordo" entre os responsáveis pelos sistemas envolve uma análise minuciosa dos sistemas em questão. É nesta fase que deverá ser feito um estudo detalhado das teorias formais representadas pelos CSC's individualmente e que se deverá estabelecer um nível de compartilhamento que não gere resultados indesejáveis.

Da troca de mensagens entre os CSC's, surge a necessidade de padronizar a interação entre eles. Para isto, fixamos um protocolo de comunicação para ser obedecido pelos CSC's que trocarem mensagens.

Na figura 3.3 abaixo, apresentamos um esquema geral de um sistema de compartilhamento, com dois CSC's conectados. Nesta figura, introduzimos um novo elemento importante para o estabelecimento do compartilhamento: um canal de comunicação. Canais de comunicação são os meios físicos através dos quais os CSC's trocam mensagens (que podem ser linha telefônica, rede de computadores, etc.).

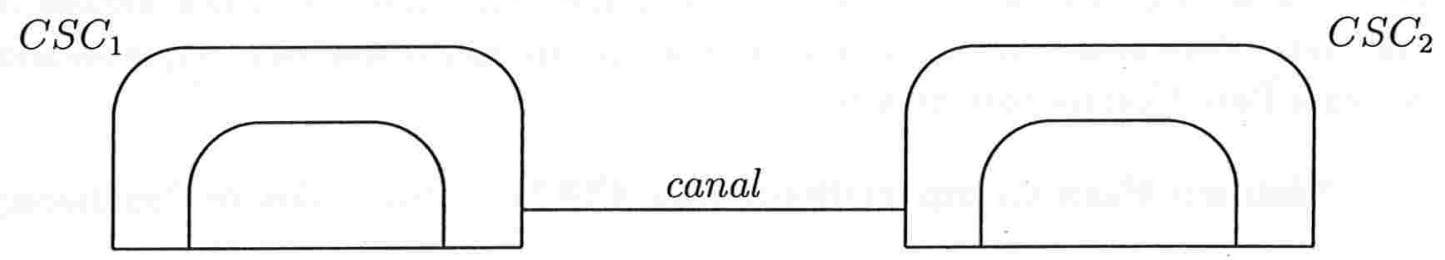

Figura 3.3: Esquematização de compartilhamento de conhecimento entre CSC's

Dizemos que o esquema de compartilhamento de conhecimento ilustrado na figura 3.3 é direto, pois os sistemas estão conectados diretamente através de uma canal de comunicação, sem a presença de sistemas intermediários dedicados ao estabelecimento e/ou gerenciamento da comunicação. Posteriormente, em 3.4, adicionaremos mais elementos ao esquema de compartilhamento para torná-lo, do ponto de vista prático, mais poderoso.

\section{Compartilhamento entre CSC's}

O sistema para compartilhamento será efetivamente ativado quando um CSC, digamos o $C S C_{1}$, tentar resolver localmente um problema e não obtiver uma solução. Neste instante,

\footnotetext{
${ }^{3}$ Para nosso propósito, a tradução corresponde a um mapeamento entre termos semanticamente equivales, conforme descrito em 3.2.1 e formalizado em 3.5.1.
} 
o $C S C_{1}$ pode estender seu poder computacional solicitando que algum outro CSC, com o qual compartilha conhecimento, resolva algum detalhe do problema que não foi capaz de resolver.

Exemplo 3.3.1 Considere dois sistemas, chamados de $S_{1}$ e $S_{2}$. Suponha que $S_{1}$ esteja resolvendo um problema $p$ e que sua teoria isoladamente seja incapaz de resolver $p$ devido à falta de uma prova para $q$. Para o compartilhamento de conhecimento assumimos, adicionalmente, que:

- $S_{1}$ "sabe" da presença de $S_{2}$;

- $S_{1}$ "sabe" que $S_{2}$ é capaz de calcular $q$.

Assim, $S_{1}$ envia a mensagem "q?" a $S_{2}$ e aguarda pela resposta da consulta. Ao receber a resposta de $S_{2}, S_{1}$ pode analisar a resposta para verificar se ela é válida (segundo seus critérios). Aceitando a resposta, $S_{1}$ pode completar a prova de $p$. Recusando-a, $S_{1}$ tem a opção de pedir uma nova solução de $q$ ao mesmo $S_{1}$ ou, "conhecendo" outro sistema capaz de resolver $q$, consultar outro servidor.

Como resultados da utilização do sistema, isto é, como resultado da tentativa de resolução de um problema, queremos uma solução para o problema proposto (se houver uma solução) e todas as deduções lógicas utilizadas na obtenção da solução. Note que cada CSC participante na solução de um problema deve fornecer todas as deduções que realizou para chegar ao resultado oferecido como resposta. Por outro lado, se não for encontrada uma solução, o sistema deverá fornecer quais deduções lógicas não foram possíveis. Finalmente, devemos deixar expresso, de forma sintética, o que entendemos por Sistema Para Compartilhamento:

Sistema Para Compartilhamento: CSC's + Protocolos de Comunicação

É claro que um sistema para compartilhamento pressupõe a existência de pelo menos dois CSC's e a existência de canais de comunicação conectando estes sistemas. No entanto, essa arquitetura para o compartilhamento de conhecimento pode ser aprimorada com o acréscimo de módulos auxiliares que facilitem a interação entre os sistemas. Um tal módulo auxiliar é um "broker", que veremos logo a seguir.

\subsubsection{Broker}

Um "broker" é um componente adicional dentro de uma arquitetura de compartilhamento de conhecimento cuja função é administrar a interação entre os CSC's. Em uma arquitetura com um broker, no lugar de um CSC consultar outro CSC diretamente, ele dirige sua consulta ao broker, que se encarrega de encaminhar a consulta para um CSC

\footnotetext{
${ }^{4}$ Optamos pelo uso do termo em inglês, broker, no lugar de traduzi-lo para algum termo equivalente em português, como intermediador, corretor, etc.
} 
adequado. Através desse modelo, não existe a obrigatoriedade de o sistema cliente dirigir sua consulta a um servidor específico. Será tarefa do broker selecionar e acionar um servidor adequado para cada consulta dirigida a ele $^{5}$.

Devido à sua função, o broker deve ter acesso a informações de todos os sistemas incluídos na arquitetura, sendo que, no mínimo, ele deve ter capacidade de averiguar a quais consultas cada sistema é capaz de responder. Para selecionar um CSC adequado para resolver uma dada consulta, o broker deverá ter acesso a uma descrição dos sistemas disponíveis no sistema para compartilhamento. Essa descrição deverá apresentar as habilidades e capacidades dos sistemas disponíveis na arquitetura.

Além disso, o broker poderá ser o responsável pela tentativa de obtenção de uma nova solução se o cliente rejeitar uma resposta fornecida para uma consulta. Desta forma, o broker coordenará um processo de "backtracking" para auxiliar o cliente a encontrar uma resposta que considere aceitável para a consulta.

Da mesma forma que um CSC, o broker é um sistema baseado em conhecimento com uma camada de comunicação dedicada ao sistema para compartilhamento de conhecimento no qual atua e obedecendo um protocolo de comunicação com os CSC's que foi previamente definido. Dependendo do nível de gerenciamento exercido pelo broker na arquitetura, o protocolo de comunicação terá um elevado grau de sofisticação. Por exemplo, para que ele seja capaz de coordenar um "backtracking", será necessário o estabelecimento de um protocolo de comunicação com o cliente que envolverá um número possivelmente elevado de mensagens trocadas entre eles.

Uma forma para se descrever as características dos sistemas disponíveis para compartilhamento de conhecimento é através das capacitações. Na figura 3.4 apresentamos graficamente uma arquitetura geral de um sistema para compartilhamento de conhecimento gerenciada por um broker.

\section{Capacitações}

Baseado nas capacitações dos sistemas presentes na arquitetura para compartilhamento de conhecimento é que o broker escolhe um servidor adequado para uma consulta. Na próxima seção apresentamos a arquitetura geral de um sistema para compartilhamento de conhecimento com broker e baseado em capacitações. No exemplo 3.3.2 descrevemos, através de um cenário, o funcionamento de um sistema para compartilhamento de conhecimento com broker e baseado em capacitações.

Exemplo 3.3.2 Considere um broker $B$ e três sistemas, chamados de $S_{1}, S_{2}$ e $S_{3}$. Suponha que $S_{1}$ esteja resolvendo um problema $p$ e que sua teoria isoladamente seja incapaz de resolver $p$ devido à falta de uma prova para um subproblema q. Para o compartilhamento de conhecimento assumimos, adicionalmente, que:

\footnotetext{
${ }^{5}$ Deve-se enfatizar, entretanto, que o broker só será capaz de mediar o contato entre um cliente e um servidor se for possível fazer as traduções entre suas linguagens.
} 
$b_{1}: B$ tem a informação de que $|q|_{S_{1}} \equiv|q|_{S_{2}}$

$b_{2}:$ B tem a informação de que $|q|_{S_{1}} \equiv|q|_{S_{3}}$

Para tentar resolver $q$ por compartilhamento de conhecimento, $S_{1}$ envia para $B$ a consulta "q?", sem especificar um servidor para resolvê-la. B então se encarrega de encontrar um sistema para resolver $q$. Baseado na informação $b_{1}, B$ dirige a pergunta " $q$ ?" a $S_{2}$, obtém a resposta e a envia para $S_{1}$. Ao receber a resposta, $S_{1}$ pode analisá-la e verificar se ela é válida (segundo seus critérios). Aceitando a resposta, $S_{1}$ pode completar a prova de $p$. Recusando-a, $S_{1}$ tem a opção de pedir uma nova solução de q ao broker, que se encarrega de obter uma nova solução, caso ela exista.

\subsection{Arquitetura Geral}

Na figura 3.4 apresentamos a arquitetura geral de um sistema para compartilhamento de conhecimento com broker e sistemas rotulados por capacitações. Temos representados $n$ CSC's, chamados $C S C_{1}, \ldots, C S C_{n}$, cada qual rotulado com sua descrição de capacitação, $C_{1}, \ldots, C_{n}$, respectivamente. Essas capacitações são acessíveis ao broker que, quando solicitado por algum $C S C_{i}, 1 \leq i \leq n$, para calcular um resultado $q$, determina, através de $C_{1}, \ldots C_{n}$, um $C S C_{j}, i \neq j$, candidato a resolver $q$ para $C S C_{i}$.

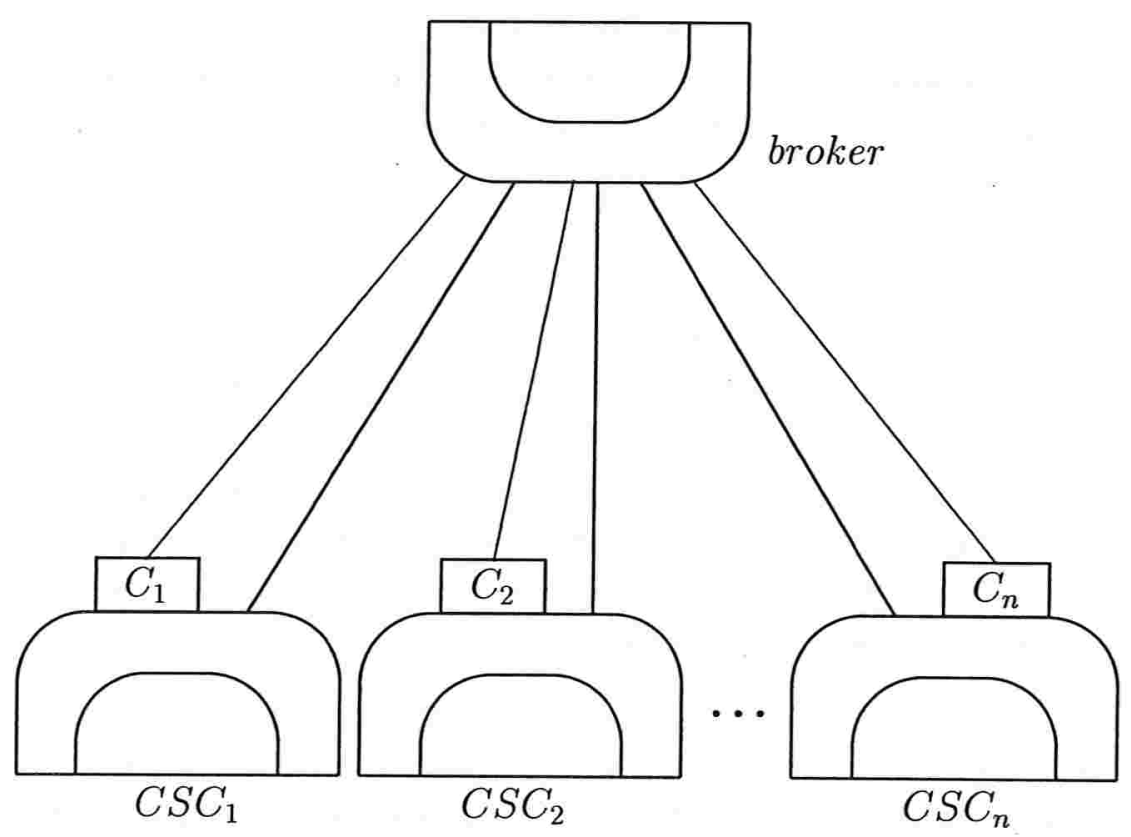

Figura 3.4: Esquematização da arquitetura geral para compartilhamento de conhecimento entre CSC's com capacitações 


\subsubsection{Compartilhamento de Conhecimento Usando a Arquite- tura Geral}

A solução de um problema, usando-se a arquitetura geral para compartilhamento de conhecimento proposta, esquematizada na figura 3.4 corresponde ao seguinte processo:

1. um CSC específico, que chamaremos de $C S C_{i}$, deve resolver um problema;

2. $C S C_{i}$ não consegue resolver (satisfatoriamente) o problema porque não consegue provar (satisfatoriamente) uma fórmula $q$;

3. $C S C_{i}$ solicita ao broker que ele obtenha uma solução para $q$;

4. baseado nas capacitações dos sistemas presentes na arquitetura, o broker seleciona um sistema, que identificaremos por $C S C_{j}$, para resolver $q$ para $C S C_{i}$;

5. uma vez determinado qual será o sistema servidor, o broker torna-se praticamente um elemento passivo do processo de compartilhamento de conhecimento, comportando-se como se fizesse parte do canal de comunicação ${ }^{6}$; desta forma, todo o processo de compartilhamento de conhecimento fica concentrado na interação entre $C S C_{i}$ e $C S C_{j}$

6. caso o resultado fornecido por $C S C_{j}$ seja considerado insatisfatório por $C S C_{i}, C S C_{i}$ pode solicitar que o broker obtenha um outro sistema capaz de provar a fórmula $q$;

7. este processo prossegue até que $C S C_{i}$ prove $q$ de forma satisfatória (segundo critérios locais e particulares de $C S C_{i}$ ) ou se $q$ não for provado e o broker não encontrar mais candidatos para provar $q$.

O processo acima descrito não impõe nenhuma particularidade adicional sobre o modelo de compartilhamento de conhecimento apresentado na seção 3.2. Ela simplesmente implementa a nossa especificação, embora, é importante enfatizar, essa arquitetura não seja adequada para outros modelos de compartilhamento de conhecimento. A arquitetura simplesmente sistematiza a nossa intenção de caracterizar o compartilhamento de conhecimento como um processo que envolve pares de sistemas. O broker funciona apenas como um intermediário cuja função é definir um servidor baseado exclusivamente na consulta feita a ele e nas capacitações dos sistemas inclusos na arquitetura. Adicionalmente, se a resposta fornecida for recusada pelo cliente, o broker pode administrar um processo de "backtracking" até que seja obtida uma solução admissível.

Embora a arquitetura proposta nesta seção seja útil, realista e geral o suficiente para apresentar os problemas e métodos encontrados no compartilhamento de conhecimento, neste trabalho estamos interessados especificamente em um dos aspectos do processo de compartilhamento de conhecimento apresentado acima, que corresponde ao item 5 . É

\footnotetext{
${ }^{6} \mathrm{O}$ broker pode, eventualmente, fazer traduções entre as linguagens de $C S C_{i}$ e $C S C_{j}$.
} 
nesse item que encontramos os aspectos formais do problema da interação entre dois sistemas baseados em conhecimento escritos, eventualmente, em formalismos distintos.

Apesar de constituir um aspecto isolado dentro do compartilhamento de conhecimento, ele por si só já apresenta uma série de dificuldades. Devemos considerar, dentre tantos detalhes, ontologias, linguagens, processos dedutivos, semântica dos sistemas e níveis de certeza usados. Na seção 3.5 aprofundaremos na análise desses detalhes.

\subsection{Aspectos Formais do Compartilhamento}

Restringindo o nosso estudo do compartilhamento de conhecimento à interação entre pares de sistemas, concentramos nossa atenção aos problemas formais que surgem dela. Vale a pena destacar que esses problemas, isoladamente, já apresentam uma série de dificuldades e de desafios. Na literatura, sua abordagem mais comum concentra-se no estabelecimento de uma ontologia comum aos sistemas que compartilham conhecimento. No entanto, [7] mostra que as ontologias não são suficientes para solucionar esse problema, sendo necessário um estudo detalhado dos formalismos lógicos considerados, dedicando um cuidado especial ao mecanismo de inferência de cada um deles.

Dentre os aspectos formais considerados, temos:

- análise das linguagens definidas pelos sistemas: mapeamento de termos das linguagens que correspondem a elementos semanticamente equivalentes; a grosso modo, isso equivale a definir uma ontologia comum ao par de sistemas;

- análise das medidas de verdade dos formalismos: analisar o significado de verdade usado pelos formalismos, como eles são medidos e como converter a informação de que uma fórmula tem um certo nível de certeza em um dos formalismos para uma informação equivalente no outro;

- análise semântica dos sistemas: verificar se a inclusão de resultados externos não faz com que um sistema torne-se formalmente inconsistente;

- estabelecimento de restrições que evitem que o compartilhamento cause problemas para a teoria formal do cliente.

Ao concentrarmos o escopo deste trabalho nesses problemas, intimamente relacionados com o item 5 da nossa descrição de compartilhamento de conhecimento, apresentado na seção anterior, podemos passar a ignorar a presença do broker e das descrições de capacitações, uma vez que eles passam a ser elementos neutros no processo. Desta forma, retornamos ao modelo de compartilhamento de conhecimento ilustrado na figura 3.3 e, adicionalmente, a nossa análise do problema deverá ser similar àquela feita para o exemplo 3.1.1. 
É importante observar que, apesar de descartada, a apresentação da arquitetura geral foi bastante útil, pois enfatizou o contexto geral no qual esta pesquisa se enquadra e a sua relevância para áreas como programação por agentes. Enquanto o problema geral é tratado exaustivamente pela comunidade científica que trabalha com agentes de software, pouca importância tem sido dada aos aspectos formais que surgem na interação entre os pares de sistemas.

A seguir exploraremos com mais detalhes os aspectos formais considerados acima.

\subsubsection{Mapeamento entre Termos da Linguagem}

O objetivo do mapeamento entre termos é de descrever uma correspondência entre pares de termos das linguagens dos sistemas que apresentem significado comum. Essa descrição pode ser feita por um mapeamento direto entre os termos ou através de uma linguagem intermediária, exclusiva para esse propósito, como, por exemplo, KIF. Não nos aprofundaremos nesse detalhe, uma vez que seu estudo já é bem explorado na literatura. Neste trabalho, usamos o mapeamento direto e consideramos que a interpretação semântica dos termos é dada, como feito no exemplo 3.1.1. Detalhes adicionais sobre este ponto, bem como referências para a literatura, podem ser obtidos nas seções 2.2.3 e 2.4.

Por simplicidade, consideramos neste trabalho que as informações compartilhadas são as informações atômicas dos formalismos. Assim, o mapeamento corresponde a um processo no qual pessoas que conheçam profundamente os sistemas em questão descrevem manualmente um mapeamento das informações atômicas de um dos formalismos para informações atômicas do outro, de tal forma que o par de informações relacionadas tenham um significado comum nos dois sistemas.

O exemplo 3.5.1 ilustra de que forma o mapeamento entre termos semanticamente equivalentes é usado para definir uma linguagem de consulta entre CSC's.

Exemplo 3.5.1 Considere sistemas $S_{1}$ e $S_{2}$ tais que $\varphi_{1}, \varphi_{2}$ e $\varphi_{3}$ são fórmulas atômicas de $S_{1}$ e $\psi_{1}$ e $\psi_{2}$ são fórmulas atômicas de $S_{2}$. Suponha que $\left|\varphi_{1}\right|_{S_{1}} \equiv\left|\psi_{1}\right|_{S_{2}},\left|\varphi_{2}\right|_{S_{1}} \equiv\left|\psi_{2}\right|_{S_{2}}$ e que $\varphi_{3}$ não seja semanticamente equivalente a nenhuma fórmula de $S_{2}$.

Desta forma, $S_{1}$ pode dirigir a consulta " $\varphi_{1}$ ?" a $S_{2}$, pois $S_{2}$ pode calcular $\psi_{1}$, que é equivalente à consulta feita. Em casos mais gerais, a consulta " $\varphi_{1} \vee \varphi_{2}$ ?" também é válida. No entanto, " $\varphi_{1} \vee \varphi_{3}$ ?" não faz sentido para $S_{2}$, pois o termo $\varphi_{3}$ não corresponde a nenhum termo válido. Note que, adicionalmente, a operação $\vee$ também deve ser válida para $S_{1}$ e também deve ser traduzida para uma operação equivalente de $S_{2}$.

No exemplo 3.5.1 consideramos o caso geral em que as informações compartilhadas não são necessariamente atômicas. Nesse caso, temos duas alternativas para resolver o problema de mapeamento entre fórmulas:

1. uma fórmula $\varphi$ de $S_{1}$ é relacionada diretamente com uma fórmula $\psi$ de $S_{2}$. Considerando que $\psi$ seja uma consulta válida a $S_{2}$, sem que seja, necessariamente, uma fórmula atômica, $S_{2}$ pode calcular diretamente $\varphi$ para $S_{1}$; 
2. uma consulta $\varphi$ de $S_{1}$ é feita ao broker. O broker se encarrega de decompor $\varphi$ em fórmulas atômicas, de encaminhar essas fórmulas para os sistemas capazes de calculá-las e, finalmente, de combinar as respostas obtidas para produzir a resposta à consulta original. Nesse caso, é necessário dispor de um broker poderoso o sufuciente realizar essa tarefa.

\subsubsection{Análise das Medidas de Crença}

É necessário estabelecer uma correspondência entre os valores-verdade dos formalismos. Para formalismos que trabalham apenas com os valores verdadeiro e falso, a solução do problema é trivial. No entanto, essa análise pode ficar complicada se os formalismos assumem conjuntos de valores-verdade mais complexos e, eventualmente, conceitualmente heterogêneos.

Por exemplo, a fórmula "é muito provável que $p$ seja verdade" pode ser convertida na fórmula probabilística " $p$ tem mais de $90 \%$ de chance de ser verdade". Note que a conversão feita não é única e sua escolha dependeu da nossa interpretação pessoal de indicadores de crença como "provável" e "90\% de chance" e da nossa suposição de que esses indicadores podem ser comparados e considerados como equivalentes. Ou seja, da mesma forma que os termos semanticamente equivalentes das linguagens dos sistemas são relacionados manualmente, os valores-verdade também o são. Por isso, pessoas que conheçam bem os sistemas devem, num primeiro instante, concordar num mapeamento satisfatório entre valores-verdade dos formalismos dos sistemas.

Os valores-verdade podem, por exemplo, ser representados por um reticulado. Nesse caso, a correspondência entre os valores-verdade é expressa como uma correspondência entre os reticulados dos sistemas. Do ponto de vista formal, podemos exigir que o valorverdade resultante de uma operação do servidor seja reproduzida na imagem da correspondência desses valores-verdade considerando uma operação equivalente do cliente. $\mathrm{O}$ exemplo 3.5.2 ilustra a importância da análise dos valores-verdade para o compartilhamento de conhecimento.

Exemplo 3.5.2 Considere os sistemas $S_{1}$ e $S_{2}$ e suponha que seus valores-verdade sejam representados pelos reticulados $R_{1}$ e $R_{2}$, respectivamente, exibidos na figura 3.5. Usando o fato que os símbolos $\top$ e true representam verdadeiro em $R_{1}$ e $R_{2}$, respectivamente, o mapeamento $|\mathrm{T}|_{S_{1}} \equiv \mid$ falso $\left.\right|_{S_{2}}$ faz com que um resultado provado como verdadeiro por $S_{2}$ seja considerado como falso em $S_{1}$.

Por outro lado, em uma consulta de $S_{1}$ a $S_{2}$ que tem como resposta o valor-verdade talvez necessita assumir um valor-verdade equivalente em $S_{1}$. No entanto, considerando apenas as equivelências de valores-verdade mencionadas acima, $S_{1}$ não tem como interpretar a resposta fornecida por $S_{2}$.

Mesmo nos casos em que o valor-verdade é representado através de grandezas numéricas, representando o grau de crença de uma informação, devemos considerar a forma como o 


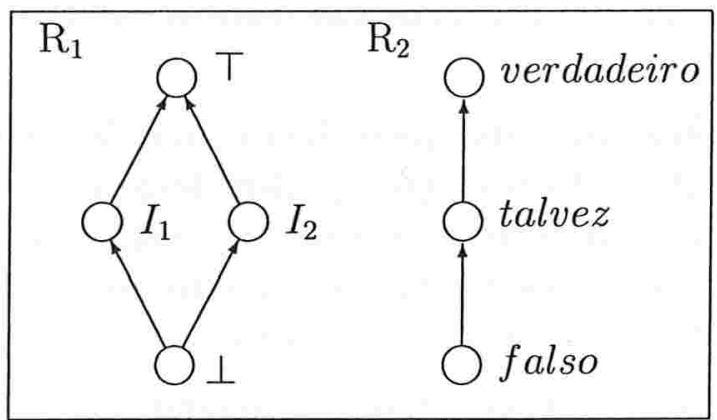

Figura 3.5: Reticulados representando valores-verdade dos formalismos $S_{1}$ e $S_{2}$.

valor é efetivamente representado. Por exemplo, alguns formalismos usam um grau de crença baseado em um único valor entre 0 e 1, que representa a probabilidade de uma fórmula ser verdadeira, enquanto outros usam um subintervalo do intervalo unitário para representar uma probabilidade equivalente. Nesse caso, também através da análise dos formalismos, devemos definir como converter a representação de um grau de crença no outro e vice-versa. Esse tipo de problema é enfrentado no nosso estudo de caso, no qual usamos sistemas baseados em valores pontuais associados a probabilidades e valores definidos por intervalos entre 0 e 1 .

\subsubsection{Análise Semântica}

Conforme ilustrado no exemplo 3.1.1, do ponto de vista formal, nem sempre o compartilhamento de conhecimento entre dois sistemas é possível. Isso se deve, principalmente, a incompatibilidades entre as teorias formais subjacentes a cada sistema, que pode fazer com que a combinação de suas teorias seja inconsistente.

Para o compartilhamento de conhecimento, é de fundamental importância conhecer como cada formalismo deduz seus resultados para avaliar a validade das deduções realizadas na derivação de um resultado a ser compartilhado. Essa análise deve levar em conta tanto a validade das regras usadas na dedução, como as premissas consideradas.

Por isso, o servidor deverá, quando solicitado, informar como um resultado foi obtido. Isso será feito com a transmissão de alguma representação da prova efetuada. Por exemplo, para um sistema baseado na linguagem Prolog, a árvore de prova do resultado cumprirá perfeitamente esse papel. Exemplos desse tipo de análise podem ser encontrados na análise do exemplo 3.1 .1 feita seção 3.1.

\subsubsection{Restrições ao Compartilhamento}

Conforme apresentado na seção 3.5.3 e ilustrado no exemplo 3.1.1, nem sempre o compartilhamento de conhecimento entre dois sistemas é possível. Isso motiva a elaboração de 
critérios que permitam prever situações nas quais o compartilhamento de conhecimento pode causar problemas.

Restrições são critérios, impostos pelo cliente, que devem ser satisfeitos pela resposta obtida para uma consulta. As restrições podem levar em consideração tanto as características da resposta propriamente dita como a forma como ela foi obtida pelo servidor. Obviamente, quanto mais fortes forem essas restrições, mais difícil será encontrar um sistema candidato a resolver a consulta proposta.

O compartilhamento de conhecimento é útil quando ele gera novas informações sem fazer com que as informações previamente conhecidas tornem-se inválidas. Dizemos que um resultado obtido por compartilhamento de conhecimento é indesejável se ele faz com que a teoria formal do cliente fique inconsistente ou se, mesmo sem tornar a teoria inconsistente, a forma com que foi produzido seja considerada inaceitável pelo cliente. São dois os principais resultados indesejáveis que encontramos no nosso modelo de compartilhamento de conhecimento:

inconsistência : a inconsistência ocorre quando um sistema $S_{1}$ recebe uma informação $\varphi$ tal que $T_{S_{1}} \cup \varphi$ torna-se inconsistente. Esse fenômeno está apresentado com detalhes na seção 3.5.3.

ciclo : um ciclo ocorre quando um sistema $S_{1}$ consulta um sistema $S_{2}$ que, por sua vez, para responder à consulta feita, consulta o mesmo $S_{1}$. Dessa forma, corre-se o risco de um sistema ficar consultando outro indefinidamente sem que se chegue a um resultado efetivo. Podemos, é claro, ter outras "formas" de ciclo, eventualmente envolvendo mais sistemas ou, até mesmo, mais ciclos para uma mesma consulta.

A escolha de um conjunto de restrições adequado depende do par de teorias formais considerado. O objetivo da construção desse conjunto é garantir a validade de um resultado, produzido externamente, dentro de uma teoria formal.

Do ponto de vista formal, identificamos três tipos de restrições:

estruturais : o cliente impõe condições sobre a forma com que o servidor pode obter a resposta para uma consulta;

semânticas : o cliente impõe condições sobre os modelos que o servidor pode assumir para o cálculo dos resultados;

arbitrárias : o cliente impõe condições para considerar o grau de validade de um resultado calculado pelo servidor como insatisfatório.

\subsection{Considerações Finais}

Neste capítulo apresentamos uma arquitetura genérica para o compartilhamento de conhecimento através da qual um sistema baseado em conhecimento pode solicitar que outro 
sistema baseado em conhecimento o auxilie a resolver um problema.

A grande vantagem dessa descrição genérica é oferecer uma descrição de um sistema para compartilhamento com ênfase nos pontos centrais deste trabalho: os sistemas baseados em conhecimento, que implementam as teorias formais participantes do sistema de compartilhamento, e o mecanismo de tradução de fórmulas e provas entre os diferentes formalismos ${ }^{7}$.

Outro detalhe importante, que influenciou profundamente na adoção dessa arquitetura específica, é que estamos supondo, no funcionamento de um sistema para compartilhamento, que temos um único problema que deverá ser resolvido por um CSC e que o compartilhamento só será tentado se o CSC não conseguir obter uma solução satisfatória.

Conforme apresentado na seção 3.1, nem sempre o cliente pode aceitar um resultado fornecido pelo servidor. Dentre as condições apresentadas como critérios para a análise da validade de um resultado, aquelas de consistência e de insuficiência envolvem uma análise detalhada da semântica dos formalismos considerados, enquanto que a condição estrutural envolve o mecanismo de inferência disponível em cada formalismo.

O estabelecimento desses critérios pressupõe, fundamentalmente, uma análise detalhada dos formalismos dos sistemas cliente e servidor. Por causa disso, torna-se difícil caracterizar uma teoria geral para avaliar a viabilidade do estabelecimento de compartilhamento de conhecimento entre sistemas genéricos.

Essa situação deixa-nos, como alternativa, a escolha de pares de formalismos e a avaliação das hipóteses que devem ser atendidas por sistemas codificados nesses formalismos para que a interação entre eles seja possível e, adicionalmente, quais critérios o cliente dispõe para avaliar a validade de uma resposta fornecida pelo servidor. Por isso, nos experimentos desenvolvidos neste trabalho, consideraremos sempre o comportamento da interação de dois sistemas, $S_{1}$ e $S_{2}$, codificados em dois formalismos, $f_{1}$ e $f_{2}$. Criamos, desta forma, quatro situações para cada experimento:

1. $S_{1}$, codificado em $f_{1}$, consulta $S_{2}$, codificado em $f_{1}$;

2. $S_{1}$, codificado em $f_{1}$, consulta $S_{2}$, codificado em $f_{2}$;

3. $S_{1}$, codificado em $f_{2}$, consulta $S_{2}$, codificado em $f_{1}$; e

4. $S_{1}$, codificado em $f_{2}$, consulta $S_{2}$, codificado em $f_{2}$.

Por isso, devido à dificuldade de se encontrar uma teoria geral para abordar o compartilhamento de conhecimento entre formalismos quaisquer, restringiremos a nossa abordagem para uma família de formalismos mais específica: formalismos para a manipulação de raciocínio com incerteza. Dentre as linguagens para tratamento de incerteza, selecionamos as redes bayesianas e a teoria de evidência de Dempster-Shafer. Esses formalismos, bem como a justificativa para sua escolha, estão apresentados no próximo capítulo.

Para o restante deste trabalho temos, nos capítulos seguintes:

\footnotetext{
${ }^{7}$ Note que, no contexto deste trabalho, o termo "formalismo" pode ser usado como sinônimo de sistema baseado em conhecimento e também de CSC.
} 
- apresentação dos formalismos considerados, destacando suas características relevantes com respeito ao modelo proposto de compartilhamento de conhecimento;

- descrição do processo de compartilhamento de conhecimento entre eles, explorando casos e situações emblemáticas que permitam uma avaliação completa dos problemas resultantes da interação entre os sistemas;

- apresentação, num apêndice, das implementações computacionais de interpretadores para os formalismos considerados. 


\section{Capítulo 4}

\section{Formalismos Utilizados}

Até este ponto, descrevemos o problema de compartilhamento de conhecimento de forma geral, sem nos preocuparmos com detalhes particulares presentes nos diversos formalismos para representação e manipulação de conhecimento. No entanto, o problema geral é complexo demais e foge ao escopo deste trabalho. Limitamos nossa abordagem ao problema de compartilhamento de conhecimento para formalismos baseados em raciocínio com incerteza, especificamente para os formalismos de redes bayesianas e teoria de evidência de Dempster-Shafer.

A seguir, apresentamos uma visão geral de raciocínio com incerteza, dando ênfase aos fundamentos matemáticos dos formalismos considerados, introduzimos a forma com que eles são utilizados na modelagem e solução de problemas e concluímos com uma análise comparativa entre eles.

As considerações e análises aqui expostas serão usadas no próximo capítulo, quando descreveremos o compartilhamento de conhecimento entre sistemas codificados nos formalismos aqui apresentados e analisados.

\subsection{Introdução}

Devido à falta de uma teoria geral que descreva o resultado da combinação de dois formalismos lógicos distintos, neste trabalho optou-se por selecionar dois formalismos arbitrários para tratamento de incerteza e averiguar como eles se comportam com respeito ao compartilhamento de conhecimento. A escolha dos formalismos de redes bayesianas e teoria de evidência de Dempster-Shafer foi baseada nos seguintes motivos:

- a teoria de evidência de Dempster-Shafer e redes bayesianas são, individualmente, largamente utilizadas com sucesso na produção de sistemas baseados em conhecimento com incerteza;

- os formalismos são de naturezas distintas: enquanto as redes bayesianas assumem 
um modelo probabilístico cuja dedução caracteriza-se pela propagação de probabilidades entre eventos condicionalmente dependentes, a teoria de evidência de Dempster-Shafer é caracterizada pela construção de um intervalo denotando o nível de certeza de uma fórmula;

- devido às diferenças entre eles, acreditamos que a tentativa de estabelecimento de compartilhamento de conhecimento entre estes formalismos evidenciará uma série de desafios formais e de ordem prática cuja análise e solução será de grande utilidade para o estudo geral de compartilhamento de conhecimento.

\subsubsection{Raciocínio com Incerteza}

Na construção de sistemas baseados em conhecimento, o conhecimento deve ser representado satisfatoriamente, o que motiva a elaboração de modelos para a codificação do conhecimento. Esses modelos devem equipar os símbolos com uma semântica adequada. Além disso, o processo de raciocínio propriamente dito deve ser modelado através de operações sobre os símbolos representados no modelo, e o valor-verdade de uma resposta deve ser obtido através da combinação apropriada dos valores-verdade dos símbolos usados no seu processo dedutivo.

À primeira vista, o cálculo da lógica clássica parece apropriado para esse propósito. No entanto, ele apenas faz distinção entre proposições verdadeiras ou falsas, enquanto que, nós, como humanos, somos capazes de lidar eficientemente e com sucesso com crenças parciais altamente subjetivas e produzir conclusões racionais a partir de informações incompletas, distorcidas e obscuras de confiabilidade restrita. Desta forma, o desenvolvimento de formalismos de representação de conhecimento nos obriga a levar em conta que devemos trabalhar com informações incertas e vagas ${ }^{1}$, que são as duas manifestações mais importantes do fenômeno de ignorância parcial.

Incerteza corresponde a uma avaliação humana de algum dado, que reflete sua crença ou dúvida na origem do dado. Este conceito abrange aqueles casos nos quais a situação ou processo real não é completamente determinado mas onde nós devemos confiar nas preferências subjetivas de algum especialista humano dentre as diferentes possibilidades.

Para esta breve apresentação raciocínio com incerteza, consultamos o capítulo inicial de [24]. A seguir, apresentamos uma visão geral do uso do raciocínio com incerteza na construção de sistemas baseados em conhecimento [5].

\section{Sistemas Baseados em Conhecimento com Incerteza}

A construção efetiva de um sistema baseado em conhecimento tem como um pré-requisito a formalisação, na maioria dos casos baseados em lógica, do conhecimento do domínio

\footnotetext{
${ }^{1}$ Não cabe nesta apresentação um estudo sobre informações vagas. Para uma introdução a este tema, consulte diretamente [24].
} 


\subsection{INTRODUÇÃO}

do problema e dos procedimentos de inferência relacionados ao sistema. Este é um passo necessário se se deseja atribuirir uma base científica aos resultados eventualmente obtidos do sistema e usados para se resolver problemas.

A primeira fase da formalização é a formulação do domínio do problema como uma teoria dedutiva, com tal exatidão que a correção de suas inferências básicas possa ser julgadas objetivamente pelo exame da linguagem na qual eles são expressos (Curry, Cf. Correa da Silva [5]). Dispomos de algumas interpretações possíveis para "formulação" e para "julgamento objetivo":

formulação : nós podemos estar interessados em uma descrição formal do próprio domínio do problema, assim provendo nossa linguagem com o maquinário apropriado para resolver problemas nesse domínio, ou podemos estar interessados em uma descrição formal dos processos de resolução de problema; nesse caso, devemos prover a linguagem com poder expressivo para prover uma representação explícita desses processos.

julgamento objetivo : pelo menos dois critérios podem ser considerados para o julgamento da adequação dos resultados obtidos através dos procedimentos de inferência de uma linguagem dedutiva. Os resultados podem ser considerados apropriados dada a boa formação matemática da linguagem ou dada a alta correlação entre eles e o fenômeno observável que estimulou a construção da linguagem.

O julgamento objetivo é mais difícil de certificar pois ele é específico para seu domínio, assim como serão os métodos para averiguá-lo. Dentro da área do raciocínio com incerteza, contudo, muitos autores propuseram classificações gerais dos tipos de incerteza com se pode deparar ao construir um sistema baseado em conhecimento, para obter protometodologias que sirvam como guias para o projeto de sistemas para aplicações reais ou que sirvam como base para o desenvolvimento de teorias gerais de incerteza.

Em [24] encontramos uma classificação, reproduzida na figura 4.1, baseada em uma estrutura de árvore. Seu objetivo é a "classificação de incerteza nos termos dos aspectos que são mais relevantes ao desenvolvimento de aplicações da inteligência artificial".

A tendência à confiança está relacionada com graus de crença subjetivos; equívoco e ambigüidade são relacionados, respectivamente, à determinação excessiva e à determinação insuficiente de valores-verdade; sistemas anômalos são aqueles sistemas que podem conter erros na sua construção.

A cada classe de incerteza pode ser associada uma abordagem padrão para revisar ou para estender sistemas formais, e nesta apresentação nós pretendemos trazer à discussão uma visão pessoal de como as abordagens para o tratamento formal de incerteza podem ser caracterizadas.

Nossa definição de sistema formal, do ponto de vista prático, é:

- duas linguagens formais, cada qual com seu alfabeto e gramática para construir sentenças bem formadas, chamadas de linguagem sintática e de linguagem semântica; 
- uma coleção de regras, chamado de sistema de inferência, para produzir novas sentenças sintáticas a partir de certas sentenças sintáticas;

- uma classe de homomorfismos, chamada de de interpretaçóes da linguagem sintática nos termos da linguagem semântica, da linguagem sintática à linguagem semântica.

Para tornar a discussão mais concreta, propomos representantes bem conhecidos para cada classe de incerteza. esses representantes são apresentados em itálico na figura 4.1

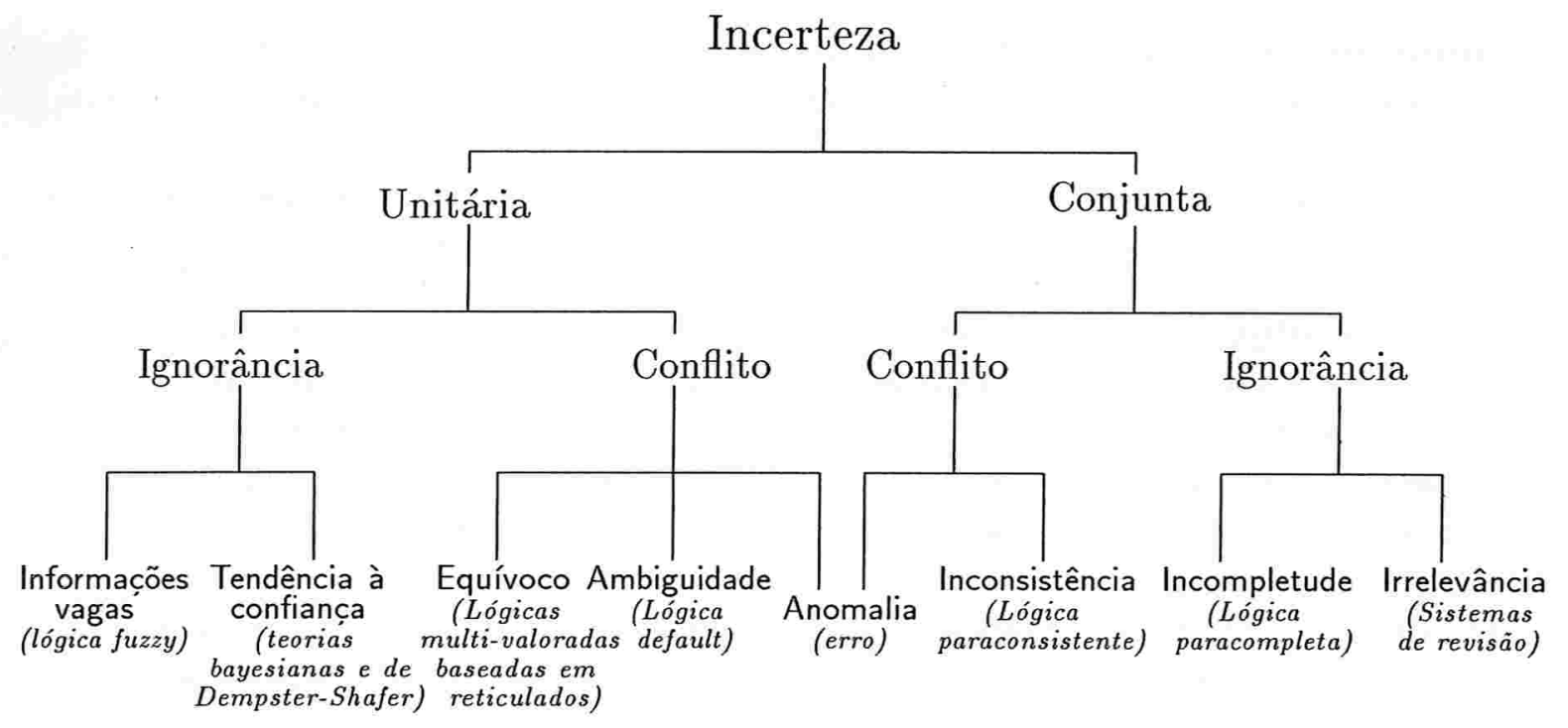

Figura 4.1: Classificação de incerteza para sistemas baseados em conhecimento

A partir da lógica proposicional clássica e da lógica de primeira ordem, propomos transformações sistemáticas de sistemas formais para acomodar as incertezas de cada classe.

\subsubsection{Mundos Possíveis}

Uma forma de interpretar o fenômeno da incerteza, e que será usada neste trabalho, é através do conceito de mundos possiveis. Segundo esta ótica, consideramos um conjunto de proposições $p_{1}, \ldots, p_{n}$, representando asserções sobre o mundo real, que podem ser verdadeiras ou falsas.

Podemos, selecionar, no mundo real, uma ocorrência do fenômeno que estamos modelando e averiguar a validade ou não de $p_{1}, \ldots, p_{n}$. A atribuição de valores-verdade a $p_{1}, \ldots, p_{n}$ dá origem a um mundo possível, isto é, uma atribuição de valores-verdade a $p_{i}$, $1 \leq i \leq n$, que representa uma ocorrência real do fenômeno modelado. Dizemos que uma tal configuração $\hat{p}_{1}, \ldots, \hat{p}_{n}$ determina um mundo possível para $p_{1}, \ldots, p_{n}$. 
Desta forma, o grau de certeza associado à veracidade da proposição $p_{i}$ corresponde à probabilidade de se selecionar um mundo possível no qual $p_{i}$ é verdadeira.

\subsection{Fundamentos Matemáticos}

Nesta seção apresentamos os fundamentos matemáticos básicos usados nos formalismos de redes bayesianas e teoria de evidência de Dempster-Shafer, que serão abordados nas seções 4.3 e 4.4, respectivamente.

Inicialmente, serão apresentados conceitos introdutórios de teoria de probabilidades, pesquisados a partir de [14, 24], e de programação em lógica, consultados em [1, 2, 4], que serão usados como elementos básicos dos formalismos considerados. A apresentação dos aspectos gerais da teoria de evidência de Dempster-Shafer foi pesquisada em [24]. Neste trabalho, usamos a caracterização da função de crença da teoria de Dempster-Shafer proposta por Fagin e Halpern, feita através de medidas interior e exterior [13].

\subsubsection{Probabilidades}

Dado um conjunto $\mathcal{X}$, uma $\sigma$-álgebra é uma família $\mathcal{U}$ de subconjuntos de $\mathcal{X}$ tal que:

S1. se $A \in \mathcal{U}$ então $\neg A=\mathcal{X}-A \in \mathcal{U}$

S2. se $\mathcal{A}=\left\{A_{1}, \ldots, A_{n}\right\}$ é uma coleção contável de conjuntos em $\mathcal{U}$ então $\bigcup_{i=1, \ldots, n} A_{n} \in \mathcal{U}$ $\mathrm{e} \bigcap_{i=1, \ldots, n} A_{n} \in \mathcal{U}$.

Resumidamente, uma $\sigma$-álgebra é um sistema de conjuntos fechado sob complementação e formação de uniões e intersecções contáveis. Por ser a união de $A$ e $\neg A, \mathcal{X} \in \mathcal{U}$. Por ser a intersecção de $A$ e $\neg A, \phi \in \mathcal{U}$, onde $\phi$ denota o conjunto vazio. Além disso, não necessariamente $\mathcal{U}$ consiste de todos os subconjuntos de $X$.

Seja $\mathcal{D}$ uma conjunto finito chamado de domínio. $X \in \mathcal{D}$ é chamado de evento. Denotamos por $\varepsilon=2^{\mathcal{D}}$ o conjunto de todos os eventos. Assim, $\phi \subseteq \varepsilon$ é o evento impossível, também chamado de falso, e $\mathcal{D}$ é o evento certo, também chamado de verdadeiro. Da maneira usual, definimos a união, interseç̧ão e o complemento de eventos. Um espaço amostral $S=(\mathcal{D}, \varepsilon)$ é uma $\sigma$-álgebra $\varepsilon$ de subconjuntos de um domínio $\mathcal{D}$.

$\operatorname{Seja}(\mathcal{D}, \varepsilon)$ um espaço amostral, onde $\mathcal{D}$ é um conjunto finito e $\varepsilon=2^{\mathcal{D}}$. Definimos uma função $p: \varepsilon \rightarrow[0,1]$, definida sobre $(\mathcal{D}, \varepsilon)$, como uma função de probabilidade se ela satisfizer as condições P1-P3 abaixo, conhecidas como axiomas de Kolmogorov.

P1. $p(A) \geq 0$, para todo $A \subseteq \Omega$;

P2. $p(\Omega)=1$;

P3. para todo $A, B \subseteq \Omega$, se $A \cap B=\phi$ então $p(A \cup B)=p(A)+p(B)$. 


\section{Probabilidade Condicional}

Se $p$ é uma medida de probabilidade sobre um espaço amostral $S$ e $E \subseteq S$ é um evento com $p(E)>0$ então, para todo evento $A \subseteq S$, a quantidade

$$
p(A \mid E)=\frac{p(A \cap E)}{p(E)}
$$

é definida como a probabilidade condicional de $A$ dado $E$. A probabilidade condicional $p(A \mid E)$ é considerada 0 quando $p(E)=0$.

Uma axiomatização comum, obtida de [22], considera que a probabilidade é uma função monotônica contínua $p$ tal que

C1. $0 \leq p(H \mid E) \leq 1$

C2. $p($ verdadeiro $\mid E)=1$

C3. $p(h \mid E)+p(\neg h \mid E)=1$

C4. $p(G \wedge H \mid E)=p(H \mid G \wedge E) \cdot p(G \mid E)$

\section{Regra da Cadeia}

Se $p$ é uma medida de probabilidade e $V_{1}, \ldots, V_{n}$ são eventos,

$$
p\left(V_{1}, \ldots, V_{n}\right)=p\left(V_{1} \mid V_{2}, \ldots, V_{n}\right) \cdot p\left(V_{2} \mid V_{3}, \ldots, V_{n}\right) \cdot \ldots \cdot p\left(V_{n-1} \mid V_{n}\right) \cdot p\left(V_{n}\right)
$$

onde a ordenação dos eventos $V_{1}, \ldots, V_{n}$ é arbitrária.

\section{Independência}

Dada uma uma medida de probabilidade $p$, dois eventos $A$ e $B$ são ditos (estatisticamente) independentes se e somente se

$$
p(A \cap B)=p(A) \cdot p(B)
$$

\section{Teorema de Bayes}

Sejam $\left\{E_{1}, \ldots E_{n}\right\}$ uma partição de um espaço amostral $S$ e $p$ uma função de probabilidade sobre $S$. Suponha que cada evento $E_{1}, \ldots, E_{n}$ tenha probabilidade maior que zero. Seja $E$ um evento qualquer tal que $p(E)>0$. Então para todo inteiro $k, 1 \leq k \leq n$, vale a fórmula de Bayes:

$$
p\left(E_{k} \mid E\right)=\frac{p\left(E_{k}\right) p\left(E \mid E_{k}\right)}{\sum_{j=1}^{n} p\left(E_{j}\right) p\left(E \mid E_{j}\right)} .
$$




\subsubsection{Programação em Lógica}

A seguir, definimos uma linguagem para programas em lógica normais que são não cíclicos, consistentes, estritos com relação às consultas e permitidos. Esses programas têm como procedimento de inferência a regra de resolução SLDNF, considerada correta e completa com relação ao modelo do completamento de Clark de programas da linguagem. Esta seção foi elaborada usando-se $[4,1]$ como referências básicas.

Por simplicidade, consideramos que os programas não apresentam símbolos funcionais, embora os resultados desta seção não impliquem esta restrição. Os símbolos da linguagem são:

variáveis: $X, Y, \ldots$;

constantes: $a, b, \ldots$;

predicados $n$-ários: $p, q, \ldots$;

conectivos: ': -' ("se"), '\+' ("não") e ',' ("e").

Um termo é uma variável ou uma constante, um átomo é uma aplicação de um predicado sobre termos e um literal é um átomo (literal positivo) ou a negação de um átomo (literal negativo). Uma cláusula normal é uma expressão da forma $p:-q_{1}, \ldots, q_{n}$ onde $p$ é um átomo, chamado cabeça da cláusula, e $q_{1}, \ldots, q_{n}$, chamdo de corpo da cláusula, é uma seqüência de literais. Quando $n=0$, a cláusula é chamada de cláusula unitária. Uma consulta é uma expressão $q_{1}, \ldots, q_{n}, \operatorname{com} n \geq 0$. Genericamente, dizemos que uma expressão nessa linguagem é um átomo, um termo, um literal, uma consulta ou uma cláusula. Um programa normal é um conjunto finito e não vazio de cláusulas normais.

Seja $\operatorname{Pr}_{\mathrm{P}}$ o conjunto dos predicados de um programa $\mathrm{P}$. A relação de dependência imediata $\sqsupseteq$ é definida da seguinte forma: dados $p, q \in P r_{\mathrm{P}}, p \sqsupseteq q$ se e somente se existe uma cláusula em $\mathrm{P}$ na qual $p$ ocorre na cabeça e $q$ ocorre no corpo.

A relação de dependência $\geq$ é definida como o fecho reflexivo-transitivo de dependência imediata em $\operatorname{Pr}_{\mathrm{P}}$ que estende $\sqsupseteq$. A expressão $p \geq q$ significa que $p$ depende hereditariamente de $q$.

Dependências sinalizadas são definidas como:

- $p \sqsupseteq_{+1} q$ se e somente se existir uma cláusula em P na qual $p$ ocorre na cabeça e $q$ ocorre em um literal positivo no corpo;

- $p \sqsupseteq_{-1} q$ se e somente se existir uma cláusula em P na qual $p$ ocorre na cabeça e $q$ ocorre em um literal negativo no corpo;

- $\geq_{+1}$ e $\geq_{-1}$ são as relações minimais que satisfazem:

$-p \geq+1 p$

$-p \sqsupseteq_{i} q \wedge q \geq_{j} r \Rightarrow p \geq_{i \times j} r$. 
Um programa $\mathrm{P}$ é dito consistente ("call consistent") se e somente se $\mathrm{P}$ não contém nenhum $p$ tal que $p \geq_{-1} p$. Se $\mathrm{P}$ também não contiver nenhum $p$ tal que $p \geq_{+1} p$, ele é chamado de não cíclico. P é dito estrito com respeito a uma consulta $\varphi$ se e somente se não existirem $p \in \mathrm{P}, q \in \varphi$ tais que $p \geq_{-1} q$ e $q \geq_{+1} p$. Dizemos que $\mathrm{P}$ é permitido se e somente se toda variável ocorrendo em cada cláusula de $\mathrm{P}$ ocorre em pelo menos um literal positivo no corpo da cláusula.

\section{Resolução SLDNF}

A computação em programas em lógica é feita através da combinação de dois mecanismos: substituição e unificação. Esta forma de computação é sintetizada em uma forma específica de prova de teoremas chamada resolução SLD (resolução Linear dirigida por Seleção de regras para cláusulas Definidas). A resolução SLD não é capaz de tratar de programas normais devido aos literais negativos no corpo das cláusulas. Para tratar de programas normais, usamos a resolução SLDNF (resolução SLD com Negação como regra de Falha finita).

Dada uma expressão $E, \operatorname{Var}(E)$ denota o conjunto das variáveis que ocorrem em $E$. Uma substituição $\theta$ é um mapeamento finito de variáveis a termos e denotado por

$$
\theta=\left\{x_{1} / t_{1}, \ldots, x_{n} / t_{n}\right\}
$$

onde $x_{1}, \ldots, x_{n}$ são distintos e $x_{i} \not \equiv t_{i}, 1 \leq i \leq n$. Uma substituição $\theta$ é dita mais geral que uma substituição $\eta$ se, para alguma substituição $\gamma$, tivermos $\eta=\theta \gamma$.

Dados dois átomos $A$ e $B$, uma substituição $\theta$ é chamada de unificador de $A$ e $B$ se $A \theta \equiv B \theta$. A substituição é chamada de unificador mais geral (denotado por umg) de $A$ e $B$ se for um unificador que defina a substituição mais geral dentre os unificadores de $A$ e $B$.

Sejam P um programa e $N=A_{1}, \ldots, A_{n}$ uma consulta. Suponha que $C=A \leftarrow$ $B_{1}, \ldots, B_{k}$ é uma cláusula de P. Se, para algum $i, 1 \leq i \leq n, A_{i}$ e $A$ unificam através de um umg $\theta$, chamamos

$$
N^{\prime}=\left(A_{1}, \ldots, A_{i-1}, B_{1}, \ldots, B_{k}, A_{i+1}, \ldots, A_{n}\right) \theta
$$

de um resolvente de $N$ e $C$ com o umg $\theta$. Adicionalmente, dizemos que $A_{i}$ é o literal selecionado no processo dedutivo.

Na resolução SLDNF, quando o literal selecionado é positivo, usa-se o próprio método de resolução SLD para se obter o novo resolvente. Quando o literal é negativo, digamos, $\neg A$, usa-se a seguinte regra para se obter o resolvente:

$\neg A$ é bem sucedido se e somente se $A$ falha finitamente,

$\neg A$ falha finitamente se e somente se $A$ é bem sucedido. 
Ou seja, se $\neg A$ é bem sucedido, ele é removido da consulta; se ele falha finitamente, a consulta falha. Dado um programa $\mathrm{P}$, seu conjunto de falha finita é o conjunto de todos os termos $A$ que não contenham variáveis e tais que exista uma árvore SLD finitamente falha contendo a consulta $A$ como raiz.

\section{Completamento de Clark}

Na lógica de primeira ordem, os resultados de correção e completude igualam as noções de semântica e implicação formal em provas: para todo conjunto de fórmulas $T \cup \varphi$, temos

$$
T \vDash \varphi \text { sse } T \vdash \varphi \text {. }
$$

Não é possível estabelecer um resultado equivalente para a resolução SLDNF e programas. Clark resolveu este problema com a substituição de um programa $P$ por seu completamento [2], denotado por $\operatorname{comp}(\mathrm{P})$ e avaliar a resolução SLDNF com relação a $\operatorname{comp}(\mathrm{P})$.

Inicialmente, é necessário introduzir a relação de igualdade e os predicados verdadeiro e falso na linguagem. Assuma que "=" é um novo símbolo de predicado que não ocorre em P. Dado um programa $\mathrm{P}$, calcula-se $\operatorname{comp}(\mathrm{P})$ da seguinte forma:

Passo 1: Transforme cada cláusula $p(\mathrm{t}):-\mathrm{L}$ em $p(\mathrm{x}):-\mathrm{x}=\mathrm{t} \quad \wedge \quad \mathrm{L}$, onde $\mathrm{x}$ é uma nova variável.

Passo 2: Transforme cada fórmula $p(\mathrm{x}):-\mathrm{F}$ obtida no passo anterior em $p(\mathrm{x}):-\exists \mathrm{yF}$, onde y são as variáveis da cláusula original.

Passo 3: Sejam $p(\mathrm{x}):-\mathrm{F}_{1}, \ldots, p(\mathrm{x}):-\mathrm{F}_{k}$ todas as fórmulas obtidas no passo anterior que apresentam $p$ como "cabeça". Troque-as por uma única fórmula $p(\mathrm{x}):-\mathrm{F}_{1} \vee \ldots \vee \mathrm{F}_{k}$. Se $F_{1} \vee \ldots \vee F_{k}$ é vazio, troque-o por verdadeiro.

Passo 4: Para cada símbolo relacional $q$ que não ocorre na cabeça de uma cláusula em $\mathrm{P}$, acrescente um fórmula $q(\mathrm{x}):-$ falso.

Passo 5: Substitua cada fórmula $p(\mathrm{x}):-\mathrm{F}$ por $\forall \mathrm{x}(p(\mathrm{x}):-\mathrm{F})$.

Passo 6: Em cada fórmula, substitua o símbolo ": -" por " $\leftrightarrow$ ".

Adicionalmente, acrescente o seguinte axioma de igualdade:

- $x \neq t$, para toda variável $x$ e termo $t$ tais que $x \not \equiv t$ e $x$ ocorre em $t$.

$\mathrm{O}$ conjunto de fórmula resultante da aplicação das operações acima define $\operatorname{comp}(\mathrm{P})$. O exemplo 4.2.1 apresenta o completamento de clark de um programa em prolog. 
Exemplo 4.2.1 Considere o seguinte programa P, escrito em Prolog (obtido de [1]):

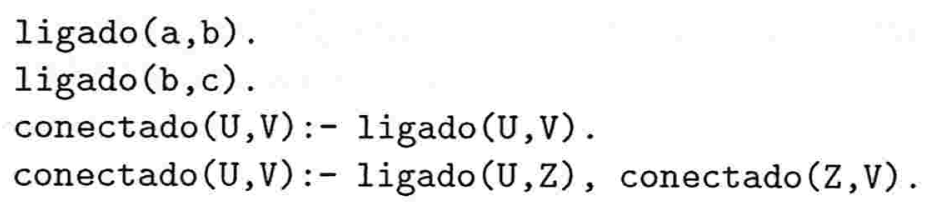

O conjunto comp $(\mathrm{P})$ é composto pelo par de fórmulas:

$$
\begin{aligned}
& \forall \mathrm{X} \forall \mathrm{Y}(\mathrm{Iigado}(\mathrm{X}, \mathrm{Y}) \leftrightarrow(\mathrm{X}=\mathrm{a} \wedge \mathrm{Y}=\mathrm{b}) \vee(\mathrm{X}=\mathrm{b} \wedge \mathrm{Y}=\mathrm{c})) \\
& \forall \mathrm{X} \forall \mathrm{Y}(\operatorname{conectado}(\mathrm{X}, \mathrm{Y}) \leftrightarrow \exists \mathrm{U} \exists \mathrm{V}(\mathrm{X}=\mathrm{U} \wedge \mathrm{Y}=\mathrm{V} \wedge \operatorname{ligado}((\mathrm{u}, \mathrm{v}) \vee \\
& \quad \exists \mathrm{U} \exists \exists \mathrm{Z}(\mathrm{X}=\mathrm{U} \wedge \mathrm{Y}=\mathrm{V} \wedge \operatorname{ligado}(\mathrm{U}, \mathrm{Z}) \wedge \operatorname{conectado}(\mathrm{Z}, \mathrm{V}))
\end{aligned}
$$

A correção da resolução SLDNF é garantida pelo seguinte teorema, cuja demonstração podem ser obtidas em [1].

\section{Teorema 4.2.1 (Correção da resolução SLDNF)}

Seja P um programa normal. Se A está no conjunto de falha finita de $\mathrm{P}$ então $\operatorname{comp}(\mathrm{P}) \models \neg(A)$.

A completude da resolução SLDNF é provada em [25], que estabelece que se um programa é normal e estrito, a resolução SLDNF é completa:

Teorema 4.2.2 (Completude da resolução SLDNF)

Sejam P um programa normal e $G$ uma consulta normais tais que $\mathrm{P} \cup\{G\}$ é estrito e permitido. Suponha que comp $(\mathrm{P}) \cup\{G\}$ é inconsistente. Então existe uma refutação $S L D N F$ de $\mathrm{P} \cup\{G\}$.

\subsubsection{Teoria de Evidência de Dempster e Shafer}

A teoria de evidência de Dempster-Shafer [24, 22] dá origem a uma abordagem para a atribuição de níveis de possibilidades a eventos. Ela é baseada na suposição de que a crença parcial em uma proposição correspondente a um evento $A \subseteq \Omega$ é quantificado através de um valor $\operatorname{Bel}(A) \in[0,1]$. Assume-se que $\operatorname{Bel}(A)$, a função de crença, verifica os seguintes axiomas:

B1. $\operatorname{Bel}(\phi)=0$

B2. $\operatorname{Bel}(\Omega)=1$

B3. para todo inteiro $n>0$ e coleção de subconjuntos $A_{1}, \ldots, A_{n} \subseteq \Omega, \operatorname{Bel}\left(A_{1} \cup \ldots \cup A_{n}\right) \geq$ $\sum_{i} \operatorname{Bel}\left(A_{i}\right)-\sum_{i<j} \operatorname{Bel}\left(A_{i} \cap A_{j}\right)+\ldots+(-1)^{n+1} \operatorname{Bel}\left(A_{1} \cap \ldots \cap A_{n}\right)$. 
Uma forma de se caracterizar uma função $\mathrm{Bel}$, principalmente ao se conșiderar a dificuldade de se testar o axioma B3., é através da definição de uma função básica de atribuição de probabilidades. A função básica de atribuição de probabilidades é função $m: 2^{\Omega} \rightarrow[0,1]$ tal que:

- $m(\phi)=0$

- $\sum_{A \subseteq \Omega} m(A)=1$.

A partir de $m$, a função $\mathrm{Bel}$ pode ser definida como:

$$
\operatorname{Bel}(A)=\sum_{B \subseteq A} m(B)
$$

Define-se também um número correspondente $P l(A)$, chamado plausibilidade de $A$, que representa a medida com que $A$ é compatível com a evidência disponível:

$$
P l(A)=1-\operatorname{Bel}(\bar{A})=\sum_{B: A \cap B \neq \phi} m(B) .
$$

Da forma com que foi definida a função $B e l$, segue que $\operatorname{Bel}(A)+\operatorname{Bel}(\bar{A}) \leq 1$. O intervalo

$$
\operatorname{Pl}(A)-\operatorname{Bel}(A)=1-(\operatorname{Bel}(A)+\operatorname{Bel}(\neg A)) \geq 0
$$

representa a probabilidade com que ambas $A$ e $\neg A$ são compatíveis com a evidência disponível. A partir da crença e da plausibilidade de um evento $A$, associa-se o intervalo

$$
[\operatorname{Bel}(A), P l(A)]
$$

como o grau de crença associado a $A$.

\section{Caracterização de Fagin e Halpern}

A caracterização de Fagin e Halpern da teoria de Dempster-Shafer [13] fornece uma realização da função $\mathrm{Bel}$ que, além de verificar os axiomas B1.-B3., vistos na seção 4.2.1, apresenta uma interpretação probabilística, obtida através de conceitos como espaço probabilístico e medidas interiores e exteriores.

A seguinte definição é bastante semelhante à caracterização de função de probabilidade vista na seção 4.2.1. Um espaço probabilístico $(S, \mathcal{X}, \mu)$ consiste em um conjunto $S$, chamado espaço amostral, uma $\sigma$-álgebra $\mathcal{X}$ de subconjuntos de $S$ cujos elementos são chamados de conjuntos mensuráveis, e uma medida de probabilidade $\mu: \mathcal{X} \rightarrow[0,1]$ tal que:

MP1. $\mu(X) \geq 0$, para todo $X \in \mathcal{X}$

MP2. $\mu(S)=1$

MP3. $\mu\left(\cup_{i=1}^{\infty} X_{i}\right)=\sum_{i=1}^{\infty} \mu\left(X_{i}\right)$, se os $X_{i}$ 's são membros de $\mathcal{X}$ disjuntos entre si. 
Em um espaço probabilístico $(S, \mathcal{X}, \mu)$, a medida de probabilidade $\mu$ não é definida em $2^{S}$ (o conjunto de todos os subconjuntos de $S$ ), mas somente em $\mathcal{X}$. Desta forma, a caracterização de probabilidade vista na seção 4.2 .1 pode ser considerada como um caso particular de um espaço probabilístico.

No entanto, podemos estender $\mu$ a $2^{S}$ em duas formas padrão, com a definição de funções $\mathcal{P}_{*}, \mathcal{P}^{*}: 2^{D} \rightarrow[0,1]$, tradicionalmente chamadas de medida interior e medida exterior induzida por $\mu$. Para um subconjunto qualquer $A \subseteq S$, definimos

$$
\begin{aligned}
& \mathcal{P}_{*}(A)=\sup \{\mu(X) \mid X \subseteq A \text { e } X \in \mathcal{X}\} \\
& \mathcal{P}^{*}(A)=\inf \{\mu(X) \mid x \supseteq A \text { e } X \in \mathcal{X}\} .
\end{aligned}
$$

Se $\mathcal{X}$ for finito (e em particular, se $S$ for finito), é fácil ver que a medida interior de $A$ é a medida do maior conjunto mensurável contido em $A$, enquanto que a medida exterior de $A$ é a medida do menor conjunto mensurável que contém $A$. Pela forma com que foi definida, $\mathcal{P}_{*}(A)$ corresponde à crença em $A$, considerando-se a definição de crença apresentada em 4.2.3. Equivalentemente, $\mathcal{P}^{*}(A)$ corresponde à plausibilidade de $A$ segundo a definição de plausibilidade apresentada em 4.2.3. Desta forma, se fosse possível calcular a probabilidade $\mathcal{P}(A)$, encontraríamos um valor tal que

$$
\mathcal{P}_{*}(A) \leq \mathcal{P}(A) \leq \mathcal{P}^{*}(A)
$$

Para eventos mensuráveis, vale a igualdade:

$$
\mathcal{P}_{*}(A)=\mathcal{P}(A)=\mathcal{P}^{*}(A) \text {. }
$$

Desta forma, adota-se o intervalo $\left[\mathcal{P}^{*}(A), \mathcal{P}_{*}(A)\right]$ como indicador do grau de incerteza associado a $A$.

As medidas interiores e exteriores podem ser estendidas para o produto cartesiano de uma partição $\left\{D_{1}, \ldots, D_{n}\right\}$ de um domínio $D$. Se assumimos que todos os eventos em cada um dos $\chi_{D_{i}}$ são independentes dois a dois, podemos estender as medidas de probabilidades aos produtos cartesianos de elementos de $D$. Dadas uma coleção $D_{1}, \ldots, D_{m}$ de elementos de uma partição de $D$, onde todos os eventos em cada um dos $\chi_{D_{i}}$ são independentes dois a dois, as álgebras $\chi_{D_{i}}$ e as medidas de probabilidades $\mathcal{P}_{i}$ de cada $D_{i}, i=1, \ldots, m$, define-se as funções $\mathcal{P}_{m *}, \mathcal{P}_{m}^{*}: 2^{D_{1} \times \ldots \times D_{m}} \rightarrow[0,1]$ tais que:

$$
\begin{aligned}
& \mathcal{P}_{m *}(A)=\sup \left\{\mathcal{P}_{m}(X): X \subseteq A, X \in \vec{\chi}\right\} \\
& \mathcal{P}_{m}^{*}(A)=\inf \left\{\mathcal{P}_{m}(X): A \subseteq X, X \in \vec{\chi}\right\}
\end{aligned}
$$

As medidas $\mathcal{P}_{m *}$ e $\mathcal{P}_{m}^{*}$ podem ser tomadas como aproximações inferiores e superiores das probabilidades de eventos não mensuráveis. Se fosse possível calcular a probabilidade $\mathcal{P}_{m}(A)$, seria obtido

$$
\mathcal{P}_{m *}(A) \leq \mathcal{P}_{m}(A) \leq \mathcal{P}_{m}^{*}(A)
$$


Para eventos mensuráveis obtém-se que:

$$
\mathcal{P}_{m *}(A)=\mathcal{P}_{m}(A)=\mathcal{P}_{m}^{*}(A) .
$$

\subsection{Redes Bayesianas}

Redes Bayesianas, consultadas em [31,37], são caracterizadas por um método de cálculo de probabilidades de eventos que verificam a regra de Bayes,

$$
P(H \mid e)=\frac{P(e \mid H) P(H)}{P(e)}
$$

a qual estabelece que a probabilidade de o evento $H$ ser verdadeiro depois de se obter a informação de que $e$ é verdadeiro pode ser calculada em função das probabilidades de $P(e), P(H)$ (probabilidade prévia de $H$ ) e de $P(e \mid H)$.

A partir das probabilidades condicionais entre eventos podemos construir um grafo dirigido da seguinte forma: representando cada evento $e$ por um vértice e para cada probabilidade condicional $P\left(e \mid e_{i}\right)$ definindo uma aresta com origem em $e_{i}$ e término em $e$ e rotulada por $P\left(e \mid e_{i}\right)$. Se $P\left(e \mid e_{i}\right)=P(e)$, omitimos a aresta referente para simplificar a representação do grafo. Grafos construídos desta forma são chamados de Redes Bayesianas. Formalmente, definimos uma Redes Bayesianas da seguinte forma [37]:

Uma rede bayesiana é um par $B=(G, \Gamma)$ onde:

- $G=(V G, A G)$ é um grafo dirigido acíclico com vértices $V G=\left\{V_{1}, \ldots, V_{n}\right\}, n \geq 1$, e arestas $A G$;

- $\Gamma=\left\{\gamma_{V_{i}} \mid V_{i} \in V G\right\}$ é um conjunto de funções reais não negativas

$$
\gamma_{V_{i}}:\left\{C_{V_{i}}\right\} \times\left\{C_{\rho_{G}\left(V_{i}\right)}\right\} \longrightarrow[0,1]
$$

chamadas de funções de avaliação de probabilidades (condicionais), tais que, para cada configuração $c_{\rho_{G}\left(V_{i}\right)}$ do conjunto $\rho_{G}\left(V_{i}\right)$ dos predecessores (imediatos) do vértice $V_{i}$ em $G$, temos que $\gamma_{V_{i}}\left(\neg v_{i} \mid c_{\rho_{G}\left(V_{i}\right)}\right)=1-\gamma_{V_{i}}\left(v_{i} \mid c_{\rho_{G}\left(V_{i}\right)}\right), i=1, \ldots, n$.

Em uma rede bayesiana, uma evidência é um evento cujo valor é dado como previamente conhecido. Chamamos de crença de um vértice $A$, denotada por $\operatorname{cr}(A)$, a probabilidade associada ao vértice $A$ considerando-se todas as evidências introduzidas na rede até então. Formalmente, se $E_{1}, \ldots, E_{j}$ são evidências e $\hat{e}_{1}, \ldots, \hat{e}_{j}$ são os valores a elas associados, $\operatorname{cr}(A)=p\left(A \mid E_{1}=\hat{e_{1}}, \ldots, E_{j}=\hat{e_{j}}\right)$.

Desta forma, dadas evidências $e_{1}, e_{2}, \ldots, e_{n}$, podemos avaliar a nova probabilidade de $e$ (em face às novas evidências) através da atualização das probabilidades dos eventos representados na rede a partir da propagação da validade de $e_{1}, e_{2}, \ldots, e_{n}$ através dos arcos da rede até que, finalmente, calculemos a probabilidade de $e$. 
Exemplo 4.3.1 Um exemplo simples de uma rede bayesiana, chamada de PobreRB, está apresentado na figura 4.2. Através dessa rede, foi modelada, de forma simplificada, uma forma de se diagnosticar se uma pessoa é pobre baseando-se na sua renda mensal e posse de imóvel.

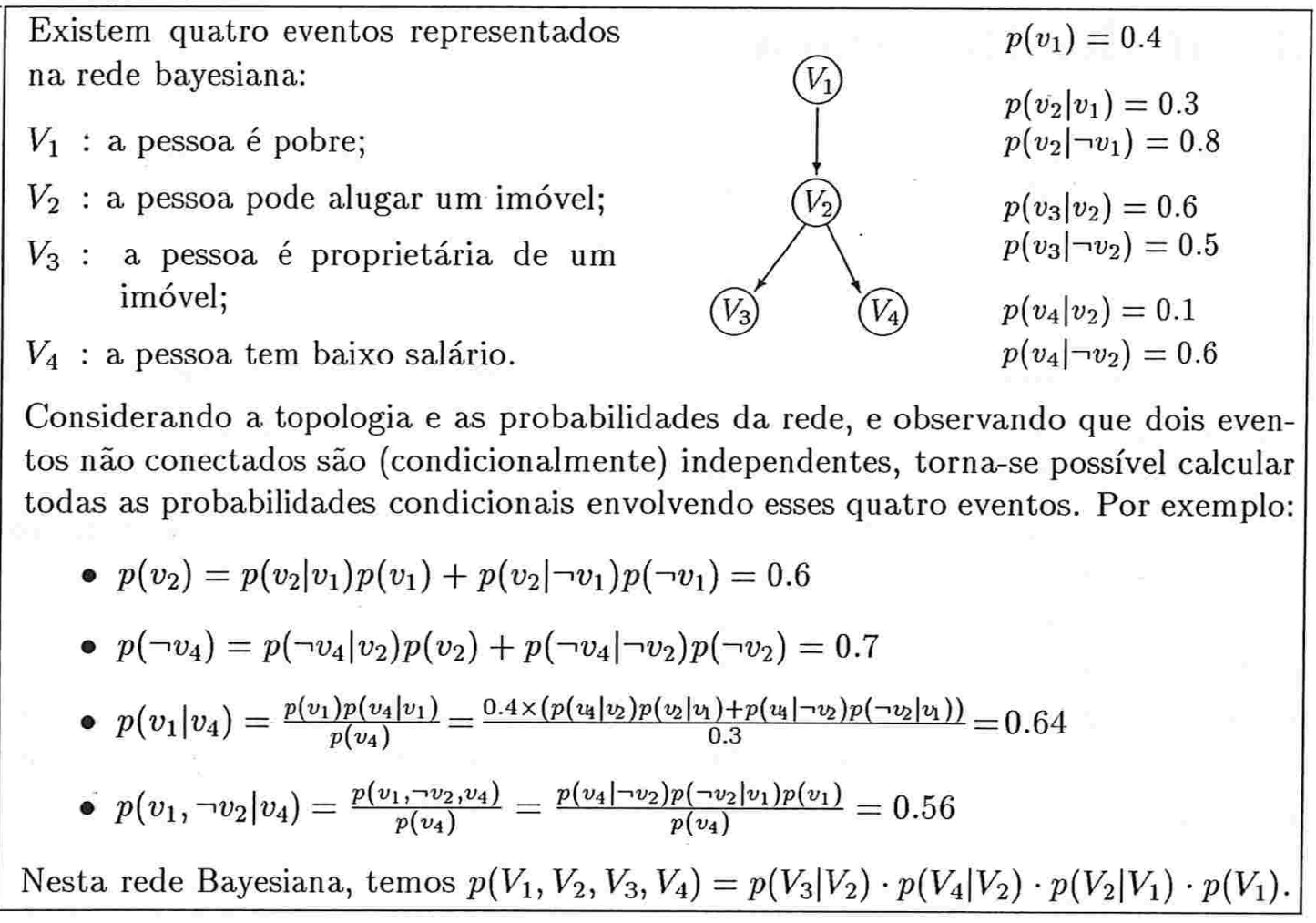

Figura 4.2: Rede bayesiana PobreRB

Para se determinar $p\left(A \mid e_{1}, \ldots, e_{n}\right)$ através de uma Rede Bayesiana, introduzimos, seqüencialmente, os valores das evidências $e_{1}, \ldots, e_{n}$. A cada evidência introduzida, alteramos os valores das crenças associadas a cada vértice, em um processo chamado de propagação de evidências, de tal forma que o vértice associado à nova evidência distribui pela rede, através de suas arestas, sem levar em consideração o sentido delas, seu novo valor de crença. Cada vértice que recebe um novo valor de crença de um vértice adjacente altera seu valor de crença, baseado na nova informação, e passa seu novo valor aos seus demais vizinhos. Repetindo esse processo para cada evidência, a rede estará representando, para cada vértice $a$, a probabilidade $p\left(a \mid e_{1}, \ldots, e_{n}\right)$. Uma Rede Bayesiana pode ser interpretada de duas maneiras distintas mas equivalentes:

- ela é usada para calcular $p\left(A \mid e_{1}, \ldots, e_{n}\right)$, ou seja, as probabilidades condicionais de eventos dado um conjunto de evidências;

- ela é usada para calcular a crença de $A$, considerando-se, implicitamente, todas as evidências coletadas até então. 
A probabilidade conjunta para os eventos $V=\left\{v_{1}, v_{2}, \ldots, v_{n}\right\}$ é calculada como:

$$
p\left(v_{1}, v_{2}, \ldots, v_{n}\right)=\prod_{v \in V} p(v \mid p a i s(v))
$$

onde pais $(v)$ é o conjunto dos vértices $u_{i}$ da rede para os quais existe uma aresta $\left(u_{i}, v\right)$.

Nas Redes Bayesianas, temos representado um modelo probabilístico completo, isto é, os valores de todas as probabilidades condicionais estão apresentados. Detalhes complementares a respeito de implementações computacionais de redes bayesianas e algoritmos de propagação de evidências podem ser obtidos diretamente em [31].

\subsection{Programação em Lógica com Probabilidades}

A teoria lógica apresentada na seção 4.2 .2 fornece um modelo de computação baseado em programação lógica limitado à lógica clássica. Uma forma de se associar níveis de incerteza à teoria lógica é obtida com a associação das cláusulas de um programa com níveis de crença fornecidos pela teoria de evidência de Dempster-Shafer. Os níveis de crença considerados serão aqueles caracterizados pelas medidas interiores e exteriores fornecidos por Fagin e Halpern.

Chamamos o formalismo lógico para tratamento de incerteza baseado em probabilidades de programação em lógica baseada na teoria de Dempster-Shafer com função de crença de Fagin e Halpern, que resumiremos por programação em lógica DSFH.

\subsubsection{Inferência na Programação em Lógica DSFH}

Dado um programa $P$, usando a realização da função de crença da teoria de evidência de Dempster-Shafer fornecida por Fagin e Halpern, apresentada na seção 4.2.3, define-se o seguinte método, obtido em [4], que foi baseado em resultados de Subrahmanian e de Fagin e Halpern, para construção de níveis de crença associados às fórmulas:

- atribui-se níveis de crença às fórmulas unitárias $\varphi$ de tal forma que a cada cláusula tem-se associado um intervalo $[a, b]$, onde $a$ é sua crença, denotada por $a=\hat{\mathcal{P}}_{*}(\varphi)$, e $b$ sua plausibilidade, denotada por $b=\hat{\mathcal{P}}^{*}(\varphi)$;

- se o nível de crença de uma fórmula unitária $\varphi$ não estiver definido, assume-se que o intervalo associado a ela é $[0,0]$, ou seja $\hat{\mathcal{P}}_{*}(\varphi)=0$ e $\hat{\mathcal{P}}^{*}(\varphi)=0$. A escolha desse intervalo corresponde a tornar a programação em lógica DSFH similar à programação em lógica tradicional no que se refere a informações inexistentes, que são assumidas como falsas;

- para se construir o intervalo $\left[\hat{\mathcal{P}}_{*}(\varphi), \hat{\mathcal{P}}^{*}(\varphi)\right]$ associado a uma fórmula não unitária $\mathrm{H}$, usa-se o seguinte método para calcular o intervalo definido por sua crença e plausibilidade: 


$$
\begin{aligned}
& \mathrm{H}:-\mathrm{Q} \Rightarrow \hat{\mathcal{P}}_{*}(\mathrm{H})=\hat{\mathcal{P}}_{*}(\mathrm{Q}) \\
& \hat{\mathcal{P}}^{*}(\mathrm{H})=\hat{\mathcal{P}}^{*}(\mathrm{Q}) \\
& \mathrm{H}:-\psi, \varphi \Rightarrow \hat{\mathcal{P}}_{*}(\mathrm{H})=\max \left\{0, \hat{\mathcal{P}}_{*}(\psi)+\hat{\mathcal{P}}_{*}(\varphi)-1\right\} \\
& \hat{\mathcal{P}}^{*}(\mathrm{H})=\min \left\{\hat{\mathcal{P}}^{*}(\psi), \hat{\mathcal{P}}^{*}(\varphi)\right\} \\
& \mathrm{H}:-\psi \Rightarrow \hat{\mathcal{P}}_{*}(\mathrm{H})=\max \left\{\hat{\mathcal{P}}_{*}(\psi), \hat{\mathcal{P}}_{*}(\varphi)\right\} \\
& \mathrm{H}:-\varphi \quad \hat{\mathcal{P}}^{*}(\mathrm{H})=\min \left\{1, \hat{\mathcal{P}}^{*}(\psi)+\hat{\mathcal{P}}^{*}(\varphi)\right\} \\
& \mathrm{H}:-\backslash+\mathrm{Q} \Rightarrow \hat{\mathcal{P}}_{*}(\mathrm{H})=1-\hat{\mathcal{P}}^{*}(\mathrm{Q}) \\
& \hat{\mathcal{P}}^{*}(\mathrm{H})=1-\hat{\mathcal{P}}_{*}(\mathrm{Q})
\end{aligned}
$$

onde as cláusulas apresentadas esqumaticamente são aquelas que fazem parte de P. Os intervalos construídos dessa forma, não necessariamente correspondem exatamente ao real intervalo associado a $\mathrm{H}$; no entanto, existe a garantia de que o intervalo real está contido no intervalo construído. Note que não existem incertezas associadas às regras da programação em lógica DSFH; a medida de incerteza manipulada neste formalismo está concentrada nos intervalos construídos no processo dedutivo.

Na programação em lógica $\mathrm{DSFH}$, em um programa $\mathbf{P}$, a prova da consulta $\mathbf{Q}=$ $Q_{1}^{\prime}, \ldots, Q_{m}^{\prime}$, onde $Q_{j}^{\prime}$ são predicados atômicos ou negação de predicados atômicos, é expressa pela construção de um intervalo $\left[\hat{\mathcal{P}}_{*}(\mathrm{Q}), \hat{\mathcal{P}}^{*}(\mathrm{Q})\right]$ no qual $\hat{\mathcal{P}}_{*}(\mathrm{Q})$ e $\hat{\mathcal{P}}^{*}(\mathrm{Q})$ são calculados a partir dos intervalos associados a $Q_{1}^{\prime}, \ldots, Q_{m}^{\prime}$. Se $Q_{i}^{\prime}$ for uma cláusula unitária, os valores $\hat{\mathcal{P}}_{*}\left(\mathbf{Q}_{\mathbf{i}}^{\prime}\right)$ e $\hat{\mathcal{P}}^{*}\left(Q_{i}^{\prime}\right)$ são dados explicitamente (caso contrário, assume-se que eles são 0.0 ). Se $Q_{i}^{\prime}$ for uma cláusula unitária, seu intervalo é recursivamente calculado usando-se as demais cláusulas incluídas no programa. Um exemplo de computação baseado nesse formalismo está apresentado no exemplo 4.4.1.

Exemplo 4.4.1 Por exemplo, considerando-se o seguinte programa:

$$
\begin{aligned}
& \mathrm{p}(\mathrm{X}) \quad:-\mathrm{q}(\mathrm{X}), \mathrm{I}+\mathrm{r}(\mathrm{X}) \\
& \mathrm{q}(\mathrm{X}) \quad:-\mathrm{S}(\mathrm{X}), \mathrm{u}(\mathrm{X})
\end{aligned}
$$

e os seguintes intervalos associados às cláusulas unitárias:

$$
\begin{aligned}
& r(b)=[0.0,0.0] \\
& r(c)=[0.8,0.9] \\
& s(a)=[0.1,0.3] \\
& s(b)=[0.2,0.4] \\
& s(c)=[0.6,0.7] \\
& u(a)=[0.3,0.4] \\
& u(b)=[0.2,0.5] \\
& u(c)=[0.4,0.7]
\end{aligned}
$$

a prova de $\mathrm{p}(\mathrm{X})$ é obtida pela combinação das provas de $\mathrm{p}(\mathrm{a}), \mathrm{p}(\mathrm{b})$ e $\mathrm{p}(\mathrm{c})$ (os valores com os quais $\mathrm{X}$ unifica). O intervalo associado a $\mathrm{p}(\mathrm{c})$ é o intervalo associado à consulta $\mathrm{s}(\mathrm{c}), \mathrm{u}(\mathrm{c}), \downarrow+\mathrm{r}(\mathrm{c})$. Usando-se as regras acima, esse intervalo é calculado como 
$[\max \{0,(0.6+0.4-1)+0.1-1\}, \min \{0.7,0.7,0.2\}]=[0,0.2]$. As provas de $\mathrm{p}(\mathrm{a})$ e $\mathrm{p}(\mathrm{b})$ são obtidas da mesma forma, gerando os intervalos $[0,0.3]$ e $[0,0.4]$, respectivamente. Note que o intervalo associado a $\mathrm{r}(\mathrm{a})$ é $[0,0]$, pois não existe uma cláusula unitária que o defina. Para completar a prova de $\mathrm{p}(\mathrm{X})$, os intervalos obtidos, $[0,0.3],[0,0.4]$ e $[0,0.2]$, são combinados e o intervalo para a crença em $\mathrm{p}(\mathrm{X})$ é $[0,0.9]$. A árvore de prova e o intervalo correspondente para a consulta $\mathrm{p}(\mathrm{X})$ são apresentados na figura 4.3.

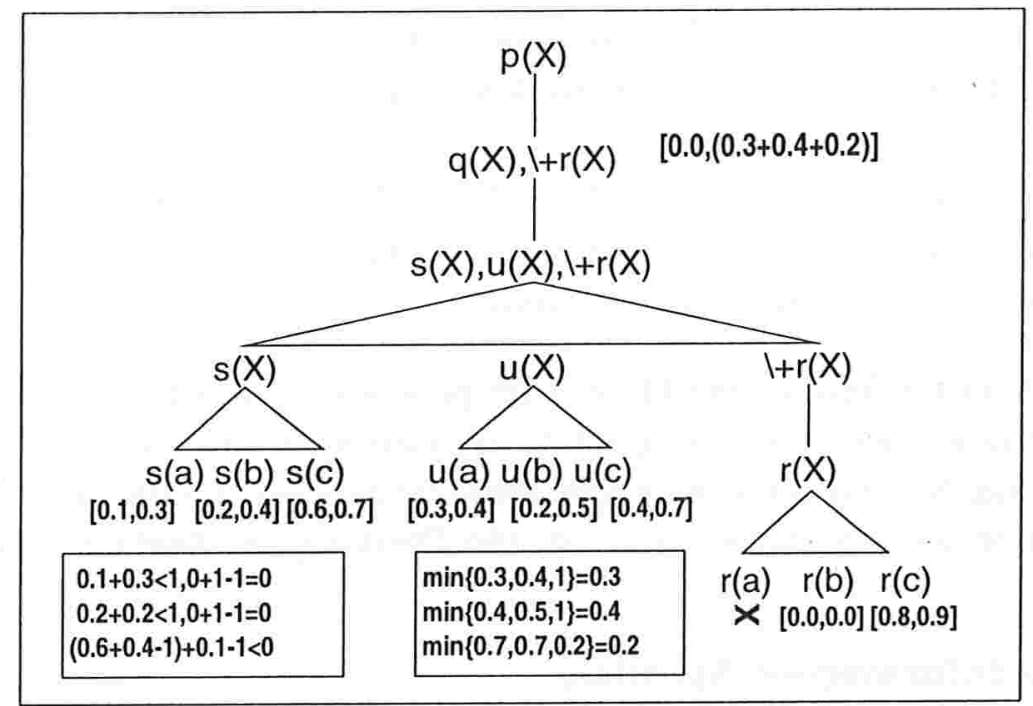

Figura 4.3: Árvore de prova e intervalo para $\mathrm{p}(\mathrm{X})$

\subsection{Comparação entre os Formalismos}

Antes de explorar o compartilhamento de conhecimento entre esses formalismos, é útil avaliar, com base nas suas descrições, apresentadas no decorrer deste capítulo, suas semelhanças e diferenças. Na comparação, será considerado como os formalismos representam o conhecimento, como representam o grau de incerteza considerado e como realizam suas inferências. Com base nos resultados obtidos, no capítulo seguinte será estabelecido de que forma um formalismo pode utilizar conhecimento fornecido pelo outro. Realizaremos nosso estudo através de duas análises:

- análise estrutural dos formalismos, e

- análise operacional dos formalismos.

\subsubsection{Análise Estrutural}

Através da análise estrutural identificamos como o conhecimento é organizado, representado, quantificado e inter-relacionado dentro de cada formalismo. Na análise estrutural 
avaliamos como as informações atômicas são representadas e relacionadas, como o grau de incerteza é representado, quais são as informações a priori consideradas e, finalmente, qual o resultado calculado pelo formalismo.

\section{Informação Atômica}

As informações atômicas constituem as unidades de conhecimento básicas capazes de serem representadas e manipuladas dentro dos formalismos.

- Redes Bayesianas: em uma rede $B=((V G, A G), \Gamma)$, as informações atômicas são associadas aos vértices de $V G$, que, por sua vez, correspondem a variáveis representando eventos de um espaço probabilístico.

- Programação em Lógica DSFH: em um programa em lógica, as informações atômicas são constituídas pelos predicados e termos básicos do programa. Os termos são definidos por suas variáveis e constantes, enquanto que os predicados são da forma $p$ :$q_{1}, \ldots, q_{n}$ onde $p$ é um átomo e $q_{1}, \ldots, q_{n}$ são literais (positivos ou negativos), $n \geq 0$.

\section{Relações entre Informações Atômicas}

As relações entre as informações atômicas caracterizam como essas informações são combinadas entre si para descrever o encadeamento das informações que será utilizado no processo dedutivo do formalismo.

- Redes Bayesianas: em uma rede $B=((V G, A G), \Gamma)$, são exatamente os arestas de $A G$ que relacionam as informações atômicas. Um aresta $a=\left(v_{1}, v_{2}\right) \in A G$ estabelece que os eventos representados por $v_{1}$ e $v_{2}$ estão relacionados de tal forma que $v_{2}$ é condicionalmente dependente de $v_{1}$.

- Programação em Lógica DSFH: em um programa em lógica, temos a relação de dependência imediata expressa nas cláusulas normais que constituem o programa. Assim, cláusulas da forma $p:-q_{1}, \ldots, q_{n}$, onde $p$ é um átomo e $q_{1}, \ldots, q_{n}$ são literais (positivos ou negativos), $n \geq 0$, estabelecem que é possível se provar $p$ através da prova de $q_{1}, \ldots, q_{n}$.

\section{Graus de Crença}

A representação dos graus de crença dos formalismos descreve como eles medem o nível de incerteza associado às suas informações. Nos dois formalismos considerados os graus de crença estão relacionados com a teoria das probabilidades, considerando-se, no caso da programação em lógica DSFH, a função de crença de Fagin e Halpern. No entanto, a forma como as probabilidades são utilizadas pelos formalismos são discrepantes, como relatamos a seguir: 
- Redes Bayesianas: tratam-se de valores de probabilidades condicionais sobre eventos, associados aos vértices da rede. Esses valores são fornecidos durante a consulta à rede, e chamados de evidências, ou calculados considerando-se as evidências fornecidas.

- Programação em Lógica DSFH: para um evento $A$, trata-se de um intervalo da forma $\left[\hat{\mathcal{P}}_{*}(A), \hat{\mathcal{P}}^{*}(A)\right]$, onde $\hat{\mathcal{P}}_{*}(A)$ é uma aproximação da crença de $A$ e $\hat{\mathcal{P}}^{*}(A)$ é uma aproximação da plausibilidade de $A$, definidas pela interpretação de Fagin e Halpern da teoria de evidência de Dempster-Shafer. Na programação em lógica $\mathrm{DSFH}, \operatorname{Bel}(A) \geq \hat{\mathcal{P}}_{*}(A)$ e $\operatorname{Pl}(A) \leq \hat{\mathcal{P}}^{*}(A)$, onde $\operatorname{Bel}(A)$ corresponde a medida interior de $A$ e $P l(A)$ corresponde à medida exterior de $A$.

\section{Informação a Priori}

Tratam-se das informações quantitativas básicas a partir das quais se calcula o grau de crença para as consultas.

- Redes Bayesianas: em uma rede $B=((V G, A G), \Gamma)$, para cada vértice $v_{i} \in V G$ define-se, através de $\Gamma$, um conjunto de funções reais não negativas que associa, para cada configuração $c$ do conjunto dos predecessores de $v_{i}$, uma probabilidade da forma $p\left(v_{i} \mid c\right)$.

- Programação em Lógica DSFH: são os intervalos $[\operatorname{Bel}(A), P l(A)]$ associados a cada cláusula unitária $A$, onde $\operatorname{Bel}(A)$ é a crença de $A$ e $P l(A)$ é a plausibilidade de $A$. Com o uso da função de crença de Fagin e Halpern, $\operatorname{Bel}(A)$ e $P l(A)$ estão associados, respectivamente, à medida interior de $A$ e à medida exterior de $A$.

\section{Resultado}

O resultado caracteriza que tipo de resposta um sistema modelado segundo esses formalismos fornece para uma consulta. Especificamente, define como é codificada a informação descrevendo a incerteza de uma resposta calculada pelo sistema. Como os dois formalismos retornam o grau de crença associado à resposta, o resultado é representado considerando-se a mesma análise de grau de crença apresentada logo acima.

- Redes Bayesianas: em uma rede $B=((V G, A G), \Gamma)$, são calculadas probabilidades condicionadas da forma $p\left(x_{1}, \ldots, x_{n} \mid e_{1}, \ldots, e_{m}\right)$ onde $x_{1}, \ldots, x_{n} \in V G$ são eventos arbitrários e $e_{1}, \ldots, e_{m} \in V G$ são os eventos considerados como evidências na consulta.

- Programação em Lógica DSFH: para cada consulta, constrói-se um intervalo $I \subseteq$ $[0,1]$ tal que para o grau de crença $c$ da consulta vale $c \in I$. Na construção do intervalo, é considerado o mecanismo de inferência apresentado em 4.4.1 que, embora não determine o intervalo $[l, u]$ correspondente ao grau de crença da consulta, obtém um intervalo $\left[l^{\prime}, u^{\prime}\right] \subseteq[l, u]$. 


\subsubsection{Análise Operacional}

Através da análise operacional descrevemos como os elementos descritos na análise estrutural são manipulados, combinados e medidos no processo dedutivo dos formalismos.

\section{Base para propagação}

A base para a propagação descreve como resultados complexos são obtidos a partir de informações básicas. As informações básicas consideradas são as informações atômicas e suas relações, os graus de crença e as informações a priori. Cada formalismo usa essas informações de forma particular no seu processo dedutivo.

- Redes Bayesianas: probabilidades condicionais, que, através da propagação de evidências, cada evidência introduzida na rede faz com que os valores das probabilidades associadas aos vértices sejam atualizados.

- Programação em Lógica DSFH: no sistema lógico, a base para a propagação é a implicação lógica, que está representada nas cláusulas do programa. Para uma cláusulas da forma $p:-q_{1}, \ldots, q_{n}$ onde $p$ é um átomo e $q_{1}, \ldots, q_{n}$ são literais (positivos ou negativos), $n \geq 0$, temos definido que para "calcular" $p$, deve-se calcular $q_{1}, \ldots, q_{n}$.

\section{Sistema de inferência}

O sistema de inferência caracteriza como os formalismos deduzem suas conclusões para as consultas feitas. Ou seja, descreve qual o processo dedutivo dos formalismos.

- Redes Bayesianas: numa rede bayesiana $B=((V G, A G), \Gamma)$ a inferência está associada às arestas de $A G$, cujas probabilidades condicionais associadas a eles estabelecem como a realização de um evento influencia em outro. A inferência é realizada através de um processo chamado de propagação de evidências: para se calcular o valor de $p\left(x_{1}, \ldots, x_{n} \mid e_{1}, \ldots, e_{m}\right)$, são introduzidos os valores das evidências $e_{1}, \ldots, e_{m}$ e, após calcular o valor das probabilidades dos eventos considerando essas evidências, calcula-se a probabilidade conjunta de $x_{1}, \ldots, x_{n}$.

- Programação em Lógica DSFH: como está baseado no modelo de programação em lógica, o sistema lógico executa a resolução SLDNF com programas e consultas normais não cíclicos, estritos com relação à consultas e permitidos. Para o cálculo do grau de crença associado a uma consulta, usa-se o método apresentado em 4.4.1.

\section{Representação de graus de crença}

A representação de graus de crença caracteriza como os formalismos descrevem os níveis de incerteza associados às informações que manipulam.

- Redes Bayesianas: devido à sua natureza probabilística, os graus de crença representados numa rede bayesiana correspondem ao valor de uma probabilidade condicional $p$. Portanto, $p$ é um número real tal que $0 \leq p \leq 1$. 
- Programação em Lógica DSFH: o grau de crença utilizado no sistema lógico é caracterizado pela crença e plausibilidade, definidas pela teoria de evidência de Dempster-Shafer. Dessa forma, o grau de crença corresponde a um intervalo $[a, b] \subseteq$ $[0,1]$.

\subsubsection{Síntese da Comparação}

A análise das características estruturais está resumida na figura 4.1, a qual revela que, apesar das diferenças evidentes entre os formalismos, eles apresentam características estruturais similares, em particular no emprego de informações atômicas básicas e no uso da teoria de probabilidades como modelo de medida de incerteza:

\begin{tabular}{|c|c|c|}
\hline & $\begin{array}{c}\text { Sistema } \\
\text { Lógico }\end{array}$ & $\begin{array}{c}\text { Rede } \\
\text { Bayesiana }\end{array}$ \\
\hline \hline $\begin{array}{c}\text { informação } \\
\text { atômica }\end{array}$ & $\begin{array}{c}\text { predicados e } \\
\text { termos básicos }\end{array}$ & $\begin{array}{c}\text { variáveis booleanas } \\
\text { representando eventos }\end{array}$ \\
\hline relações & cláusulas normais & arestas direcionadas \\
\hline $\begin{array}{c}\text { graus de } \\
\text { crença }\end{array}$ & $\begin{array}{c}\text { intervalos de } \\
\text { probabilidade }\end{array}$ & $\begin{array}{c}\text { valores de } \\
\text { probabilidades }\end{array}$ \\
\hline $\begin{array}{c}\text { informação } \\
\text { a priori }\end{array}$ & $\begin{array}{c}\text { intervalos para } \\
\text { cláusulas unitárias }\end{array}$ & $\begin{array}{c}\text { probabilidades } \\
\text { na rede }\end{array}$ \\
\hline resposta & $\begin{array}{c}\text { intervalos para } \\
\text { consultas }\end{array}$ & $\begin{array}{c}\text { probabilidades dadas } \\
\text { hipóteses evidenciais }\end{array}$ \\
\hline
\end{tabular}

Tabela 4.1: Similaridades estruturais entre programação em lógica DSFH e redes bayesianas para raciocínio com incerteza

Embora os dois formalismos sejam caracterizados pela propagação de suas representações de graus de crença, de natureza probabilística, através de unidades de conhecimento básicas, as formas de propagação dos níveis de certeza são bastante distintas, conforme resumido na tabela 4.2 .

\subsection{Considerações Complementares}

Dadas as descrições dos formalismos incluídas neste capítulo e a descrição do modelo de compartilhamento de conhecimento adotado, apresentada no capítulo anterior, já dispomos de todos os recursos necessários para, finalmente, realizar os experimentos de compartilhamento de conhecimento entre redes bayesianas e programação em lógica DSFH.

$\mathrm{Na}$ análise dos formalismos, foi considerada a natureza probabilística que eles apresentam. A partir das probabilidades que eles representam, foi estabelecido a semântica dos mundos possíveis, apresentada em 4.1.2. A partir dos mundos possíveis, será estabelecido um critério para avaliar em que condições o uso de informações externas não causará problemas em um sistema. 


\begin{tabular}{|c|c|c|}
\hline & $\begin{array}{c}\text { Sistema } \\
\text { Lógico }\end{array}$ & $\begin{array}{c}\text { Rede } \\
\text { Bayesiana }\end{array}$ \\
\hline \hline base para \\
propagação & $\begin{array}{c}\text { implicação } \\
\text { lógica }\end{array}$ & $\begin{array}{c}\text { condicionamento } \\
\text { probabilístico }\end{array}$ \\
\hline $\begin{array}{c}\text { sistema de } \\
\text { inferência }\end{array}$ & resolução & condicionamento \\
\hline $\begin{array}{c}\text { representação de } \\
\text { graus de crença }\end{array}$ & $\begin{array}{c}\text { baseado em } \\
\text { intervalos }\end{array}$ & valor \\
único
\end{tabular}

Tabela 4.2: Diferenças operacionais entre programação em lógica DSFH e redes bayesianas para raciocínio com incerteza

As características sintetizadas nas tabelas 4.1 e 4.2 constituirão os fundamentos básicos a partir dos quais serão relacionados os sistemas que compartilham conhecimento. Em especial, devemos considerar o fato de que as medidas de incerteza consideradas pelos formalismos são sensivelmente distintas.

As implementações de programas que realizam os formalismos estão documentadas no apêndice, com redes bayesianas em 6.2.1 e programação em lógica DSFH em 6.2.2. 


\section{Capítulo 5}

\section{Compartilhamento de Conhecimento entre Programação em Lógica DSFH e Redes Bayesianas}

Neste capítulo trataremos do problema do compartilhamento de conhecimento especificamente para os formalismos de redes bayesianas e programação em lógica DSFH. Os formalismos foram apresentados no capítulo anterior, no qual demos um destaque especial para suas características que serão consideradas na nossa abordagem de compartilhamento de conhecimento, que foi apresentada no capítulo 3. Para efetivamente estabelecer o compartilhamento de conhecimento entre esses formalismos, usamos a comparação feita em 4.5, na qual relacionamos suas semelhanças e diferenças. Usamos uma arquitetura simplificada, apresentada em 3.3 , mas poderosa o suficiente para descrever, do ponto de vista formal, a interação de dois sistemas que compartilham conhecimento.

O desenvolvimento deste capítulo está baseado na classificação da interação de um par de sistemas em três tipos básicos de consultas entre eles, determinados pela dificuldade de se estabelecer o compartilhamento de conhecimento, partindo do caso idealizadamente simples até o caso mais geral.

\subsection{Introdução}

Conforme apresentado e justificado no capítulo anterior, estamos considerando fundamentalmente a interação entre pares de sistemas modelados segundo os formalismos de redes bayesianas e programação em lógica DSFH. Sem perda de generalidade, chamaremos os sistemas de $S_{1}$ e $S_{2}$ e convencionaremos que o sistema $S_{1}$ é o cliente e o sistema $S_{2}$ é o servidor, considerando-se a primeira consulta, aquela que inicia a interação entre os sistemas. Como cada sistema pode ser codificado em um dos dois formalismos, teremos que analisar quatro tipos de configurações de interações possíveis entre eles: 
- $S_{1}$ modelado por Programação em Lógica DSFH e $S_{2}$ modelado por Programação em Lógica DSFH;

- $S_{1}$ modelado por Programação em Lógica DSFH e $S_{2}$ modelado por Redes Bayesianas;

- $S_{1}$ modelado por Redes Bayesianas e $S_{2}$ modelado por Programação em Lógica DSFH; e

- $S_{1}$ modelado por Redes Bayesianas e $S_{2}$ modelado por Redes Bayesianas.

Para cada uma dessas configurações, vamos considerar três tipos básicos de consultas entre os sistemas:

Consultas Unidirecionais: um sistema $S_{1}$ faz uma consulta ao sistema $S_{2}$, que responde à consulta usando somente o conhecimento local que dispõe. Trata-se do caso mais simples, que corresponde a uma pergunta seguida imediatamente pela resposta. O grande cuidado que deve ser tomado nesse tipo de consulta está relacionado com a consistência do sistema cliente, isto é, impedir que uma informação obtida por compartilhamento de conhecimento invalide o modelo formal adotado pelo sistema.

Consultas Bidirecionais Restritas: um sistema $S_{1}$ faz uma consulta ao sistema $S_{2}$ que, para responder à consulta, faz uma outra consulta ao sistema $S_{1}$; a consulta que $S_{2}$ faz a $S_{1}$ usa somente uma parte do conhecimento de $S_{1}$ de tal forma que a interação entre o par de sistemas se restrinja à consulta do cliente e que a resposta do servidor utilize o resultado obtido com o auxílio da resposta obtida de uma consulta do servidor ao cliente, sendo que o cliente responde à consulta baseando-se exclusivamente no seu conhecimento local;

Consultas Bidirecionais Genéricas: um sistema $S_{1}$ faz uma consulta ao sistema $S_{2}$ que, para responder à consulta, faz uma outra consulta ao sistema $S_{1}$ mas tal que $S_{2}$ não restringe sua consulta à parte do conhecimento de $S_{1}$. Neste caso, estamos particularmente interessados em formas de detectar e impedir a geração de resultados indesejáveis, como, por exemplo, ciclos infinitos ou inconsistência.

Essa classificação em três tipos de consultas tem por objetivo apresentar e explorar, de forma gradual, crescente no nível de dificuldade, detalhes, problemas e soluções encontrados na interação entre os sistemas. Nas consultas unidirecionais exploramos os casos simples de interação. Através desses casos, esperamos dominar os princípios básicos do compartilhamento de conhecimento entre esses formalismos para, nos casos mais complicados, explorarmos somente as situações mais emblemáticas. Nas consultas bidirecionais genéricas, exploramos os casos gerais nos quais existe a possibilidade de criação de ciclos nas consultas dos sistemas, que constitui o problema central deste tipo de consulta. 
Identificamos, adicionalmente, um caso intermediário que será útil para explorar as interações nas quais um mesmo sistema cliente passa a ser servidor na solução de um mesmo problema.

No estabelecimento do compartilhamento de conhecimento entre dois sistemas, devemos considerar os seguintes problemas:

- a tradução sintática da consulta feita por $S_{1}$ para uma pergunta a $S_{2}$ que preserve a semântica da consulta original;

- a tradução do valor de verdade da resposta obtida por $S_{2}$ para um valor de verdade aceito pelo formalismo de $S_{1}$; e

- o impacto de informações externas, obtidas pelo compartilhamento de conhecimento, na consistência de um sistema.

Como as traduções e os critérios de consistência dependem fundamentalmente dos formalismos para raciocínio com incerteza utilizados em $S_{1}$ e em $S_{2}$, devemos averiguar a interação de pares de sistemas considerando-se, que tanto o cliente como o servidor podem estar escritos em um formalismo específico. Assim, para cada um dos tipos básicos de consultas apresentado acima, devemos considerar individualmente cada um dos quatro casos possíveis de interações entre sistemas.

A figura 5.1 ilustra o esquema geral da interação de um par de sistemas, $S_{1}$ e $S_{2}$. Para calcular o grau de incerteza de uma informação atômica local $p$, o sistema $S_{1}$ faz uma consulta ao sistema $S_{2}$. Usando a informação de que $q$ de $S_{2}$ é semanticamente equivalente a $p, S_{2}$ pode calcular e retornar a $S_{1}$ o grau de crença de $q$, que poderá ser usado por $S_{1}$ como um indicador do grau de crença de $p$. Entre a consulta original $q$ de $S_{1}$ a $S_{2}$ e a resposta $r_{q}$ fornecida por $S_{2}$, podem ocorrer outras consultas entre os sistemas. A classificação em três tipos básicos de consultas busca tratar dessa parte intermediária entre a consulta original e a resposta obtida para ela.

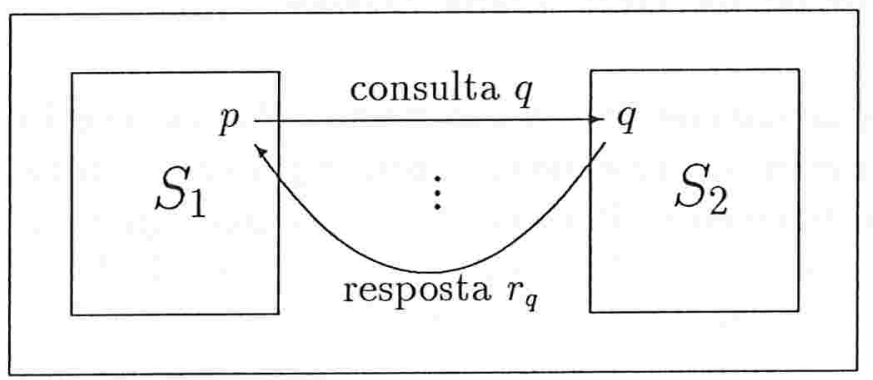

Figura 5.1: Esquema geral da interação dos sistemas $S_{1}$ e $S_{2}$ onde $|p|_{S_{1}} \equiv|q|_{S_{2}}$

O fato de $p$ de $S_{1}$ ser equivalente a $q$ de $S_{2}$ é determinado através da nossa interpretação humana da semântica dos sistemas. No decorrer desse capítulo, para enfatizar esse 
aspecto humano do estabelecimento de ligacões entre termos dos sistemas, usaremos a denominação ligação manual. No caso da figura 5.1, nós ligamos manualmente $p$ de $S_{1}$ a $q$ de $S_{2}$. Essa ligação manual é determinada por uma ou mais pessoas que conheçam profundamente os sistemas envolvidos. Dessa forma, quando um usuário faz uma consulta a um sistema que se beneficia do compartilhamento do conhecimento de um outro sistema, as ligações entre os sistemas já foram estabelecidas previamente.

No restante deste capítulo apresentamos:

1. uma análise da consistência dos sistemas para definir em que condições o conhecimento obtido de outros sistemas pode comprometer sua consistência;

2. o mapeamento entre um par de sistemas, o cliente e o servidor, considerando-se os quatro tipos de configurações de interações entre sistemas;

3. o compartilhamento de conhecimento entre os sistemas, considerando-se os três tipos básicos de consultas e, para cada tipo de consulta, as quatro configurações básicas de interações; e

4. finalmente, uma análise dos resultados obtidos e as considerações finais do capítulo.

Convencionamos chamar genericamente de sistema DSFH um sistema baseado em conhecimento modelado segundo o formalismo de programação em lógica DSFH. Analogamente, uma sistema modelado através de uma rede bayesiana será simplesmente chamado de rede.

\subsection{Consistência dos Sistemas}

Assumimos que os sistemas considerados neste trabalho são consistentes e queremos que, mesmo com o uso de informações externas obtidas por compartilhamento de conhecimento, eles continuem consistentes. Por isso, na nossa abordagem de compartilhamento de conhecimento, dedicamos um cuidado especial com o estudo da influência dos resultados fornecidos pelo servidor para a teoria formal do cliente.

Em 4.1.2 foi apresentado a semântica de mundos possíveis dos formalismos considerados. Devido à natureza probabilística dos formalismos considerados, a idéia de independência, apresentada em 4.2.1, é fundamental para garantir que informações externas usadas pelos sistemas não corrompam a semântica de mundos possíveis deles. A seguir apresentamos o papel dos mundos possíveis e das medidas de probabilidades na semântica dos formalismos usados. 


\subsubsection{Programação em Lógica DSFH}

Nos sistemas modelados na programação em lógica DSFH, a toda informação está associado um intervalo representando o seu grau de crença. A única excessão corresponde às informações atômicas ausentes no sistema, cujo intervalo é, conseqüentemente, assumido como sendo $[0.0,0,0]$. Dessa forma, uma informação atômica $r(a)^{1}$, ausente num programa em lógica DSFH, é assumida como falsa em todos os mundos possíveis inicialmente capazes de interpretar o programa. O intervalo de probabilidades a ser associado a r (a), também ausente no programa, caracteriza as aproximações, interior e exterior, da probabilidade de se selecionar randomicamente um mundo possível e $r(a)$ ser verdadeira nele; ou seja, dois eventos aninhados pertencentes à álgebra $\chi_{D_{r(a)}}$, onde $D_{r(a)}$ é um subconjunto apropriado dos mundos possíveis "relevantes" para $r(a)$, para os quais uma medida de probabilidade é conhecida. Como $r$ (a) náo ocorre no programa original, ela é assumida como sendo não verdadeira em qualquer mundo possível empregado inicialmente para interpretar o programa. Como conseqüência, se alguma informação auxiliar for obtida para avaliar a probabilidade de $\mathrm{r}(\mathrm{a})$, ela deve estar associada a um subconjunto completamente novo de mundos possíveis, que previamente não eram utilizados para interpretar o programa.

Da mesma forma, todas as hipóteses consideradas nas consultas realizadas pelo sistema lógico não devem influenciar na validade das suas informações locais. Assim, se um sistema em programação em lógica DSFH faz uma consulta $c$ a outro sistema, deve-se considerar o conjunto $\mathcal{C}$ das hipóteses assumidas em $c$. $\mathrm{O}$ conhecimento de $\mathcal{C}$ não pode influenciar no grau de crença das informações assumidas pelo sistema.

É importante efatizar que não dispomos de uma forma automática para determinar se alguma informação de um sistema influencia na álgebra de mundos possíveis do outro. Para contornar esse problema, impomos algumas restrições de independência entre as informações calculadas pelos sistemas. E a análise dessas restrições é baseada na interpretação humana dos sistemas considerados. Dessa forma, podemos garantir que as medidas de incerteza, calculadas por sistemas que usam informações externas, são corretas. Trata-se de uma suposição bastante forte porque é humanamente impossível que pessoas sejam capazes de realizar essa análise em sistemas complexos. Por outro lado, sem ela não podemos garantir que os resultados fornecidos por sistemas que se beneficiam do compartilhamento de conhecimento sejam válidos.

\subsubsection{Redes Bayesianas}

No caso de uma rede bayesiana consultar um outro sistema, temos que considerar o fato de que uma rede bayesiana representa um modelo probabilístico completo. Todas as probabilidades condicionais possíveis de serem consultadas a partir dos eventos probabilísticos representados na rede podem ser matematicamente calculados. Por isso, nunca podere-

\footnotetext{
${ }^{1} \mathrm{O}$ uso do termo $\mathrm{r}$ (a) corresponde a um abuso de linguagem que cometemos para simplificar a notação; eventualmente $r(a)$ pode corresponder a $r\left(a_{1}, \ldots, a_{n}\right)$.
} 
mos supor que uma rede bayesiana faz consultas referentes a informações que não podem ser calculadas localmente. $\mathrm{O}$ que se busca com o compartilhamento de conhecimento é obter valores de probabilidades mais "expressivos" para alguns eventos modelados na rede. Assim, o compartilhamento de conhecimento, quando o cliente é uma rede bayesiana, corresponde a atribuir determinados valores a certos eventos, tratando-os como evidências.

Considere uma rede $R B$ tal que, ao responder a uma consulta $c=p\left(v_{1}, \ldots, v_{n} \mid e_{1}, \ldots, e_{m}\right)$ não obtenha um valor satisfatório, segundo o ponto de vista do usuário. Para um evento $x \notin\left\{e_{1}, \ldots, e_{m}\right\}$ de $R B$, a probabilidade $p(x)$ corresponde à probabilidade de se selecionar randomicamente um mundo possível e $x$ ser verdadeiro nele. A mesma análise das aproximações interior e exterior se aplica às probabilidades representadas na rede, mas, desta vez, as medidas interior e exterior coincidem, pois a medida de probabilidade de $c$ é conhecida. Trata-se de um evento pertencente à álgebra $\chi_{D_{p\left(v_{1}, \ldots, v_{n} \mid e_{1}, \ldots, e_{m}\right)}}$, onde $D_{p\left(v_{1}, \ldots, v_{n} \mid e_{1}, \ldots, e_{m}\right)}$ é um subconjunto apropriado dos mundos possíveis relevantes para $p\left(v_{1}, \ldots, v_{n} \mid e_{1}, \ldots, e_{m}\right)$. Assumindo $x$ como uma evidência, selecionamos somente os mundos possíveis que têm $x$ como verdadeiro (ou, se for o caso, falso). Com o processo de propagação de evidências, considerando somente esses mundos possíveis, as probabilidades dos eventoos representados na rede são ajustadas para corresponder à nova álgebra de mundos possíveis considerada.

Como no caso da programação em lógica DSFH, todas as informações embutidas na consulta feita pela rede bayesiana não devem influenciar nas probabilidades dos demais eventos da rede. Ou seja, somente o valor do evento que será assumido como evidência no processo de compartilhamento de conhecimento deve ter sua probabilidade alterada como resultado do processo.

O comentario feito no final da seção 5.2.1 permanece válido aqui. Da mesma forma, as mesmas hipóteses a respeito da independência entre as medidas de incerteza dos sistemas que participam de um processo de compartilhamento devem ser consideradas, embora não sejam automaticamente tratadas neste trabalho.

\subsection{Mapeamentos entre Sistemas}

Devido à ênfase do nosso estudo à interação entre pares de sistemas, não usamos ontologias para descrever o domínio definido por eles. Simplesmente, definimos um mapeamento direto entre informações atômicas de um sistema com consultas feitas ao outro. Esse mapeamento é estabelecido com base em uma interpretação do significado das informações relacionadas, conforme exemplificado na figura 5.1.

Para os propósitos deste trabalho, assumimos que, por exemplo, uma informação atômica $p$, de um sistema $S_{1}$, é semanticamente equivalente à consulta $q$, de um sistema $S_{2}$. Tomando esta decisão, eliminamos um problema complexo e importante, mas que foge ao escopo deste trabalho, para podermos concentrar nossos esforços na interação entre o par de sistemas. Em geral usa-se uma ontologia para fazer a correspondência entre termos semanticamente equivalentes. $\mathrm{O}$ uso de uma ontologia corresponde a definir uma 
descrição formal dos conceitos representados no domínio a que se referem os sistemas e estabelecer a equivalência entre as informações dos sistemas e os conceitos da ontologia. Assim, se os sistemas se comprometerem com essa ontologia, as informações equivalentes são relacionadas com o mesmo conceito.

O relacionamento entre o cliente e o servidor é definida exclusivamente através do mapeamento entre termos semanticamente comuns dos sistemas. Para isso, relacionamos uma informação atômica do cliente com uma consulta capaz de ser respondida pelo servidor. Esse relacionamento é definido com base nas características do par de formalismos considerados, o cliente e o servidor, que foram relacionadas e comparadas em 4.5. Além disso, devemos considerar as questões referentes à consistência dos sistemas, como relatado em 5.2. A seguir, para cada combinação possível de sistemas, apresentamos como o relacionamento é definido. Exemplos de interações de sistemas são apresentados nas seções 5.4 e 5.5 .

\subsubsection{Sistema DSFH consulta Sistema DSFH}

Nesta configuração de par de sistemas, como eles são baseados na programação em lógica, tem-se uma situação bastante similar àquela apresentada no exemplo 3.1 .1 do capítulo 3 . A única novidade é a inclusão de intervalos para representar o nível de certeza associado às fórmulas.

\section{Mapeamento entre os Formalismos}

Considere um sistema $S_{1}$, modelado pela programação em lógica DSFH, no qual não está presente a fórmula atômica $r(a)$, cujo intervalo de crença é, conseqüentemente, assumido como $[0.0,0.0]$. Sabendo-se que existe um outro sistema, chamado de $S_{2}$, que seja capaz de responder a uma consulta $s(b)$ que seja semanticamente equivalente a $r(a)$, ou seja, $|r(\mathrm{a})|_{S_{1}} \equiv|\mathrm{s}(\mathrm{b})|_{S_{2}}$, é possível compartilhar o conhecimento de $S_{2}$ para provar $\mathrm{r}(\mathrm{a})$. Para isso, ligamos manualmente a fórmula atômica $r(\mathrm{a})$ de $S_{1}$ à consulta $\mathrm{s}(\mathrm{b})$ do outro. Dessa forma, o compartilhamento de conhecimento possibilita que o sistema cliente seja capaz de calcular um resultado, que previamente era assumido por falta de informação, através de uma estimativa mais confiável para seu grau de crença.

Como os formalismos lógicos são semelhantes, não existe a necessidade de tradução ou de adaptação do formato da consulta feita por $S_{1}$ a $S_{2}$ e da resposta de $S_{2}$ a $S_{1}$. Basta, simplesmente, associar $|r(\mathrm{a})|_{S_{1}} \mathrm{com}|\mathrm{s}(\mathrm{b})|_{S_{2}}$ e o intervalo $|[l b, u b]|_{S_{2}}$ fornecido como resposta para $\mathrm{s}(\mathrm{b})$ pode ser interpretado diretamente como o intervalo $|[l b, u b]|_{S_{1}}$ associado a $r(a)$.

\section{Semântica}

Como vimos em 5.2.1, r(a) não deve estar presente em $S_{1}$. Dessa forma, ao assumir, originalmente, o intervalo $[0.0,0.0]$ para a fórmula, assume-se também que $r$ (a) é falso em todos os mundos possíveis capazes de interpretar $S_{1}$. O conjunto dos mundos possíveis 
selecionados com a prova de $\mathrm{s}(\mathrm{b})$ por $S_{2}$ deve ser disjunto do conjunto dos mundos possíveis usados inicialmente para interpretar o programa, e a álgebra e as medidas de probabilidades baseadas neste conjunto de mundos possíveis devem ser independentes das outras álgebras e medidas usadas na interpretação do programa original. Caso contrário, a semântica dos intervalos de probabilidades gerados por $S_{2}$ estarão corrompidos devido à duplicação das informações geradas pelos dois sistemas. As imposições sobre os conjuntos de mundos possíveis, de álgebras e de medidas de probabilidades devem ser garantidas ao se ligar $r(a)$ com $s(b)$. Essas garantias são baseadas na interpretação humana dos sistemas considerados, constituindo, portanto, um passo delicado no estabelecimento do compartilhamento de conhecimento entre esses sistemas.

Uma vez ligadas $r(a)$ e s(b), nós estendemos o conjunto de mundos possíveis, de álgebras e de medidas de probabilidades considerados inicialmente para o sistema lógico com o conjunto de mundos possíveis relevantes a $\mathrm{s}(\mathrm{b})$ e provas provenientes do servidor podem ser empregadas dentro das provas do cliente como se pertencessem ao programa original.

\section{Uso do Compartilhamento de Conhecimento}

Para ativar o compartilhamento de conhecimento durante a operação do sistema $S_{1}$, basta fazer com que o cliente inclua no seu código uma cláusula da forma

$$
t_{[l b, u b]}:-\operatorname{consulta}\left(S_{2}, c,[l b, u b]\right) .
$$

e fazer com que a cláusula consulta transfira o controle do programa para a camada de interface do $S_{1}$. A camada de interface se encarregará de contatar o sistema $S_{2}$, fazer-lhe a consulta $\mathrm{s}(\mathrm{b})$, esperar pela resposta $[l b, u b]$ e repassá-la como intervalo associado a $\mathrm{r}(\mathrm{a})$.

Nas seções 5.4.1, 5.5.1 e 5.6, consideramos os três tipos básicos de consultas para interações entre dois sistemas baseados na programação em lógica DSFH.

\subsubsection{Sistema DSFH consulta Rede}

Neste caso, é necessário fazer conversões entre os formalismos considerando, principalmente, as diferenças entre as representações de verdade utilizadas por eles, como analisado na seção 4.5. Este caso foi apresentado e exemplificado fartamente em [6].

\section{Mapeamento entre Sistemas}

Considere um sistema $S_{1}$, modelado pela programação em lógica DSFH, no qual não está presente a fórmula atômica $r(a)$, cujo intervalo de crença é, conseqüentemente, assumido como $[0.0,0.0]$. Para que uma rede seja capaz de fornecer o grau de crença de $r(a)$, ela deve ser capaz de criar um intervalo que represente a crença e a plausibilidade da fórmula. Para isso, a consulta do sistema lógico é desmembrada em duas consultas para a rede, de tal forma que se obtenha os valores extremos do intervalo. Dessa forma, o compartilhamento de conhecimento possibilita que o sistema cliente seja capaz de calcular um resultado, 
que previamente era assumido por falta de informação, através de uma estimativa mais confiável para seu grau de crença.

Sabendo da existência de uma rede bayesiana, chamada $S_{2}$, que seja capaz de calcular o grau de crença de $r(a)$, podemos associar o cálculo de $r(a)$ em $S_{1}$ a uma consulta equivalente de $S_{2}$. Para construir um intervalo a partir das probabilidades fornecidas por $S_{2}$, ligamos manualmente a consulta de $S_{1}$ a um intervalo $\left[i_{1}, i_{2}\right]$ tal que:

$\left\{\begin{array}{l}i_{1} \text { é a probabilidade associada a uma consulta da forma } \\ \qquad p\left(v_{1}, \ldots, v_{m}, v_{m+1}, \ldots, v_{n} \mid e_{1}, \ldots, e_{r}\right) \text { à } S_{2} ; \\ i_{2} \text { é a probabilidade associada a uma consulta da forma } p\left(v_{1}, \ldots, v_{m} \mid e_{1}, \ldots, e_{r}\right) \text { à } S_{2} .\end{array}\right.$ Como a consulta associada a $i_{1}$ é mais específica que a associada a $i_{2}$ teremos que

$$
0 \leq i_{1} \leq i_{2} \leq 1
$$

Com esses valores, construímos o intervalo associado a $\mathrm{r}(\mathrm{a})$, obtido por compartilhamento de conhecimento, como $\left[i_{1}, i_{2}\right]$.

\section{Semântica}

Como vimos em 5.2.1, r (a) não deve estar presente em $S_{1}$. Devemos (manualmente) ligar $r$ (a) a um par de eventos da rede, $\left(v_{1}, \ldots, v_{m} \mid e_{1}, \ldots, e_{r}\right)$ e $\left(v_{1}, \ldots, v_{m}, v_{m+1}, \ldots, v_{n} \mid e_{1}, \ldots, e_{r}\right)$. $\mathrm{O}$ conjunto dos mundos possíveis selecionados pelas evidências $e_{1}, \ldots, e_{r}$ deve ser disjunto do conjunto dos mundos possíveis usados inicialmente para interpretar o programa, e a álgebra e as medidas de probabilidades baseadas neste conjunto de mundos possíveis devem ser independentes das outras álgebras e medidas usadas na interpretação original do programa. Caso contrário, a semântica dos intervalos de probabilidades gerados pela rede estarão corrompidos devido à duplicação das informações geradas pelos dois sistemas.

Uma vez ligadas $r(a)$ e o par de eventos da rede, nós estendemos o conjunto de mundos possíveis, de álgebras e de medidas de probabilidades considerados inicialmente para o sistema lógico com o conjunto de mundos possíveis relevantes a $e_{1}, \ldots, e_{r}$, e cálculos provenientes da rede podem ser empregados dentro das provas do sistema lógico como se pertencessem ao programa original.

\section{Uso do Compartilhamento de Conhecimento}

Para ativar o compartilhamento de conhecimento durante a operação do sistema $S_{1}$, basta fazer com que o cliente inclua no seu código uma cláusula da forma

$$
t_{[l b, u b]}:-\operatorname{consulta}\left(S_{2}, c_{1}, l b\right) \text {, consulta }\left(S_{2}, c_{2}, u b\right) .
$$

e fazer com que a cláusula consulta transfira o controle do programa para a camada de interface do $S_{1}$. A camada de interface se encarregará de contatar o sistema $S_{2}$, fazer-lhe as consultas $c_{1}$ e $c_{2}$, esperar pelas respostas $l b$ e $u b$ e usá-las para construir o intervalo associado a $t$.

Nas seções 5.4.2, 5.5.2 e 5.6 consideramos os três tipos básicos de consultas para 
interações entre um sistemas baseado na Programação em lógica DSFH consultando uma rede bayesiana.

\section{Observações Adicionais}

Note que no caso de se considerar um intervalo consistindo de um único valor, podemos codificar a cláusula anterior como

$$
t_{[b, b]}:-\operatorname{consulta}\left(S_{2}, c, b\right) .
$$

onde $c$ é uma consulta da forma $p\left(v_{1}, \ldots, v_{m} \mid e_{1}, \ldots, e_{r}\right)$ a $S_{2}$ e $b$ é o valor da probabilidade. Com esse valor, construímos o intervalo associado a $r(a)$, obtido por compartilhamento de conhecimento, como $[b, b]$.

\subsubsection{Rede Consulta Rede}

Como os dois sistemas são redes bayesianas, temos uma situação na qual as probabilidades da servidora são usadas para modificar as probabilidades calculadas pela cliente. A informação buscada pela cliente será usada para caracterizar um evento como evidência ou não.

\section{Mapeamento entre Sistemas}

O mapeamento relacionando o par de redes bayesianas, $R B_{1}$, a cliente, e $R B_{2}$, a servidora, é feito ao atribuir um novo valor a um evento, transformando-o numa evidência. Considere uma rede $R B_{1}$, que, ao calcular uma probabilidade $p\left(v_{1}, \ldots, v_{n} \mid e_{1}, \ldots, e_{m}\right)$, obtém um valor insatisfatório para ela. Sabendo-se que existe uma outra rede, chamada de $R B_{2}$, que seja capaz de, através de uma consulta $p\left(v_{1}^{\prime}, \ldots, v_{n^{\prime}}^{\prime} \mid e_{1}^{\prime}, \ldots, e_{m^{\prime}}^{\prime}\right)$, atribuir o valor a uma nova evidência $x$ de $R B_{1}$ tal que $x \notin\left\{e_{1}, \ldots, e_{m}\right\}$, ou seja, $|x|_{R B_{1}} \equiv\left|p\left(v_{1}^{\prime}, \ldots, v_{n^{\prime}}^{\prime} \mid e_{1}^{\prime}, \ldots, e_{m^{\prime}}^{\prime}\right)\right|_{R B_{2}}$, é possível compartilhar o conhecimento de $R B_{2}$ auxiliar no cálculo de $p\left(v_{1}, \ldots, v_{n} \mid e_{1}, \ldots, e_{m}\right)$.

Como alternativas para atribuir um novo valor à nova evidência $x$ de $R B_{1}$ podemos considerar:

1. associar o valor de $x$ com a consulta $p\left(v_{1}^{\prime}, \ldots, v_{n^{\prime}}^{\prime} \mid e_{1}^{\prime}, \ldots, e_{m^{\prime}}^{\prime}\right)$ a $R B_{2}$ de tal forma que um valor arbitrariamente alto da resposta da consulta seja associado como verdadeiro e um valor arbitrariamente baixo como falso. Dessa forma, atribui-se um valor verdadeiro ou falso à nova evidência; ou

2. associar o valor de $x$ com a consulta $p\left(v_{1}^{\prime}, \ldots, v_{n^{\prime}}^{\prime} \mid e_{1}^{\prime}, \ldots, e_{m^{\prime}}^{\prime}\right)$ a $R B_{2}$ de tal forma que a resposta da consulta seja assumida como valor da evidência. No entanto, essa alternativa viola a definição das redes bayesianas, feita em 4.3, pois as evidências devem ser consideradas ou verdadeiras ou falsas e não exatamente um valor real $p\left(v_{1}^{\prime}, \ldots, v_{n^{\prime}}^{\prime} \mid e_{1}^{\prime}, \ldots, e_{m^{\prime}}^{\prime}\right) \in[0.0,1.0]$.

Neste trabalho, devido à nossa caracterização de redes bayesianas, segundo a qual as evidências são ou verdadeiras ou falsas, adotamos a primeira alternativa como estratégia para uso das informações compartilhadas. 


\section{Semântica}

Como vimos em 5.2.2, devemos garantir que $x \notin\left\{e_{1}, \ldots, e_{m}\right\}$. Devemos (manualmente) ligar um evento $x$ da rede $R B_{1}$ a um evento $\left(v_{1}, \ldots, v_{n} \mid e_{1}, \ldots, e_{r}\right)$ da rede $R B_{2}$. O conjunto dos mundos possíveis selecionados pelas evidências $e_{1}, \ldots, e_{r}$ deve ser disjunto do conjunto dos mundos possíveis usados inicialmente para interpretar a rede, e a álgebra e as medidas de probabilidades baseadas neste conjunto de mundos possíveis devem ser independentes das outras álgebras e medidas usadas na interpretação original da rede. Caso contrário, a semântica dos intervalos de probabilidades gerados pela rede estarão corrompidos devido à duplicação das informações geradas pelos dois sistemas. Feita a ligação, nós ligamos manualmente

- um valor alto de $p\left(v_{1}, \ldots, v_{n} \mid e_{1}, \ldots, e_{r}\right)$ com o valor verdadeiro atribuído à nova evidência $x$; e

- um valor baixo de $p\left(v_{1}, \ldots, v_{n} \mid e_{1}, \ldots, e_{r}\right)$ com o valor falso atribuído à nova evidência $x$.

Devemos ficar atentos com relação ao significado de "valor alto" e de "valor baixo" usados para atribuir o valor-verdade à evidência pois esses conceitos são relativos.

Dessa forma, nós estendemos o conjunto de mundos possíveis, de álgebras e de medidas de probabilidades considerados inicialmente para a rede com o conjunto de mundos possíveis relevantes a $e_{1}, \ldots, e_{r}$, e cálculos provenientes da rede servidora podem ser empregados dentro da rede cliente como se pertencessem à consulta original.

\section{Uso do Compartilhamento de Conhecimento}

Como uma rede bayesiana, em princípio, tem a capacidade de calcular todas as probabilidades relacionadas aos seus eventos, devemos analisar de que forma o compartilhamento de conhecimento é usado pelas redes. Uma solução é fornecer sempre ao usuário a resposta baseada exclusivamente nas evidências explicitamente embutidas na consulta e, através da camada de interface, oferecer a possibilidade de recalcular a probabilidade com o auxílio de evidências adicionais fornecidas por outros sistemas baseados em conhecimento.

Nas seções 5.4.3, 5.5.3 e 5.6 consideramos os três tipos básicos de consultas para interações entre dois sistemas baseados no formalismo de redes bayesianas.

\section{Observações Adicionais}

Um cuidado especial que devemos considerar nesse tipo de consulta é a possibilidade de, para uma consulta da forma $p(a \mid r)$ feita a uma rede bayesiana, usar o compartilhamento de conhecimento para atribuir um novo valor ao evento $r$. Nesse caso, cria-se um caso de conflito, pois está embutido na consulta que $r$ é verdadeiro e, portanto, faz parte da premissa para a operação da rede. Portanto, por uma questão de consistência, devemos impor que o compartilhamento de conhecimento não deve ser usado para redefinir o valor de uma evidência que já tem um valor previamente associado. 


\subsubsection{Rede Consulta Sistema DSFH}

Como o sistema cliente é uma rede bayesiana e o servidor é baseado em intervalos, temos uma situação na qual os intervalos produzidos pelo servidor são usados para gerar valores para modificar as probabilidades calculadas pela cliente. A informação buscada pela cliente será usada para caracterizar um evento como evidência ou não.

\section{Mapeamento entre Teorias}

O mapeamento, relacionando uma nova evidência de uma rede e uma consulta a um sistema lógico, é feito ao atribuir um novo valor, obtido a partir de um intervalo calculado pelo sistema lógico, a um evento, transformando-o numa evidência. Considere uma rede $R B_{1}$, que, ao calcular uma probabilidade $p\left(v_{1}, \ldots, v_{n} \mid e_{1}, \ldots, e_{m}\right)$, obtém um valor considerado, pelo usuário, como insatisfatório. Sabendo-se que existe um sistema DSFH, chamada de $S$, que seja capaz de, através de uma consulta $\mathrm{s}(\mathrm{b})$, determinar o valor de uma nova evidência $x$ de $R B_{1}$ tal que $x \notin\left\{e_{1}, \ldots, e_{m}\right\}$, é possível compartilhar o conhecimento de $R B_{2}$ auxiliar no cálculo de $p\left(v_{1}, \ldots, v_{n} \mid e_{1}, \ldots, e_{m}\right)$. O mapeamento entre as teorias relaciona o valor de uma nova evidência $x$ da rede bayesiana com o intervalo associado a uma fórmula atômica da teoria lógica. Como uma consulta $\mathrm{s}(\mathrm{b})$ para a lógica DSFH retorna um intervalo $[l b, u b]$ como resposta, temos como opções para o mapeamento:

- usar extremo inferior do intervalo, $l b$, como valor da evidência;

- usar extremo superior do intervalo, $u b$, como valor da evidência;

- usar um ponto interno do intervalo, eventualmente o ponto médio $(l b+u b) / 2$.

Neste trabalho usaremos a terceira alternativa. Uma justificativa para essa decisão está relatada nas Observações Adicionais, logo adiante.

Como alternativas para atribuir um novo valor à nova evidência $x$ de $R B_{1}$ podemos considerar:

1. associar o valor de $x$ com a consulta s(b) de $S$ de tal forma que o intervalo $[l b, u b]$ obtido como resposta seja usado para produzir o valor $c=(l b+u b) / 2$. Com um valor arbitrariamente alto de $c$ atribui-se verdadeiro a $x$, enquanto que com um valor arbitrariamente baixo atribui-se falso. Dessa forma, atribui-se um valor verdadeiro ou falso à nova evidência.

2. associar o valor de $x$ com a consulta $\mathrm{s}(\mathrm{b})$ de $S$ de tal forma que o intervalo $[l b, u b]$ obtido como resposta seja usado para produzir o valor $c=(l b+u b) / 2$ que será atribuído a $x$. No entanto, essa alternativa viola a definição das redes bayesianas, feita em 4.3, pois as evidências devem ser consideradas ou verdadeiras ou falsas e não exatamente um valor real $c \in[0.0,1.0]$. 


\section{Semântica}

Como vimos em 5.2.2, devemos garantir que $x \notin\left\{e_{1}, \ldots, e_{m}\right\}$. Ligamos manualmente um evento $x$ da rede $R B_{1}$ a uma consulta $\mathrm{s}(\mathrm{b})$ do sistema DSFH $S$. O conjunto dos mundos possíveis selecionados com a prova de $\mathrm{s}(\mathrm{b})$ deve ser disjunto do conjunto dos mundos possíveis usados inicialmente para interpretar a rede, e a álgebra e as medidas de probabilidades baseadas neste conjunto de mundos possíveis devem ser independentes das outras álgebras e medidas usadas na interpretação original da rede. Caso contrário, a semântica dos intervalos de probabilidades gerados por $S_{1}$ estarão corrompidos devido à duplicação das informações geradas pelos dois sistemas.

Feita a ligação, e obtendo um intervalo $[l b, u b]$ associado a $\mathrm{s}(\mathrm{b})$, nós associamos um valor alto, respectivamente, baixo, de $(l b+u b) / 2$ com o valor verdadeiro, respectivamente, falso, associado à nova evidência $x$. Assim, podemos associar

- um valor alto de $(l b+u b) / 2$ com o valor verdadeiro atribuído à nova evidência $x$;

- um valor baixo de $(l b+u b) / 2$ com o valor falso atribuído à nova evidência $x$; e.

- um valor médio de $(l b+u b) / 2$ com o indício que o sistema DSFH não deve ser usado para gerar uma nova evidência na rede.

Devemos ficar atentos com relação ao significado de "valor alto" e de "valor baixo" usados para atribuir o valor-verdade à evidência pois esses conceitos são relativos.

Dessa forma, nós estendemos o conjunto de mundos possíveis, de álgebras e de medidas de probabilidades considerados inicialmente para a rede com o conjunto de mundos possíveis relevantes para a prova de $\mathrm{s}(\mathrm{b})$, e cálculos provenientes das provas do sistema DSFH podem ser empregados nos cálculos da rede como se pertencessem à consulta original.

\section{Uso do Compartilhamento de Conhecimento}

Como a rede bayesiana sempre tem a capacidade de calcular todas as probabilidades relacionadas aos seus eventos, devemos analisar uma forma natural de empregar o compartilhamento de conhecimento ao se consultar uma rede bayesiana. O mais indicado é deixar que a camada de interface gerencie o processo de consulta à rede. Dessa forma, a rede sempre oferece primeiro uma resposta baseada no seu conhecimento local e, se o usuário considerar essa resposta inadequada, usa-se o compartilhamento de conhecimento para tentar obter outra melhor.

Nas seções $5.4 .4,5.5 .4$ e 5.6 consideramos os três tipos básicos de consultas para interações entre uma rede bayesiana consultando um sistema baseados na Programação em lógica DSFH.

\section{Observações Adicionais}

Como vimos em 4.4, o intervalo $I$ calculado para uma consulta $p$ pelo método de inferência da lógica DSFH não é exatamente o intervalo definido pela crença e plausibilidade de $p$, 
$[\operatorname{Bel}(p), P l(p)]$, mas um tal que $I \subseteq[\operatorname{Bel}(p), P l(p)]$. Essa constatação é forte o suficiente para se questionar a validade de se usar algum dos extremos de $I$ como valor retornado à rede.

Uma abordagem alternativa para a combinação do modelo probabilístico com a teoria lógica com valores de verdade baseados em intervalos é considerar-se duas soluções calculadas para a rede bayesiana: uma para o extremo inferior do intervalo e outra para o extremo superior. Dessa forma, utiliza-se como resultado fornecido pela rede o intervalo definido pelas duas respostas obtidas. A grande desvantagem dessa abordagem é a alteração da semântica do resultado calculado pela rede. Uma outra opção é considerar todos os valores definidos pelo intervalo em um mecanismo de "backtracking" para que o usuário tenha a opção de analisar o papel desses valores nos cálculos da rede.

\subsection{Consultas Unidirecionais}

Nesse tipo de consulta, consideramos um sistema $S_{1}$ que, durante a resolução de um problema, consulta um sistema $S_{2}$ que retorna a $S_{1}$ uma resposta baseada exclusivamente no seu conhecimento local. Um esquema geral de uma consulta unidirecional está apresentada na figura 5.2 .

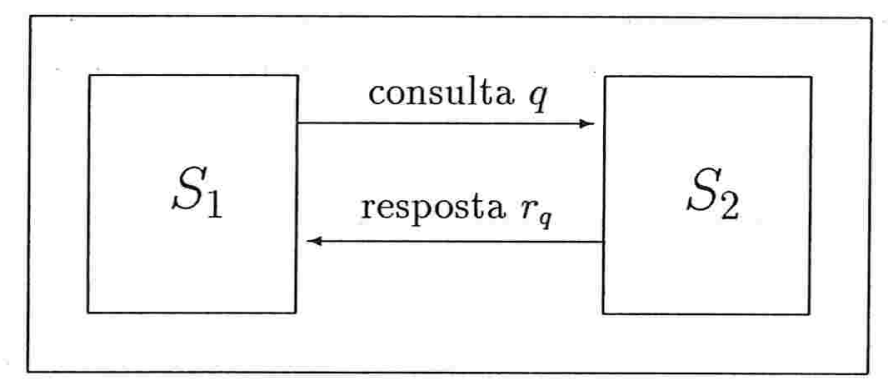

Figura 5.2: Esquema geral de uma consulta unidirecional de $S_{1}$ a $S_{2}$

Trata-se do tipo mais simples de interação entre sistemas, pois $S_{2}$ sempre fornecerá uma resposta para a consulta $q$, que pode ser a informação de que $S_{2}$ não é capaz de prová-la. Neste caso, não existe risco de fatores externos a $S_{2}$ influenciarem na resposta obtida. Segundo esse tipo de consulta, $S_{1}$ pode consultar $S_{2}$ diversas vezes durante a solução de um mesmo problema. O que estamos caracterizando é que, em cada consulta, $S_{2}$ calcula, isoladamente e baseado exclusivamente no seu conhecimento local, o nível de incerteza da resposta da consulta feita. A seguir, analisaremos as consultas unidirecionais para cada um dos quatro casos possíveis de interações entre sistemas. 


\subsubsection{Sistema DSFH Consulta Sistema DSFH}

Trata-se de um caso similar ao apresentado com lógica clássica no exemplo 3.1, sendo que, desta vez, as lógicas dos sistemas cliente e servidor manipularão intervalos em suas inferências. A apresentação dessa configuração, juntamente com a análise da consistência da semântica dos mundos possíveis para esse caso foi feita em 5.3.1.

Suponhamos que uma fórmula atômica $r(a)$ não esteja presente no sistema $S_{1}$. Sabendo da existência de um outro sistema, chamado $S_{2}$, que seja capaz de calcular s(b) tal que $|\mathrm{s}(\mathrm{b})|_{S_{2}} \equiv|\mathrm{r}(\mathrm{a})|_{S_{1}}$, podemos manualmente ligar o cálculo de $r(\mathrm{a})$ em $S_{1}$ à consulta s(b) de $S_{2}$. Como os dois sistemas assumem a mesma representação para suas medidas de certeza, o intervalo calculado pelo servidor pode ser usado diretamente pelo cliente. $\mathrm{O}$ exemplo 5.4.1 ilustra o compartilhamento de conhecimento obtido entre sistemas desses tipos.

Exemplo 5.4.1 Considere os seguintes dois sistemas DSFH, chamados de $S_{1}$ e de $S_{2}$, apresentados na figura 5.3. A prova de $\mathrm{p}$ (a) é obtida considerando-se o intervalo $[0.0,0.0]$

$$
\begin{array}{ll}
p(X):-q(X), \backslash+r(X) . & m(X):-p(X), \backslash+q(X) . \\
q(X):-s(X), t(X) . & p(e)=[0.8,1.0] . \\
s(a)=[0.7,0.9] . & \\
r(a)=[0.0,0.2] . &
\end{array}
$$

Figura 5.3: Dois sistemas DSFH: $S_{1}$, à esquerda, e $S_{2}$, à direita.

para a fórmula atômica $\mathrm{t}(\mathrm{a})$, pois ela não está presente em $S_{1}$. No entanto, supondo que $|\mathrm{t}(\mathrm{a})|_{S_{1}} \equiv|\mathrm{m}(\mathrm{e})|_{S_{2}}$, construímos a árvore de prova para $\mathrm{p}(\mathrm{a})$ realizada por $S_{1}$ com compartilhamento de conhecimento de $S_{2}$ exibida na figura 5.4. Como os formalismos usados em $S_{1}$ e $S_{2}$ são idênticos, o intervalo obtido para $\mathrm{m}(\mathrm{e})$ por $S_{1}$ pode ser utilizado diretamente, sem a necessidade de nenhuma conversão, como o nível de crença de $\mathrm{t}(\mathrm{a})$ por $S_{2}$.

Nesse caso, o compartilhamento de conhecimento corresponde à extensão de uma árvore de prova, a partir de uma fórmula atômica não disponível, com uma prova, para essa mesma fórmula, obtida por outro sistema. Note ainda que, no exemplo 5.4.1, o sistema $S_{2}$ apresenta uma fórmula atômica, q(e), cujo valor é assumido como $[0.0,0.0]$ por falta de informação mais precisa. No exemplo 5.5.1 apresentamos uma nova versão desse mesmo exemplo, com o sistema $S_{2}$ usando o compartilhamento de conhecimento para obter essa informação inexistente.

\subsubsection{Sistema DSFH Consulta Rede}

Nessa configuração, o compartilhamento de conhecimento consiste em montar o intervalo relacionado a uma fórmula atômica, inexistente no sistema lógico, a partir das probabilidades calculadas por uma rede bayesiana. Como o intervalo é caracterizado por um par 


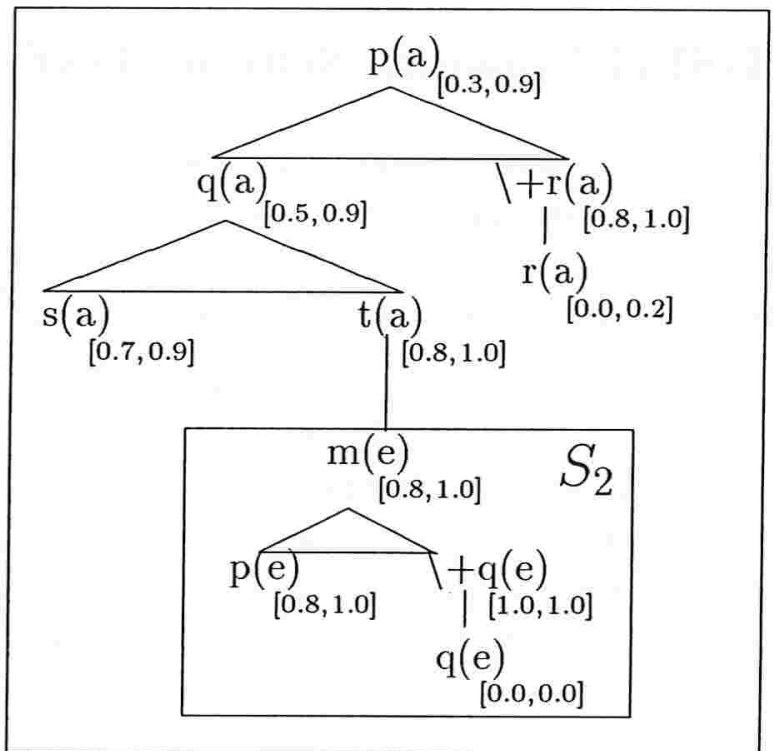

Figura 5.4: Prova de p(a) de $S_{1}$ usando m(e) de $S_{2}$

de valores, enquanto que a rede bayesiana calcula um valor unitário, torna-se necessário obter uma forma coerente de se construir o intervalo a partir de uma ou mais consultas à rede. A apresentação dessa configuração, juntamente com a análise da consistência da semântica dos mundos possíveis para esse caso foi feita em 5.3.2.

O exemplo 5.4.2, apresentado originalmente em [6], ilustra o compartilhamento de conhecimento obtido entre sistemas desses tipos.

Exemplo 5.4.2 Suponha que uma universidade queira criar um sistema baseado em conhecimento para decidir se um estudante receberá alojamento grátis da universidade ou não. O critério pelo qual a decisão é tomada baseia-se nas seguintes informações a respeito do estudante:

situação financeira : se o estudante possui renda suficiente para pagar por outro alojamento;

desempenho acadêmico : se o estudante apresenta bom histórico acadêmico na universidade; $e$

condição médica : se o estado médico do estudante pode ser considerado potencialmente perigoso para os outros estudantes do mesmo alojamento. O diagnóstico da situação médica do estudante é baseado nos seus registros de vacinação e nas doenças contagiosas que apresenta.

O seguinte programa apresenta uma teoria lógica simples para decidir se o estudante é um bom candidato para receber alojamento grátis da universidade: 


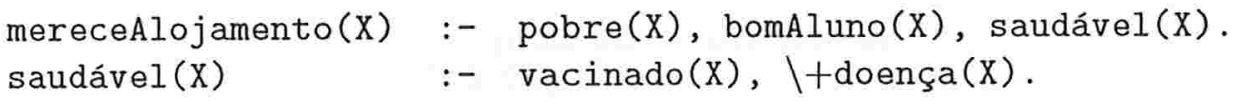

$\begin{array}{lll}\operatorname{pobre}(\mathrm{John}) & =[0.7,0.7] \\ \operatorname{pobre}(\text { Paul) } & =[0.6,0.9] \\ \text { doença(John) } & =[0.5,0.7] \\ \text { vacinado(Jonh) } & =[0.5,0.5] \\ \text { vacinado(Paul) } & =[0.7,0.9]\end{array}$

Não existe forma explícita de se calcular a crença em bomAluno(X), que será, conseqüentemente, assumido como improvável por falta de informação. Alternativamente, podemos "construir" o intervalo de crença baseados na informação disponível nos registros dos estudantes da universidade, usando o conhecimento compartilhado pela rede bayesiana exibida na figura 5.5, chamada BomAlunoBN, que pode ser usada para decidir se um estudante é um bom aluno com base na sua informação acadêmica: resultados de provas e freqüência às aulas. Ligando manualmente as seguintes informações:

Descrição das variáveis (nós) da rede:

A : o estudante é um bom aluno;

$\mathrm{B}$ : o estudante não falta às aulas;

C : o estudante tem bom desempenho nas provas;

D : o estudante teve bom desempenho no vestibular;

E : o estudante tem boas notas finais nas disciplinas.

$$
\begin{aligned}
& p(a)=0.5 \\
& p(b \mid a)=0.8 \\
& p(b \mid \neg a)=0.4 \\
& p(c \mid a)=0.9 \\
& p(c \mid \neg a)=0.1 \\
& p(d \mid c)=0.9 \\
& p(d \mid \neg c)=0.5 \\
& p(e \mid c)=0.9 \\
& p(e \mid \neg c)=0.4
\end{aligned}
$$

Exemplo de consultas a esta rede bayesiana:

- $p(a \mid c)=(p(a) p(c \mid a)) /(p(c))=0.9$

- $p(a, b \mid c)=(p(a, b, c)) /(p(c))=(p(a) p(b \mid a) p(c \mid a)) /(p(c))=0.72$

Figura 5.5: Rede bayesiana que modela a "qualidade" de um estudante

- $\mid$ bomAluno(John $)\left.\right|_{P} \equiv|[p(a, b \mid c), p(a \mid c)]|_{\text {BomAlunoBN }}$

- $\mid$ bomAluno(Paul $)\left.\right|_{P} \equiv|[p(a, b \mid c), p(a \mid c)]|_{\text {BomAlunoBN }}$

a árvore de prova para mereceAlojamento(John), incluindo uma representação para o conhecimento compartilhado pela rede bayesiana está apresentada na figura 5.6. 


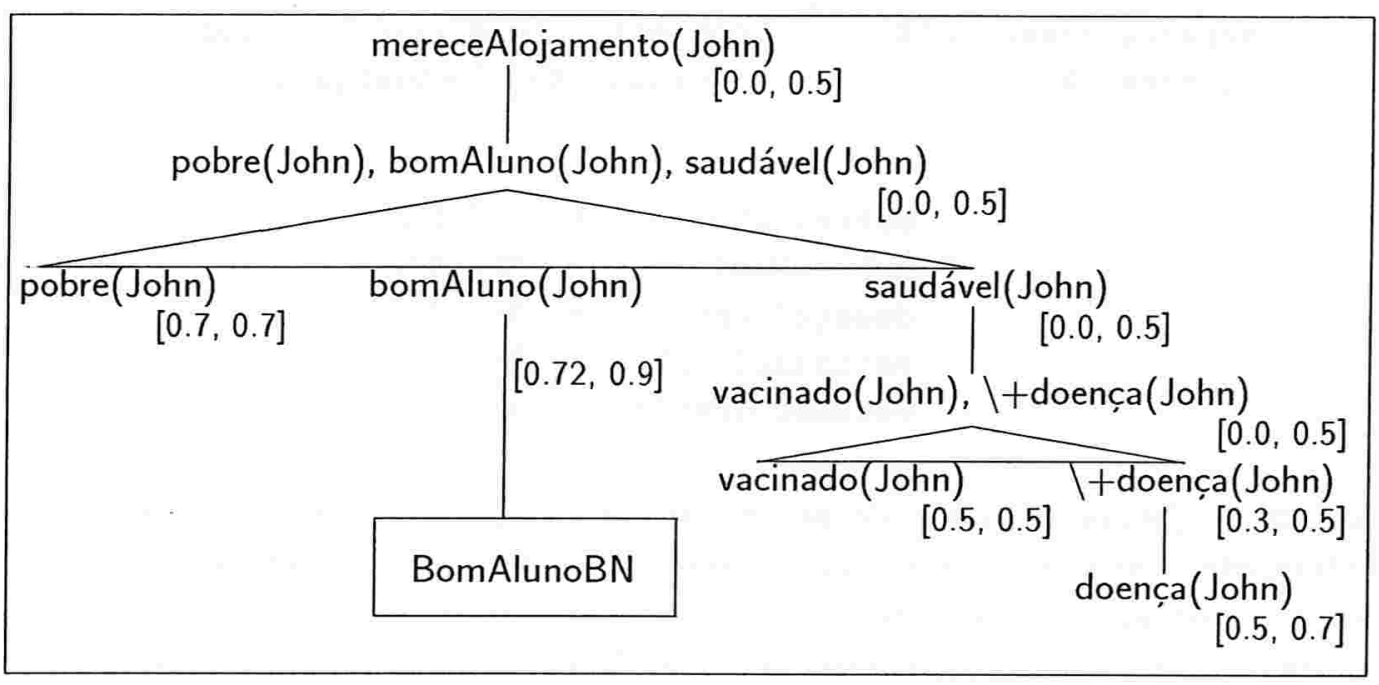

Figura 5.6: Árvore de prova de mereceAlojamento(John) com compartilhamento de conhecimento

\subsubsection{Rede Consulta Rede}

No caso de uma rede bayesiana consultando outra rede, usamos as probabilidades disponíveis na servidora para corroborar o tratamento de um evento da cliente como uma evidência. A apresentação dessa configuração, juntamente com a análise da consistência da semântica dos mundos possíveis para esse caso foi feita em 5.3.3.

Um exemplo de uma rede bayesiana consultando outra rede bayesiana é apresentado no exemplo 5.4.3.

Exemplo 5.4.3 Considere a rede bayesiana $R B_{x}$ representada no lado esquerdo da figura 5.7. Nessa rede, a consulta $p\left(x_{1} \mid x_{4}\right)$ tem como resposta o valor 0.314. Ou seja, a evidência considerada, $x_{4}$, pouco influiu na probabilidade de $x_{1}$, reduzindo ligeiramente esse valor. Por outro lado, o evento $x_{3}$ tem um forte impacto na probabilidade de $x_{1}$, devido aos valores associados ao arco $\left(x_{1}, x_{3}\right)$. De fato, $p\left(x_{1} \mid x_{4}, x_{3}\right)=0.805$, ou seja, se obtivermos a informação de que $x_{3}$ é verdadeiro, teremos aumentado consideravelmente a probabilidade de $x_{1}$ também ser.

Considerando que a rede $R B_{y}$, representada na parte esquerda da figura 5.7, pode ser usada para calcular a probabilidade do evento $x_{3}$ de tal forma que seja possivel usar o valor obtido para usar $x_{3}$ como uma evidência no cálculo de $p\left(x_{1} \mid x_{4}\right)$. Usando o compartilhamento de conhecimento, torna-se possivel associar manualmente $x_{3}$ com a probabilidade $p\left(y_{1} \mid y_{3}\right)$. Como $p\left(y_{1} \mid y_{3}\right)=0.8571$, podemos assumir que $x_{3}$ é uma evidência verdadeira e, assim, associar o cálculo da probabilidade original, $p\left(x_{1} \mid x_{4}\right)$, com $p\left(x_{1} \mid x_{4}, x_{3}\right)=0.805$.

Se em uma consulta a uma rede bayesiana, um usuário especifica, explicitamente, o valor de um evento, usado como evidência, é questionável o uso do compartilhamento de 


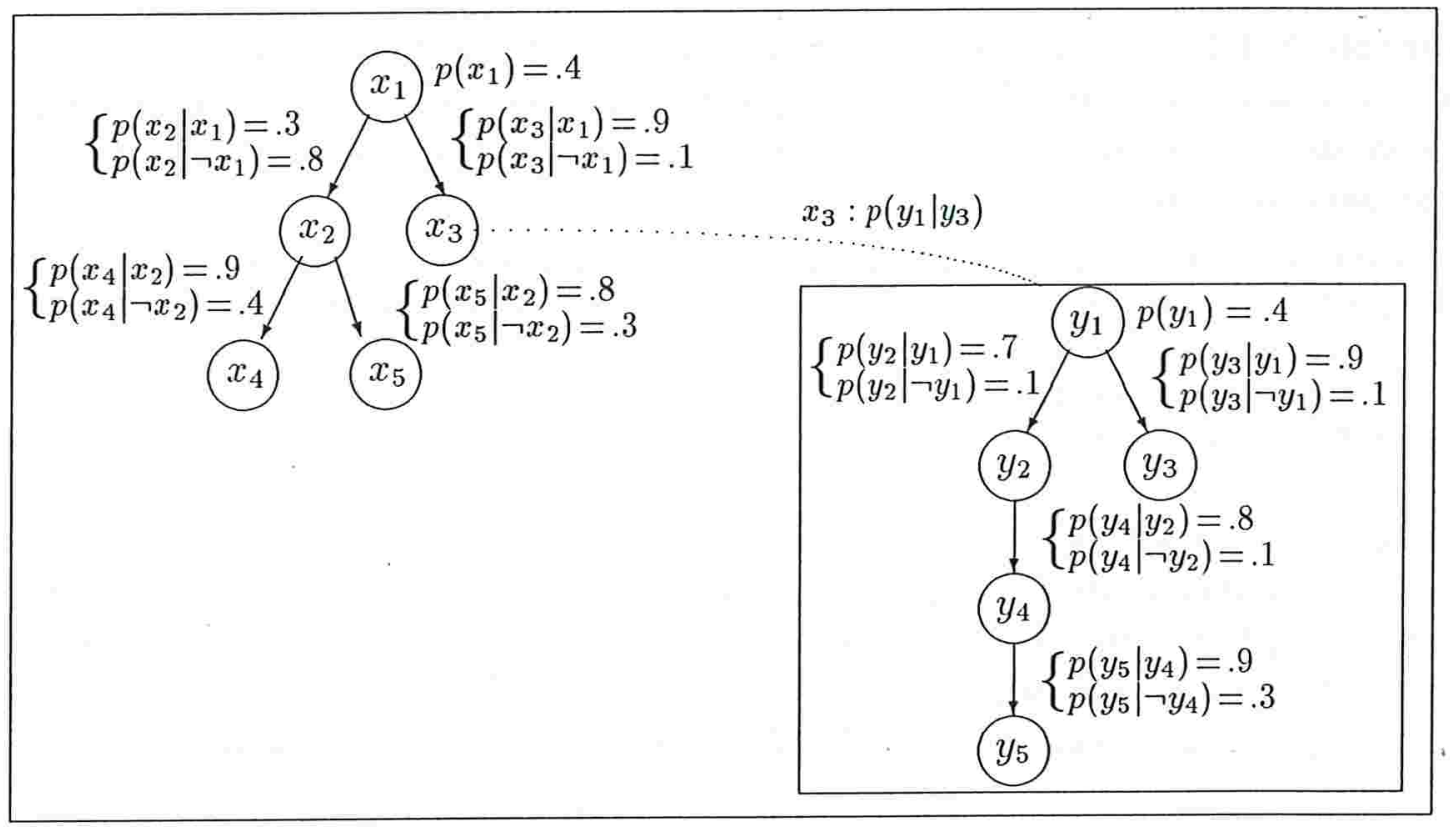

Figura 5.7: Consulta unidirecional com uma rede consultando outra

conhecimento para associar um novo valor a esse mesmo evento, como mostra o exemplo 5.4.4.

Exemplo 5.4.4 Considere a mesma rede bayesiana $R B_{x}$ representada no lado esquerdo da figura 5.7. Nessa rede, a consulta $p\left(x_{1} \mid \neg x_{3}\right)$ tem como resposta o valor 0.690. Usando o compartilhamento do conhecimento da rede $R B_{y}$, de forma equivalente àquela feita no exemplo 5.4.3, obtemos o valor 0.8571 para a consulta $p\left(x_{1} \mid x_{3}\right)$. No entanto, existe um problema com o novo resultado, obtido com o compartilhamento de conhecimento: associou-se um novo valor ao evento $x_{3}$, ignorando a evidência estipulada na consulta $\grave{a}$ rede $R B_{x}$.

\subsubsection{Rede Consulta Sistema DSFH}

Desta vez usamos o programa em lógica para introduzir novas evidências na rede bayesiana. Inicialmente, devemos convencionar uma forma de se estabelecer uma correspondência entre o intervalo associado à resposta da consulta feita ao programa em lógica em uma probabilidade a ser usada pela rede. A apresentação dessa configuração, juntamente com uma análise preliminar da consistência da semântica dos mundos possíveis para esse caso, foi feita em 5.3.4.

Um exemplo de uma rede bayesiana consultando um sistema baseado na lógica DSFH é apresentado no exemplo 5.4.5. 
Exemplo 5.4.5 Considere a mesma rede bayesiana $R B_{x}$ utilizada no exemplo 5.4.3. Como vimos, $p\left(x_{1} \mid x_{4}\right)=0.314$, enquanto que $p\left(x_{1} \mid x_{4}, x_{3}\right)=0.805$. Como antes, a possibilidade de assumir $x_{3}$ como verdadeiro (ou, se for o caso, falso) influenciará sensivelmente na probabilidade de $x_{1}$.

Desta vez, relacionamos a probabilidade associada ao evento $x_{3}$ com o grau de crença da resposta da consulta $\mathrm{p}(\mathrm{a})$ fornecida pelo seguinte programa em lógica DSFH:

$$
\begin{array}{ll}
p(X):-q(X), \backslash+r(X) . & s(a)=[0.8,0.9] . \\
q(X):-s(X), t(X) . & t(a)=[0.9,1.0] .
\end{array}
$$

Usando o compartilhamento de conhecimento, torna-se possivel obter um valor melhor para a probabilidade de $p\left(x_{1} \mid x_{4}\right)$, como ilustrado na figura 5.8. O intervalo de crença associado a $\mathrm{p}(\mathrm{a})$ é $[0.7,0.9]$, que produz, como ponto intermediário, 0.8 como o grau de crença retornado à rede bayesiana. Usando-se esse valor como base, transformamos $x_{3}$ em uma evidência verdadeira e o valor da resposta à consulta feita a $R B_{x}$ é 0,805.

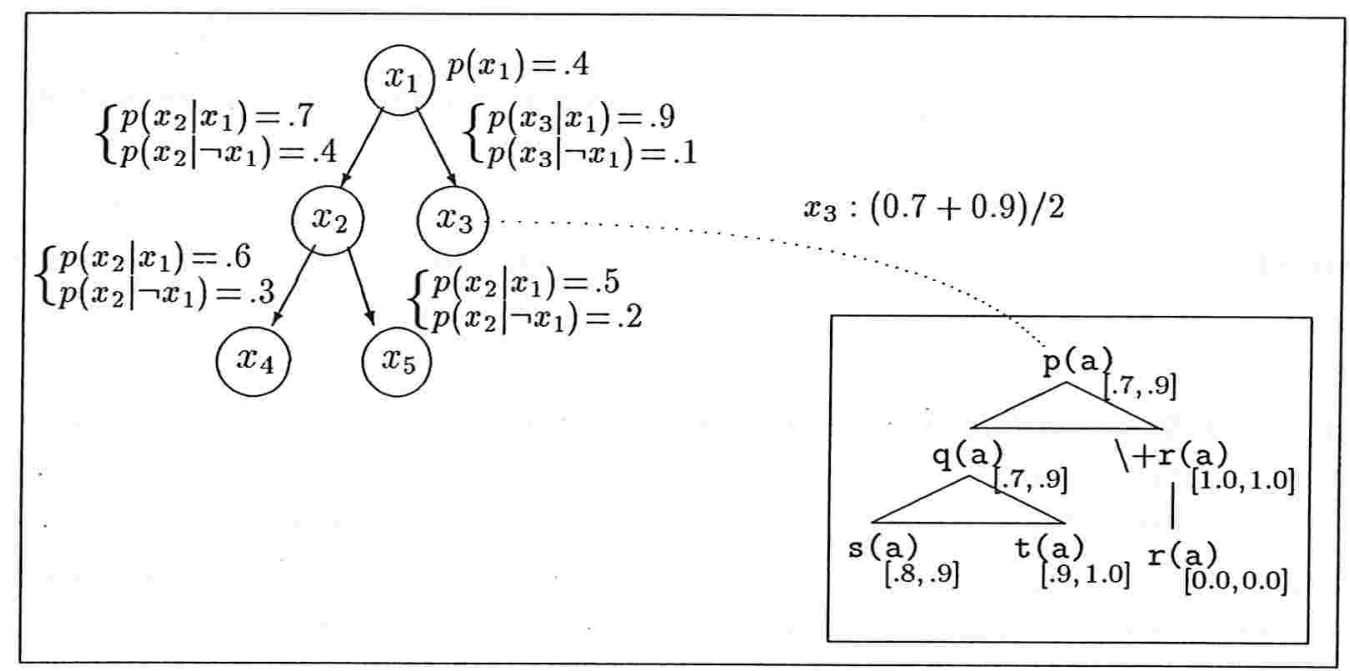

Figura 5.8: Consulta unidirecional com uma rede bayesiana consultando um sistema lógico

É importante notar que, para provar $\mathrm{p}(\mathrm{a}), S_{2}$ assumiu, por falta de informação, que o intervalo de $r(a)$ é $[0.0,0.0]$. Essa informação poderia ser obtida externamente através do compartilhamento de conhecimento, como será feito no exemplo 5.5.4.

\subsection{Consultas Bidirecionais Restritas}

Um esquema geral de uma consulta bidirecional restrita está apresentada na figura 5.9, onde representamos um sistema $S_{1}$ que, para resolver um problema $p$, faz uma consulta $q$ ao sistema $S_{2}$. Para resolver $q, S_{2}$ faz uma consulta $t$ a $S_{1}$ que, baseado exclusivamente nas suas informações locais, e sem haver risco de fazer novamente uma consulta a $S_{2}$, 
fornece uma resposta $r_{t}$ para a consulta $t$. Com a resposta fornecida por $S_{1}, S_{2}$ calcula a resposta $r_{q}$ para a consulta original de $S_{1}$ e retorna o resultado a $S_{1}$.

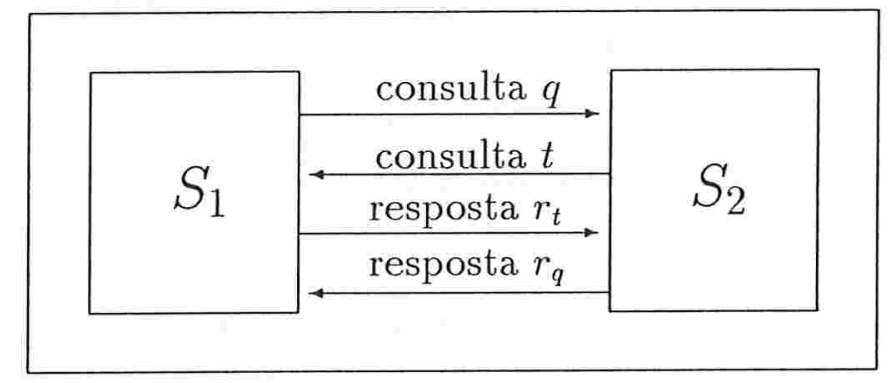

Figura 5.9: Esquema geral de uma consulta bidirecinal restrita de $S_{1}$ a $S_{2}$

Nas consultas bidirecionais, convencionamos dizer que um sistema $S_{1}$ "consulta" outro sistema $S_{2}$ se $S_{1}$ ao resolver um problema $p$, solicita a ajuda de $S_{2}$ e, portanto, a consulta que $S_{2}$ faz de volta a $S_{1}$ é resultado da consulta original de $S_{1}$ para resolver $p$.

Nesse tipo de consultas, devemos tomar cuidado com a possibilidade de geração de circularidades nas consultas dos sistemas. O que caracteriza as consultas bidirecionais restritas é o uso de apenas dois passos de compartilhamento de conhecimento na interação entre os sistemas. Os dois passos são:

1. $S_{1}$ faz uma consulta inicial $q$ a $S_{2}$; e

2. $S_{2}$, por causa da consulta inicial, faz uma consulta $t$ a $S_{1}$.

Cada um deles corresponde a uma consulta unidirecional, devendo ser analisado segundo os critérios apresentados em 5.4. Um detalhe importante que devemos também considerar nesse caso, e que também vale para as consultas bidirecionais genéricas, que veremos em 5.6, é o fato de um mesmo sistema, chamado de $S_{1}$ na nossa caracterização, é utilizado duas vezes no processo iniciado com a consulta $q$. Para analisar a consistência da resposta construída devemos considerar:

1. a resposta $r_{q}$ para a consulta $q$, fornecida por $S_{2}$ deve ter sua consistência garantida; para isso, devemos considerar uma consulta unidirecional, tendo $S_{2}$ como cliente e $S_{1}$ como servidor, tal que, atendendo às hipóteses de independência de álgebras de mundos possíveis, apresentadas no caso unidirecional, seja consistente;

2. da mesma forma, quando $S_{1}$ recebe a resposta para $q$, todas as hipóteses de consistência, considerando-se os formalismos dos sistemas, também devem ser garantidas.

Como $S_{1}$ participou da obtenção da resposta $r_{q}$, devemos garantir que os mundos possíveis relevantes empregados para se obter $r_{q}$ não influenciem na consistência de $S_{1}$ ao resolver p. Por isso, devemos garantir que a álgebra de mundos possíveis relevantes considerada 
em $S_{1}$ para resolver $p$ seja independente da álgebra de mundos possíveis do próprio $S_{1}$ para resolver $t$.

A seguir, analisamos as consultas bidirecionais restritas para cada um dos quatro casos possíveis de interações entre sistemas.

\subsubsection{Sistema DSFH Consulta Sistema DSFH}

Seja $S_{1}$ um sistema DSFH e suponha que uma fórmula atômica $r$ (a) não esteja presente nele. Sabendo da existência de um outro sistema DSFH, chamado $S_{2}$, que seja capaz de calcular s(b) tal que $|\mathbf{s}(\mathrm{b})|_{S_{2}} \equiv|\mathrm{r}(\mathrm{a})|_{S_{1}}$, podemos manualmente ligar o cálculo de $\mathrm{r}$ (a) em $S_{1}$ à consulta $\mathrm{s}(\mathrm{b})$ de $S_{2}$. Da mesma forma, supondo que, para resolver $\mathrm{s}(\mathrm{b}), S_{2}$ necessite de uma fórmula atômica $\mathrm{t}(\mathrm{c})$, ausente em $S_{2}$, mas que seja equivalente a uma consulta u (d) feita a $S_{1}$. Como os dois sistemas assumem a mesma representação para suas medidas de certeza, o intervalo calculado pelo servidor pode ser usado diretamente pelo cliente.

Para contornar o problema da circularidade usamos a relação de dependência entre as cláusulas do programa em lógica, apresentada em 4.2.2:

Sejam $S_{1}$ e $S_{2}$ dois sistemas baseados na Lógica DSFH. Se $S_{1}$, ao resolver um problema $p$, faz a consulta " $q$ ?" para $S_{2}$ e, para resolver essa consulta, $S_{2}$ faz a consulta " $q^{\prime}$ ?" a $S_{1}$, devemos garantir que a relação $q^{\prime} \geq q$ não se verifica.

Dessa forma, garantimos que, para a solução de " $q$ ??", $S_{1}$ não precisará resolver (novamente) $q$ e, conseqüentemente, não se corre o risco de refazer a consulta " $q$ ?" a $S_{2}$, dando inicio a um loop infinito. Por outro lado, essa restrição, isoladamente, não resolve o problema da consistência dos sistemas, pois informações usadas para provar $q^{\prime}$ podem corromper a semântica da prova de $p$ por $S_{1}$. Por isso, devemos garantir que os mundos possíveis relevantes usados para $S_{1}$ isoladamente provar $p$ são disjuntos dos mundos possíveis relevantes usados para $S_{1}$ provar $q^{\prime}$. Assim, conjuntamente com as hipóteses consideradas nas duas consultas unidirecionais entre sistemas DSFH, nós estendemos o conjunto de mundos possíveis, de álgebras e de medidas de probabilidades consideradas inicialmente com o conjunto de mundos possíveis relevantes a $\mathbf{s}(\mathrm{b})$, que, por sua vez foi estendido com os mundos possíveis relevantes para provar $\mathrm{u}(\mathrm{d})$.

Um exemplo de consulta bidirecional restrita entre sistemas baseados na Lógica DSFH está apresentado no exemplo 5.5.1.

Exemplo 5.5.1 Considere os sistemas $S_{1}$ e $S_{2}$, similares aos apresentados no exemplo 5.4.1 e reproduzidos na figura 5.10 abaixo:

Como a fórmula atômica $\mathrm{t}$ (a) não está em $S_{1}$, a prova de $\mathrm{p}(\mathrm{a})$ é obtida considerandose o intervalo $[0.0,0.0]$ para a fórmula. Supondo que $|\mathrm{t}(\mathrm{a})|_{S_{1}} \equiv|\mathrm{m}(\mathrm{e})|_{S_{2}}$, construímos a árvore de prova para $\mathrm{p}(\mathrm{a})$ realizada por $S_{1}$ com compartilhamento de conhecimento de 


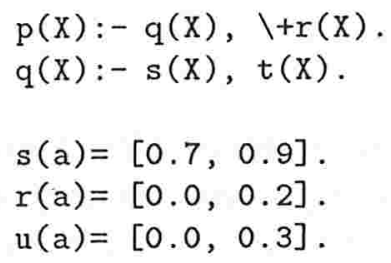

$$
\begin{aligned}
& m(X):-p(X), \backslash+q(X) . \\
& p(e)=[0.8,1.0] .
\end{aligned}
$$

Figura 5.10: Sistemas $S_{1}$, à esquerda, e $S_{2}$, à direita.

$S_{2}$ foi exibida na figura 5.4. No entanto, como q(e) está ausente em $S_{2}$, supondo que $\left.\mathrm{lq}(\mathrm{e})\right|_{S_{2}} \equiv|\mathrm{u}(\mathrm{a})|_{S_{1}}$, podemos usar o conhecimento de $S_{1}$ para fornecer uma informação inexistente em $S_{2}$.

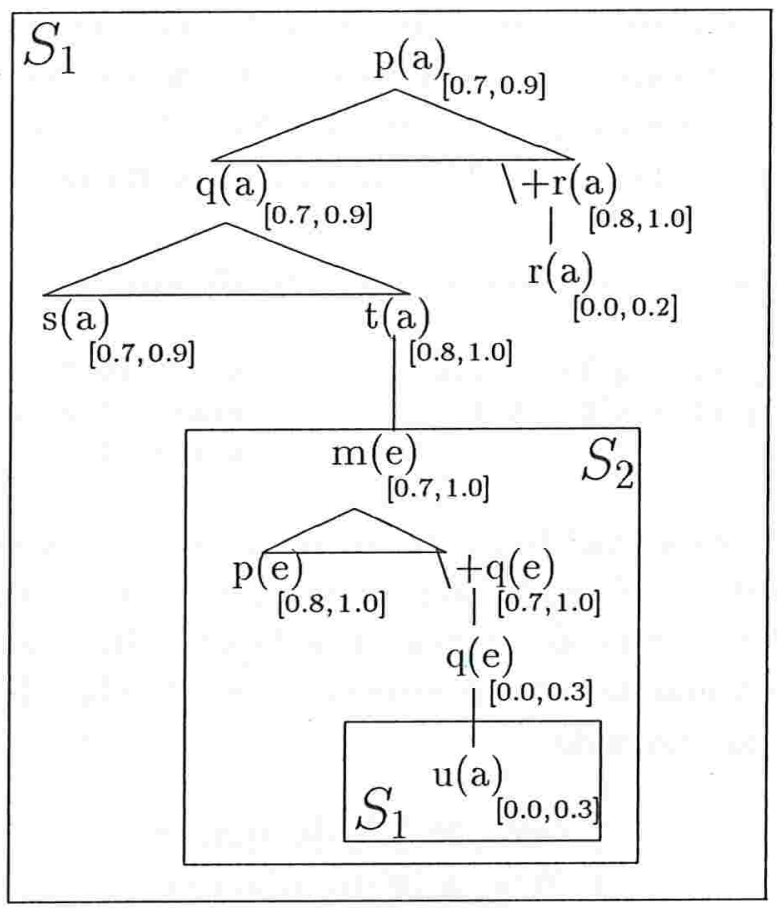

Figura 5.11: Consulta bidirecional restrita com um sistema DSFH consultando outro sistema DSFH

Note que em $S_{1}$ as provas de u(a) e de $\mathrm{p}(\mathrm{a})$ são completamente independentes. De fato, as cláusulas de $S_{2}$ podem ser particionadas em dois conjuntos, cada um usado para fazer uma das provas mostradas no exemplo. Dessa forma, garantimos que em cada passo do compartilhamento de conhecimento, os resultados externos não influenciam na semântica do sistema, podendo ser usados normalmente como se fossem obtidos localmente.

Como os formalismos usados em $S_{1}$ e $S_{2}$ são idênticos, os intervalos obtidos para as informações compartilhadas podem ser utilizados diretamente pelos sistemas clientes, sem a necessidade de nenhuma conversão, como o nivel de crença das informações inexistentes nos sistemas. 


\subsubsection{Sistema DSFH Consulta Rede}

Nesse caso, a teoria lógica, para solucionar um problema, faz uma consulta a uma rede bayesiana. Devemos lembrar sempre que a rede bayesiana é capaz de calcular todas as probabilidades referentes às consultas válidas feitas a ela. Por isso, a rede sempre vai retornar uma resposta, baseada exclusivamente no seu conhecimento local, para a consulta feita. Para ativar a consulta bidirecional, o sistema lógico deverá solicitar que a rede forneça uma outra solução para a consulta, através de um mecanismo de "backtracking".

A mesma análise, feita em 5.5.1, a respeito das duas provas feitas por $S_{1}$ cabe neste caso. A única diferença corresponde ao fato de que, desta vez, temos uma consulta de um sistema DSFH a uma rede e uma consulta da rede ao sistema lógico. O exemplo 5.5.2 apresenta uma situação de compartilhamento de conhecimento entre um sistema DSFH e uma rede bayesiana na qual o sistema DSFH faz a consulta inicial que, para ser satisfatoriamente resolvida pela rede, realiza uma consulta de volta ao sistema DSFH.

Exemplo 5.5.2 Considere o sistema $S_{1}$ apresentado abaixo

$$
\begin{array}{ll}
p(X):-q(X), \backslash+r(X) . & s(a)=[0.7,0.9] . \\
q(X):-s(X), t(X) . & r(a)=[0.0,0.2] . \\
& u(a)=[0.9,1.0] .
\end{array}
$$

Como a informação atômica t (a) não está presente em $S_{1}$, seu grau de crença é assumido como o intervalo $[0.0,0.0]$. Suponha que exista uma rede bayesiana, chamada de $R B$, que seja capaz de obter o grau de crença para $\mathrm{t}(\mathrm{a})$. Através do compartilhamento de conhecimento, ligando manulamente os extremos do intervalo de crença de $t(a),[l b, u b]$, com consultas à rede, por exemplo,

$$
\left\{\begin{array}{l}
|u b|_{S_{1}} \equiv\left|p\left(y_{1} \mid y_{5}\right)\right|_{R B}, e \\
|l b|_{S_{1}} \equiv\left|p\left(y_{1}, y_{2} \mid y_{5}\right)\right|_{R B}
\end{array}\right.
$$

podemos associá-lo a um par de consultas à rede rede bayesiana $R B$ representada no lado direito da figura 5.12. Para o par de consultas, é obtido o intervalo [0.4151,0.4370] para $\mathrm{t}(\mathrm{a})$, o que produz o intervalo $[0.0,0.4370]$ para $\mathrm{p}(\mathrm{a})$.

$\mathrm{Na}$ tentativa de se obter uma solução melhor, o sistema lógico pode consultar novamente a rede para que ela obtenha uma nova solução para as mesmas consultas

$$
\left\{\begin{array}{l}
|u b|_{S_{1}} \equiv\left|p\left(y_{1} \mid y_{5}\right)\right|_{R B}, e \\
|l b|_{S_{1}} \equiv\left|p\left(y_{1}, y_{2} \mid y_{5}\right)\right|_{R B}
\end{array}\right.
$$

Para responder à nova consulta, supondo que o evento $y_{3}$ da rede é semanticamente equivalente à consulta $\mathrm{u}(\mathrm{a})$ de $S_{1}$, podemos relacionar o valor da probabilidade associada ao vértice $y_{3}$ de $R B$ com a consulta u(a) feita a $S_{1}$. Note que, u(a) não é dependente de nenhuma cláusula utilizada na prova de $\mathrm{p}(\mathrm{a})$. O intervalo de crença de u(a), $[0.9,1.0]$, justifica o uso de $y_{3}$ como evidência pela rede. Assim, a consulta $p\left(y_{1} \mid y_{5}\right)$ 


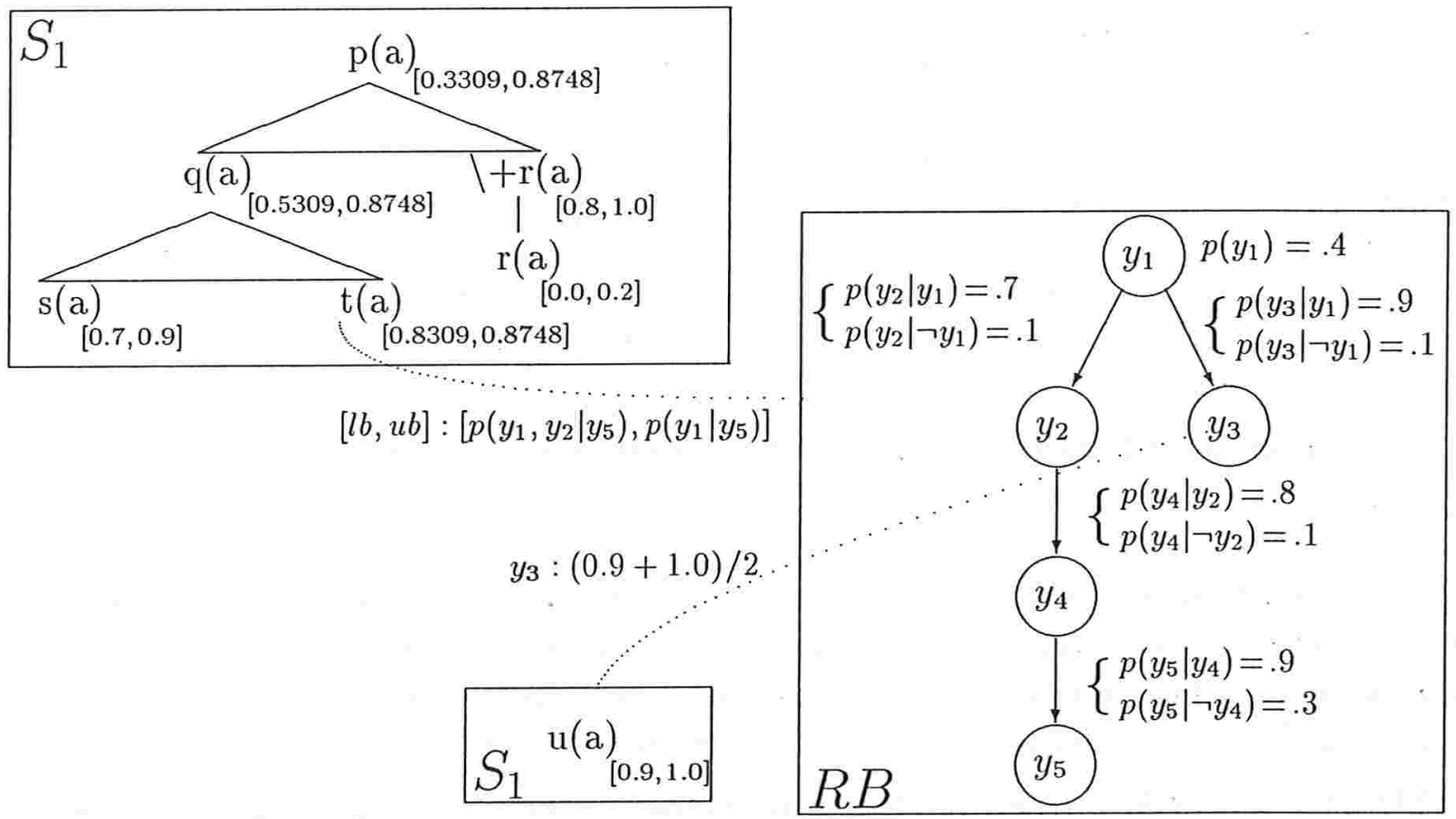

Figura 5.12: Consulta bidirecional restrita com um sistema DSFH consultando uma rede

será calculada como $p\left(y_{1} \mid y_{5}, y_{3}\right)=0.8748$ e a consulta $p\left(y_{1}, y_{2} \mid y_{5}\right)$ será calculada como $p\left(y_{1}, y_{2} \mid y_{5}, y_{3}\right)=0.8309$, associando o intervalo [0.8309, 0.8748] a $\mathrm{t}$ (a). Esse último intervalo, produz $[0.3309,0.8748]$ como intervalo de crença para $\mathrm{p}(\mathrm{a})$. A prova para a consulta está exibida na figura 5.12.

Neste caso, em que uma rede é usada para fornecer um par de consultas, ambas considerando o mesmo conjunto de evidências, qualquer informação externa consultada pela rede deve ser aplicada para as duas consultas usadas para gerar o intervalo do sistema lógico. Caso contrário, não será possível garantir que o intervalo resultante corresponda a dois eventos aninhados.

\subsubsection{Rede Consulta Rede}

No caso das consultas circulares entre redes bayesianas, o problema que pode ocorrer é a criação de ciclos dirigidos com o estabelecimento das consultas circulares entre os sistemas, conforme esquematizado na figura 5.13, onde temos representadas duas redes bayesianas, chamadas de $X$ e de $Y$.

A rede $X$ apresenta vértices $x_{i}$ e $x_{j}$ tais que $x_{j}$ é condicionalmente dependente de $x_{i}$. Equivalentemente, a rede $Y$ apresenta vértices $y_{k}$ e $y_{l}$ tais que $y_{l}$ é condicionalmente dependente de $y_{k}$. No estabelecimento do compartilhamento de conhecimento entre essas redes, assumiram-se as ligações tais que $y_{k}$ fornece evidência a $x_{j}$ e $x_{i}$ fornece evidência 


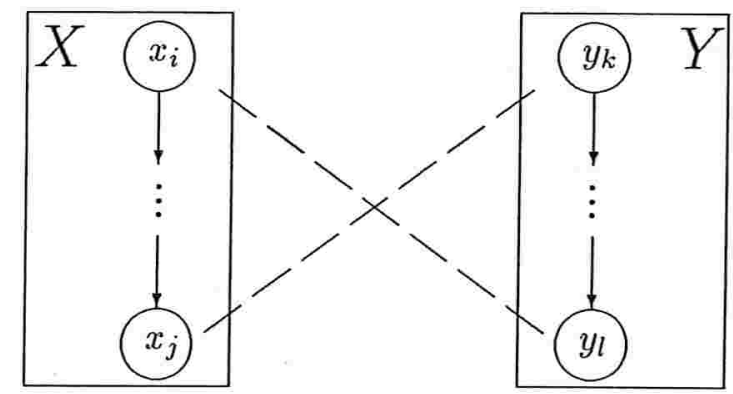

Figura 5.13: Esquema de um circuito dirigido em uma rede bayesiana

para $y_{l}$. Essa configuração, esquematizada na figura 5.13, apresenta um problema na interpretação dos sistemas, criando uma circularidade na relação de dependência entre eventos. De um ponto de vista mais geral, devemos impor condições fortes que garantam a independência das informações assumidas pelos sistemas.

Seja $S_{1}$ uma rede que, ao resolver uma consulta $p\left(v_{1}, \ldots, v_{n} \mid e_{1}, \ldots, e_{n}\right)$, obtenha a resposta $c$. Supondo a existência de uma outra rede que possa ser utilizada para atribuir o valor-verdade de um evento $x$ de $S_{1}, x \notin\left\{e_{1}, \ldots, e_{n}\right\}$, podemos usá-lo para obter uma melhor estimativa para a consulta. Analogamente, se essa nova estimativa não for satisfatória, e sabendo-se que existe um vértice de $S_{2}$ que pode ter seu valor-verdade definido a partir de uma consulta a $S_{1}$, podemos usar novamente o compartilhamento de conhecimento para fornecer uma melhor resposta a $S_{1}$, o que produzirá uma nova estimativa para a consulta original de $S_{1}$.

Como $S_{1}$ é usado duas vezes no processo completo, devemos impedir que as hipóteses assumidas em uma das consultas causem problemas para a as hipóteses assumidas na outra. Para resolver esse problema, impomos que, além de as duas consultas unidirecionais consideradas atenderem as restrições impostas nas consultas unidirecionais, devemos garantir que as duas consultas respondidas por $S_{1}$ sejam independentes.

Um exemplo de uma consulta bidirecional restrita com uma rede bayesiana consultando outra rede bayesiana é apresentado no exemplo 5.5.3.

Exemplo 5.5.3 Considere a rede $R B_{z}$ apresentada no lado esquerdo da figura 5.14. Nessa rede, a probabilidade $p\left(z_{4} \mid z_{2}\right)=0.625$. No entanto, a hipótese de $z_{5}$ ser verdadeiro fornece o valor $p\left(z_{4} \mid z_{2}, z_{5}\right)=0.9375$. Sabendo da existência de uma outra rede bayesiana, chamada de $R B_{k}$ e apresentada do lado direito da figura 5.14, que possa ser utilizada para definir o valor da probabilidade de o evento $z_{5}$ ser verdadeiro, podemos compartilhar seu conhecimento. Associando $z_{5}$ com o evento $p\left(k_{1} \mid k_{4}\right)=0.4428$ de $R B_{k}$ não se ganha grande suporte para o uso de $z_{5}$ como evidência. Mas, ao se solicitar uma nova resposta para $R B_{k}$ e sabendo que o evento $k_{3}$ está ligado manualmente ao evento $p\left(z_{3} \mid z_{1}\right)=0.8999$ de $R B_{z}$, podemos assumir $k_{3}$ como evidência para a consulta feita a $R B_{k}$, usando a probabilidade $p\left(k_{1} \mid k_{4}, k_{3}\right)=0.8773$ para fornecer um alto indicio de que $z_{5}$ é uma evidência verdadeira. Dessa forma, podemos usar $p\left(z_{4} \mid z_{2}\right)$ como equivalente a $p\left(z_{4} \mid z_{2}, z_{5}\right)=0.9375$. 


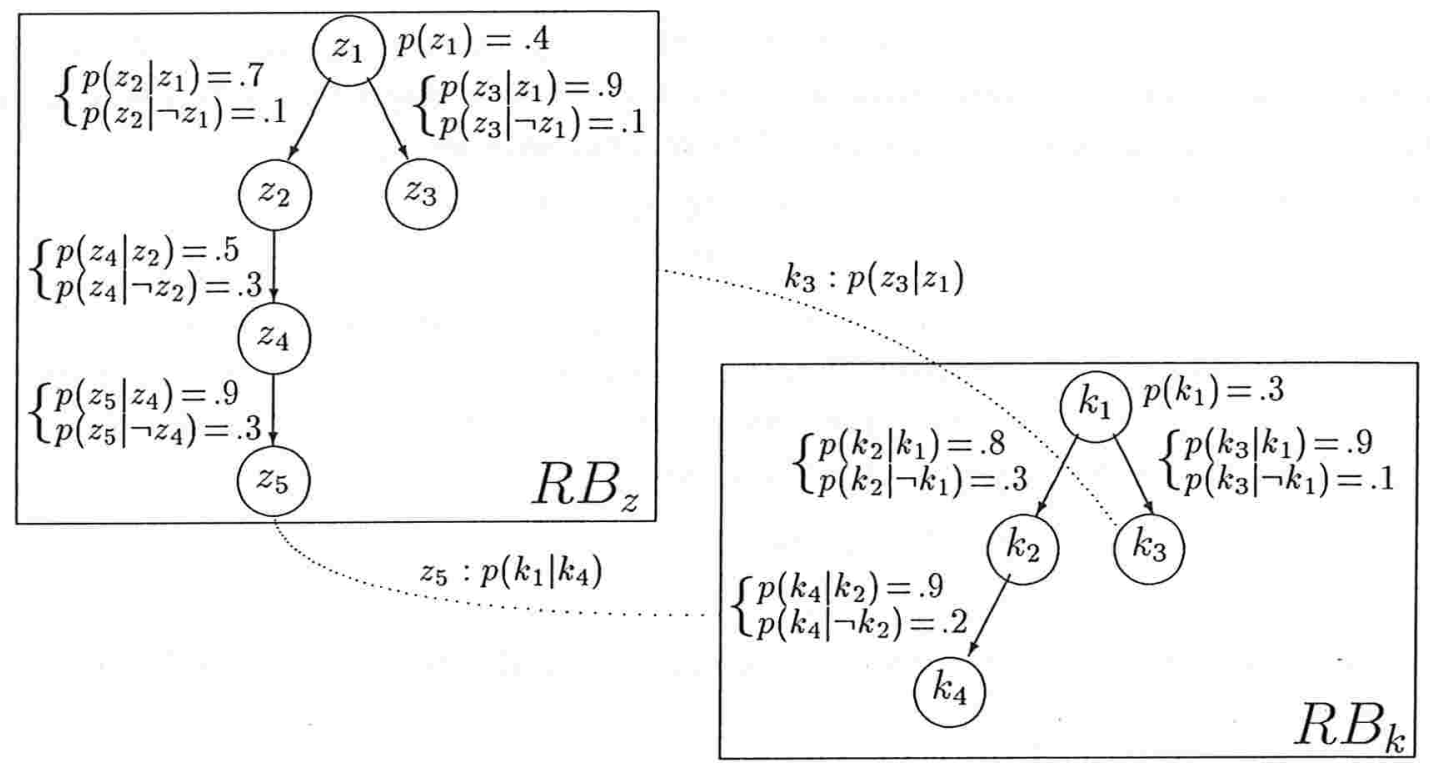

Figura 5.14: Um exemplo de consulta bidirecional restrita com uma rede bayesiana consultando outra rede bayesiana

Note que as duas consultas feitas a $R B_{z}$ são independentes devido às escolhas dos eventos utilizados nas duas consultas.

Uma forma de se evitar que sejam produzidas uma série de respostas para uma consulta em que o servidor seja uma rede, é convencionar que, junto com a consulta, é também enviado um valor $v$ que seja usado como referência para a resposta calculada pela rede. Dessa forma, uma consulta como $p\left(y_{1} \mid y_{2}\right) \geq 0.8$ de $R B_{x}$ para $R B_{y}$ pode especificar para que $R B_{y}$ tente obter uma solução para a consulta que seja maior ou igual a 0.8. Assim, a própria $R B_{y}$ pode se encarregar de buscar informações externas para satisfazer a imposição do cliente.

\subsubsection{Rede Consulta Sistema DSFH}

Da mesma forma como antes, devemos impor que, nas duas consultas unidirecionais envolvidas no processo, as álgebras de medidas de probabilidades dos mundos possíveis dos sistemas não sejam corrompidas. Assim como visto em 5.5.3, como $S_{1}$ é usado duas vezes no processo completo, devemos impedir que as hipóteses assumidas em uma das consultas causem problemas para a semântica assumida na outra. Para resolver esse problema, devemos garantir que as duas consultas respondidas por $S_{1}$ sejam independentes. Um exemplo de uma rede consultando um sistema DSFH é apresentado no exemplo 5.4.5.

Exemplo 5.5.4 Considere a mesma rede bayesiana $R B_{z}$ utilizada no exemplo 5.5.3. Como vimos, $p\left(z_{4} \mid z_{2}\right)=0.625$, enquanto que $p\left(z_{4} \mid z_{2}, z_{5}\right)=0.805$, ou seja, a possibi- 
lidade de assumir $z_{5}$ como verdadeiro influenciará na probabilidade de $x_{1}$. Desta vez, relacionamos a probabilidade associada ao evento $z_{5}$ com a resposta da consulta $\mathrm{p}(\mathrm{a})$, fornecida pelo seguinte programa em lógica DSFH, chamado de $S_{2}$ :

$$
\begin{array}{ll}
p(X):-q(X), r(X) . & s(a)=[0.8,1.0] . \\
q(X):-s(X), t(X) . & t(a)=[0.9,1.0] .
\end{array}
$$

$S_{2}$, por sua vez, não apresenta a informação atômica $r(\mathrm{a})$, necessáría para a prova de $\mathrm{p}(\mathrm{a})$. Em vez de associar o valor padrão [0.0,0.0] a $\mathrm{r}(\mathrm{a})$, usamos novamente o compartilhamento de conhecimento, por exemplo ligando manualmente o intervalo de crença da informação atômica com o intervalo $[l b, u b]$ tal que:

$$
\left\{\begin{array}{l}
|u b|_{S_{1}} \equiv\left|p\left(z_{3} \mid z_{1}\right)\right|_{R B_{z}}, e \\
|l b|_{S_{1}} \equiv\left|p\left(z_{3} \mid z_{1}\right)\right|_{R B_{z}},
\end{array}\right.
$$

Dessa forma, o grau de crença de $\mathrm{r}(\mathrm{a})$ é assumido como $[0.9,0.9]$, o que produz $[0.6,0.9]$

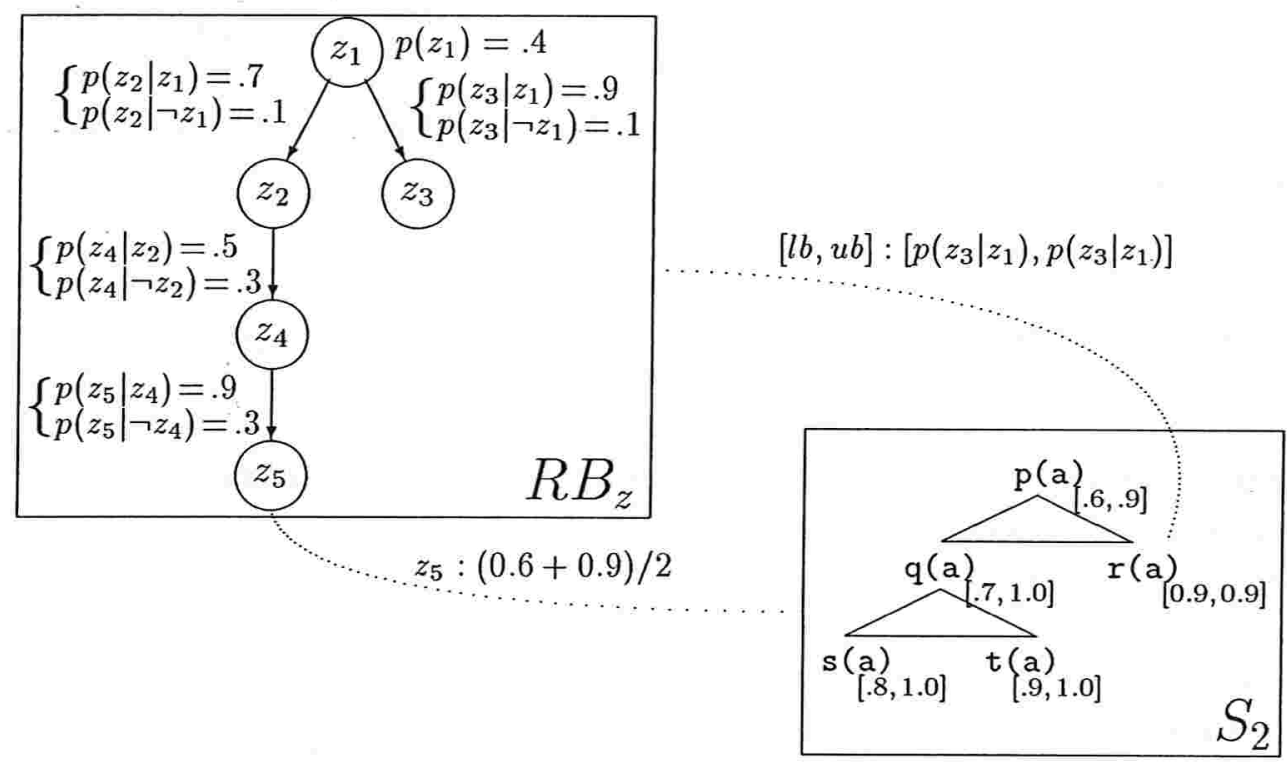

Figura 5.15: Um exemplo de consulta bidirecional restrita com uma rede consultando um sistema DSFH

como grau de crença de $\mathrm{p}(\mathrm{a})$. A partir do grau de crença de $\mathrm{p}$ (a) obtemos o valor 0.75 como suporte à probabilidade de $z_{5}$ ser verdadeiro. Assumindo $z_{5}$ como evidência para a consulta original a $R B_{z}$, obtém-se o valor 0.9375 como resposta. Esse processo está ilustrado na figura 5.15 .

\subsection{Consultas Bidirecionais Genéricas}

Finalmente, chegamos ao caso mais geral das interações entre sistemas. Nesse tipo de consulta, consideramos um sistema $S_{1}$ que, ao resolver um problema $p=q$, encaminha 
uma consulta $q_{1}$ a um sistema $S_{2}$ que, por sua vez, pode consultar novamente $S_{1}$, iniciando um processo que pode ser, eventualmente, longo. Um esquema geral de uma consulta bidirecional genérica está apresentada na figura 5.16, onde representamos os sistema $S_{1}$ e $S_{2}$ e a seqüência de consultas entre eles.

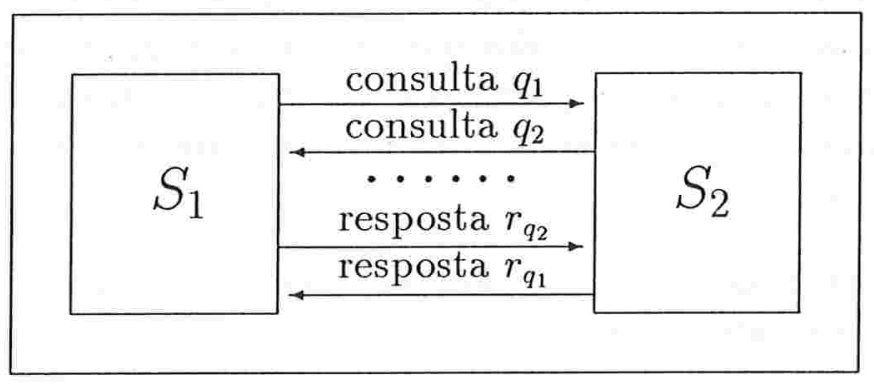

Figura 5.16: Esquema geral de uma consulta bidirecional genérica de $S_{1}$ a $S_{2}$

A grande dificuldade no estabelecimento desse tipo de consultas reside na definição de alguma forma de controle que impeça a criação de ciclos infinitos nas consultas dos sistemas e que também evite que a semântica dos sistemas seja corrompida por causa de duplicação das informações manipuladas pelos sistemas.

Para analisar esse tipo de consulta, é conveniente definir formalmente alguma estratégia para descrever a seqüência de consultas executadas de tal forma que seja possível averiguar, durante o compartilhamento de conhecimento, que sistemas estão envolvidos no processo e que problemas eles estão resolvendo. Numa arquitetura para compartilhamento de conhecimento, um sistema pode ser utilizado de duas formas:

1. diretamente, ao ser consultado por um usuário; ou

2. indiretamente, ao ser solicitado, por um outro sistema da arquitetura, que compartilhe seu conhecimento.

Sempre que um sistema $S_{1}$ é consultado por um usuário para resolver um problema $p$, é atribuído o valor inicial $\mathcal{H}_{S_{1}}^{t}=\left(\left\langle S_{1}, p\right\rangle\right)$ para o histórico para resolução de p por $S_{1}$. Toda vez que um sistema $S_{i}$ for consultar um sistema $S_{j}$ para resolver um subproblema $p_{j}$, ele não somente envia a consulta $p_{j}$ para $S_{j}$ como o histórico completado com o rótulo da consulta sendo efetuada $\left\langle S_{j}, p_{j}\right\rangle$. Dentro da arquitetura para compartilhamento de conhecimento adotada neste trabalho, podemos considerar que a camada de interface pode se responsabilizar pela manipulação do histórico.

Da forma como definido, e considerando apenas as interações entre pares de sistemas tratadas neste trabalho, o histórico $\mathcal{H}_{S_{1}}^{t}$ é uma seqüência $\left(\left\langle S_{1}, p=q_{1}\right\rangle,\left\langle S_{2}, q_{2}\right\rangle, \ldots,\left\langle S_{n}, q_{n}\right\rangle\right)$ onde

$$
S_{i}=\left\{\begin{array}{l}
S_{1}, \text { se } i \text { for ímpar; ou } \\
S_{2}, \text { se } i \text { for par }
\end{array}\right.
$$


e $q_{i}$ é a consulta feita do sistema $S_{i-1}$ ao sistema $S_{i}, 1<i \leq n$.

Ao contrário de como fizemos anteriormente, não analisaremos as consultas bidirecionais genéricas considerando os quatro casos possíveis de interações entre sistemas. Com as consultas unidirecionais, vimos como um par de sistemas pode compartilhar conhecimento. Com as bidirecionais restritas, vimos como, numa seqüência de consultas, devemos considerar os sistemas cliente e servidor das duas consultas envolvidas no processo, bem como os sistemas que aparecem na origem e no término da seqüência. Agora, podemos generalizar a nossa análise, considerando os mesmos critérios de avaliação de consistência usados anteriormente:

- para cada consulta do sistema $S_{i}$ para o sistema $S_{j}$, considerar a análise da semântica da interação dos sistemas; e

- além disso, devemos avaliar se, dois sistemas que não estejam ligados diretamente (através de uma consulta direta de um ao outro) não tenham sua semântica corrompida devido a dependências existentes entre eles.

Infelizmente, no caso geral não podemos garantir a consistência dos sistemas. Através do histórico das interações podemos averiguar se dois sistemas foram usados e, até mesmo, que problemas que resolviam em cada fase retratada no histórico. No entanto, não dispomos de uma forma automática para decidir se uma solução $r_{q_{i}}$ obtida por um sistema $S_{i}$ para um problema $q_{i}$ é independente de uma solução $r_{q_{j}}$ obtida por um sistema $S_{j}$ para um problema $q_{j}$, onde, eventualmente, $S_{i}$ e $S_{j}$ podem ser o mesmo sistema. O estudo desse problema, por si só complexo, deixamos para uma oportunidades futura.

\subsection{Análise dos Resultados}

Nas consultas unidirecionais e bidirecionais restritas, casos em que as interações dos sistemas são bem controladas, conseguimos, com sucesso, implementar o compartilhamento de conhecimento entre pares de sistemas. No entanto, a forma como o compartilhamento de conhecimento é utilizado por um sistema depende das propriedades matemáticas do formalismo utilizado no sistema:

- no caso da programação em lógica DSFH, o compartilhamento de conhecimento é útil para calcular o intervalo de crença de informações inexistentes no próprio sistema e cujos valores eram assumidos, previamente, como $[0.0,0.0]$; e

- nas redes bayesianas, o compartilhamento de conhecimento é útil para calcular o valor de novas evidências para alguns eventos representados como vértices das redes.

Para os propósitos deste trabalho, foi de fundamental importância o estudo matemático feito dos formalismos considerados. Foi a partir dele que estabelecemos uma interpretação do fenômeno da incerteza, modelado pelos formalismos, que serviu para relacionar as representações de graus de crença, distintas entre si, presente nos formalismos. Em 
particular, a teoria das probabilidades forneceu um ferramental poderoso para a análise dos formalismos, particularmente devido à nossa adoção, para o sịstema lógico, da função de crença definida por Fagin e Halpern.

Para a abordagem algébrica dos mundos possíveis dos sistemas, foi de fundamental importância a idéia de independência na análise dos sistemas. Entretanto, essa propriedade 'é tratada de formas diferentes pelos dois formalismos:

redes bayesianas: a relação de independência está muito bem definida dentro do próprio modelo das redes bayesiana, bastando explorar suas propriedades estruturais; e

programação em lógica DSFH: a relação de independência não está definida, mas a análise de mundos possíveis relevantes gera uma partição do domínio dos sistemas, de tal forma que as partições fiquem independentes entre si.

Entretanto, para tornar o compartilhamento de conhecimento viável do ponto de vista prático, é preciso obter uma forma de automatizar a análise da independênncia, que realizamos manualmente neste trabalho.

Outro detalhe que merece ser destacado diz respeito à escolha da arquitetura para compartilhamento de conhecimento que foi utilizada. Conforme pode ser visto nos experimentos realizados, foi realmente desnecessário considerar comunidades de sistemas, com protocolos avançados e, até mesmo, linguagens para comunicação sofisticadas. Para nossos propósito, bastou considerar que as informações equivalentes dos sistemas estavam "manualmente ligadas" para dedicar todo o nosso esforço no uso dessas informações pelos sistemas e no estudo do impacto que elas causavam nas suas teorias formais. A seguir, analisamos os resultados obtidos em cada um dos três tipos básicos de interação de sistemas.

\subsubsection{Consultas Unidirecionais}

Por se tratar do caso mais simples, no qual o sistema servidor responde à consulta com base exclusivamente no seu conhecimento local, foi sempre possível obter uma solução baseada nas informações obtidas por compartilhamento de conhecimento.

Como consideramos, para nosso estudo de caso, dois formalismos com representações distintas para o grau de crença de uma informação, tivemos que definir uma forma coerente de transformar o grau de crença, obtido por um sistema, no grau de crença utilizado pelo outro. Por exemplo, um sistema DSFH que faz uma consulta a uma rede bayesiana tem a sua consulta desmembrada em duas consultas à rede, de forma a definir os dois extremos do intervalo de crença buscado.

Para tornar possível o compartilhamento de conhecimento, foram impostas as restrições de consistência, com o objetivo de manter a consistência semântica dos sistemas que compartilham conhecimento. Devido à interpretação probabilística dos sistemas, consideramos a álgebra de medidas de probabilidades dos mundos possíveis como o significado 
das medidas de incerteza manipuladas pelos sistemas. Dessa forma, a relação de independência entre álgebras tornou-se de fundamental importância para operacionalizar a obtenção de informações externas por um sistema como o produto cartesiano de álgebras. Por sua vez, a relação de independência também é tratada de formas distintas pelos formalismos considerados:

redes bayesianas: a independência está representada na topologia da rede, pois as arestas da rede representam a relação de dependência direta entre eventos; e

programação em lógica DSFH: a independência está relacionada com a relevância de certas informações para uma prova, de tal forma que, para se produzir provas para $p$ e $q$, se for possível particionar um programa em dois conjuntos, cada qual associado a $p$ ou a $q$, mas não a ambos, tais que cada uma das provas utilize somente as cláusulas de uma das partições, $p$ e $q$ serão independentes.

\subsubsection{Consultas Bidirecionais Restritas}

Trata-se de um caso um pouco mais geral que as consultas unidirecionais, onde cada sistema faz o papel tanto de cliente como de servidor. Nas consultas bidirecionais restritas temos um processo constituído por duas consultas unidirecionais em seqüência. No entanto, além de manter as restrições semânticas para as duas consultas unidirecionais, devemos considerar também os sistemas:

- que fez a primeira consulta, e

- que respondeu à última consulta.

As informações embutidas nessas consultas devem também ser independentes, embora os sistemas não estejam diretamente relacionados no processo. Como, além disso, esses dois papéis são desempenhados pelo mesmo sistema, devemos tomar muito cuidado ao se estabelecer os critérios de independência para que as medidas probabilísticas das semânticas de mundos possíveis dos sistemas não sejam corrompidas.

Além de manter as restrições de consistência, foram incluídas as restrições operacionais, que têm o objetivo de impedir que os sistemas, através do compartilhamento de conhecimento, criem "ciclos de consultas" que sejam encaminhadas indefinidamente.

\subsubsection{Consultas Bidirecionais Genéricas}

Trata-se do caso mais geral da interação de um par de sistemas, onde pode ocorrer uma seqüência arbitrariamente longa de consultas entre eles. Para controlar a seqüência de consultas, introduzimos o histórico das interações, que tem como objetivo descrever a seqüencia de consultas entre os sistemas.

Usando a análise dos formalismos empregada nas consultas unidirecionais e os critérios de independência considerados nas consultas unidirecionais e bidirecionais restritas, generalizamos a abordagem adotada e concluímos: 
- tornou-se possível evitar a ocorrência de ciclos de consultas entre sistemas, uma vez que, para isso acontecer, um mesmo sistema deverá fazer uma mesma consulta ao outro, o que é proibido pela política de compartilhamento que introduzimos com a adoção do histórico das interações; e

- a garantia da consistência dos sistemas permanece como fator delicado no compartilhamento de conhecimento uma vez que devemos considerar a independência de todas as informações obtidas durante a seqüência de consultas retratadas no histórico.

\subsection{Considerações Finais}

O que devemos enfatizar em face aos experimentos feitos é que, se para este caso específico foi necessário analisar minuciosamente o par de formalismos considerados, no caso geral também tal tipo de análise constitui-se fundamental. Da mesma forma com que não foi possível decidir a respeito da independência das informações obtidas nas consultas bidirecionais genéricas, também questionamos a solução deste problema nos casos gerais em que os formalismos do cliente e do servidor não são especificados.

Daí concluímos que se uma análise detalhada dos formalismos considerados foi de fundamental importância para este estudo de caso, influenciando sensivelmente na viabilidade e na possibilidade (do ponto de vista formal) do compartilhamento de conhecimento, no caso geral, não restrito aos formalismos de redes bayesianas e programação em lógica DSFH, tal análise também será fundamental.

Por isso, o compartilhamento de conhecimento não se resolve somente com um relacionamento entre termos semanticamente equivalentes dos sistemas, seja ele feito através de ontologias ou não. É necessário analisar o par de sistemas que interagem para, a partir de suas características, estabelecer de que forma uma informação externa compromete os resultados que o sistema produz.

Além disso, vale a pena destacar que o uso de evidências somente ou verdadeiras ou falsas nas redes bayesianas serviu para mostrar uma abordagem do compartilhamento de conhecimento no qual as informações obtidas não possuem uma interpretação puramente probabilística, mas é utilizada para decidir pela veracidade de um evento. Desviou-se um pouco da interpretação probabilística dos formalismos considerados, mas foi antecipada uma análise que deverá ser feita quando, por exemplo, tentar-se estabelecer o compartilhamento de conhecimento entre uma lógica similar à lógica clássica e as redes bayesianas.

Este trabalho surgiu da generalização de [6], que tratava apenas das consultas unidirecionais que consideravam o sistema DSFH como cliente e as redes bayesianas como servidoras. Devido à importância do artigo para o desenvolvimento deste trabalho, decidimos pela sua inclusão como apêndice deste texto no Apêndice B. 


\section{Capítulo 6}

\section{Conclusões Finais}

Neste trabalho consideramos o problema de compartilhamento de conhecimento entre sistemas baseados em conhecimento. Consideramos que os sistemas utilizados são modelados segundo os formalismos de redes bayesianas e programação em lógica baseada na teoria de evidência de Dempster-Shafer com função de crença de Fagin e Halpern.

Para a apresentação da área, introduzimos uma série de conceitos e disciplinas relacionadas com o compartilhamento de conhecimento, enfatizando a presença de alguma forma de compartilhamento de conhecimento em áreas como inteligência artificial distribuída, agentes de software e bancos de dados distribuídos.

Uma vez apresentada a área, introduzimos o modelo de compartilhamento de conhecimento considerado neste trabalho. O modelo considera que o compartilhamento de conhecimento é completamente caracterizado por um par de sistemas, o cliente e o servidor, e que, para os nossos propósitos, podemos considerar que o compartilhamento de conhecimento é implementado através da ligação manual de uma informação atômica do cliente com uma consulta capaz de ser respondida pelo servidor. Através desse modelo simplificado, tornou-se possível analisar certos aspectos formais do compartilhamento de conhecimento que, em geral, não são estudados na literatura. Em particular, possibilitou o estudo do impacto de informações externas nas teorias formais representadas pelos sistemas envolvidos no processo.

Para testar o modelo computacional proposto, abordamos o problema de compartilhamento de conhecimento para sistemas baseados em raciocínio com incerteza e considerando os formalismos de redes bayesianas e programação em lógica DSFH. Para realizar os experimentos, consideramos três tipos básicos de consultas entre os sistemas:

- consultas unidirecionais;

- consultas bidirecionais restritas; e

- consultas bidirecionais genéricas. 
Para cada um desses tipos básicos, testamos as quatro possibilidades para interação entre um par de sistemas, chamados de $S_{1}$ e de $S_{2}$ :

- $S_{1}$ modelado por Programação em Lógica DSFH e $S_{2}$ modelado por Programação em Lógica DSFH;

- $S_{1}$ modelado por Programação em Lógica DSFH e $S_{2}$ modelado por Redes Bayesianas;

- $S_{1}$ modelado por Redes Bayesianas e $S_{2}$ modelado por Programação em Lógica DSFH; e

- $S_{1}$ modelado por Redes Bayesianas e $S_{2}$ modelado por Redes Bayesianas.

Os experimentos foram realizados através de um mapeamento direto entre informações atômicas do sistema cliente a uma consulta feita ao sistema servidor. Esse mapeamento foi definido com base na nossa interpretação dos sistemas com o objetivo de averiguar qual o impacto de informações externas na semântica dos sistemas. Nos experimentos deparamonos com dois problemas principais decorrentes do compartilhamento de conhecimento entre sistemas:

criação de ciclos: existe a possibilidade de, num encadeamento de consultas entre dois sistemas, um sistema refazer uma consulta feita previamente na cadeia de consultas, provocando um ciclo que, se não for controlado, pode se tornar infinito; e

independência: a existência de dependências entre as informações dos sistemas considerados para a solução de um problema faz com que as medidas de probabilidades utilizadas como graus de crença das informações dos sistemas tornem-se erradas.

O uso do histórico das interações entre sistemas resolve satisfatoriamente o problema da geração de ciclos, uma vez que é capaz de registrar, na seqüência de consultas encadeadas, os sistemas participantes e as consultas que resolvem. Por outro lado, a análise da independência das informações compartilhadas envolve uma análise mais minuciosa, exigindo um estudo, para cada formalismo considerado, da forma como cada consulta é resolvida e do impacto de cada resolução de subproblemas na criação de dependências com relação às outras provas de consultas feitas no mesmo encadeamento.

Para completar a nossa apresentação teórica do problema de compartilhamento de conhecimento entre os formalismos considerados, implementamos programas que realizam o compartilhamento de conhecimento. Nossa implementação foi baseada em recursos computacionais simples e são facilmente encontrados em plataformas mais sofisticadas e de fácil adaptação.

Com base nos experimentos realizados neste trabalho, concluímos: 
- é difícil estabelecer propriamente o compartilhamento de conhecimento entre sistemas formais, sendo que para resolver esse problema é importante uma análise dos detalhes matemáticos dos sistemas envolvidos;

- o uso de arquiteturas e de protocolos de comunicação são importantes para descrever o papel dos sistemas em uma "comunidade" de sistemas, mas não oferecem meios para explorar os detalhes matemáticos dos formalismos;

- da mesma forma, o uso de ontologias ou de linguagens pré-definidas voltadas para a descrição das propriedades dos sistemas não resolve completamente o problema de interação entre eles. Por exemplo, somente a análise do mecanismo de inferência da programação em lógica DSFH justifica o uso do valor médio do intervalo obtido para uma consulta como valor a ser usado por uma rede bayesiana que usa esse conhecimento; e

- o estudo da semântica dos sistemas revelou-se como o fator delicado no compartilhamento de conhecimento; especificamente para este trabalho, supomos que a análise semântica é feita por pessoas que garantam a independência de uma informação compartilhada em relação à álgebra de mundos possíveis do sistema que a utiliza. No entanto, esse tipo de tratamento é irreal em aplicações práticas, eventualmente constituídas por sistemas complexos demais para terem suas semanticas estudadas artesanalmente.

Neste trabalho, buscamos estudar alguns aspectos específicos do compartilhamento de conhecimento, deixando uma série de outros aspectos para serem tratados em uma oportunidade futura. Dentre eles, destacamos:

- explorar a arquitetura geral de compartilhamento de conhecimento, apresentada no capítulo 3, como uma plataforma dedicada para a resolução distribuída de problemas através da participação de um conjunto de sistemas heterogêneos;

- testar o uso das capacitações para resolver o problema do mapeamento entre termos semanticamente equivalentes dos sistemas;

- implementar backtracking nas consultas, permitindo que um sistema, após fornecer um resultado para uma consulta, possa ser reconsultado para fornecer outro. A dificuldade dessa tarefa reside na criação de formas que obrigue os sistemas a fornecer uma nova solução e não dar sempre a mesma resposta;

- elaborar uma aplicação real para as idéias propostas neste trabalho, possibilitando o estudo do compartilhamento de conhecimento na solução de problemas;

- estender o trabalho com a análise do compartilhamento considerando a inclusão de um outro formalismo para raciocínio com incerteza, como, por exemplo, a lógica fuzzy, que não é baseada na teoria das probabilidades; 
- estudar o problema da independência entre as álgebras das medidas de probabilidades de mundos possíveis dos sistemas para averiguar se existe alguma forma de se decidir, através do histórico das interações dos sistemas, mesmo com a inclusão de alguma informação adicional, se as soluções obtidas durante o processo são independentes; e

- implementar programas utilizando um ambiente de processamento distribuído com mais recursos, como, por exemplo em Java, que traz a vantagem adicional de possibilitar o compartilhamento de conhecimento via Internet.

Este trabalho está diretamente relacionado com o projeto "Cooperação Entre Sistemas Baseados em Conhecimento", financiado pelo convênio CAPES/British Council, 070/98, sob coordenação geral do Prof. Flávio Soares Correa da Silva. 


\section{Apêndice A}

Neste capítulo apresentaremos os programas desenvolvidos para este trabalho. Os programas constituem-se basicamente de interpretadores para os formalismos considerados, redes bayesianas e programação em lógica DSFH, que utilizamos nos experimentos realizados.

\subsection{Introdução}

Neste trabalho, supomos que o compartilhamento é efetuado quando um sistema, chamado de cliente, não dispõe de meios para provar satisfatoriamente um resultado e procura por um outro sistema, chamado de servidor, que prove o resultado procurado. Dessa forma, limitamos o funcionamento de cada sistema dentro da arquitetura para compartilhamento de conhecimento da seguinte forma:

- Um sistema cliente solicita que um sistema servidor prove algo;

- O sistema cliente aguarda que o servidor forneça alguma resposta; e

- O sistema cliente pode aceitar ou não uma prova fornecida pelo servidor.

\subsubsection{Arquitetura Computacional Proposta}

A arquitetura computacional considerada é aquela ilustrada na figura 3.4 e reproduzida na figura 6.1, a seguir. Com o objetivo de descrever componentes genéricos, facilmente adaptáveis e de fácil implementação, na modelagem dos componentes da arquitetura assumimos a política de não particularizá-la para ferramentas específicas. A escolha das linguagens e plataformas computacionais usadas para o desenvolvimento dos sistemas foi feita levando-se em consideração a facilidade com que sistemas desenvolvidos nelas são capazes de interagir entre si.

\section{Descrição dos Componentes da Arquitetura}

O modelo, simplificado o suficiente para descrever a interação de um par de sistemas, está apresentado na figura 6.1, que inclui dois sistemas, $C S C_{1}$ e $C S C_{2}$, que, ligados por um 
canal de comunicação, estão aptos a compartilhar conhecimento.

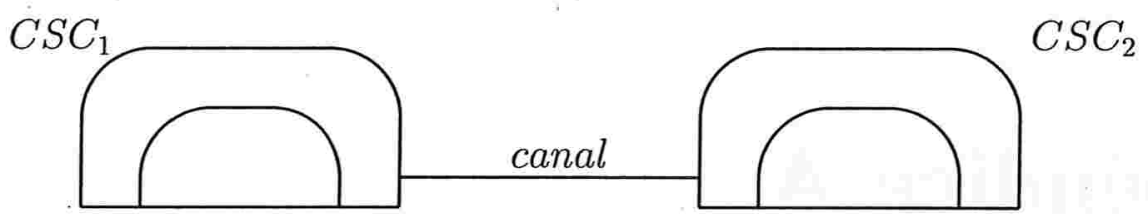

Figura 6.1: Esquematização de compartilhamento de conhecimento entre CSC's

Para a implementação dessa arquitetura, consideramos os seguintes componentes:

sistema baseado em conhecimento: usamos programas que implementam interpretadores para os formalismos da programação em lógica DSFH e das redes bayesianas, apresentados em 6.2.2 e 6.2.1, respectivamente;

software para fazer consulta para outro sistema: para simplificar o modelo computacional necessário para implementar o compartilhamento de conhecimento, convencionamos que as consultas entre sistemas serão implementadas pela execução de processos (do sistema operacional UNIX); e

software para responder à consulta de outro sistema: para simplificar o modelo computacional necessário para implementar o compartilhamento de conhecimento, convencionamos que a comunicação dos resultados das consultas serão feitas através de arquivos contendo as respostas para elas.

\subsection{Implementação dos Formalismos}

Para implementar sistemas nos formalismos de Redes Bayesianas e Teoria Lógica DSFH, foi preciso implementar interpretadores para esses formalismos. A seguir descrevemos as implementações de cada um deles, dando detalhes de sua modelagem, instruções de uso e informações sobe sua disponibilidade para cópia.

\subsubsection{Implementação do Interpretador para Rede Bayesiana}

Programa adaptado do programa Bayes, obtido em http://www.cs.cmu.edu/afs/cs/ project/ai-repository/ai/areas/reasonng/probabl/bayes/, escrito originalmente na linguagem Pascal e implementado a partir de [27], para um programa similar escrito em C.

\section{Documentação do Programa}

Este programa é uma implementação básica do algoritmo de propagação de evidências de Judea Pearl para redes bayesianas estruturadas como árvores e representadas na forma 
de grafos. As funções podem ser divididos em quatro grupos básicos:

Suporte Matemático: funções básicas que realizam operações sobre vetores e matrizes:

Normalize - Normaliza um vetor de tal forma que a soma de suas entradas seja 1 MakeIdentityVector - Produz um vetor com todas as suas entradas valendo 1.0 TermProduct - Faz o produto, termo a termo, de dois vetores TermQuotient - Faz o quociente, termo a termo, de dois vetores MatMult - Rotina simplificada de multiplicação de matrizes

Núcleo: as rotinas desse grupo foram apresentadas na edição de agosto de 1989 da revista AI Expert [27]:

ReviseBelief - Altera as informações de um vértice UpdateNode - Rotina de propagação de evidências SubmitEvidence - Processa uma nova evidência na rede

Suporte Geral: Funções auxiliares para entrada e saída de dados:

ReadString - Lê uma linha de um arquivo

FindNode - Procura na rede um determinado vértice especificado por um nome

DumpNetwork - Exibe informações do estado corrente da rede

DumpNode - Exibe informações do estado corrente de um vértice da rede

ReadNet - Lê descrição de uma rede bayesiana

ReadNodes - Lê informações sobre os vértices da rede

ReadLinks - Lê informações sobre as arestas da rede

Funções Adicionais: Funções criadas para os experimentos deste trabalho:

CondProb - Calcula uma probabilidade condicional

Evidence - Prepara uma nova evidência para ser processada

possivelCompartilhamento - Verifica se é possivel definir uma nova evidência através do compartilhamento de conhecimento

\section{Uso do Programa}

Para usar o programa, basta executar o comando "bayes" usando-se o seguinte formato para a chamada:

$$
\text { bayes 〈nome da rede〉〈eventos〉〈evidências〉 }
$$

onde 〈nome da rede〉 é um nome usado para identificar a rede bayesiana. Esse mesmo nome é utilizado para identificar os arquivos com a descrição da rede; são eles:

〈nome da rede〉.nod é o nome do arquivo que contém a descrição dos nós da rede bayesiana e as probabilidades associadas a eles, apresentando o seguinte formato: 
〈Nome do primeiro nó〉

〈Número de valores do primeiro nó〉

〈Nome do primeiro valor do primeiro nó)

〈Probabilidade a priori do primeiro valor do primeiro nó) (ignorado exceto para o nó raiz)

〈Nome do segundo valor do primeiro nó)

〈Probabilidade a priori do segundo valor do primeiro nó〉 (ignorado exceto para o nó raiz)

〈Nome do n-ésimo valor do primeiro nó〉

〈Probabilidade a priori do n-ésimo valor do primeiro nó) (ignorado exceto para o nó raiz)

〈Nome do segundo nó)

$\cdots$

etc.

〈nome da rede〉. Ink é o nome do arquivo que contém a descrição dos arcos da rede e suas respectivas probabilidades, apresentando o seguinte formato:

〈Nome do nó origem do primeiro arco)

〈Nome do nó destino do primeiro arco)

〈Primeira linha da matriz CP

〈Segunda linha da matriz CP

$\langle$-ésima linha da matriz CP

〈Nome do nó origem do segundo arco)

〈Nome do nó destino do segundo arco)

〈Primeira linha da matriz CP

〈Segunda linha da matriz CP

$\langle$ n-ésima linha da matriz CP $\rangle$

etc.

〈eventos〉 e 〈evidências〉 são utilizados para se especificar a consulta à rede, onde 〈eventos〉 é uma lista de vértices, separados por vírgulas e sem espaços em branco, cuja probabilidade conjunta será calculada, e 〈evidências〉 é uma lista de vértices, também separados por vírgulas e sem espaços em branco, que serão assumidos como verdadeiros ou falsos, usando-se a convenção que, para especificar uma evidência como falsa, prefixa-se seu nome com o símbolo '-'.

Por exemplo, a chamada

bayes RBx X3 X2, $-\mathrm{X} 5$

executa o programa bayes usando a rede $\mathrm{RBx}$, armazenada nos arquivos $\mathrm{RBx}$.nod $\mathrm{e}$ $\mathrm{RBx}$. Ink, e fazendo a consulta $p(\mathrm{X} 3 \mid \mathrm{X} 2, \neg \mathrm{X} 5)$. 


\subsubsection{Implementação do Interpretador para a Programação em Lógica DSFH}

O programa interpretador do formalismo da programação em lógica DSFH foi desenvolvido especialmente para [4], com ligeiras adaptações para seu uso com o sistema SWI Prolog e para o uso do compartilhamento de conhecimento.

\section{Documentação do Programa}

O interpretador da programação em lógica DSFH considera consultas da forma:

Ib (G, D): o grau de crença da consulta G é pelo menos D; e

ub (G, D): o grau de crença da consulta G é no máximo D.

Dessa forma, [1b(G,D), ub(G,D)] é o intervalo de crença calculado para a consulta G.

$\mathrm{O}$ interpretador considera programas similares aos programas escritos em Prolog, com as seguintes alterações:

- uso do operador "neg" para calcular a negação de um predicado;

- uso do operador "\&" para especificar a conjunção de predicados (substituindo o operador ",", usual na linguagem Prolog); e

- uso do operador "compartilha" para especificar, nos programas, que uma informação deve ser obtida através do compartilhamento de conhecimento.

\section{Uso do Programa}

Instruções para uso do interpretador para a programaçào em lógica DSFH:

1. inicie a operação do meta-interpretador SWI-Prolog;

2. consulte um programa chamado "dsfh.pl" (adaptação do programa "ebel.pl", desenvolvido para [4]);

3. carregue os programas a serem executados, usando o comando "load_file( $($ nome $\rangle)$ " que acessa os arquivos $\langle$ nome $\rangle$.obj e $\langle$ nome $\rangle$.bel, contendo, respectivamente, a estrutura lógica do programa e os intervalos de crença para as informações atômicas.

4. faça as consultas:

$\mathrm{ub}(\mathrm{Q}, \mathrm{S}) . \rightarrow$ o grau de crença da consulta $G$ é no máximo $\mathrm{D}$

It $(Q, S)$. $\rightarrow$ o grau de crença da consulta $G$ é pelo menos $D$ 


\subsection{Implementação da Arquitetura}

Para a "simulação" de um ambiente distribuído, consideramos cada sistema como um processo, na plataforma UNIX, independente dos demais. Para comunicação, utilizamos a geração de processos do sistema UNIX, através do comando system da linguagem C. Como não é possível fazer comunicação entre os processos, o resultado fornecido pelo servidor é gravado em um arquivo que será lido pelo cliente.

Como usamos um sistema baseado em programação em lógica, na linguagem Prolog, e um sistema probabilístico implementado na linguagem $\mathrm{C}$, as formas com que os sistemas acessam informações externas são distintas. A seguir, mostramos como cada sistema consulta essas informações.

\subsubsection{Implementação da Comunicação entre Componentes}

\section{Redes Bayesianas}

A função principal do interpretador para as redes bayesianas está exibida no código abaixo. Os comandos internos ao "do...while" serão repetidos enquanto for possível obter uma solução alternativa pelo compartilhamento de conhecimento. Para o cálculo da probabilidade condicional, usa-se a lista dos eventos relevantes, armazenada na variável lisEventos, e a lista de evidências consideradas, armazenada na variável lisEvidencias. A rede bayesiana é acessada através da variảvel NodeList.

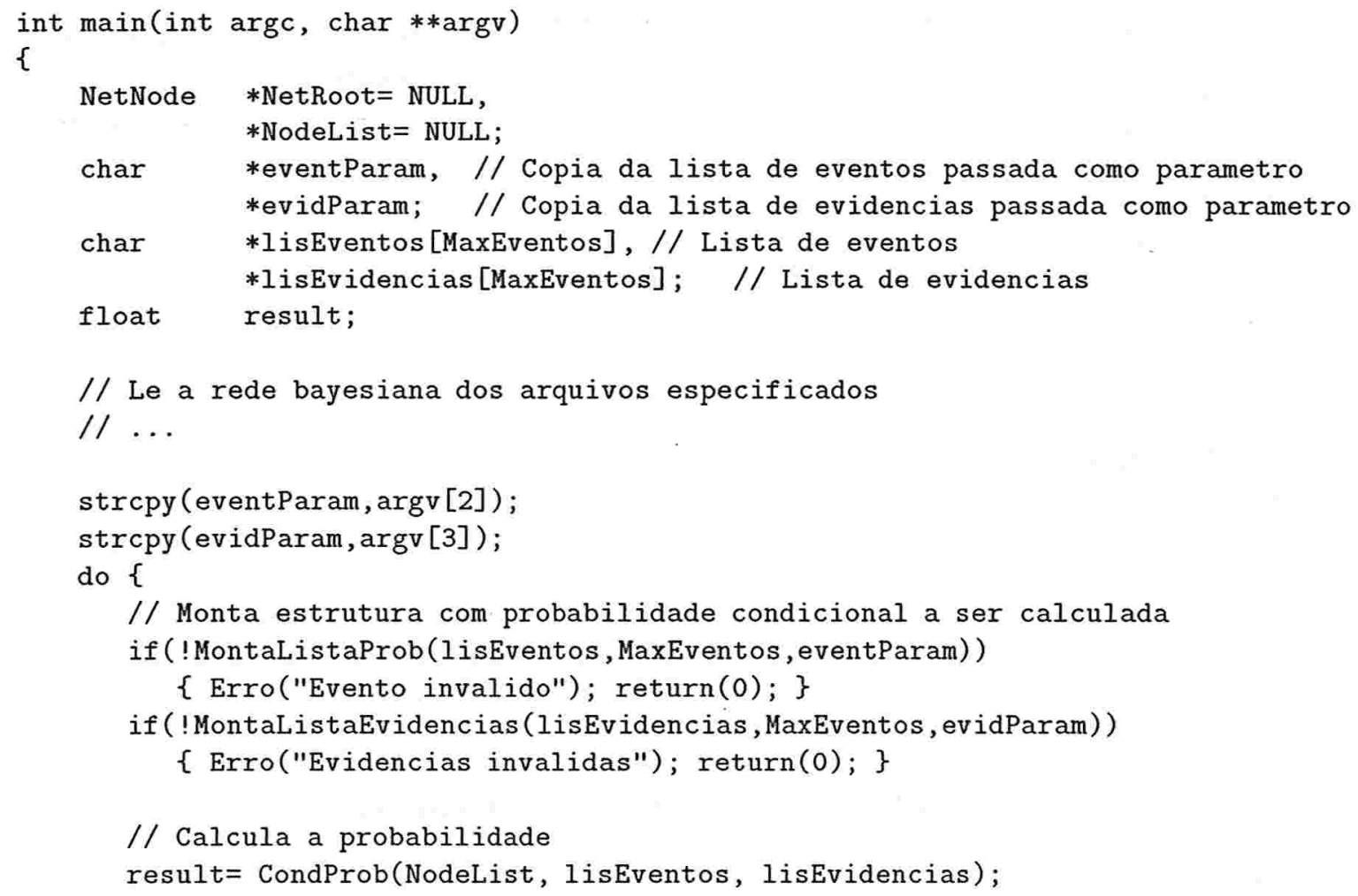




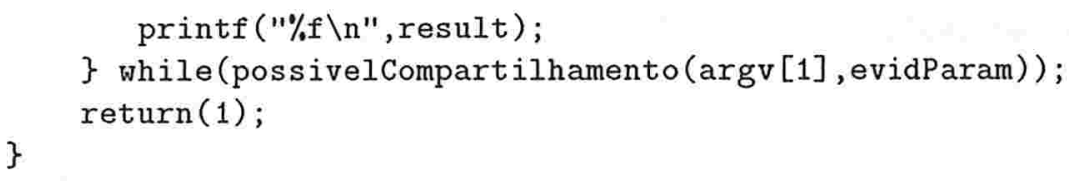

Para testar se é possível obter uma outra solução com o compartilhamento de conhecimento, usamos a função possivelCompartilhamento, que recebe como parâmetros o nome da rede bayesiana e a lista de evidências digitada pelo usuário. Essa função procura por um arquivo que deverá conter as informações sobre como buscar as informações externas.

O formato do arquivo com as informações para o compartilhamento de conhecimento para a rede $\mathrm{RBx}$, chamado de $\mathrm{RBx}$. ext, está mostrado abaixo:

$\mathrm{X} 3$

b redes/RBy Y1 Y3> RBx.ksval

0.8

Na primeira linha especificamos o nome do vértice que poderá ser associado com uma evidência a ser definida pelo compartilhamento de conhecimento. Na segunda, a linha de comando que deverá ser executada para ativar o sistema servidor, que terá sua saída redirecionada para o arquivo chamado $\mathrm{RBx} . \mathrm{ksval}$. Na última linha incluímos um valor que será usado como referência para a adoção ou não do vértice especificado como uma evidência.

A seguir, listamos a função possivelCompartilhamento, responsável pela tentativa de obter informações de outros sistemas. A função procura pelo arquivo ". ext" referente à rede sendo utilizada e determina se o evento especificado pode ser utilizado como uma evidência. Se for possível, será executado o comando definido no arquivo, e o valor obtido como resposta será comparado com o valor de referência especificado.

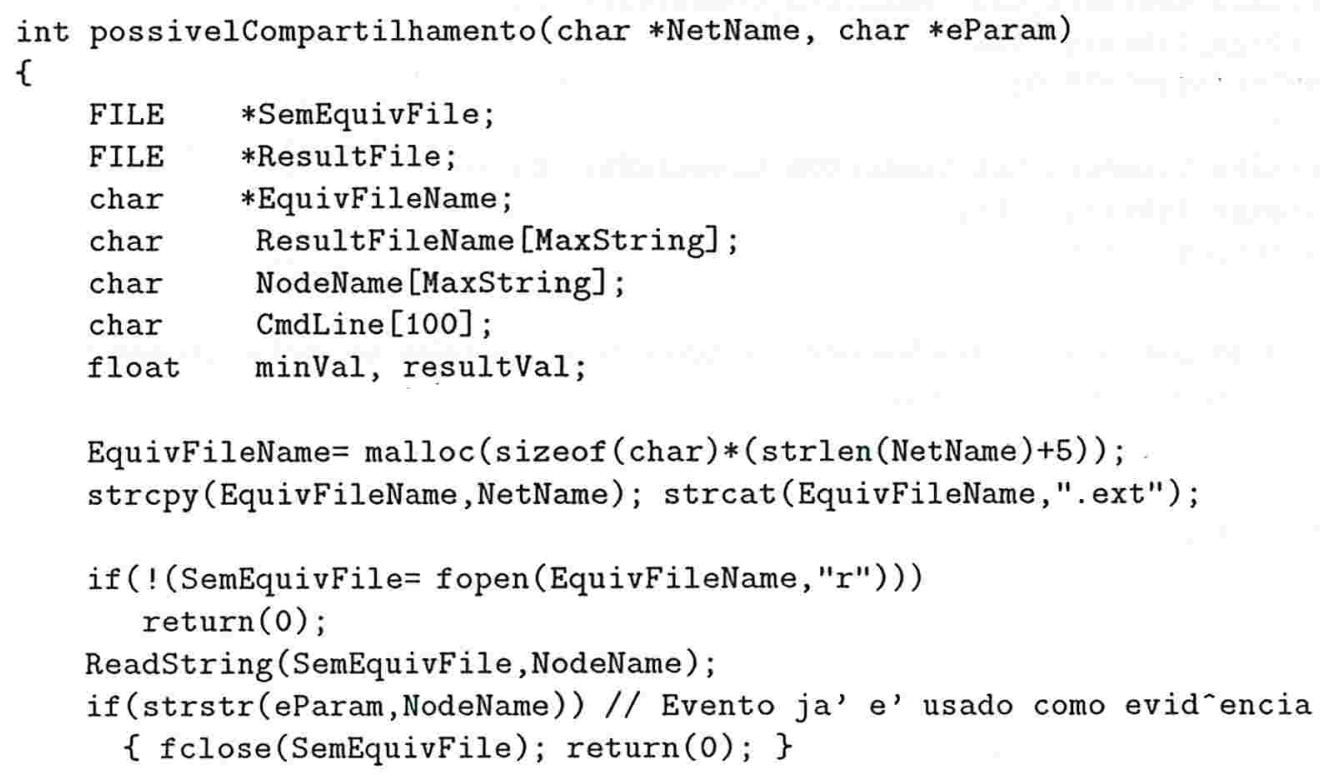




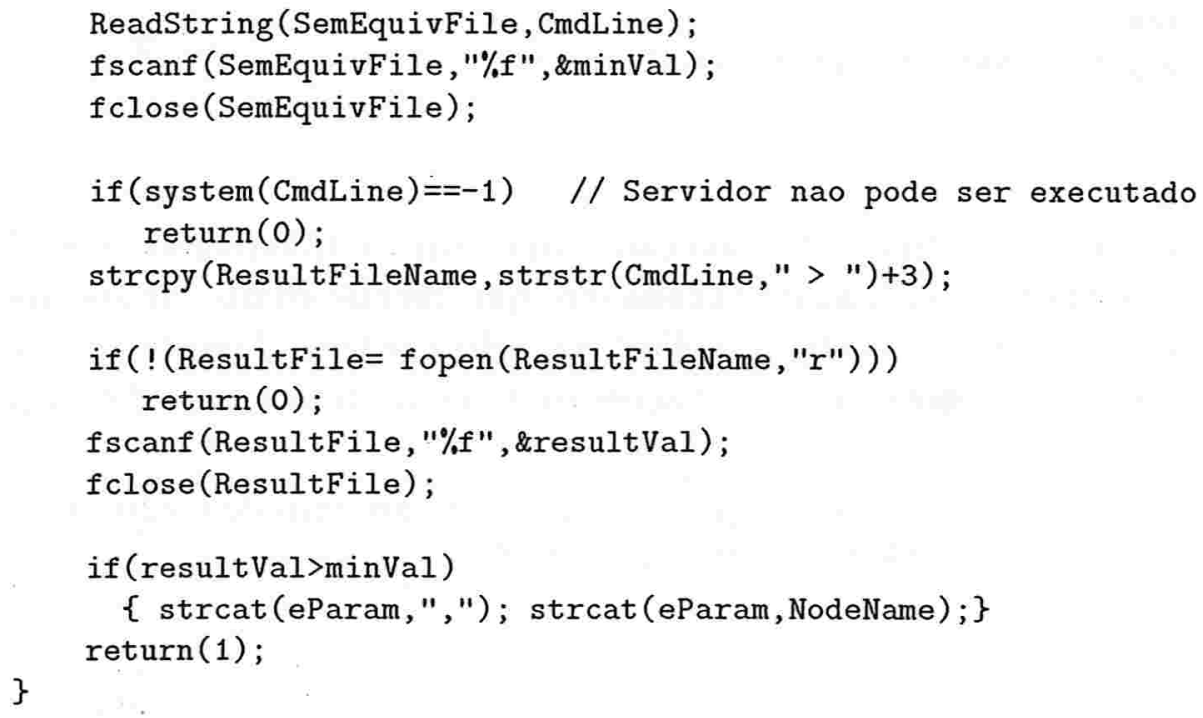

\section{Programação em Lógica DSFH}

Para fazer com que um programa em lógica DSFH consulte informações externas, foi preciso definir um operador para que o meta-interpretador do programa busque pela informação. Por isso, foi definido o operador compartilha que especifica:

- que biblioteca externa deve ser utilizada;

- que consultas correspondem aos extremos do intervalo buscado.

O código a seguir apresenta a parte do meta-interpretador que é responsável pelo tratamento do novo operador e manipulação do grau de crença retornado.

1b_ground (compartilha bounds (A, Lib, ConsultLB, ConsultUB), D) :load_foreign_library(Lib), libConsult (ConsultLB, D).

ub_ground (compartilha bounds (A, Lib, ConsultUB, ConsultUB), D) :load_foreign_library(Lib), libConsult (ConsultUB,D).

Os seguintes predicados são utilizados para se fazer uma consulta ao meta interpretador através de um comando no sistema Unix:

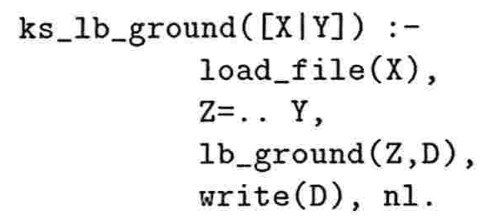




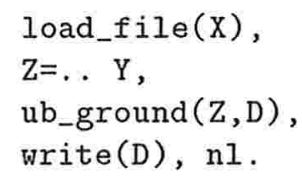

Por exemplo, para se consultar o extremo inferor do intervalode crença de s(a), cláusula definida no programa s1.pl, executamos

\section{dsfh ks_ub_ground s1 s a}

Para tornar possível a execução do SWI-Prolog de tal forma, é preciso embarcar o interpretador em um programa em C (com a utilização do programa plld, que acompanha o SWI-Prolog). O seguinte código em C, utilizado no programa dsfh.c, especifica o segundo parâmetro utilizado na linha de comando como o nome do predicado a ser executado pelo Prolog. Em seguida, é montada uma lista com os três parâmetros seguintes, de tal forma que o primeiro elemento seja o nome do programa que deverá ser interpretado, o segundo seja o predicado a ser consultado e o terceiro, o parâmetro utilizado com o predicado.

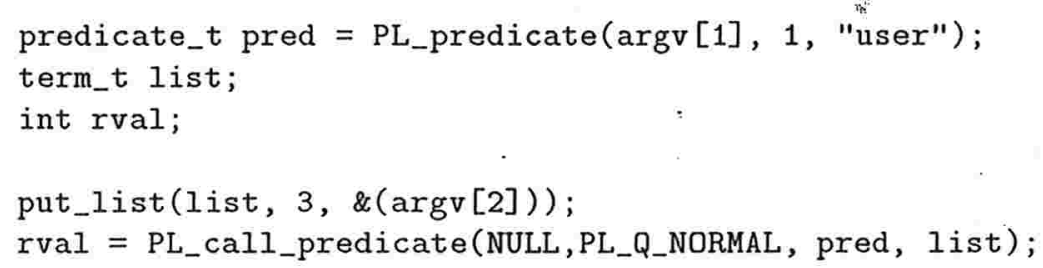




\section{Apêndice B}

Devido à sua importância para a pesquisa apresentada neste trabalho, incluímos, a seguir, uma reprodução do artigo [6], apresentado na Conferência internacional de Processamento e Tratamento de Incerteza, realizado em Madri nos dias 3-7 de julho de 2000. 


\section{Knowledge Sharing Between a Probabilistic Logic and Bayesian Belief Networks}

\author{
Flávio S. Corrêa da Silva*. \\ Instituto de Matemática e Estatística \\ Universidade de São Paulo, São Paulo, Brazil \\ fcsoime.usp.br \\ Jaume Agustí \\ Institut d'Investigació en Intel.ligencia Artificial \\ Campus UAB 08193 Bellaterra, Barcelona, España \\ agustioiia.csic.es.
}

\begin{abstract}
Knowledge sharing and reuse has been considered an important issue for cost-effective use of knowledge-based systems, especially after the development and popularisation of object-based techhologies and Internet-based decentralised computing. Up until now, the majority of research tackling this issue has been founded on the assumption that there can be a common domain description - a shared ontology - which suits everyone with an interest in the knowledge. Unfortunately, getting an agreed ontology for a collection of systems can be a difficult problem and, even when this problem can be solved, it may not be enough for effective knowledge sharing, since the way we represent knowledge is intimately linked to theinferences we expect to perform with it. A nice example of this situation can befound in systems for reasoning under uncertainty, where even if we do have a shared ontology for the problem being solved we must still establish semantic links between the inferences performed within each system to actually have knowledge being shared and reused.

In the present paper we study a significant instance of this problem. We introduce a simple yet effective logical system for intervalbased probabilisticreasoning, then discuss the difficulties to have this system being able to consult bayesian belief networks to complete its own inferences, and how these difficulties can be remedied. Finally, some simple motivating examples are introduced to suggest "practical" applications for this knowledge sharing scenario.
\end{abstract}

Keywords: Knowledge sharing, Bayesian belief network, probabilistic logic.

\footnotetext{
"Partially sponsored by FAPESP, Grant no.93/0603-01

'Partially sponsored by CAPES PhD scholarship
}

\author{
Roberto Cássio de Araújo ${ }^{\dagger}$ \\ Instituto de Matemática e Estatística \\ Universidade de São Paulo, São Paulo, Brazil \\ bob@ime.usp.br \\ Ana Cristina V. de Melo \\ Instituto de Matemática e Estatística \\ Universidade de São Paulo, São Paulo, Brazil \\ acvmQime:usp.br
}

\section{Introduction}

Mainstream research in knowledge sharing among knowledge-based systems concentrates on mapping different notations to describe problems and their solving procedures, while making the assumption that the inference mechanisms employed in these systems are compatible $[21,12,10,16,19,23]$.

There is good reason for making this assumption because it is difficult without it to guarantee that the meaning of knowledge expressed in one system is preserved when used by another system. However, this is a rather strong assumption to be made when one considers the (re)use of previously existing systems for knowledge sharing.

Alternatively, we have considered within the research project DECaFf-KB - Distributed Environment for Cooperation Among Formalisms for Knowledge-based Systems - the situation in which the relationships between inferences performed in different systems are not evident (or even do not exist at all) $[7,6]$. Consider for example two systems for uncertain reasoning: the first one prepared to compute probability intervals for first-order sentences via a resolution-based inference procedure, and the second one a bayesian belief network that can compute the probability of a statement given an arbitrary set of assumptions. Both systems share a lot of semantic information, however the differences between the internal procedures to construct answers to queries create difficulties to establish the connections between answers from each system.

We suggest that in order to establish proper connection between knowledge and information conveyed by such systems an analysis must be carried through, based on three levels of understanding of the connection:

1. conceptual level: in which the semantic links between information and knowledge taken into account within each system are established;

2. architectural level: in which the actual proce- 
dures to implement these links are designed - e.g. via a knowledge broker; and

3. implementation level: in which specific strategies to implement the procedures designed above are developed.

To make this article self-contained, in section 2 we recall some basic definitions of probability theory that will be needed in the following sections. In order to make this discussion more direct and effective, we specialise it to particular systems: in section 3 we introduce a simple logical system to calculate probability bounds for first-order statements based on a resolution-style inference procedure, and in section 4 we present a simplified model for bayesian belief networks, that are expected nevertheless to contain the main features and properties of those formalisms. In section 5 we detail the three-level-based analysis proposed above, and illustrate how the first two levels characterise a solution for knowledge sharing between the logical system and the bayesian belief network. In sections 6 and 7 we present two illustrative examples, to give a flavour of how this specific knowledge sharing setting can be used for practical applications. Fínally, in section 8 we present some final remarks and suggestions for future work.

\section{Preliminary Definitions}

Given a finite set $D$, an algebra $\chi_{D}$ on $D$ is a set of subsets of $D$ such that (i) $D \in \chi_{D}$; (ii) $A \in \chi_{D} \Rightarrow$ $\neg A \in \chi_{D}$; (iii) $A, B \in \chi_{D} \Rightarrow A \cup B \in \chi_{D}$.

A subset of $D$ is called an event on $D$. Events belonging to $\chi_{D}$ are called measurable events.

A probability measure on $\chi_{D}$ is a function $\mathcal{P}: \chi_{D} \rightarrow$ $[0,1]$ such that (i) $\mathcal{P}(D)=1$ (total probability); (ii) $A \cap B=\{\} \Rightarrow \mathcal{P}(A \cup B)=\mathcal{P}(A)+\mathcal{P}(B)$ (finite additivity).

Given two measurable events $A, B \in \chi_{D}$, the conditional probability $\mathcal{P}(A \mid B)$ is defined as:

$$
\mathcal{P}(\dot{A} \mid B)= \begin{cases}\frac{\mathcal{P}(A \cap B)}{\mathcal{P}(B)}, & \mathcal{P}(B) \neq 0 \\ 0, & \mathcal{P}(B)=0\end{cases}
$$

Two measurable events $A, B$ are called independent iff $\mathcal{P}(A \mid B)=\mathcal{P}(A)$ which, as a corollary, gives that $\mathcal{P}(A \cap B)=\mathcal{P}(A) \times \mathcal{P}(B)$.

The set $D$ can be partitioned into $m$ subsets $D_{1}, \ldots, D_{m}$ such that (i) $D_{i} \cap D_{j}=\{\}, i, j=1, \ldots, m, i \neq j$; and (ii) $D=\bigcup_{1}^{m} D_{i}$.

We can have independent probability measures $\mathcal{P}_{\boldsymbol{i}}$ for algebras $\chi_{D i}$ (probability measures for two algebras $\chi_{1}$ and $\chi_{2}$ are independent iff each event $X_{i} \in \chi_{1}$ is independent of every event $Y_{j} \in \chi_{2}$ and vice-versa) for each set $D_{i}$. If we assume that all events in each
$\chi_{D i}$ are pairwise independent, we can extend measures to cartesian products of the sets $D_{i}$ of a partition of $D$ : the cartesian product of a collection of bases of algebras of elements $D_{1}, \ldots, D_{m}$ of a partition of $D$ is the basis $\vec{\chi}^{\prime}$ of an algebra of the cartesian product of the sets $D_{1}, \ldots, D_{m}$, and the measure $\overrightarrow{\mathcal{P}}: \vec{\chi} \rightarrow[0,1]$ on the corresponding algebra $\vec{\chi}$ is defined as:

- $\overrightarrow{\mathcal{P}}(\vec{A})=\prod_{1}^{m} \mathcal{P}_{\boldsymbol{i}}\left(A_{i}\right)$.

where $\vec{A}=\left[A_{1}, \ldots, A_{m}\right], A_{i} \in \chi_{D_{i}}, \mathcal{P}_{i}$ is the probability measure defined on $\chi_{D i}$.

Probability measures can be extended to nonmeasurable events, i.e. sets $A_{j} \in 2^{D} \backslash \chi_{D}$. Given $D, \chi_{D}$ and $\mathcal{P}$, we define the inner and outer extensions to $\mathcal{P}$ $\left(\mathcal{P}_{*}\right.$ and $\mathcal{P}^{*}$, respectively) as [8]:

$$
\text { - } \begin{aligned}
\mathcal{P}_{*}, \mathcal{P}^{*}: 2^{D} & \rightarrow[0,1] \\
\mathcal{P}_{*}(A) & =\sup \left\{\mathcal{P}(X): X \subseteq A, X \in \chi_{D}\right\} \\
& =\mathcal{P}\left(\bigcup X: X \subseteq A, X \in \chi_{D}^{\prime}\right) \\
\mathcal{P}^{*}(A) & =\inf \left\{\mathcal{P}(X): A \subseteq X, X \in \chi_{D}\right\} \\
& =\mathcal{P}\left(\bigcup X: X \cap A \neq\{\}, X \in \chi_{D}^{\prime}\right)
\end{aligned}
$$

Inner and outer measures can be extended to cartesian products of a partition of $D$. Given a collection $D_{1}, \ldots, D_{m}$ of elements of a partition of $D$, and given also the algebras $\chi_{D_{i}}$ and probability measures $\mathcal{P}_{i}$ of each $D_{i}, i=1, \ldots, m$, we have:

$$
\text { - } \begin{aligned}
\mathcal{P}_{m *}, \mathcal{P}_{m}^{*}: & 2^{D_{1} \times \ldots \times D_{m}} \rightarrow[0,1] \\
\mathcal{P}_{m *}(A) & =\sup \left\{\mathcal{P}_{m}(X): X \subseteq A, X \in \vec{\chi}\right\} \\
& =\mathcal{P}_{m}\left(\bigcup X: X \subseteq A, X \in \vec{\chi}^{\prime}\right) \\
\mathcal{P}_{m}^{*}(A) & =\inf \left\{\mathcal{P}_{m}(X): A \subseteq X, X \in \vec{\chi}\right\} \\
& =\mathcal{P}_{m}\left(\bigcup X: X \cap A \neq\{\}, X \in \vec{\chi}^{\prime}\right)
\end{aligned}
$$

The measures $\mathcal{P}_{m *}$ and $\mathcal{P}_{m}^{*}$ can be regarded as approximations from below and from above to the probabilities of non-measurable events: if we could evaluate the probability $\mathcal{P}_{m}(A)$, then we would have that $\mathcal{P}_{m *}(A) \leq \mathcal{P}_{m}(A) \leq \mathcal{P}_{m}^{*}(A)$. Indeed, for measurable events we have that $\mathcal{P}_{m *}(A)=\mathcal{P}_{m}(A)=\mathcal{P}_{m}^{*}(A)$.

\section{A Simple System for Probabilistic Reasoning}

In this section we introduce a simple logical system for probabilistic reasoning, that employs a resolution-style SLDNF deductive system for clausal theories and can be implemented as a pure PROLOG meta-interpreter $[1,20]$. This system is a simplified version of what was presented in [5] and implemented in [3].

The system we present here allows the deduction of degrees of belief apportioned by a rational agent to statements represented as normal clauses and queries. These degrees of belief are represented as probabilities on possible worlds, that can be loosely understood as hypothetical scenarios capable of accomodating the problem being solved, following the foundations for well-known formalisms like Incidence Calculus [2, 4], 
Probabilistic Logic [14] and the Dempster-Shafer Theory of Evidence $[18,9]$.

Following [11, 22, 3], let us consider the special class of clausal theories called function-free normal programs under restrictions of call consistency, strictness with respect to queries, and allowedness, having as inference procedure the $S L D N F$ Resolution Rule, that is known to be sound and complete with respect to the model of the Clark's completion of programs in the language.

This defines a rich subset of first-order logic with a computationally efficient inference procedure and a formally specified declarative semantics. A program $\mathbf{P}$ is a theory consisting of a collection of normal clauses $H:-Q_{1}, \ldots, Q_{n}$ and unit clauses $H_{i}$, and proofs will be triggered by a query $Q_{1}^{\prime}, \ldots, Q_{m}^{\prime}$, where $H, H_{i}$ are atomic predicates and $Q_{j}, Q_{k}^{\prime}$ are atomic predicates or negations of atomic predicates.

A set of possible worlds is a collection of worlds (or states, or interpretations), each of them assigning different truth-values to the formulae in our language. Intuitively, a possible world should be viewed as a conceivable hypothetical scenario upon which we can construct our reasoning.

Given a program $\mathbf{P}$ and a set of possible worlds $\Omega=$ $\left\{\omega_{1}, \ldots\right\}$, a rigid formula is a formula which is always assigned the same truth-value in all possible worlds.

We assume in our language that, given a program $\mathbf{P}$, each possible world $\omega_{i}$ can assign a different truthvalue to the set of unit clauses in $\mathbf{P}$. We assume that the normal clauses occurring in $\mathbf{P}$ are rigid.

The degree of belief attached to a query is the probability of selecting a possible world at random and the query being true in that world. One possible way of evaluating the degree of belief in a query could then be to trigger repeatedly a program for each $\omega_{i} \in \Omega$, to identify the subset of $\Omega$ in which the query is true, and then, based on a probability measure defined for an algebra on $\Omega$, to evaluate the probability of the query being true (or at least the inner and outer approximations of it).

This procedure becomes computationally intractable as the size of $\Omega$ grows. Alternatively, following [13], approximate solutions can be obtained for the inner and outer approximations for the probability of a query $\psi=Q_{1}^{\prime}, \ldots, Q_{m}^{\prime}$ (henceforth queries will be denoted with greek letters), denoted as $\hat{\mathcal{P}}_{*}(\psi)$ and $\hat{\mathcal{P}}^{*}(\psi)$ respectively:

$$
\begin{aligned}
\text { H }:-Q \Rightarrow \quad \hat{\mathcal{P}}_{*}(\mathrm{H})=\hat{\mathcal{P}}_{*}(\mathrm{Q}) \\
\hat{\mathcal{P}}^{*}(\mathrm{H})=\hat{\mathcal{P}}^{*}(\mathrm{Q})
\end{aligned}
$$

$$
\begin{aligned}
& \text { H. }:-\psi \Rightarrow \hat{\mathcal{P}}_{*}(\mathrm{H})=\max \left\{\hat{\mathcal{P}}_{*}(\psi), \hat{\mathcal{P}}_{*}(\varphi)\right\} \\
& \text { H: }:-\varphi \quad \hat{\mathcal{P}}^{*}(\mathrm{H})=\min \left\{1, \hat{\mathcal{P}}^{*}(\psi)+\hat{\mathcal{P}}^{*}(\varphi)\right\} \\
& \mathrm{H}:-\backslash+\mathrm{Q} \Rightarrow \hat{\mathcal{P}}_{*}(\mathrm{H})=1-\hat{\mathcal{P}}^{*}(\mathrm{Q}) \\
& \hat{\mathcal{P}}^{*}(\mathrm{H})=1-\hat{\mathcal{P}}_{*}(\mathrm{Q})
\end{aligned}
$$

In a program $P$, the proof of a query $Q=Q_{1}^{\prime}, \ldots, Q_{m}^{\prime}$ is expressed by the construction of an interval $\left[\hat{\mathcal{P}}_{*}(Q), \hat{\mathcal{P}}^{*}(Q)\right]$ where $\hat{\mathcal{P}}_{*}(Q)$ and $\hat{\mathcal{P}}^{*}(Q)$ are calculated from the intervals associated to $Q_{1}^{\prime}, \ldots, Q_{m}^{\prime}$. If $Q_{i}^{\prime}$ is a unit clause, the values $\hat{\mathcal{P}}_{*}\left(Q_{i}^{\prime}\right)$ and $\hat{\mathcal{P}}^{*}\left(Q_{i}^{\prime}\right)$ are explicitly given (if they're not given, they're assumed to be 0.0 ). If $Q_{i}^{\prime}$ is a normal clause, its interval is recursively calculated using the clauses included in the program.

Example 3.1 For example, considering the following program:

$$
\begin{aligned}
& p(x) \quad:-q(x), 1+r(x) \\
& q(X) \quad-s(x), u(x)
\end{aligned}
$$

And the following intervals associated to unit clauses:

$$
\begin{array}{ll}
r(b)=[0.0 ; 0.0] & s(c)=[0.6,0.7] \\
r(c)=[0.8,0.9] & u(a)=[0.3,0.4] \\
s(a)=[0.1,0.3] & u(b)=[0.2,0.5] \\
s(b)=[0.2,0.4] & u(c)=[0.4,0.7]
\end{array}
$$

The proof of $\mathrm{p}(\mathrm{X})$ is obtained by the combination of the proofs of $\mathrm{p}(\mathrm{a}), \mathrm{p}(\mathrm{b})$ and $\mathrm{p}(\mathrm{c})$ (the values to which $\mathrm{X}$ unifies). The interval associated to $\mathrm{p}(\mathrm{c})$ is the interval associated to the query $\mathrm{s}(\mathrm{c}), \mathrm{u}(\mathrm{c}), 1+\mathrm{r}(\mathrm{c})$. Using the rules above, this interval is bound to $[\max \{0,(0.6+$ $0.4-1)+0.1-1\}, \min \{0.7,0.7,0.2\}]=[0,0.2]$. The proofs of $\mathrm{p}(\mathrm{a})$ and $\mathrm{p}(\mathrm{b})$ are obtained in the same way, with corresponding intervals set to $[0,0.3]$ and $[0,0.4]$. Notice that the interval associated to $\mathrm{r}(\mathrm{a})$ is $[0,0]$, since there's no unit clause defining it. To complete the proof of $\mathrm{p}(\mathrm{X})$, the resulting intervals, $[0,0.3]$, $[0,0.4]$ and $[0,0.2]$, are combined and the interval for the belief on $\mathrm{p}(\mathrm{X})$ is $[0,0.9]$. The proof tree and corresponding interval for the query $\mathrm{p}(\mathrm{X})$ are as presented in figure 1.

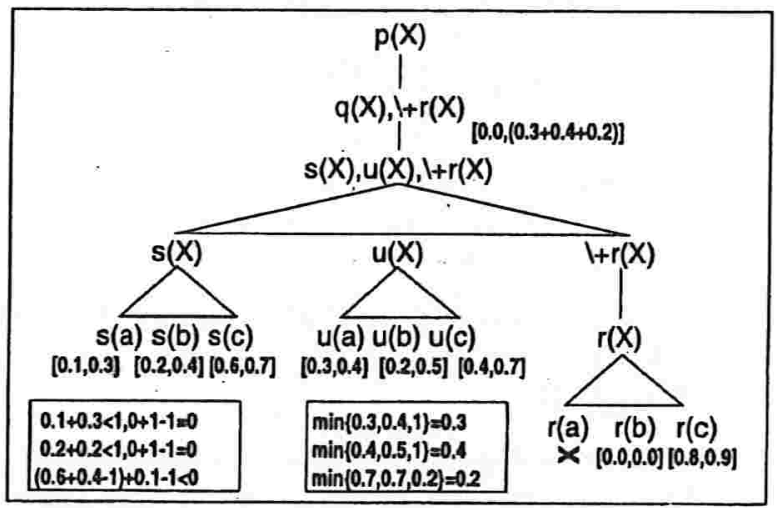

Figure 1: Proof Tree and Interval for $p(x)$ 


\section{Bayesian Belief Networks}

A Bayesian belief network is a directed acyclic graph in which nodes stand for propositional variables and an edge from node $V_{i}$ to node $V_{j}$ means that the beliefs about truth values assigned to the variable represented by the node $V_{i}$ influences the ones of the variable represented by the node $V_{j}$.

For abbreviation, we will use $v_{i}$ to denote the proposition $V_{i}=$ true, and $\neg v_{i}$ to denote the proposition $V_{i}=$ false. Given a set $V$ of variables, a conjunction $c_{V}$ of assignments to these variables is called a configuration of $V$. More formally, following [24], a bayesian belief network is a tuple $B=(G, P)$ where:

- $G=(V G, A G)$ is an acyclic digraph with nodes $V G=\left\{V_{1}, \ldots, V_{n}\right\}, n \geq 1$, and edges $A G$;

- $P=\left\{p_{V_{i}} \mid V_{i} \in V G\right\}$ is a set of real-valued nonnegative functions

$$
p_{V_{i}}:\left\{C_{V_{i}}\right\} \times\left\{C_{\rho_{G}\left(V_{i}\right)}\right\} \longrightarrow[0,1]
$$

called (conditional) probability assessment functions, such that for each configuration $c_{\rho G}\left(V_{i}\right)$ of the set $\rho_{G}\left(V_{i}\right)$ of (immediate) predecessors of node $V_{i}$ in $G$, we have that $p_{V_{i}}\left(\neg v_{i} \mid c_{\rho_{G}\left(V_{i}\right)}\right)=$ $1-p_{V_{i}}\left(v_{i} \mid c_{\rho_{G}\left(V_{i}\right)}\right)$.

The main application of belief networks is in representation and manipulation of knowledge via the calculation of how evidences support hypotheses, i.e., what is the probability of a hypothesis being true considering a specified collection of evidences. This is done via probability propagation along the network via the definition of conditional probability (cf. section 2) and specific values for probabilities given in the nodes and edges of the network.

Example 4.1 The belief network shown in figure 2, that will be called PoorBN, represents a simple way to diagnose whether a person is poor based on their salary and household status.

Many interesting algorithms for efficient propagation of probabilities along belief networks have been developed. The interested reader is addressed e.g. to [15] for a compilation of the major results in this field of research.

\section{An Architecture for Knowledge Sharing}

If we compare the formalisms for uncertain reasoning presented in the previous sections we observe they contain structural similarities, as presented in table 1 .

Both systems were created to propagate their (probability-based) representations of degrees of belief along pieces of knowledge, so it is not surprising that they contain operators to perform conceptually equivalent tasks, as indicated by their structural similarities. However, the procedures employed within each
There are four variables represented in the network: $V_{1}$ : person is poor;

$V_{2}$ : person rents a house;

$V_{3}$ : person owns a house;

$V_{4}$ : person has low salary.

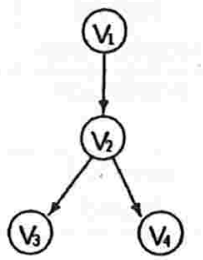

$$
\begin{aligned}
& p\left(v_{1}\right)=0.4 \\
& p\left(v_{2} \mid v_{1}\right)=0.3 \\
& p\left(v_{2} \mid \neg v_{1}\right)=0.8 \\
& p\left(v_{3} \mid v_{2}\right)=0.6 \\
& p\left(v_{3} \mid \neg v_{2}\right)=0.5 \\
& p\left(v_{4} \mid v_{2}\right)=0.1 \\
& p\left(v_{4} \mid \neg v_{2}\right)=0.6
\end{aligned}
$$

Considering the topology and the probabilities of the network, and observing that two disconnected variables are (conditionally) independent, it is possible to calculate every conditional probability involving these four variables. For example:

$$
\begin{aligned}
& p\left(v_{2}\right)=p\left(v_{2} \mid v_{1}\right) p\left(v_{1}\right)+p\left(v_{2} \mid \neg v_{1}\right) p\left(\neg v_{1}\right)=0.6 \\
& \text { - } p\left(\neg v_{4}\right)=p\left(\neg v_{4} \mid v_{2}\right) p\left(v_{2}\right)+p\left(\neg v_{4} \mid \neg v_{2}\right) p\left(\neg v_{2}\right)=0.7 \\
& \text { - } p\left(v_{1} \mid v_{4}\right)=\frac{p\left(v_{1}\right) p\left(v_{4} \mid v_{1}\right)}{p\left(v_{4}\right)}= \\
& \quad=\frac{0.4 \times\left(p\left(v_{4} \mid v_{2}\right) p\left(v_{2} \mid v_{1}\right)+p\left(v_{4} \mid \neg v_{2}\right) p\left(\neg v_{2} \mid v_{1}\right)\right)}{0.3}=0.64 \\
& \text { - } p\left(v_{1}, \neg v_{2} \mid v_{4}\right)=\frac{p\left(v_{1}, \neg v_{2}, v_{4}\right)}{p\left(v_{4}\right)}= \\
&=\frac{p\left(v_{4} \mid \neg v_{2}\right) p\left(\neg v_{2} \mid v_{1}\right) p\left(v_{1}\right)}{p\left(v_{4}\right)}=0.56
\end{aligned}
$$

Figure 2: The belief network PoorBN

Table 1: Structural similarities between lógical system and belief network for uncertain reasoning.

\begin{tabular}{|c|c|c|}
\hline & $\begin{array}{c}\text { Logical } \\
\text { System }\end{array}$ & $\begin{array}{c}\text { Belief } \\
\text { Network }\end{array}$ \\
\hline \hline $\begin{array}{c}\text { atomic } \\
\text { information }\end{array}$ & $\begin{array}{c}\text { predicates and } \\
\text { ground terms }\end{array}$ & boolean variables \\
\hline relations & normal clauses & directed graph edges \\
\hline $\begin{array}{c}\text { degrees } \\
\text { of belief }\end{array}$ & $\begin{array}{c}\text { probability } \\
\text { intervals }\end{array}$ & $\begin{array}{c}\text { probability } \\
\text { values }\end{array}$ \\
\hline $\begin{array}{c}\text { a priori } \\
\text { information }\end{array}$ & $\begin{array}{c}\text { intervals for } \\
\text { unit clauses }\end{array}$ & $\begin{array}{c}\text { probabilities } \\
\text { on the network }\end{array}$ \\
\hline output & $\begin{array}{c}\text { intervals for } \\
\text { queries }\end{array}$ & $\begin{array}{c}\text { probabilities given } \\
\text { evidential assumptions }\end{array}$ \\
\hline
\end{tabular}

system to effectively propagate degrees of belief is very dissimilar, as presented in table 2.

If we look again at example 3.1 , we observe that $r(a)$ and $r(b)$ are indistinguishable, even though we have explicit information about the evaluated degree of belief for $r(b)$ whereas the corresponding evaluation for $r(a)$ is obtained by default given the lack of information about that unit clause.

Let us say we have a bayesian belief network, which 
Table 2: Operational differences between logical system and belief network for uncertain reasoning

\begin{tabular}{|c|c|c|}
\hline & $\begin{array}{c}\text { Logical } \\
\text { System }\end{array}$ & $\begin{array}{c}\text { Belief } \\
\text { Network }\end{array}$ \\
\hline \hline $\begin{array}{c}\text { basis for } \\
\text { propagation }\end{array}$ & $\begin{array}{c}\text { logical } \\
\text { implication }\end{array}$ & $\begin{array}{c}\text { probabilistic } \\
\text { conditioning }\end{array}$ \\
\hline $\begin{array}{c}\text { inference } \\
\text { system }\end{array}$ & resolution & conditioning \\
\hline $\begin{array}{c}\text { representation of } \\
\text { degrees of belief }\end{array}$ & $\begin{array}{c}\text { interval } \\
\text { based }\end{array}$ & $\begin{array}{c}\text { single } \\
\text { valued }\end{array}$ \\
\hline
\end{tabular}

can provide information about the probability interval related to $r(a)$. In this section we are going to present how and under what conditions the connection between queries from the logical system and answers from the belief network can be established.

The connection must be established as a functional transformation from atomic queries from the logical system to specified conditional probabilities in the belief network, and then back from the (single valued) probability estimations from the belief network to the (interval based) probability values in the logical system. The interpretation of queries and answers in each system must be compatible with each other, hence the connection must be established at the semantic level. We call this semantic view of the connection the conceptual level of the knowledge sharing problem (figure 3).

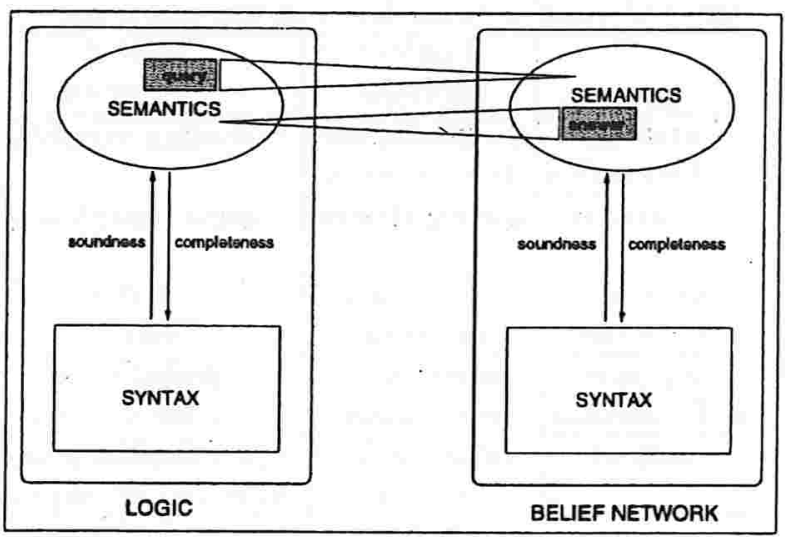

Figure 3: Connection between two KBSs: Conceptual Level

Once we have this connection established, we must provide the systems with an operational counterpart to their query and answer passing procedures. This must be designed at the syntactical level, in order to be liable to be implemented (figure 4), e.g. by means of a brokering system. A broker is a module in this architeture that contains the description of the systems that share knowledge. The task of the broker is to accept queries, format them acordingly and convey them to appropriate auxilary systems based on the de- scriptions of the systems. For a detailed presentation of a brokering system, the reader is referred to [17]. This syntactical view of the connection gives rise to the achitetural level of the knowledge sharing problem.

Finally, the actual implementation of the communication procedures must be designed and made, giving rise to the implementation level of the knowledge sharing problem (figure 5). A more detailed presentation of this level of the knowledge sharing problem will be left for future articles.

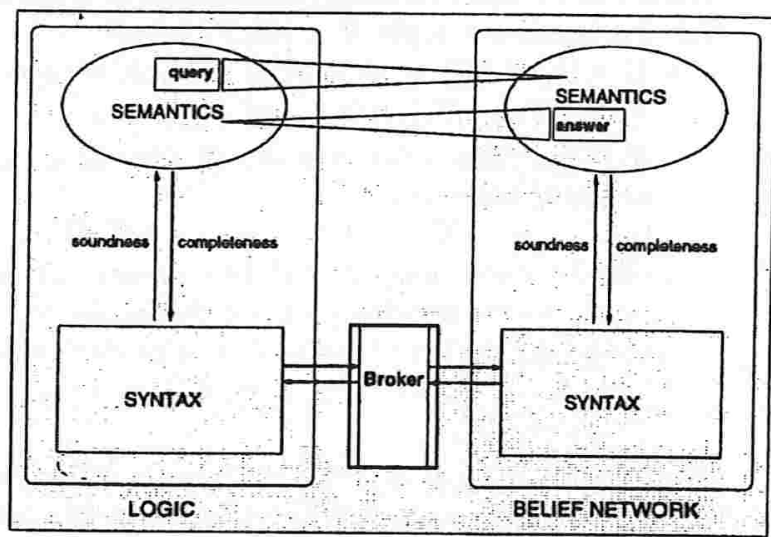

Figure 4: Connection between two KBSs: Architectural Level

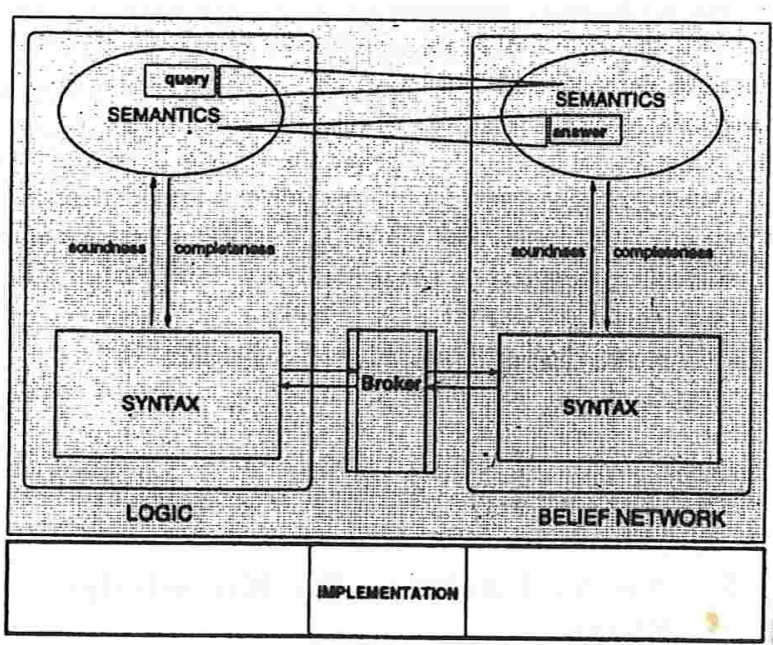

Figure 5: Connection between two KBSs: Implementation Level

The desired probability interval to be associated to $r(a)$ - that is missing in the original program - characterises the inner and outer approximations for the probability of selecting at random a possible world and $r$ (a) being true in that world, i.e. , two nested events belonging to the algebra $\chi_{D_{r(a)}}$, where $D_{r(a)}$ is an appropriate subset of possible worlds "relevant" to $\mathrm{r}(\mathrm{a})$, for which a probability measure is known. Since $r(a)$ 
does not occur in the original program, it is assumed not to be true in any possible world initially employed to interpret the program. As a consequence, if auxiliary information is obtained from a bayesian belief network to evaluate the probability of $r(a)$ it must be associated to a completely fresh subset of possible worlds, not used before to interpret the program.

We must (manually) link $r(a)$ to a pair of events from the belief network $\left(v_{1}, \ldots, v_{m} \mid e_{1}, \ldots, e_{r}\right)$ and $\left(v_{1}, \ldots, v_{m}, v_{m+1}, \ldots, v_{n} \mid e_{1}, \ldots, e_{r}\right)$. The set of possible worlds selected by the evidences $e_{1}, \ldots, e_{r}$ must be disjoint with the set of possible worlds initially used to interpret the program, and the algebra and probability measure based on this set of possible worlds must be independent from the other algebras and measures used in the initial interpretation of the program, otherwise the semantics of the probability intervals generated by the belief network will be corrupted, because of duplicated information generated by the two systems.

Once we link $r(a)$ and the pair of events from the belief network, we extend the set of possible worlds, algebras and probability measures considered initially for the logic program with the set of possible worlds relevant to $e_{1}, \ldots, e_{r}$, and evaluations provenient from the bayesian belief network can be employed within proofs in the logical system as if they belonged to the original program.

In order to clarify how we can use this semantic extension of a logical system with knowledge shared by a belief network, in the following sections we present two illustrative examples. In the first one, we use a belief network to complete a proof generated by a logical program. In the second one, we build a simple logical program that constructs its proofs based solely on information generated by three separate belief networks.

\section{Consulting One Bayesian Belief Network}

Suppose that a university wants to create a knowledge based system to decide whether a student shall receive free lodging in the university student accomodation facilities. The criteria upon which the decision is based considers the following information about the student:

financial situation : whether the student has means to pay for external accomodation;

academic performance : whether the student has good academic records;

medical condition : whether the student medical status can be considered potentially harmful to other students in the lodging. The diagnostic of the medical situation of a student is based on the student's vaccination records and on contagious diseases from which they are diagnosed to suffer.
A simple logical theory to decide whether a student is a good candidate to receive free lodging by the university can be given by:

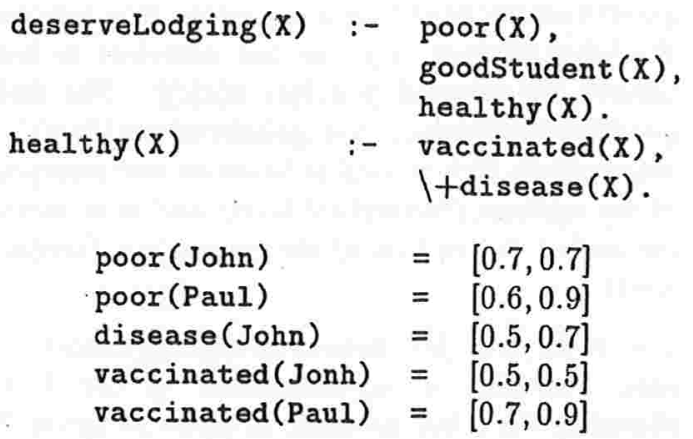

There are no explicit means to calculate the belief on goodStudent $(X)$, which will therefore assumed to be improbable by default. Alternatively, we could "build" the belief interval based on information available in the university students records, using knowledge shared by the belief network given below:

Example 6.1 The belief network in figure 6 , called GoodStudentBN, can be used to decide whether a student is a "good" student based on their academic information: exam results and lecture attendance information.

Description of the variables (nodes) of the network:

A : student is good

B : student goes to every lecture

C : student has good exam results

D : student has good university admission exam results

E : student has good exam results in university courses

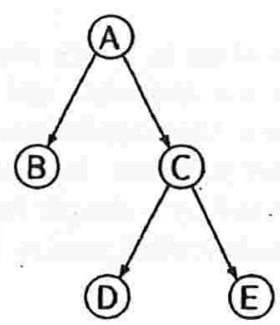

$$
\begin{aligned}
& p(a)=0.5 \\
& p(b \mid a)=0.8 \\
& p(b \mid \neg a)=0.4 \\
& p(c \mid a)=0.9 \\
& p(c \mid \neg a)=0.1 \\
& p(d \mid c)=0.9 \\
& p(d \mid \neg c)=0.5 \\
& p(e \mid c)=0.9 \\
& p(e \mid \neg c)=0.4
\end{aligned}
$$

Examples of queries to this belief network:

$$
\begin{aligned}
& p(c)=p(c \mid a) p(a)+p(c \mid \neg a) p(\neg a)=0.5 \\
& \text { - } p(a \mid c)=\frac{p(a) p(c \mid a)}{p(c)}=0.9 \\
& \text { - } p(a, b \mid c)=\frac{p(a, b, c)}{p(c)}=\frac{p(a) p(b \mid a)(p(c \mid a))}{p(c)}=0.72
\end{aligned}
$$

Figure 6: Belief network to model the "quality" of a student 
Since we do not have specific information about the academic performance of John or Paul, we will replace both queries goodStudent(John) and goodStudent (Paul) by a corresponding concept from the belief network, e.g. we can associate to both unit clauses the interval $[p(a, b \mid c), p(a \mid c)]$. The link from goodStudent (John) and goodStudent (Paul) to the interval $[p(a, b \mid c), p(a \mid c)]$ is based on our interpretation of the systems (conceptual level) and it is included in the broker description of the connection (architectural level).

The proof tree for deservelodging(John), in this case, including a representation of the knowledge shared by the belief network, is given in figure $\gamma$.

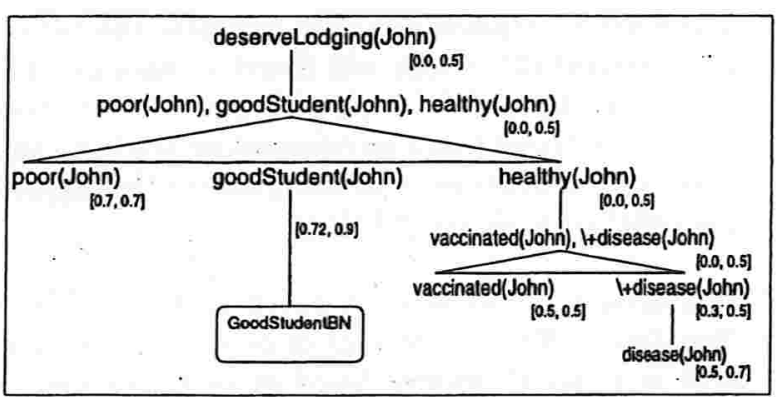

Figure 7: Proof tree for deserveLodging (John) with knowledge sharing

The role of the broker in this computation is to accept a query from the logical system and discover another system that can "prove" it. Since we have linked the formula goodStudent (John) and a pair of queries to a belief network, the broker asks the belief network for the two values, builds an interval, and returns the interval to the logical system.

\section{Consulting Multiple Bayesian Belief Networks}

Let us consider now a situation in which that several individual belief networks are available and we want to build a system that uses the capabilities of these networks to solve a complex problem. In example 7.1, three belief networks are used by a simple logical theory to decide whether a student shall receive free lodging by the university.

Example 7.1 Let us assume we have access to the belief networks shown in examples 4.1 and 6.1 and, additionally, to the network, called HealthBN, presented in figure 8.

Based on these individual networks we can build a very simple logical theory to decide whether a student should receive free lodging by the university:

$$
\begin{aligned}
\text { deserveLodging }(X):- & \operatorname{poor}(X), \\
& \text { goodStudent }(X), \\
& \text { healthy }(X) .
\end{aligned}
$$

Description of the variables (nodes) of the network:

H: person is healthy;

V: person is vaccinated against contagious diseases;

D: person is infected with contagious disease.

$$
\text { (V) (D) } \begin{aligned}
& p(h)=0.8 \\
& p(v \mid h)=0.9 \\
& p(v \mid \neg h)=0.4 \\
& p(d \mid h)=0.1 \\
& p(d \mid \neg h)=0.6
\end{aligned}
$$

Examples of queries to this belief network:

- $p(d)=p(d \mid h) p(h)+p(d \mid \neg h) p(\neg h)=0.2$

- $p(h \mid \neg d)=\frac{p(h) p(\neg d \mid h)}{p(\neg d)}=0.9$

- $p(h, v \mid \neg d)=\frac{p(h, v, \neg d)}{p(\neg d)}=\frac{p(v \mid h) p(\neg d \mid h) p(h)}{p(\neg d)}=0.81$

Figure 8: Belief network to model the health of a person

Let us say we have engineered the relations between the needed knowledge and what can be conveyed by the belief networks. This is presented in table 3.

Table 3: Links between formulas and probability intervals

\begin{tabular}{|lll|}
\hline logic formula & network & associated interval \\
\hline \hline poor(John) & PoorBN & {$\left[p\left(v_{1}, \neg v_{2} \mid v_{4}\right), p\left(v_{1} \mid v_{4}\right)\right]$} \\
poor(Paul) & PoorBN & {$\left[p\left(v_{1}, \neg v_{2} \mid v_{4}\right), p\left(v_{1} \mid v_{4}\right)\right]$} \\
goodStudent (John) & GoodStudentBN & {$[p(a, b \mid c), p(a \mid c)]$} \\
goodStudent (Paul) & GoodStudentBN & {$[p(a, b \mid c), p(a \mid c)]$} \\
heal thy (John) & HealthBN & {$[p(h, v \mid \neg d), p(h \mid \neg d)]$} \\
heal thy (Paul) & HealthBN & {$[p(h, v \mid \neg d), p(h \mid \neg d)]$} \\
\hline
\end{tabular}

The broker in this example contains the information shown in table 3 and; for each query of the logical system, asks the appropriate belief network for the corresponding pair of values, builds an interval, and returns the interval to the logical system.

Using these links, the proof tree for the formula deservelodging(Paul) is presented in the figure 9. Notice that, although in this simple example the links associate the same intervals to Paul and John, this will not necessarily be the case in all problems.

\section{Conclusion}

In the present article we have discussed a specific nontrivial knowledge sharing scenario, in which semantic information about how inferences are performed within participating systems is essential for proper knowledge sharing to occur. Namely, we have considered how bayesian belief networks can offer the result of their inferences to a resolution-based logical system to assign probability intervals to clausal queries.

The results presented here take into account only a simple situation, in which information provided by the networks is completely missing in the logical system. 


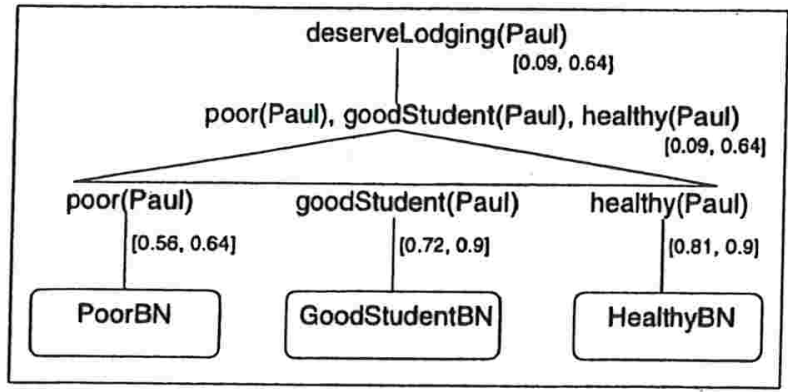

Figure 9: Proof tree for deserveLodging (Paul) with knowledge sharing

Also, it is not considered how the connection between systems would have to be made so that logical theories could also provide useful information to belief networks. These two scenarios are being taken into account at the moment under the auspices of the project DECaFf-KB - Distributed Environment for Cooperation Among Formalisms for Knowledge-based Systems - and shall be presented in future papers.

Nevertheless, some interesting points should be highlighted:

- the approach described here can be regarded as a useful problem solving strategy when the problem does not belong to a single domain, and a good solution for it is achieved by the combination of the results obtained in its multiple domains;

- this approach can also be seen as an effective software (re)use strategy, where a brokering system can link information available in existing systems to specific queries of new ones;

- the possibility of use a logical system as an intelligent "interface" to combine information generated by a collection of belief networks;

\section{Acknowledgements}

This work was sponsored by the Consortium British Council/CAPES (Brazil), Grant no. 070/98.

\section{References}

[1] K. R. Apt. Logic Programming. In J. van Leeuwen, editor, Handbook of Theoretical Computer Science, pages 493-574. Elsevier - MIT Press, 1994.

[2] A. Bundy. Incidence Calculus: a Mechanism for Probabilistic Reasoning. Journal of Automated Reasoning, 1(3):263-284, 1985.

[3] F. S. Correa da Silva. Automated Reasoning with Uncertainties. $\mathrm{PhD}$ thesis, University of Edinburgh, Department of Artificial Intelligence, 1992.

[4] F. S. Correa da Silva and A. Bundy. A Rational Reconstruction of Incidence Calculus. Technical Report 517, University of Edinburgh, Department of Artificial Intelligence, 1991.

[5] F. S. Correa da Silva, D. S. Robertson, and J. Hesketh. Automated Reasoning with Uncertainties. In M. Masuch and L. Pawlos, editors, Knowledge Representation and Uncertainty - ch. 5 - a preliminary version was presented at the APLOC - Applied Logic Conference (Logic at Work), 1992. Springer Verlag LNAI 808, 1994.

[6] F. S. Correa da Silva, W. W. Vasconcelos, J. Agusti, D. S. Robertson, and A. C. V. Melo. Why Ontologies are not Enough for Knowledge Sharing. In SpringerVerlag, editor, $12^{\text {th }}$ International Conference on Industrial and Engineering Applications of Artificial Intelligence and Expert Systems (Lecture Notes in Artificial Intelligence, v. 1611), pages 520-529, Cairo (Egypt), 1999.

[7] F. S. Correa da Silva, W. W. Vasconcelos, and D. S. Robertson. Cooperation Between Knowledge Based Systems. In $4^{\text {th }}$ World Congress on Expert Systems, pages 819-825, Mexico, 1998.

[8] R. M. Dudley. Real Analysis and Probability. Wadsworth \& Brooks/Cole, 1989.

[9] R. Fagin and J. Y. Halpern. Uncertainty, Belief, and Probability. Technical Report RJ-6191, IBM Research Report, 1989.

[10] P. Gray. KRAFT - Knowledge Reuse and Fusion/Transformation. http:// www.csd.abdn.ac.uk/ apreece/ Research/ KRAFT/ KRAFTinfo.html.

[11] K. Kunen. Signed Data Dependencies in Logic Programs. Journal of Logic Programming, 7:231-245, 1989.

[12] R. Neches and D. Gunning. The Knowledge Sharing Effort. http:// www-ksl.stanford.edu/ knowledgesharing/ papers/ kse-overview.html.

[13] R. Ng and V. S. Subrahmanian. Probabilistic Logic Programming. Information and Computation, 1992.

[14] N. J. Nilsson. Probabilistic Logic. Artificial Intelligence, 28:71-87, 1986.

[15] J. Pearl. Probabilistic Reasoning in Intelligent Systems: Networks of Plausible Inference. Morgan Kaufmann, 1988.

[16] A. Preece, K. Hui, A. Gray, Philippe Marti, T. BenchCapon, D. Jones, and Z. Cui. The KRAFT Architecture for Knowledge Fusion and Transformation. In Expert Systems 1999, 1999.

[17] D. S. Robertson, J. Agusti-Cullel, F. S. Correa da Silva, and W. W. Vasconcelos. A Lightweight Capability Communication Mechanism. In IEA-AIE'2000 (submitted), 2000.

[18] G. Shafer. A Mathematical Theory of Evidence. Princeton Univ. Press, 1976.

[19] M. J. R. Shave. Ontological Structures for Knowledge Sharing. New Review of Information. Networking (submitted), 1997.

[20] L. Sterling and E. Shapiro. The Art of PROLOG. MIT Press, 1986.

[21] V. S. Subrahmanian. Hermes - a Heterogeneous Reasoning and Mediator System. http:// www.cs.umd.edu/ projects/ hermes/index.html.

[22] D. Turi. Logic Programs with Negation: Classes, Models, Interpreters. Technical Report CS-R8943, Centre for Mathematics and Computer Science, 1989.

[23] M. Uschold and M. Gruninger. Ontologies: Principles, Methods and Applications. Knowledge Engineering Review, 11(2):93-136, 1996. ISSN 0269-8889.

[24] L. van der Gaag. Bayesian Belief Networks: Odds and Ends. The Computer, 39:97-113, 1996. 


\section{Referências Bibliográficas}

[1] K. R. Apt. Logic programming. In J. van Leeuwen, editor, Handbook of Theoretical Computer Science, p.493-574. Elsevier - MIT Press, 1994.

[2] K. R. Apt and R. N. Bol. Logic programming and negation: A survey. Journal of Logic Programming, v.19-20, p.9-71, 1994.

[3] R. M. Colomb. Impact of semantic heterogeneity on federating databases. The Computer Journal, v.40, n.5, p.235-244, 1997.

[4] F. S. Correa da Silva. Automated Reasoning with Uncertainties. PhD thesis, University of Edinburgh, Department of Artificial Intelligence, 1992.

[5] F. S. Correa da Silva. Formalisations of Uncertain Reasoning. In LNAI 1611, p.1-3, 1999.

[6] F. S. Correa da Silva, R. C. Araujo, J. Agusti-Cullel, and A. C. V. Melo. Knowledge Sharing Between a Probabilistic Logic and Bayesian Belief Networks. In Spain Universidad Politécnica de Madrid, editor, International Conference on Processing and Management of Uncertainty'2000, p.1299-1306, Madrid (Spain), 2000.

[7] F. S. Correa da Silva, W. W. Vasconcelos, J. Agusti, D. S. Robertson, and A. C. V. Melo. Why Ontologies are not Enough for Knowledge Sharing. In Springer-Verlag, editor, $12^{\text {th }}$ International Conference on Industrial and Engineering Applications of Artificial Intelligence and Expert Systems (Lecture Notes in Artificial Intelligence, $v$. 1611), p.520-529, Cairo (Egypt), 1999.

[8] F. G. Cozman. Credal networks. Artificial Intelligence, v.120, p.199-233, 2000.

[9] DECaFf-KB. Decaff-kb - distributed environment for cooperation among formalisms for knowledge bases. http://www.ime.usp.br/ fcs/DECaFf1.html.

[10] E. Denti and A. Omicini. An architecture for tuple-based coordination of multi-agent systems. Software - Practice and Experience, v.29, n.12, p.1103-1121, out 1999.

[11] E. H. Durfee, V. R. Lesser, and D. D. Corkill. Trends in cooperative distributed problem solving. IEEE Transactions on Knowledge and Data Engineering, v.1, n.1, p.63-83, 1989. 
[12] R. Engelmore and T. (eds.) Morgan. Blackboard Systems. Addison-Wesley, England, 1988 .

[13] R. Fagin and J. Y. Halpern. Uncertainty, Belief, and Probability. Technical Report RJ-6191, IBM Research Report, 1989.

[14] W. Feller. An Introduction to Probability Theory and Its Applications, Volume II. John Wiley \& Sons, 1966.

[15] T. Finin, R. Fritzson, D. McKay, and R. McEntire. KQML - A language and protocol for knowledge and information exchange. Technical Report CS-94-02, Computer Science Department, University of Maryland and Valley Forge Engineering Center, Unisys Corporation, Computer Science Department, University of Maryland,UMBC Baltimore MD 21228, 1994.

[16] FIPA. Fipa - foundation for intelligent physical agents. http://www.fipa.org.

[17] M. R. Genesereth and S. P. Ketchpel. Software agents. Communications of the Association for Computing Machinery, v.37, n.7, 1994.

[18] P. Gray. Kraft - knowledge reuse and fusion/transformation. http://www.csd.abdn.ac.uk/ apreece/Research/KRAFT/KRAFTinfo.html.

[19] T. R. Gruber. Toward principles for the design of ontologies used for knowledge sharing. http://ksl-web.stanford.edu/KSL_Abstracts/KSL-93-04.html, 1993.

[20] J. Hendler. Making sense out of agents. IEEE Intelligent Systems, p.32-37, 1999.

[21] H. F. Korth and A. Silberschatz. Database Systems Concepts. McGraw-Hill, 1986.

[22] P. Krause and D. Clark. Representing uncertain knowledge. Kluwer Academic Press, Dordrecht, NL, 1993.

[23] C. W. Krueger. Software reuse. ACM Computing Surveys, v.24, n.2, p.131-183, 1992.

[24] R. Kruse, E. Schwecke, and J. Heinsohn. Uncertainty and Vagueness in Knowledge Based Systems. Artificial Intelligence. Springer Verlag, Berlin, 1991.

[25] K. Kunen. Signed Data Dependencies in Logic Programs. Journal of Logic Programming, v.7, p.231-245, 1989.

[26] LuCe. Logic tuple centres. http://lia.deis.unibo.it/Research/LuCe/.

[27] P. Morawski. Programming bayesian belief networks. AI Expert, v.4, n.8, p.74-79, 1989.

[28] R. Neches and D. Gunning. The knowledge sharing effort. http://www.ksl.stanford.edu/knowledge-sharing/papers/kse-overview.html. 
[29] J. M. S. Nogueira. Protocolos e serviços de comunicação: princípios, especificação e teste. Versão preparada para a V Escola Brasileiro-Argentina de Informática (V EBAI), 1991.

[30] H. S. Nwana and N. T Ndumu. An introduction to agent technology. In H. S. Nwana and Azarmi N., editors, Software Agents and Soft Computing, LNAI 1198, p.3-26. Springer, 1997.

[31] J. Pearl. Probabilistic Reasoning in Intelligent Systems: Networks of Plausible Inference. Morgan Kaufmann, 1988.

[32] D. S. Robertson, J. Agusti-Cullel, F. S. Correa da Silva, and W. W. Vasconcelos. A Lightweight Capability Communication Mechanism. In IEA-AIE'O000 (submitted), 2000 .

[33] A. Saffiotti and Umkehrer E. PULCINELLA: A general tool for propagating uncertainty in valuation networks. In Procs. of the 7th Conf. on Uncertainty in AI, p.323-331, Los Altos, CA 94022, USA, 1991. Morgan Kaufmann Publishers.

[34] M. J. R. Shave. Ontological structures for knowledge sharing. Submetido para publicação no 'New Review of Information Networking'.

[35] A. P. Sheth and J. A. Larson. Federated database systems for managing distributed, heterogeneous, and autonomous databases. ACM Computing Surveys, v.22, n.3, p.183-236, 1990. Also published in/as: Bellcore, TM-STS-016302, 1990.

[36] V. S. Subrahmanian. Hermes - a Heterogeneous Reasoning and Mediator System. http:// www.cs.umd.edu/ projects/ hermes/index.html.

[37] L. van der Gaag. Bayesian Belief Networks: Odds and Ends. The Computer, v.39, p.97-113, 1996.

[38] G. Wiederhold. Mediators in the architeture of future information systems. IEEE Computer, v.25, n.3, p.38-49, 1992.

[39] M. Wooldridge and N. R. Jennings. Intelligent agents: Theory and practice. Versão preliminar submetida para publicação na The Knowledge Engineering Review, 1995. 